\title{
ESTUDO COMPARATIVO DA INTERAÇÃO SOLO-GEOGRELHA POR MEIO DE ENSAIOS DE ARRANCAMENTO MONOTÔNICO E CÍCLICO UTILIZANDO EQUIPAMENTOS DE PEQUENAS E GRANDES DIMENSÕES
}

Dissertação apresentada à Escola de Engenharia de São Carlos, da Universidade de São Paulo, como parte dos requisitos para obtenção do título de Mestre em Ciências, Programa de Pós-Graduação em Geotecnia.

Orientador: Prof. Dr. Jefferson Lins da Silva

\author{
São Carlos - SP \\ 2016
}


AUTORIZO A REPRODUÇÃO TOTAL OU PARCIAL DESTE TRABALHO, POR QUALQUER MEIO CONVENCIONAL OU ELETRÔNICO, PARA FINS DE ESTUDO E PESQUISA, DESDE QUE CITADA A FONTE.

Rincón Barajas, Sergio Arturo

Estudo comparativo da interação solo-geogrelha por meio de ensaios de arrancamento monotônico e cíclico utilizando equipamentos de pequenas e grandes dimensões / Sergio Arturo Rincón Barajas; orientador Jefferson Lins da Silva. São Carlos, 2016.

Dissertação (Mestrado) - Programa de Pós-Graduação e Área de Concentração em Geotecnia -- Escola de Engenharia de São Carlos da Universidade de São Paulo, 2016.

1. Reforço de solo. 2. Interação solo-geossintético. 3. Geogrelha. 4. Arrancamento monotônico. 5. Arrancamento cíclico. 6. Resistência ao arrancamento pós-ciclagem. 7. Equipamento de pequenas dimensões. 8. Equipamento de grandes dimensões. I. Título. 


\section{FOLHA DE JULGAMENTO}

Candidato: SERGIO ARTURO RINCON BARAJAS

Título da dissertação: "Estudo comparativo da interação solo-geogrelha por meio de ensaios de arrancamento monotônico e cíclico utilizando equipamentos de pequenas e grandes dimensões"

Data da defesa: 02.08 .2016

\section{Comissão Julgadora:}

Prof. Dr. Jefferson Lins da Silva (Orientador)

(Escola de Engenharia de São Carlos/EESC)

Prof. Dr. Sidnei Helder Cardoso Teixeira

(Universidade Federal do Paraná/UFPR)

Prof. Dr. Glauco Tulio Pessa Fabbri

(Escola de Engenharia de São Carlos/EESC)
Resultado:

APROVADO

APROVADO

APROJ ADO

Coordenador do Programa de Pós-Graduação em Geotecnia:

Prof. Dr. Edmundo Rogério Esquivel

Presidente da Comissão de Pós-Graduação:

Prof. Associado Luís Fernando Costa Alberto 

Dedicado a mis padres y hermano, porque en la distancia siempre fueron mi mayor apoyo y motivación para alcanzar esta gran meta. 



\section{Agradecimentos}

Agradeço à minha família pelo apoio incondicional durante estes dois anos de formação e trabalho fora de casa, porque mesmo estando longe, nunca senti a sua falta.

À minha mãe Elizabeth, o motor da minha vida, porque sempre esteve do meu lado me apoiando, me motivando e dando sempre o melhor dela para que eu estivesse bem, tranquilo e sem sentir a falta do seu amor e carinho.

Ao meu pai Arturo, porque ao igual que minha mãe, sempre se sentiu orgulhoso dos seus filhos, esteve atento da minha formação como pessoa e profissional, e sempre esteve acompanhando à minha mãe durante a ausência dos seus filhos em casa.

Ao meu irmão Jorge, pelas conversas, pelos conselhos e pela motivação dada durante esta etapa de formação no estrangeiro.

À minha linda namorada Melissa, porque desde que começou fazer parte da minha vida, com seu amor e compreensão sempre foi um apoio incondicional durante a etapa final do mestrado.

Ao prezado professor Jefferson, pela sua excelente orientação, amizade, confiança e total compromisso durante a minha formação como Mestre em Geotecnia na melhor universidade da América Latina.

Ao Departamento de Geotecnia da Escola de Engenharia de São Carlos, da Universidade de São Paulo, pela oportunidade dada para crescer profissionalmente neste lindo ramo da engenharia civil.

Aos professores do Departamento de Geotecnia da EESC-USP por terem contribuído na minha formação profissional com a sua experiência e valiosos conhecimentos.

Ao Professor Glauco Fabbri do Departamento de Transportes da EESC-USP e à Professora Delma de Mattos Vidal do ITA pelas suas valiosas contribuições para o crescimento da pesquisa.

À Maristela, à Neiva e ao Álvaro, funcionários do Departamento de Geotecnia da EESCUSP, pela sua amabilidade e eficiência administrativa durante o mestrado.

Aos técnicos do Departamento de Geotecnia da EESC-USP, Oscar, José Luis, Benedito, Décio e Senhor Antônio, pela sua total disposição e colaboração durante a realização dos ensaios das disciplinas e dos ensaios de caracterização dos materiais utilizados no projeto de pesquisa. 
Aos técnicos do Laboratório de Geossintéticos da EESC-USP, Clever, Tiago, Manoel e Leonardo pela sua grande ajuda, colaboração e ensinamentos relacionados aos ensaios envolvidos na pesquisa.

Ao aluno de graduação em engenharia civil da EESC-USP, Murilo Sticca Papa, pela sua grande ajuda na realização dos ensaios de caracterização do solo, assim como na sua preparação para os ensaios piloto executados, cujos resultados foram mostrados no exame de qualificação.

Aos técnicos do Laboratório de Estradas do Departamento de Transportes da EESC-USP, Antonio Gigante, Paulo Toyama e João Domingos, pela sua grande colaboração na realização dos ensaios de CBR e Módulo de Resiliência.

Aos amigos brasileiros do Departamento de Geotecnia da EESC-USP, em especial ao Moisés, à Tati, à Paula, ao Lucas Nascimento, à Yara e ao Gabriel Pedroso, pela sua companhia e valiosa amizade durante o mestrado.

À Kate, ao Guido, à Zorany, à Juliana, ao Sergio Pardo, ao Juan Camilo e ao Edwin, grandes amigos que fizeram parte da minha família colombiana no Brasil.

Ao Christian e ao "Andresito" pela valiosa amizade e grande colaboração durante a etapa final dos ensaios de arrancamento cíclico.

À Loana e ao Jorge, grandes amigos do Departamento de Transportes da EESC-USP que me forneceram arquivos importantes para complementar a revisão bibliográfica do projeto de pesquisa.

À empresa Huesker Ltda. pelo fornecimento da geogrelha utilizada nos ensaios de arrancamento monotônico e cíclico.

À CAPES, Coordenadoria de Aperfeiçoamento de Pessoal de Nível Superior, pela bolsa concedida durante o mestrado.

Ao grande Brasil, minha segunda pátria, que me acolheu e me brindou grandes benefícios durante os meus estudos de intercâmbio e de mestrado.

À empresa Maccaferri de Colombia Ltda. pela licença concedida para defender o mestrado no Brasil.

A todos vocês, "¡muchas gracias!”. 
"No te rindas, por favor no cedas, aunque el frío queme, aunque el miedo muerda, aunque el sol se esconda y se calle el viento, aún hay fuego en tu alma, aún hay vida en tus sueños, porque la vida es tuya y tuyo también el deseo, porque cada día es un comienzo nuevo, porque esta es la hora y el mejor momento". 



\section{RESUMO}

RINCÓN B., S. A. Estudo comparativo da interação solo-geogrelha por meio de ensaios de arrancamento monotônico e cíclico utilizando equipamentos de pequenas e grandes dimensões. 2016. 187 p. Dissertação de Mestrado - Departamento de Geotecnia, Escola de Engenharia de São Carlos, Universidade de São Paulo, São Carlos, 2016.

O melhor comportamento de uma estrutura de solo reforçado com geossintéticos não depende só da elevada resistência à tração da inclusão, mas também da sua rigidez e do nível de carregamento sob o qual a estrutura está submetida. Dessa maneira, a interação entre o reforço e as respectivas camadas de solo ao seu redor torna-se de grande importância, pois a mobilização cisalhante combina a deformação da interface solo-reforço e o alongamento do geossintético. Sendo que a melhor forma de avaliar a interação entre o solo e a geogrelha é por meio de ensaios de arrancamento, pensa-se na realização de ensaios de arrancamento cíclico para analisar a interação dinâmica entre o solo e a inclusão quando certas estruturas são submetidas a esse tipo de solicitação. Por causa disso, o objetivo principal deste trabalho é analisar o efeito produzido por carregamentos monotônicos e cíclicos de interface numa geogrelha biaxial de polipropileno, quando inserida na interface de um solo argiloso e um solo arenoso sob diferentes tensões de confinamento. Para isso, são utilizados os equipamentos de pequenas e grandes dimensões do Laboratório de Geossintéticos da EESC-USP, visando avaliar a sua relação e a viabilidade de uso do equipamento de pequenas dimensões. Inicialmente foram realizados ensaios de arrancamento monotônico em ambos os equipamentos sob tensões de confinamento de 25,50 e $100 \mathrm{kPa}$, sendo que as resistências obtidas com as tensões de 25 e 100 $\mathrm{kPa}$ permitiram definir as amplitudes do carregamento cíclico correspondentes ao $20 \%$ de tais valores. Adicionalmente, após a aplicação dos 10.000 ciclos de carga correspondentes à capacidade do equipamento, foi aplicado novamente um carregamento monotônico com o intuito de determinar o efeito do carregamento dinâmico na resistência ao arrancamento e assim poder realizar as respectivas comparações com os valores iniciais. Com base nos resultados obtidos, foi possível observar a diferença no grau de confinamento entre ambos os equipamentos, sendo maior no de grandes dimensões por causa da melhor distribuição das tensões sobre a área ocupada pela geogrelha. Adicionalmente, o grau de confinamento em ambos os equipamentos também influenciou a diferença no efeito do carregamento dinâmico, sendo de desconfinamento no de grandes dimensões e de densificação no de pequenas dimensões. 
Palavras-chave: Reforço de solo, interação solo-geossintético, geogrelha, arrancamento monotônico, arrancamento cíclico, resistência ao arrancamento pós-ciclagem, equipamento de pequenas dimensões, equipamento de grandes dimensões. 


\begin{abstract}
RINCÓN B., S. A. Comparative study of soil-geogrid interaction through monotonic and cyclic pullout tests using small and large dimensions equipments. 2016. 187 p. Master Thesis - Department of Geotechnical Engineering, Engineering School of Sao Carlos, University of Sao Paulo, Sao Carlos, 2016.

The best behavior of a reinforced soil structure with geosynthetics not only depends on the high tensile strength of the inclusion, but also on its rigidity and the loading level in which the structure is subjected. Thus, the interaction between the reinforcement and the respective layers of soil around, becomes very important because the shear mobilization combines the deformation of the soil-reinforcement interface and the lengthening of the geosynthetic. Since the best way to assess the soil-geogrid interaction is through pullout tests, it is thought in performing cyclic pullout tests to examine the dynamic soil-inclusion interaction when some structures are submitted to that kind of loads. Because of that, the main objective of this work is to analize the effect that is produced by monotonic and cyclic interface loading on a biaxial polypropylene geogrid, when it is inserted into the interface of a clayey soil and a sandy soil under different confinement stresses. For that, the small and large dimensions equipments of the Geosynthetics Laboratory at EESC-USP are used, looking to evaluate their relationship and the feasibility of using a small dimensions equipment. Initially, they were performed monotonic pullout tests in both equipments under confinement stresses of 25,50 and $100 \mathrm{kPa}$, wherein the pullout strengths obtained with 25 and $100 \mathrm{kPa}$ allowed the definition of the load cyclic amplitudes, which corresponded to $20 \%$ of such values. Additionally, after applying 10.000 load cycles, corresponding to the capacity of the equipment, it was applied a monotonic loading in order to determine the dynamic loading effect on pullout strength, being useful to compare such values with the initial response. Based on the obtained results, it was possible to observe the difference in the confinement degree between both equipments, being higher in the large one because of the better stress distribution on the geogrid area. Aditionally, the confinement degree in both equipments also influenced the difference in the dynamic loading effect, being deconfinement in the soil-geogrid interface of the large one and densification in the other one.
\end{abstract}

Keywords: Soil reinforcement, soil-geosynthetic interaction, geogrid, monotonic pullout, cyclic pullout, post-cyclic pullout strength, small dimension equipment, large dimension equipment. 



\section{LISTA DE FIGURAS}

Figura 2.1. Ondulações, rodeiros e atoleiros (ESTRADAS VICINAIS DE TERRA. Manual Técnico para Conservação e Recuperação, 1988)

Figura 2.2. Excesso de pó (ESTRADAS VICINAIS DE TERRA. Manual Técnico para Conservação e Recuperação, 1988)

Figura 2.3. (a) Rocha aflorante; (b) Camada de revestimento primário; (c) Obturação de cavidades com pedra e argamassa (ESTRADAS VICINAIS DE TERRA. Manual Técnico para Conservação e Recuperação, 1988)

Figura 2.4. Pista molhada derrapante (ESTRADAS VICINAIS DE TERRA. Manual Técnico para Conservação e Recuperação, 1988)

Figura 2.5. Pista seca derrapante (ESTRADAS VICINAIS DE TERRA. Manual Técnico para Conservação e Recuperação, 1988)

Figura 2.6. Buracos (ESTRADAS VICINAIS DE TERRA. Manual Técnico para Conservação e Recuperação, 1988)

Figura 2.7. Erosões em ravina (ESTRADAS VICINAIS DE TERRA. Manual Técnico para Conservação e Recuperação, 1988)

Figura 2.8. Distribuição de tensões no subleito em (a) pavimento sem reforço e (b) pavimento com reforço de base (Gupta, 2009)

Figura 2.9. Comparação entre o módulo de elasticidade e o módulo de resiliência (Campos, 2013)

Figura 2.10. Variação do módulo de resiliência com adição de finos num agregado britado de rocha ígnea (Adaptado de Jorenby e Hicks, 1986)

Figura 2.11. Influência da composição granulométrica de um material gnaisse-granítico na variação do módulo de resiliência (Adaptado de Barksdale e Itani, 1989)

Figura 2.12. Variação do módulo de resiliência com o teor de umidade no solo argiloso siltoso A-7-6 (Adaptado de Mohammad et al., 1995).

Figura 2.13. Variação do módulo de resiliência com o teor de umidade no solo arenoso A-3 (Adaptado de Mohammad et al., 1995)

Figura 2.14. Esquema de interação da geogrelha com um material granular (http://www.mathworks.com/matlabcentral/answers/uploaded_files/23014/gt2.jpg em Julho de 2014).

Figura 2.15. Tipos de geogrelha de acordo a sua geometria

Figura 2.16. Variação do TBR para diferentes espessuras de base granular em uma deflexão de $25 \mathrm{~mm}$ (Adaptado de Collin et al., 1996)

Figura 2.17. Afundamento de trilha de roda (ATR) - (a) Pavimento sem reforço e (b) pavimento reforçado com geogrelha na interface base-subleito (Modificado de Maccaferri, 2012)

Figura 2.18. Tensões laterais induzidas no geossintético devidas ao tráfego veicular (Meyer et

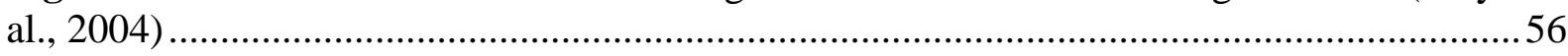

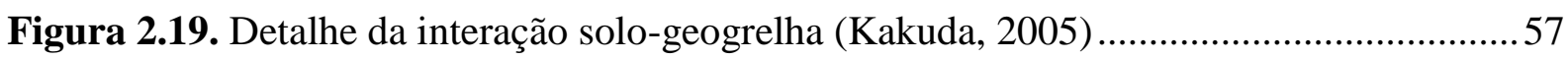


Figura 2.20. Resistências atritiva e passiva na interface solo-geogrelha (Voottipruex et al.,

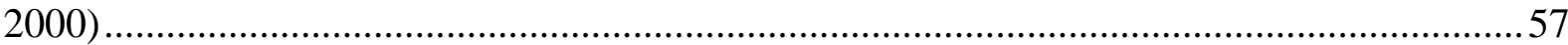

Figura 2.21. Quantidade de elementos longitudinais vs. Força máxima de arrancamento (Kakuda, 2005)

Figura 2.22. Quantidade de elementos transversais vs. Tensão máxima de arrancamento para (a) 8 elementos longitudinais e (b) 12 elementos longitudinais (Kakuda, 2005)

Figura 2.23. Influência da tensão de confinamento na (a) Resistência a arrancamento e na (b) Taxa de deslocamento relativo dos nós da geogrelha (Alfaro et al., 1995)

Figura 2.24. Comportamento da força de arrancamento e do deslocamento da inclusão para diferentes tensões de confinamento (Ochiai et al., 1996). 64

Figura 2.25. Modelo do dente de serra para representar o fenômeno de dilatância (Bolton, 1986 apud Kakuda, 2005).

Figura 2.26. Influência qualitativa do aumento da dimensão dos grãos de solo reforçado com geogrelha em condição de cisalhamento direto (Jewell et al., 1984)

Figura 2.27. Rugosidades avaliadas na parede frontal do equipamento (Palmeira e Milligan, 1989). .68

Figura 2.28. Relação entre a tensão cisalhante e normal vs. Deslocamento nos ensaios de arrancamento para diferentes rugosidades (Palmeira e Milligan, 1989) 68

Figura 2.29. Efeito do comprimento da manga na (a) Resistência ao arrancamento e nos (b) Empuxos horizontais na parede frontal do equipamento (Farrag et al., 1993).....

Figura 2.30. Resultados de arrancamento para diferentes espessuras de solo arenoso (Farrag et al., 1993)

Figura 2.31. Variação da resistência ao arrancamento em função da taxa de deslocamento aplicada (Lopes e Ladeira, 1996)

Figura 2.32. Variação da resistência ao arrancamento em função da taxa de deslocamento aplicada (Kakuda, 2005)

Figura 2.33. Variação da resistência ao arrancamento para taxas de deslocamento de 1,2 e 5 $\mathrm{mm} / \mathrm{min}$ (Kakuda, 2005) 73

Figura 2.34. Onda Haversine (Adaptado de NCHRP, 2004) 75

Figura 2.35. Representação esquemática da resistência pós-ciclagem de uma geogrelha inserida em um solo granular (Adaptado de Moraci e Cardile, 2009) 76

Figura 2.36. Resultados de arrancamento monotônico e resistência pós-ciclagem sob tensão de confinamento de $10 \mathrm{kPa}$ e frequência de 0,10 Hz. (a) Geogrelha extrudada e (b) Geogrelha tecida (Moraci e Cardile, 2009)

Figura 2.37. Resultados de arrancamento monotônico e resistência pós-ciclagem sob tensão de confinamento de $25 \mathrm{kPa}$ e frequência de 0,10 Hz. (a) Geogrelha extrudada e (b) Geogrelha tecida (Moraci e Cardile, 2009).

Figura 2.38. Resultados de arrancamento monotônico e resistência pós-ciclagem sob tensão de confinamento de $50 \mathrm{kPa}$ e frequência de 0,10 Hz. (a) Geogrelha extrudada e (b) Geogrelha tecida (Moraci e Cardile, 2009).

Figura 2.39. Influência do arrancamento cíclico na resistência ao arrancamento monotônico (Adaptado de Nayeri e Fakharian, 2009) 
Figura 2.40. Ilustração do cálculo do módulo de cisalhamento de interface (Adaptado de

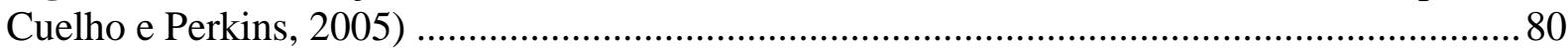

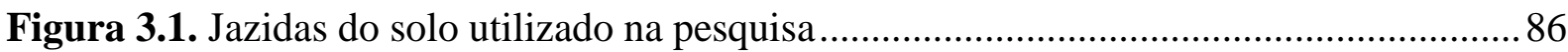

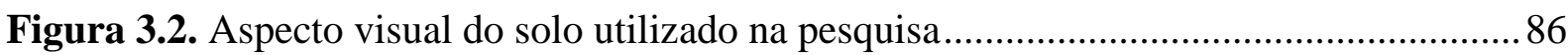

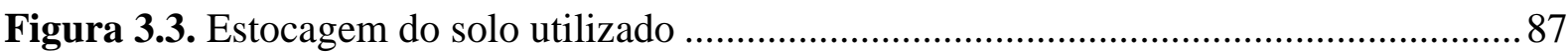

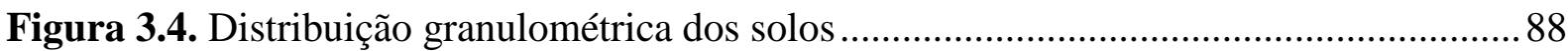

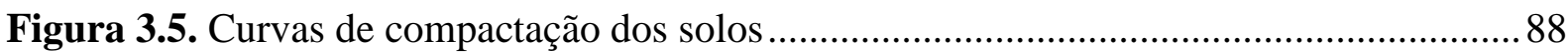

Figura 3.6. Curvas de tensão de desvio versus deformação axial ......................................... 89

Figura 3.7. Trajetórias de tensões obtidas a partir dos ensaios triaxiais................................ 90

Figura 3.8. Variação do módulo de resiliência em função da tensão de desvio......................92

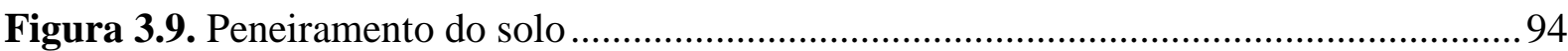

Figura 3.10. Conservação do solo peneirado dentro do Laboratório de Geossintéticos .........94

Figura 3.11. Processo de secagem do solo ......................................................................... 95

Figura 3.12. Homogeneização e conservação do solo em ambiente controlado .....................95

Figura 3.13. Ajuste da umidade ótima do solo .................................................................... 96

Figura 3.14. Material de reforço utilizado nos ensaios de arrancamento monotônico e cíclico

Figura 3.15. Curvas de resistência à tração não confinada para corpos de prova com 5

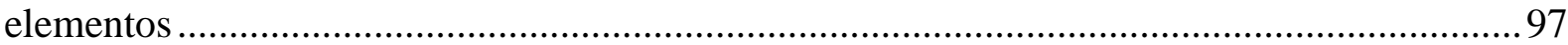

Figura 3.16. Variação da resistência à tração com o número de elementos ............................ 99

Figura 3.17. Variação do módulo de rigidez com o número de elementos ..............................99

Figura 3.18. Equipamento de grandes dimensões $(1,50 \mathrm{~m}$ de comprimento, $0,70 \mathrm{~m}$ de largura e $0,48 \mathrm{~m}$ de altura)

Figura 3.19. Equipamento de pequenas dimensões $(24,5 \mathrm{~cm}$ de comprimento, $30 \mathrm{~cm}$ de largura e $14,5 \mathrm{~cm}$ de altura) 100

Figura 3.20. Graxa de cálcio grafitada 101

Figura 3.21. Lubrificação das geomembranas em cada parede interna do equipamento de pequeno porte 101

Figura 3.22. Painel de controle do sistema de aplicação de carga 102

Figura 3.23. Sistema de válvulas para o controle da passagem de óleo no sistema hidráulico 103

Figura 3.24. Adaptação do equipamento de pequenas dimensões na caixa de grande porte 103

Figura 3.25. Sistema de controle do ar comprimido para a aplicação das tensões de confinamento 104

Figura 3.26. Garra responsável pela distribuição homogênea da tração na geogrelha 104

Figura 3.27. Definição da relação do tamanho dos corpos de prova a partir das dimensões da inclusão no equipamento de pequenas dimensões 
Figura 3.28. Definição do tamanho do corpo de prova no equipamento de grandes dimensões 106

Figura 3.29. Detalhe da fixação do fio de aço inextensível nos elementos longitudinais instrumentados

Figura 3.30. Localização dos pontos de medição dos deslocamentos na região confinada dos corpos de prova

Figura 3.31. Localização da célula de tensão total no equipamento de pequenas dimensões

Figura 3.32. Localização das células de tensão total no equipamento de grandes dimensões

Figura 3.33. Sistema de aquisição de dados

Figura 4.1. Instrumentação da região confinada da geogrelha no equipamento de pequenas dimensões

Figura 4.2. Curvas de força de arrancamento vs. deslocamento no equipamento de pequenas dimensões

Figura 4.3. Envoltória de resistência ao arrancamento no equipamento de pequenas dimensões

Figura 4.4. Processo de instalação da célula de tensão total no equipamento de pequenas dimensões

Figura 4.5. Variação da tensão de confinamento nos ensaios de arrancamento monotônico Equipamento de pequenas dimensões

Figura 4.6. Curvas de força de arrancamento vs. deslocamento para uma tensão de confinamento de $25 \mathrm{kPa}$ - Equipamento de pequenas dimensões

Figura 4.7. Exumação da geogrelha após o ensaio de arrancamento monotônico no equipamento de pequenas dimensões $-25 \mathrm{kPa}$

Figura 4.8. Curvas de força de arrancamento vs. deslocamento para uma tensão de confinamento de $50 \mathrm{kPa}$ - Equipamento de pequenas dimensões 128

Figura 4.9. Exumação da geogrelha após o ensaio de arrancamento monotônico no equipamento de pequenas dimensões $-50 \mathrm{kPa}$.

Figura 4.10. Curvas de força de arrancamento vs. deslocamento para uma tensão de confinamento de $100 \mathrm{kPa}$ - Equipamento de pequenas dimensões .

Figura 4.11. Exumação da geogrelha após o ensaio de arrancamento monotônico no equipamento de pequenas dimensões $-100 \mathrm{kPa}$

Figura 4.12. Instrumentação da região confinada da geogrelha no equipamento de grandes dimensões

Figura 4.13. Curvas de força de arrancamento vs. deslocamento no equipamento de grandes dimensões

Figura 4.14. Envoltória de resistência ao arrancamento no equipamento de grandes dimensões

Figura 4.15. Localização em planta das células de tensão total - Equipamento de grandes dimensões 
Figura 4.16. Localização em profundidade das células de tensão total - Equipamento de grandes dimensões.

Figura 4.17. Variação da tensão de confinamento nos ensaios de arrancamento monotônico Equipamento de grandes dimensões

Figura 4.18. Curvas de força de arrancamento vs. deslocamento para uma tensão de confinamento de $25 \mathrm{kPa}$ - Equipamento de grandes dimensões.......................................... 136

Figura 4.19. Exumação da geogrelha após o ensaio de arrancamento monotônico no

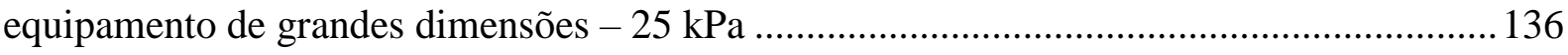

Figura 4.20. Variação da tensão horizontal no ensaio de arrancamento monotônico $-25 \mathrm{kPa}$

Figura 4.21. Curvas de força de arrancamento vs. deslocamento para uma tensão de confinamento de $50 \mathrm{kPa}$ - Equipamento de grandes dimensões.

Figura 4.22. Exumação da geogrelha após o ensaio de arrancamento monotônico no equipamento de grandes dimensões $-50 \mathrm{kPa}$

Figura 4.23. Variação da tensão horizontal no ensaio de arrancamento monotônico - $50 \mathrm{kPa}$

Figura 4.24. Curvas de força de arrancamento vs. deslocamento para uma tensão de confinamento de $100 \mathrm{kPa}$ - Equipamento de grandes dimensões ....................................... 140

Figura 4.25. Exumação da geogrelha após o ensaio de arrancamento monotônico no equipamento de grandes dimensões $-100 \mathrm{kPa}$

Figura 4.26. Variação da tensão horizontal no ensaio de arrancamento monotônico - $100 \mathrm{kPa}$

Figura 4.27. Comparação das curvas de força de arrancamento vs. deslocamento, $P P=$ pequeno porte, $\mathrm{GP}=$ grande porte

Figura 4.28. Comparação das envoltórias de resistência ao arrancamento

Figura 4.29. Comparação das curvas de força de arrancamento vs. deslocamento - Tensão de confinamento de $25 \mathrm{kPa}$

Figura 4.30. Exumação das geogrelhas após os ensaios de arrancamento monotônico nos dois equipamentos $-25 \mathrm{kPa}$

Figura 4.31. Comparação das curvas de força de arrancamento vs. deslocamento - Tensão de confinamento de $50 \mathrm{kPa}$

Figura 4.32. Exumação das geogrelhas após os ensaios de arrancamento monotônico nos dois equipamentos $-50 \mathrm{kPa}$

Figura 4.33. Comparação das curvas de força de arrancamento vs. deslocamento - Tensão de confinamento de $100 \mathrm{kPa}$

Figura 4.34. Exumação das geogrelhas após os ensaios de arrancamento monotônico nos dois equipamentos $-100 \mathrm{kPa}$. 148

Figura 4.35. Detalhe da variação da carga cisalhante ao longo do tempo no equipamento de pequenas dimensões durante os primeiros 15 segundos.

Figura 4.36. Arrancamento cíclico e resistência pós-ciclagem no equipamento de pequenas dimensões 
Figura 4.37. Resistência pós-ciclagem e resistência ao arrancamento monotônico no equipamento de pequenas dimensões $-25 \mathrm{kPa}$

Figura 4.38. Exumação das geogrelhas após os ensaios de arrancamento monotônico e cíclico no equipamento de pequenas dimensões $-25 \mathrm{kPa}$

Figura 4.39. Resistência pós-ciclagem e resistência ao arrancamento monotônico no equipamento de pequenas dimensões $-100 \mathrm{kPa}$

Figura 4.40. Exumação das geogrelhas após os ensaios de arrancamento monotônico e cíclico no equipamento de pequenas dimensões $-100 \mathrm{kPa}$ 156

Figura 4.41. Detalhe da variação da carga cisalhante ao longo do tempo no equipamento de grandes dimensões durante os primeiros 10 segundos 158

Figura 4.42. Arrancamento cíclico e resistência pós-ciclagem no equipamento de grandes dimensões

Figura 4.43. Resistência pós-ciclagem e resistência ao arrancamento monotônico no equipamento de grandes dimensões $-25 \mathrm{kPa}$ 160

Figura 4.44. Exumação das geogrelhas após os ensaios de arrancamento monotônico e cíclico no equipamento de grandes dimensões $-25 \mathrm{kPa}$ 161

Figura 4.45. Detalhe dos ciclos de carga para a obtenção do módulo de cisalhamento de interface $\mathrm{G}_{\mathrm{i}}-25 \mathrm{kPa}$. 162

Figura 4.46. Resistência pós-ciclagem e resistência ao arrancamento monotônico no equipamento de grandes dimensões $-100 \mathrm{kPa}$

Figura 4.47. Exumação das geogrelhas após os ensaios de arrancamento monotônico e cíclico no equipamento de grandes dimensões $-100 \mathrm{kPa}$

Figura 4.48. Detalhe dos ciclos de carga para a obtenção do módulo de cisalhamento de interface $\mathrm{G}_{\mathrm{i}}-100 \mathrm{kPa}$

Figura 4.49. Comparação do arrancamento cíclico e da resistência pós-ciclagem nos dois equipamentos $-25 \mathrm{kPa}$

Figura 4.50. Exumação das geogrelhas após os ensaios de arrancamento cíclico nos dois equipamentos $-25 \mathrm{kPa}$ 168

Figura 4.51. Comparação do arrancamento cíclico e da resistência pós-ciclagem nos dois equipamentos $-100 \mathrm{kPa}$

Figura 4.52. Exumação das geogrelhas após os ensaios de arrancamento cíclico nos dois equipamentos $-100 \mathrm{kPa}$ 


\section{LISTA DE TABELAS}

Tabela 2.1. Características dos principais polímeros utilizados na fabricação de geogrelhas (Vertematti, 2004)

Tabela 2.2. Equipamentos de arrancamento cíclico no mundo (Modificada de Napa G., 2011)

Tabela 3.1. Coordenadas dos pontos de máxima tensão de cisalhamento no círculo de Mohr

Tabela 3.2. Propriedades geotécnicas dos solos

Tabela 3.3. Constantes de regressão dos modelos mais representativos na estimativa do módulo de resiliência

Tabela 3.4. Propriedades da geogrelha Fornit D30/30-40T utilizada nos ensaios de arrancamento monotônico e cíclico

Tabela 3.5. Resistência à tração não confinada no sentido longitudinal e módulo de rigidez em função do número de elementos

Tabela 3.6. Efeito do peso próprio de uma estrutura de pavimento sobre a inclusão em cada equipamento

Tabela 4.1. Valores de resistência de arrancamento para cada tensão de confinamento Equipamento de pequenas dimensões

Tabela 4.2. Parâmetros de resistência de interface no equipamento de pequenas dimensões

Tabela 4.3. Valores de resistência de arrancamento para cada tensão de confinamento Equipamento de grandes dimensões

Tabela 4.4. Parâmetros de resistência de interface no equipamento de grandes dimensões . 134

Tabela 4.5. Comparação dos valores de resistência de arrancamento - $25 \mathrm{kPa}$

Tabela 4.6. Comparação dos valores de resistência de arrancamento - $50 \mathrm{kPa}$ 146

Tabela 4.7. Comparação dos valores de resistência de arrancamento - $100 \mathrm{kPa}$

Tabela 4.8. Parâmetros de carga cíclica no equipamento de pequenas dimensões 151

Tabela 4.9. Valores de resistência ao arrancamento monotônico inicial e pós-ciclagem no equipamento de pequenas dimensões $-25 \mathrm{kPa}$

Tabela 4.10. Valores de resistência ao arrancamento monotônico inicial e pós-ciclagem no equipamento de pequenas dimensões $-100 \mathrm{kPa}$................................................................ 156

Tabela 4.11. Parâmetros de carga cíclica no equipamento de grandes dimensões.

Tabela 4.12. Valores de resistência ao arrancamento monotônico inicial e pós-ciclagem no equipamento de grandes dimensões $-25 \mathrm{kPa}$

Tabela 4.13. Parâmetros para a obtenção do módulo de cisalhamento de interface $\mathrm{G}_{\mathrm{i}}-25 \mathrm{kPa}$

Tabela 4.14. Valores de resistência ao arrancamento monotônico inicial e pós-ciclagem no equipamento de grandes dimensões $-100 \mathrm{kPa}$ 
Tabela 4.15. Parâmetros para a obtenção do módulo de cisalhamento de interface $\mathrm{G}_{\mathrm{i}}-100 \mathrm{kPa}$ 166

Tabela 4.16. Comparação dos valores de resistência pós-ciclagem - $25 \mathrm{kPa}$ 168

Tabela 4.17. Comparação dos valores de resistência pós-ciclagem - $100 \mathrm{kPa}$ 169 


\section{LISTA DE ABREVIATURAS E SIGLAS}

AASHTO

ABNT

ASTM

ATR

CAUQ

CBR

CD

CLP

$\mathrm{CP}$

$\mathrm{CTH}$

CTV

$\mathrm{CU}$

DER

EESC

Gp

ISO

$\mathrm{L}$

LVDT

NBR

NCHRP

PEAD

PET

PP

$\mathrm{Pp}$

PVC

SNV

SP

SUCS

$\mathrm{T}$

TBR

USP
American Association of State Highway and Transportation Officials Associação Brasileira de Normas Técnicas

American Society for Testing and Materials

Afundamento de Trilha de Roda

Concreto Asfáltico Usinado a Quente

California Bearing Ratio

Consolidated Drained

Controlador Lógico Programável

Corpo de Prova

Célula de Tensão Horizontal

Célula de Tensão Vertical

Consolidated Undrained

Departamento de Estradas de Rodagem de São Paulo

Escola de Engenharia de São Carlos

Grande porte

International Organization for Standardization

LVDT

Linear Variable Differential Transformer

Norma Brasileira

National Cooperative Highway Research Program

Polietileno de Alta Densidade

Poliéster

Polipropileno

Pequeno porte

Polyvinyl Chloride (Policloreto de Vinila)

Sistema Nacional de Viação

São Paulo

Sistema Unificado de Classificação de Solos

Tell-tale

Traffic Benefit Ratio

Universidade de São Paulo 
Ultravioleta 


\section{LISTA DE SÍMBOLOS}

$s^{\prime} \quad$ Abscissas das trajetórias de tensões

$a \quad$ Adesão

$T_{R} \quad$ Afundamento em trilha de roda

$\delta_{i} \quad$ Ângulo de atrito de interface

$\phi$ Ângulo de atrito interno

F $\quad$ Carga aplicada à geogrelha

$V_{i} \quad$ Carga cisalhante

$c^{\prime} \quad$ Coesão drenada

$x_{2} \quad$ Comprimento confinado da amostra no equipamento de grande porte

$x_{1} \quad$ Comprimento confinado da amostra no equipamento de pequeno porte

$l \quad$ Comprimento inicial confinado da amostra

$k_{1}, k_{2}, k_{3} \quad$ Constantes de regressão do modelo

$\varepsilon_{a} \quad$ Deformação axial

$\varepsilon_{r} \quad$ Deformação axial resiliente

$\delta \quad$ Deslocamento

$\delta_{\text {máx }} \quad$ Deslocamento máximo da geogrelha

$\Delta_{b}$

Deslocamento médio acumulado permanente na amostra por causa do arrancamento

$\delta_{\min } \quad$ Deslocamento mínimo da geogrelha

$D_{50} \quad$ Diâmetro médio das partículas de solo

$F_{a} \quad$ Força de arrancamento

$S_{r} \quad$ Grau de saturação

$I_{p} \quad$ Índice de plasticidade

$y_{2} \quad$ Largura confinada da amostra no equipamento de grande porte

$y_{1} \quad$ Largura confinada da amostra no equipamento de pequeno porte

w Largura da amostra

$w_{L} \quad$ Limite de liquidez

$w_{P} \quad$ Limite de plasticidade

$\rho_{s} \quad$ Massa específica dos sólidos

$\rho_{d} \quad$ Massa específica seca

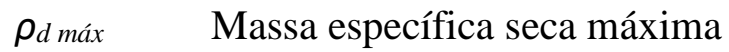




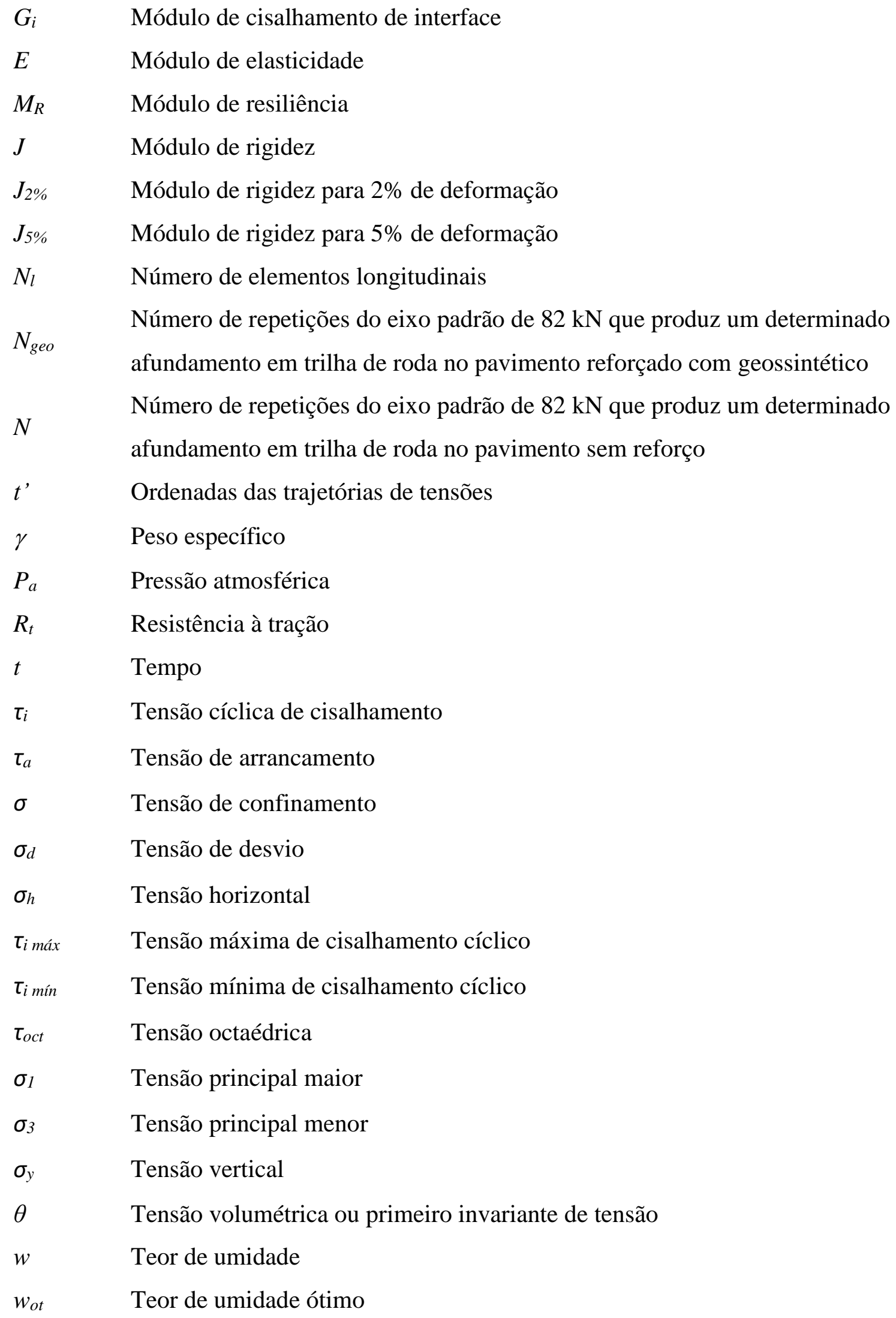




\section{SUMÁRIO}

1. INTRODUÇÃ

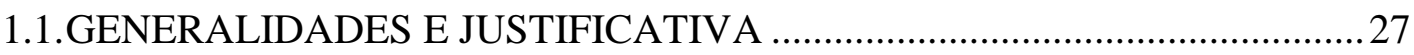

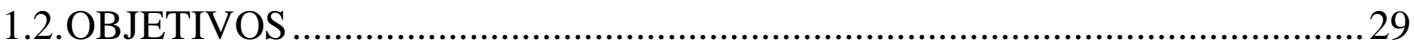

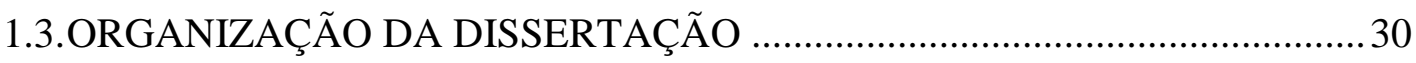

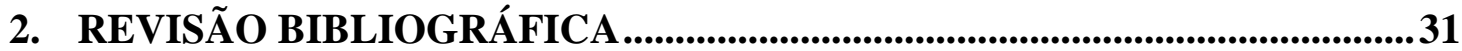

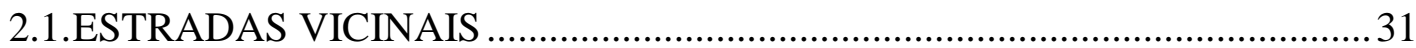

2.1.1.Problemas mais comuns em uma estrada vicinal .......................................32

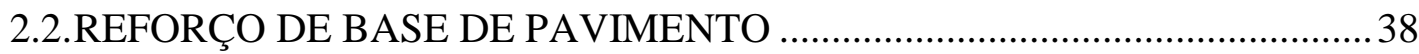

2.3.PROPRIEDADES RESILIENTES DOS SOLOS _.......................................40

2.4.TIPOS DE GEOSSINTÉTICOS UTILIZADOS EM PAVIMENTAÇÃO.........48

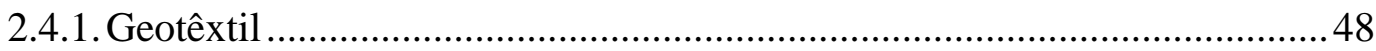

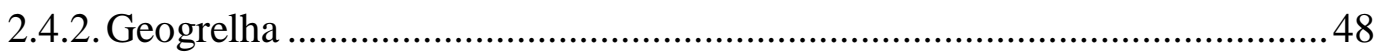

2.5.EFEITOS DOS GEOSSINTÉTICOS COMO REFORÇO DE BASE DE

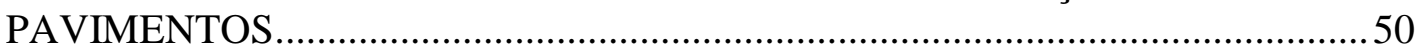

2.5.1.Espessura da camada granular e posicionamento do geossintético.............51

2.5.2. Capacidade de suporte do subleito ......................................................... 52

2.5.3. Propriedades mecânicas do geossintético ...................................................54

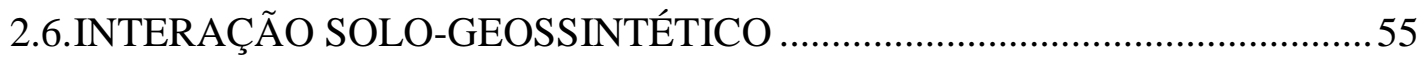

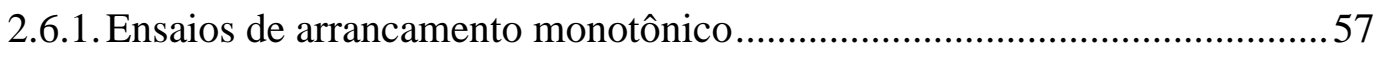

2.6.2. Ensaios de arrancamento cíclico ......................................................... 73

3. MATERIAIS E MÉTODOS........................................................................8 85

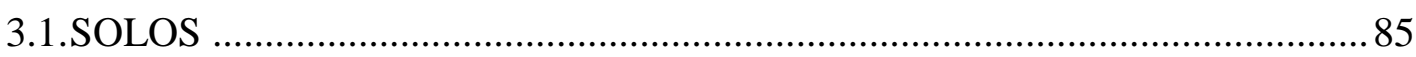

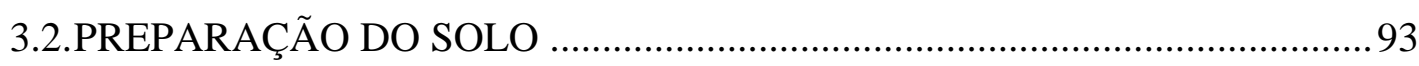

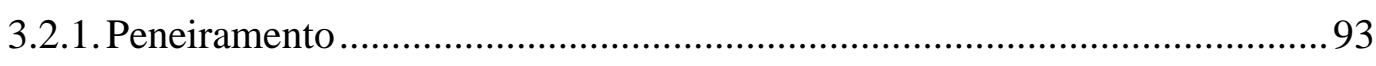

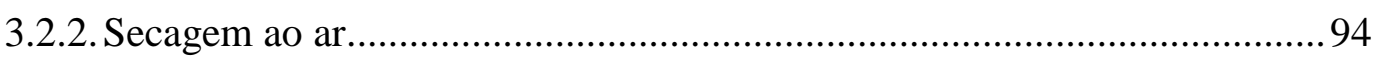

3.2.3. Ajuste da umidade ótima e homogeneização na betoneira ........................ 95

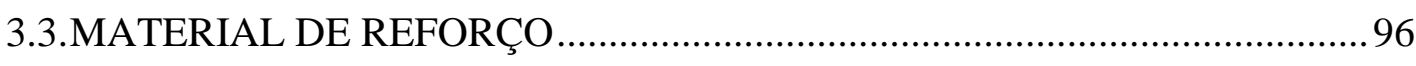

3.4.EQUIPAMENTOS E PROCEDIMENTOS DE MONTAGEM ........................ 99

3.4.1. Procedimento de montagem do equipamento de pequenas dimensões ..... 108

3.4.2. Procedimento de montagem do equipamento de grandes dimensões ....... 111

3.5.INSTRUMENTAÇÃO E AQUISIÇÃO DE DADOS .................................... 114 
4. RESULTADOS E DISCUSSÃO ...............................................................19

4.1.ARRANCAMENTO MONOTÔNICO ……………………………………..... 120

4.1.1.Equipamento de pequenas dimensões ..................................................... 121

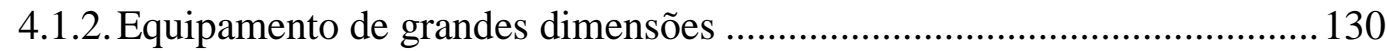

4.1.3. Comparação dos resultados obtidos nos dois equipamentos....................... 141

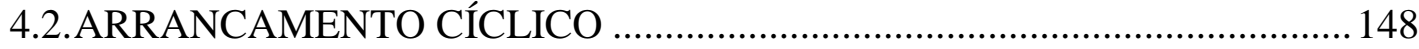

4.2.1.Equipamento de pequenas dimensões ........................................................ 150

4.2.2. Equipamento de grandes dimensões ........................................................ 156

4.2.3. Comparação dos resultados obtidos nos dois equipamentos....................... 166

5. CONCLUSÕES E SUGESTÕES PARA TRABALHOS FUTUROS .............171

REFERÊNCIAS BIBLIOGRÁFICAS......................................................................177 


\section{Capítulo 1}

\section{INTRODUÇÃO}

\subsection{Generalidades e justificativa}

$\mathrm{Na}$ atualidade, a alta demanda da construção civil, o crescimento populacional e a escassez de terrenos urbanos, têm sido os motivos principais para as obras de engenharia se tornarem um grande desafio para os projetistas, pois veem-se obrigados a construir sobre solos com características desfavoráveis, por exemplo, com baixa capacidade de suporte e com o lençol freático superficial. Sendo assim, existe a necessidade de adotar soluções geotécnicas adequadas que permitam melhorar as condições do terreno, viabilizando a construção de qualquer tipo de obra de engenharia nesses locais.

Com o passar do tempo, as técnicas de reforço de materiais com baixa resistência à tração, como o solo, continuam evoluindo e sendo cada vez mais empregadas em obras civis. Assim, desde a segunda metade do século XX, vêm-se usando fitas de aço, malhas hexagonais de dupla torção e, a partir da década de 60, vários tipos de geossintéticos (Sieira, 2003).

O uso desses materiais em obras de solo reforçado apresenta inúmeras vantagens técnicas, construtivas e econômicas em comparação com as técnicas tradicionais, levando-os a serem cada vez mais utilizados e difundidos.

Uma das aplicações dos geossintéticos é o seu uso como material de reforço em diferentes estruturas, sendo de grande utilidade no caso das estradas, pois é uma solução econômica que permite trabalhar com solos de baixa capacidade de suporte, reduz consideravelmente as deformações causadas pelo tráfego e aumenta a vida útil da estrutura de pavimento, contribuindo assim na diminuição dos custos envolvidos na construção e manutenção desse tipo de obras.

Segundo o Sistema Nacional de Viação (SNV), dos quase 1,7 milhão de 
quilômetros de estradas que cortam o Brasil, pelo qual escoa $58 \%$ do volume nacional de cargas, 80,3\% das estradas - mais de 1,3 milhão de quilômetros - são não pavimentadas (http://oglobo.globo.com/brasil/no-brasil-80-das-estradas-nao-contamcom-pavimentacao-13710994 em 10/2014). Dessa maneira, é preciso garantir a funcionalidade e o bom estado dessas estradas adotando soluções econômicas, pois o fato de pavimentá-las envolveria uma grande quantidade de recursos.

Com relação à aplicação dos geossintéticos como materiais de reforço em estradas não pavimentadas, as pesquisas desenvolvidas por Cunha (1991); Fannin e Sigurdsson (1996); Giroud et al. (2004); Hufenus et al. (2006); Pimentel (2007); Palmeira e Antunes (2010); Góngora (2011); Ibrahim et al. (2012); Perkins et al. (2012); Latha (2013) e Ravi et al. (2014), mostram a grande quantidade de benefícios que esses materiais geram nesse tipo de estradas quando a estrutura é submetida a um carregamento cíclico.

Segundo Perkins (1999), a função do material de reforço de base de pavimentos é desenvolvida pela interação entre as camadas de solo e o geossintético contido no interior ou na parte inferior da base. Assim, o ensaio que melhor avalia a interação entre o solo e o geossintético é o de arrancamento, pois a mobilização cisalhante combina a deformação da interface solo-reforço e o alongamento do geossintético (Palmeira e Milligan, 1989).

Com a passagem dos veículos sobre a estrada é produzido um efeito dinâmico na estrutura de pavimento, onde são geradas tensões laterais na base logo abaixo do carregamento aplicado, comprometendo ao mesmo tempo o desempenho e a vida útil do pavimento. Considerando então o efeito dinâmico por causa do tráfego e a interação entre as camadas de solo e o geossintético, pensa-se na realização de ensaios de arrancamento cíclico com o intuito de avaliar esse efeito, tal como fizeram Raju e Fannin (1998); Meyer et al. (2004); Nernheim e Meyer (2004); Cuelho e Perkins (2005); Holley (2009); Moraci e Cardile (2009); Nayeri e Fakharian (2009), Moraci e Cardile (2011), Napa G. (2011) e Campos (2013).

Dessa maneira, neste trabalho é analisado o efeito produzido por carregamentos monotônicos e cíclicos de interface numa geogrelha biaxial de polipropileno inserida na interface de um solo argiloso e um solo arenoso, a qual é submetida a diferentes tensões de confinamento nos equipamentos de pequenas e grandes dimensões do Laboratório de Geossintéticos da EESC-USP. 


\subsection{Objetivos}

Com o uso dos equipamentos de arrancamento de pequenas e grandes dimensões do Laboratório de Geossintéticos da EESC-USP, o objetivo geral deste trabalho é comparar o efeito dos carregamentos monotônicos e cíclicos de interface aplicados na geogrelha biaxial de polipropileno utilizada como reforço da estrutura mencionada, sob diferentes tensões de confinamento.

Dessa maneira, foram definidos os seguintes objetivos específicos:

- Definir e caracterizar dois tipos de solo da região de São Carlos - SP que serão utilizados como material de subleito e de base para simular uma estrada vicinal;

- Definir e caracterizar por meio de ensaios físicos e mecânicos a geogrelha a ser utilizada como material de reforço das estruturas propostas nos dois equipamentos;

- Realizar ensaios de arrancamento monotônico e cíclico nos equipamentos de pequenas e grandes dimensões do Laboratório de Geossintéticos da EESCUSP, com o intuito de comparar o efeito dos carregamentos aplicados na interface solo-geogrelha sob diferentes tensões de confinamento;

- Comparar e analisar os resultados obtidos por meio de cada equipamento, levando em consideração as propriedades dos tipos de solo utilizados; a área ocupada pela geogrelha em cada equipamento; os resultados obtidos e as recomendações de outros pesquisadores que realizaram os mesmos tipos de ensaio; a tensão de confinamento aplicada e a sua distribuição sobre a área interna de cada equipamento; o tipo de geogrelha utilizado como material de reforço e o nível de tensão cisalhante aplicado;

- Analisar o efeito do carregamento dinâmico na resistência ao arrancamento monotônico obtida após a aplicação dos ciclos de carga em cada equipamento;

- Analisar o comportamento resiliente do sistema por meio do módulo de cisalhamento de interface obtido para cada tensão de confinamento aplicada no equipamento de grandes dimensões;

- Dar sugestões para trabalhos futuros com o intuito de continuar enriquecendo 
o tema abordado nesta pesquisa.

\subsection{Organização da dissertação}

Esta dissertação é composta por 5 capítulos. No capítulo 2 apresenta-se a revisão bibliográfica onde são levados em consideração aspectos gerais das estradas não pavimentadas junto com os problemas mais comuns que nelas se apresentam; a aplicação dos geossintéticos como reforço de base de pavimentos; as características dos geossintéticos mais utilizados para desempenhar funções de reforço e aspectos importantes relacionados à interação entre o solo e o geossintético por meio dos ensaios de arrancamento monotônico e cíclico, tanto em equipamentos de pequenas como de grandes dimensões.

O capítulo 3, trata da caracterização completa dos materiais e os métodos utilizados na execução dos ensaios de arrancamento monotônico e cíclico nos equipamentos de pequenas e grandes dimensões do Laboratório de Geossintéticos da EESC-USP. Por outro lado, também são especificados os procedimentos de preparação do solo e de montagem dos equipamentos, os quais serão de grande utilidade nas próximas pesquisas onde sejam realizados os mesmos tipos de ensaio.

No capítulo 4 mostram-se os resultados obtidos a partir dos ensaios de arrancamento monotônico e cíclico em ambos os equipamentos, assim como a sua respectiva análise e discussão com base no efeito da tensão de confinamento e a sua distribuição sobre a área ocupada pela geogrelha; nas características dos solos utilizados para conformar as estruturas propostas; nas características da geogrelha utilizada como material de reforço; no nível de tensão cisalhante aplicado e na influência do carregamento dinâmico aplicado.

Finalmente, o capítulo 5 apresenta a conclusão da dissertação com base nos resultados obtidos em cada equipamento e as sugestões para futuras pesquisas relacionadas com o tema abordado. 


\section{Capítulo 2}

\section{REVISÃO BIBLIOGRÁFICA}

\subsection{Estradas vicinais}

Segundo o Manual Básico de Estradas e Rodovias Vicinais (2012), as estradas vicinais, que podem ser pavimentadas ou não, são em geral municipais, locais, de uma só pista e representam mais de $80 \%$ da extensão total das estradas do estado de São Paulo, mesmo que suportem menos de $10 \%$ do tráfego total. No entanto, com o avanço da tecnologia com relação às produções agrícolas e aos equipamentos de transporte, existem regiões onde o transporte de grandes produções é feito por meio das estradas vicinais com uso de veículos pesados, tal como acontece no caso da cana de açúcar, álcool, papel de celulose e grãos de exportação.

Dessa maneira, as estradas e rodovias vicinais passam a desempenhar funções que não foram previstas em sua concepção, tais como:

- Complementar a utilização dos sistemas coletor e arterial;

- Promover a integração demográfica territorial e cultural da região na qual se situam;

- Possibilitar a elevação do nível de renda do setor primário, facilitando o escoamento da produção e dos insumos (atividades agropecuárias, agroindustriais, de mineração, etc.);

- Permitir acessos a locais turísticos e históricos, entre outros.

Como qualquer rodovia, as estradas vicinais também devem garantir condições satisfatórias de tráfego, e para isso, é imprescindível que apresentem uma boa capacidade de suporte e boas condições de rolamento e aderência (Santos et al., 1988). 
Os problemas que ocorrem com maior frequência nas estradas não pavimentadas estão relacionados com a baixa capacidade de suporte do subleito, pois podem aparecer deformações devidas ao tráfego em forma de ondulações transversais e de rodeiros, intensificando-se ainda mais com a ação da chuva. Dessa maneira, para garantir uma boa capacidade de suporte e evitar as deformações frente às solicitações de tráfego, recomenda-se usar materiais granulares devidamente compactados (Santos et al., 1988).

Embora os materiais granulares compactados permitam melhoria quanto à diminuição das deformações, não estão garantindo as boas condições de rolamento e aderência. Uma estrada com boa aderência e boas condições de rolamento não permite patinação das rodas dos veículos e não existe esburacamento nem materiais soltos.

Os materiais granulares, tais como areia e cascalho, são os responsáveis pelas boas condições de atrito, mas isso não é suficiente pois não existe ligação entre os grãos. Dessa maneira, não se garantem as condições satisfatórias de tráfego, surgindo a necessidade de utilizar um material que aglutine fortemente os grãos e que impeça a aparição de problemas como patinação, formação de "costelas de vaca" e de buracos (Santos et al., 1988).

Considerando que o material ligante natural mais adequado é a argila, pode-se concluir que para garantir uma boa capacidade de suporte e boas condições de rolamento e aderência numa estrada vicinal, precisa-se de uma camada de revestimento devidamente compactada, conformada por uma mistura de material granular e argila.

\subsubsection{Problemas mais comuns em uma estrada vicinal}

Como já foi mencionado anteriormente, é comum encontrar problemas numa estrada vicinal, os quais podem piorar com a ação conjunta da chuva e do tráfego. Sendo assim, as principais causas que originam esses problemas estão relacionadas com a baixa capacidade de suporte do subleito, com o mau desempenho da superfície de rolamento e com a deficiência do sistema de drenagem, sendo que a última sempre agrava os problemas, mesmo não sendo a sua causa original (Santos et al., 1988).

Dessa maneira, a seguir são mostrados os problemas observados com maior frequência nas estradas vicinais. 


\subsubsection{Ondulações, rodeiros e atoleiros}

Segundo Santos et al. (1988), as ondulações, rodeiros e atoleiros, apresentadas na Figura 2.1 a seguir, têm como causas principais a baixa capacidade de suporte do subleito e a ausência ou deficiência do sistema de drenagem. Dessa maneira, a solução para esses problemas deve começar com a retirada da água acumulada no local através de valetas e sangras. Posteriormente, coloca-se uma camada de reforço e finalmente, executa-se o revestimento primário garantindo um sistema de drenagem adequado.
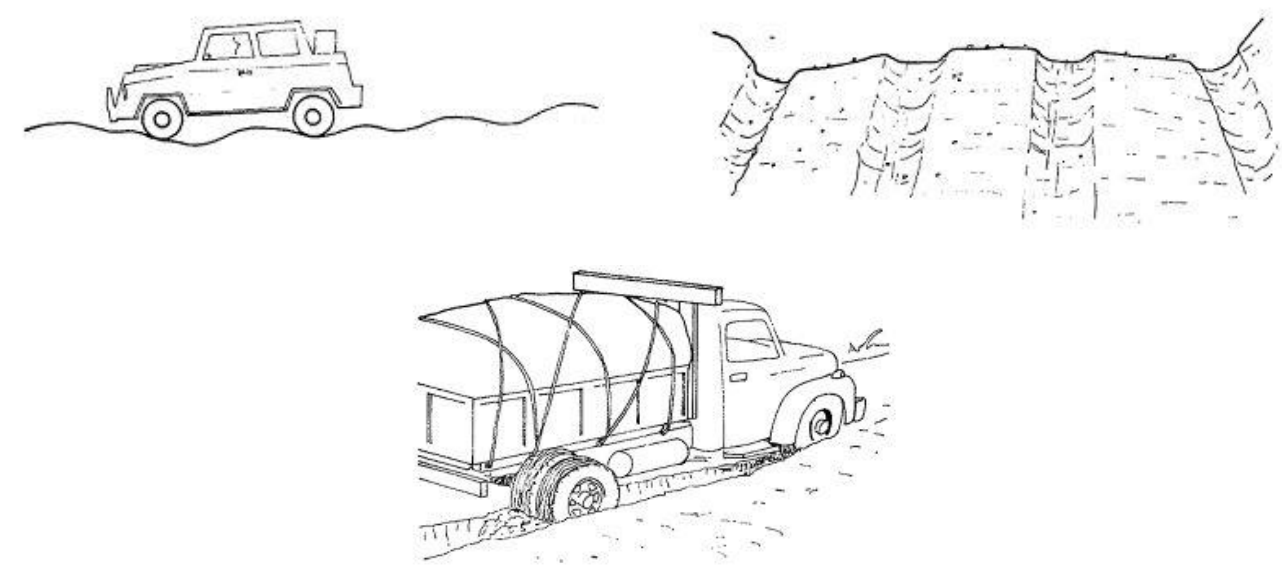

Figura 2.1. Ondulações, rodeiros e atoleiros (ESTRADAS VICINAIS DE TERRA. Manual Técnico para Conservação e Recuperação, 1988)

Por outro lado, os atoleiros são formados em muitos casos por causa da presença do lençol freático no leito da estrada. Quando isso ocorrer, a camada de reforço e o revestimento primário não são suficientes, precisando então da construção de um dreno profundo que permita rebaixar o nível da água. A profundidade do dreno geralmente é de cerca de 1,50 m e o comprimento depende da extensão do trecho problemático.

\subsubsection{Areiões de espigão}

Este tipo de problema acontece normalmente em regiões de solos arenosos, onde é muito pequena ou inexistente a presença de argila. O problema surge por causa da ação combinada do tráfego e da lavagem do material por causa da chuva, caracterizandose pela presença de uma camada de areia solta em tempo seco. Assim, como solução a 
esse problema propõe-se a mistura de argila com a areia do leito na proporção 1:2,5 (Santos et al., 1988).

\subsubsection{Areiões de baixada}

Os areiões de baixada também acontecem em regiões onde predominam os solos arenosos, só que neste caso, a formação destes areiões é causada pela ação da água que traz a areia de trechos altos adjacentes. Dessa maneira, é possível afirmar que a solução para este problema é a mesma do caso anterior, sendo ainda fundamental dar uma solução à erosão dos trechos altos, pois caso contrário, se acumulariam novas camadas de areia sobre o trecho da baixada (Santos et al., 1988).

\subsubsection{Excesso de pó}

Segundo Santos et al. (1988), a causa principal deste problema é a presença de uma grande quantidade de material fino sobre a estrada, onde em épocas secas, formamse nuvens de poeira com o tráfego veicular (Figura 2.2), colocando em risco a sua segurança, gerando problemas de saúde nas pessoas que moram perto da estrada e afetando a vida útil dos motores dos veículos. Dessa maneira, a solução proposta para este problema baseia-se num revestimento primário selante.

No caso dos solos finos siltosos, este problema se agrava pois a formação de poeira é mais intensa e a capacidade de suporte desse material é baixa.

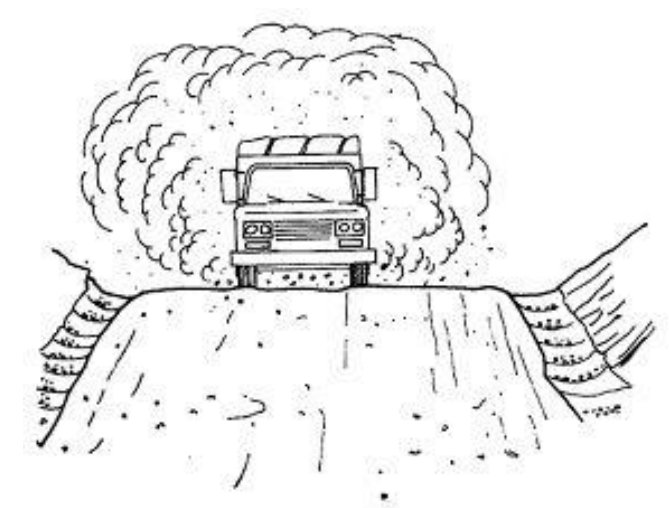

Figura 2.2. Excesso de pó (ESTRADAS VICINAIS DE TERRA. Manual Técnico para Conservação e Recuperação, 1988) 


\subsubsection{Rocha aflorante}

Este tipo de problema acontece normalmente em regiões onde a camada de solo é pouco espessa ou onde existe a presença de grandes blocos disseminados no solo. Assim, a exposição do leito rochoso numa estrada vicinal (Figura 2.3.a), que também pode ser por causa da ação de processos erosivos ou pela constante passagem dos veículos, faz com que a pista se torne bastante irregular, prejudicando ou até inviabilizando o tráfego (Santos et al., 1988).

Quanto às soluções, Santos et al. (1988) propõem a execução de uma camada de revestimento primário de cobertura (Figura 2.3.b), ou a obturação das cavidades com pedra e argamassa de cimento quando o trecho for curto (Figura 2.3.c).

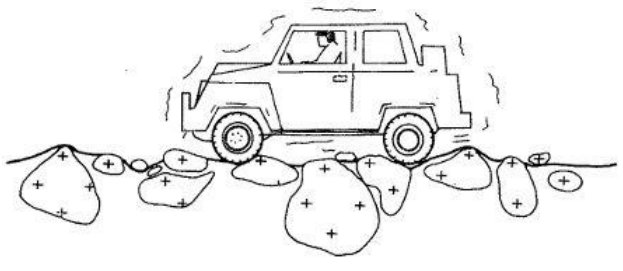

(a)

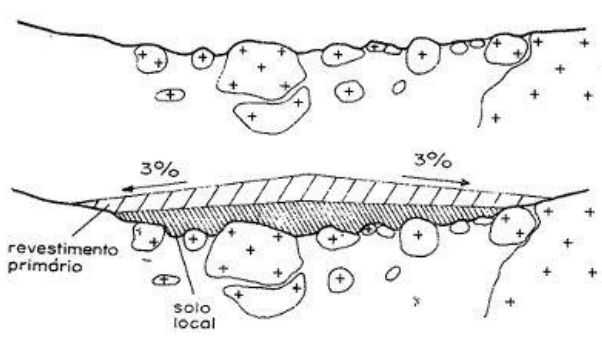

(b)
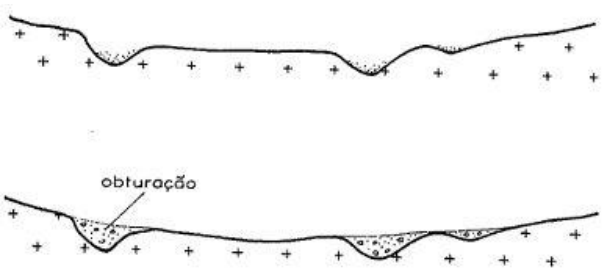

(c)

Figura 2.3. (a) Rocha aflorante; (b) Camada de revestimento primário; (c) Obturação de cavidades com pedra e argamassa (ESTRADAS VICINAIS DE TERRA. Manual Técnico para Conservação e Recuperação, 1988)

\subsubsection{Pista molhada derrapante}

Quando existem trechos muito argilosos é muito comum ter uma pista derrapante e escorregadiça quando molhada, pois fica sem atrito e sem aderência (Figura 2.4). Dessa maneira, se a capacidade de suporte for boa, a solução mais adequada para esse 
problema leva em consideração o agulhamento de material granular diretamente sobre o leito da estrada (Santos et al., 1988).

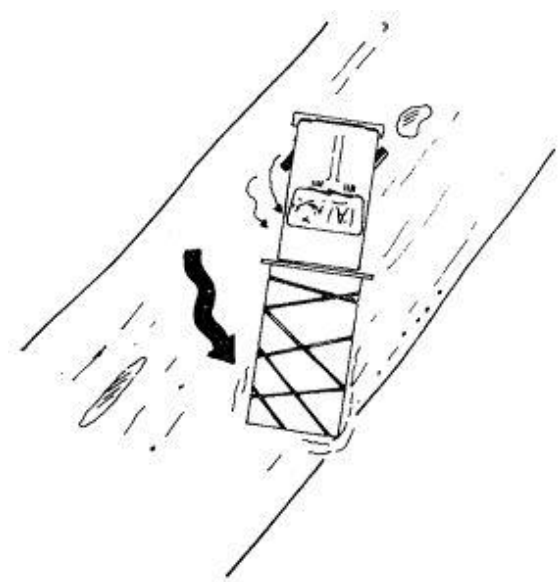

Figura 2.4. Pista molhada derrapante (ESTRADAS VICINAIS DE TERRA. Manual Técnico para Conservação e Recuperação, 1988)

\subsubsection{Pista seca derrapante}

Quando existe presença de material granular de qualquer tamanho sem ligante ou o material de revestimento da estrada encontra-se deteriorado por causa de uma má execução, a pista torna-se derrapante em estado seco (Figura 2.5). Dessa maneira, a principal solução para esse problema baseia-se na substituição do material granular superficial por um revestimento primário. No caso em que o leito for argiloso e o material granular muito grosseiro, é possível pensar na realização de um agulhamento (Santos et al., 1988).

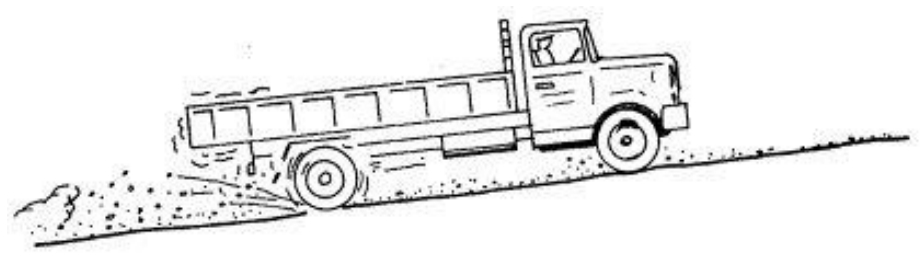

Figura 2.5. Pista seca derrapante (ESTRADAS VICINAIS DE TERRA. Manual Técnico para Conservação e Recuperação, 1988) 


\subsubsection{Buracos}

Segundo Santos et al. (1988), a formação dos buracos se dá pela expulsão dos sólidos por parte do tráfego em locais onde existe empoçamento de água (Figura 2.6). Sendo assim, a principal causa desse problema é a drenagem insuficiente da pista, a inexistência de um tratamento primário e/ou a falta de ligante argiloso.

Sendo que a principal causa dos buracos é um sistema de drenagem mal dimensionado e/ou executado, recomenda-se então a construção de abaulamentos transversais, valetas e sangras, e posteriormente proceder tapando os buracos isolados.

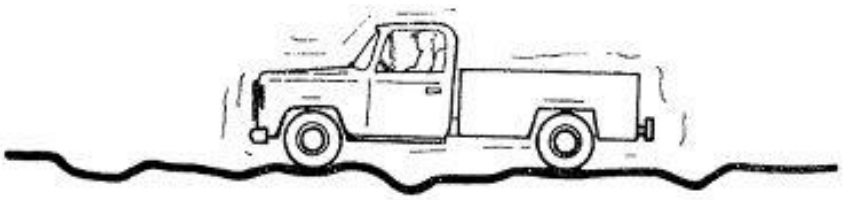

Figura 2.6. Buracos (ESTRADAS VICINAIS DE TERRA. Manual Técnico para Conservação e Recuperação, 1988)

\subsubsection{Erosões em ravina}

As erosões em ravina são um dos problemas mais sérios que acontecem nas estradas vicinais, pois podem evoluir até apresentar grandes dimensões. Sua principal causa de ocorrência é a inexistência ou deficiência de um sistema de drenagem, que dá origem a erosões em forma de sulcos onde os solos têm pouca coesão, podendo evoluir para grandes ravinamentos sob a ação de enxurradas, ou até as denominadas voçorocas se a erosão atingir o lençol freático (Figura 2.7).

Sendo assim, a solução do problema baseia-se na execução de um sistema eficiente de drenagem onde o escoamento e o empoçamento das águas sobre a estrada seja evitado (Santos et al., 1988). 


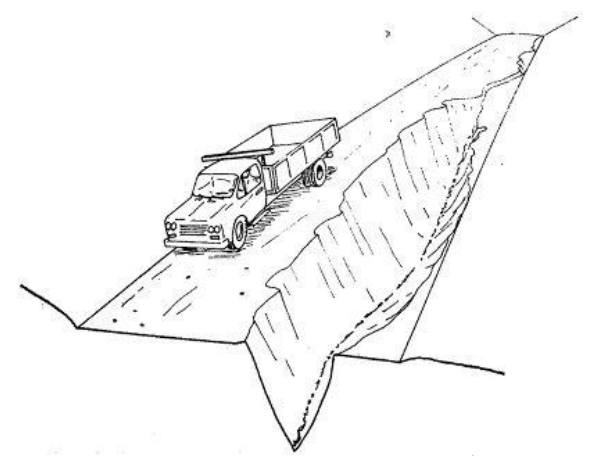

Figura 2.7. Erosões em ravina (ESTRADAS VICINAIS DE TERRA. Manual Técnico para Conservação e Recuperação, 1988)

\subsection{Reforço de base de pavimento}

Tal como acontece nas estruturas, onde o concreto é reforçado com aço, na geotecnia o solo precisa ser reforçado com elementos resistentes à tração quando for muito deformável e sua capacidade de suporte for muito baixa.

O solo é um material que, dependendo do seu estado e das suas características, tem uma boa resistência aos esforços compressivos, mas a sua resistência à tração é muito baixa. Por causa disso, em alguns casos precisa ser modificada por meio de técnicas que melhorem o seu desempenho e capacidade.

Segundo Vertematti (2004), as técnicas empregadas para reforço de solos têm evoluído consideravelmente, dando grande importância aos geossintéticos pois permitem associações e combinações com solos e agregados, resultando em soluções mais práticas, leves, esbeltas, confiáveis e econômicas.

Mesmo que a função principal do geossintético em uma determinada obra seja o reforço, existem certas variações nos tipos de solicitações relacionadas ao tempo de duração, à intensidade, ao mecanismo de interação, ao nível de deformação, etc., que exigem estudos diferenciados e específicos para cada aplicação (Vertematti, 2004).

No caso das estruturas de pavimento apoiadas sobre subleitos com baixa capacidade de suporte, os problemas mais comuns estão relacionados às deformações causadas pela baixa resistência do solo, onde ao invés de utilizar camadas de reforço com grandes espessuras, o geossintético, especificamente a geogrelha, está se tornando a solução mais adequada devido a sua instalação simples, a sua elevada resistência à tração e à excelente interação mecânica com o material no qual ela é inserida. 
No entanto, a aplicação dos geossintéticos como materiais de reforço em obras rodoviárias requer uma consideração especial, pois o tráfego gera um efeito dinâmico na inclusão, submetendo-a a ciclos de carga e descarga. Assim, é necessário estudar as suas propriedades relevantes para a sua correta especificação.

Segundo Klein et al. (2003), a inserção de um geossintético como material de reforço de pavimentos proporciona algumas melhorias em seu desempenho tais como redução das espessuras das camadas granulares e aumento da sua vida útil, contribuindo assim para uma redução considerável dos custos durante a construção e manutenção da obra.

De igual maneira, Kakuda (2005) menciona com base nos resultados de diferentes pesquisas que ao comparar pavimentos reforçados e pavimentos sem reforço, as estruturas com reforço de base apresentaram uma vida útil até três vezes maior e as espessuras das camadas foram reduzidas entre $20 \%$ e $50 \%$.

Sendo que o uso da geogrelha como material de reforço de base de pavimento proporciona uma série de benefícios para a estrutura, como o aumento da capacidade de suporte da camada granular, o excelente desempenho da inclusão está relacionado em grande parte a quatro tipos de comportamento: o intertravamento, o impedimento dos movimentos laterais, o confinamento e a separação entre as camadas (Kakuda, 2005).

Assim, na Figura 2.8 mostra-se o efeito do uso da geogrelha como material de reforço de base de pavimento em relação à distribuição mais homogênea das tensões no subleito.

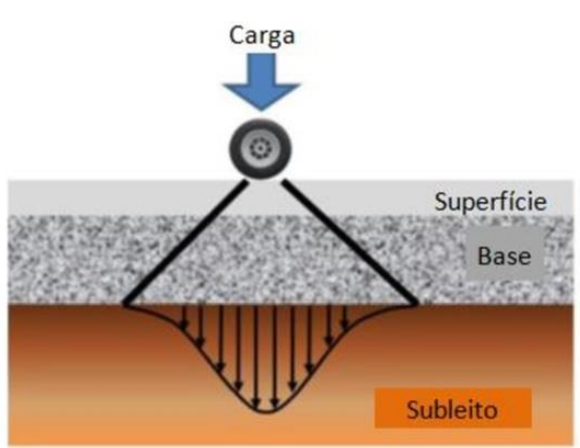

(a)

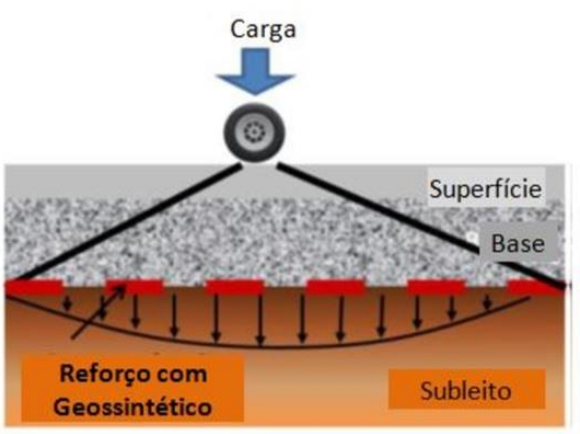

(b)

Figura 2.8. Distribuição de tensões no subleito em (a) pavimento sem reforço e (b) pavimento com reforço de base (Gupta, 2009) 
Por outro lado, Antunes (2008) menciona que as geogrelhas são mais utilizadas como material de reforço de pavimentos rodoviários em três situações:

a) Na construção de pavimentos sobre solos moles ou com baixa capacidade de suporte;

b) Quando existe a necessidade de melhorar o desempenho do pavimento ou aumentar a sua vida útil;

c) Com o objetivo de reduzir as deformações elásticas e plásticas ocasionadas pelo tráfego.

Dessa maneira, os geossintéticos, especificamente as geogrelhas, podem ser utilizadas como material de reforço de base de pavimentos em construção, ou também, como reforço de capa asfáltica quando pretende-se restaurar pavimentos flexíveis degradados.

\subsection{Propriedades resilientes dos solos}

No momento em que um veículo passa por uma estrada, os pneus transmitem cargas que são absorvidas pela estrutura de pavimento. Dessa maneira, um elemento diferencial de solo localizado no subleito é submetido a um estado de tensões que ao mesmo tempo induzem um estado de deformações. Se o comportamento do material do subleito for considerado elástico, isotrópico e homogêneo, as tensões e as deformações seriam relacionadas com o módulo de elasticidade e com o coeficiente de Poisson (Mendoza e Lázares, 2003).

Entretanto, as cargas transmitidas pelos veículos geram um efeito dinâmico nos materiais que compõem a estrutura de pavimento, submetendo-os a ciclos de carga e descarga onde a deformação total induzida recupera-se parcialmente ao diminuir o tempo de aplicação da carga, implicando assim que os materiais não apresentem um comportamento totalmente elástico pois parte da deformação não é recuperada. Por causa disso, é preciso introduzir o termo de módulo de resiliência $\left(\mathrm{M}_{\mathrm{R}}\right)$, que corresponde a um módulo de elasticidade no qual são relacionadas as cargas aplicadas com as deformações recuperáveis (Mendoza e Lázares, 2003).

Assim, na norma técnica AASHTO T 307-99 define-se o módulo de resiliência de um solo como a relação entre a tensão de desvio $\left(\sigma_{\mathrm{d}}\right)$ aplicada repetidamente em uma 
amostra de solo em ensaio triaxial, e a correspondente deformação recuperável ou resiliente $\left(\varepsilon_{\mathrm{r}}\right)$, conforme mostrado na Equação (2.1) e na Figura 2.9 a seguir:

$$
M_{R}=\frac{\sigma_{d}}{\varepsilon_{r}}
$$

Onde:

- $\mathrm{M}_{\mathrm{R}}$ : Módulo de resiliência em [MPa];

- $\sigma_{\mathrm{d}}$ : Tensão de desvio $\left(\sigma_{1}-\sigma_{3}\right)$, aplicada repetidamente;

- $\varepsilon_{\mathrm{r}}$ : Deformação axial resiliente, correspondente a um determinado número de aplicações de $\sigma_{\mathrm{d}}$.

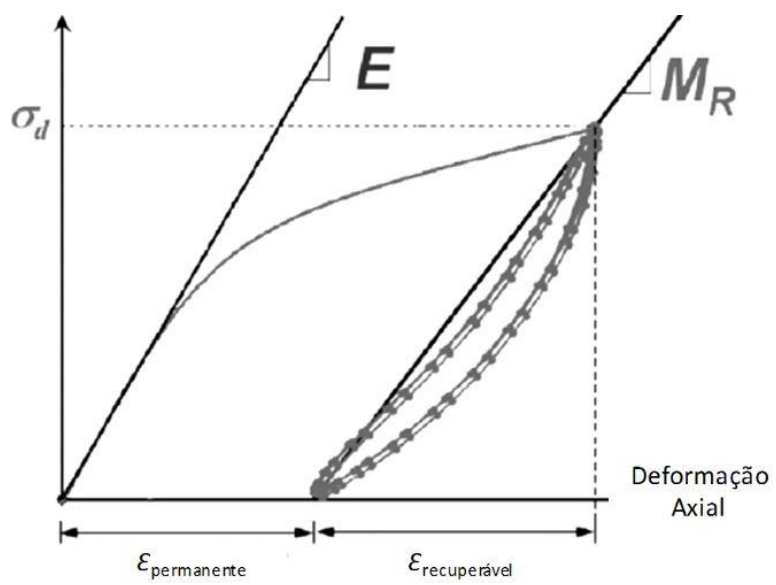

Figura 2.9. Comparação entre o módulo de elasticidade e o módulo de resiliência (Campos, 2013)

Segundo Marmitt et al. (2010), em estudos anteriores foram obtidos resultados no laboratório em que o comportamento resiliente dos solos é influenciado por fatores como o estado de tensões, a composição granulométrica, a umidade do material, a densidade e a energia de compactação. Assim, Viana (2007) faz uma recopilação de trabalhos onde foi analisada a variação do módulo de resiliência em função de cada um dos fatores mencionados anteriormente.

Com relação ao estado de tensões, Hicks e Monismith (1971) apud Viana (2007) e Uzan (1985) chegaram a concluir que o módulo de resiliência geralmente apresenta um comportamento não linear com a variação do estado de tensões no solo, que pode 
ser por causa da ação de carregamentos externos, de alterações nas espessuras das camadas que compõem a estrutura do pavimento e de diferenças no peso específico dos materiais.

Por outro lado, os modelos que existem sobre o comportamento do módulo de resiliência em função das tensões atuantes no solo levam em consideração os resultados do ensaio triaxial cíclico para a obtenção das constantes de calibração, sendo que com o avanço das ferramentas computacionais, atualmente os modelos são mais sofisticados pois envolvem mais componentes de tensão e um maior número de constantes de regressão (Viana, 2007).

Hicks e Monismith (1971) apud Viana (2007) apresentaram os primeiros modelos onde o módulo de resiliência dos materiais granulares era relacionado com a tensão de confinamento ou com a soma das tensões principais, como mostrado nas Equações (2.2) e (2.3) a seguir:

$$
M_{R}=k_{1} \sigma_{3}{ }^{k_{2}}
$$

e

$$
M_{R}=k_{1} \theta^{k_{2}}
$$

Onde:

- $\mathrm{M}_{\mathrm{R}}$ : Módulo de resiliência;

- $\mathrm{k}_{1}$ e k2: Constantes de regressão do modelo obtidas a partir dos resultados de ensaios triaxiais cíclicos;

- $\sigma_{3}$ : Tensão de confinamento;

- $\theta=\sigma_{1}+\sigma_{2}+\sigma_{3}$ : Tensão volumétrica ou primeiro invariante de tensão.

Como pode-se observar, nas Equações (2.2) e (2.3) mostradas anteriormente sugere-se a relação não linear que existe entre o módulo de resiliência e o estado de tensões no solo. Entretanto, no caso da Equação (2.2) o módulo de resiliência é relacionado de forma não linear com a tensão de confinamento, a qual no ensaio triaxial cíclico não é diretamente responsável pelo cisalhamento ou pela geração de deformações angulares no material (Viana, 2007). 
Por causa disso, Uzan (1985) sugeriu um modelo que apresentava uma boa concordância com o comportamento dos materiais granulares, pois dependia da tensão de desvio aplicada e levava em consideração as tensões cisalhantes atuantes no solo, como mostrado na Equação (2.4) a seguir.

$$
M_{R}=k_{1} \theta^{k_{2}} \sigma_{d}^{k_{3}}
$$

Onde:

- $\mathrm{M}_{\mathrm{R}}$ : Módulo de resiliência;

- $\mathrm{k}_{1}, \mathrm{k}_{2}$ e $\mathrm{k}_{3}$ : Constantes de regressão do modelo;

- $\sigma_{\mathrm{d}}=\sigma_{1}-\sigma_{3}$ : Tensão de desvio;

- $\sigma_{\mathrm{d}}>0,1 \sigma_{3}$;

- $\theta=\sigma_{1}+\sigma_{2}+\sigma_{3}$ : Tensão volumétrica ou primeiro invariante de tensão.

Por outro lado, Witczak e Uzan (1988) apud Viana (2007) desenvolveram um modelo semelhante ao proposto por Uzan (1985), pois também leva em consideração a tensão volumétrica $(\theta)$ e a tensão de desvio $\left(\sigma_{\mathrm{d}}\right)$, como mostrado nas Equações (2.5), (2.6) e (2.7) a seguir.

$$
\frac{M_{R}}{P_{a}}=k_{1}\left(\frac{\theta}{P_{a}}\right)^{k_{2}}\left(\frac{\tau_{o c t}}{P_{a}}\right)^{k_{3}}
$$

Onde,

- $\mathrm{M}_{\mathrm{R}}$ : Módulo de resiliência;

- $\mathrm{k}_{1}, \mathrm{k}_{2}$ e $\mathrm{k}_{3}$ : Constantes de regressão do modelo;

- $\mathrm{P}_{\mathrm{a}}$ : Pressão atmosférica;

- $\theta=\sigma_{1}+\sigma_{2}+\sigma_{3}$ : Tensão volumétrica ou primeiro invariante de tensão.

- $\tau_{\text {oct: }}$ Tensão octaédrica. Ver Equação (2.6).

$$
\tau_{o c t}=\frac{\sqrt{\left(\sigma_{1}-\sigma_{2}\right)^{2}+\left(\sigma_{1}-\sigma_{3}\right)^{2}+\left(\sigma_{2}-\sigma_{3}\right)^{2}}}{3}
$$


Adicionalmente, no ensaio triaxial tem-se que as tensões $\sigma_{2}$ e $\sigma_{3}$ são iguais e que a diferença das tensões $\sigma_{1}$ e $\sigma_{3}$ corresponde à tensão de desvio $\sigma_{\text {d. }}$ Por causa disso, a Equação (2.6) fica reduzida na seguinte Equação:

$$
\tau_{o c t}=\sigma_{d} \frac{\sqrt{2}}{3}
$$

Finalmente, na Equação (2.8) a seguir é mostrado um outro modelo que na maioria das vezes apresenta o melhor ajuste matemático, mas não tem uma relação física respectiva ao comportamento resiliente dos materiais. Tal modelo é conhecido na literatura como composto ou combinado, pois a determinação do módulo de resiliência depende tanto da tensão de confinamento quanto da tensão de desvio.

$$
M_{R}=k_{1}{\sigma_{3}}^{k_{2}}{\sigma_{d}}^{k_{3}}
$$

Onde,

- $\mathrm{M}_{\mathrm{R}}$ : Módulo de resiliência;

- $\mathrm{k}_{1}, \mathrm{k}_{2}$ e $\mathrm{k}_{3}$ : Constantes de regressão do modelo;

- $\sigma_{3}$ : Tensão de confinamento;

- $\sigma_{\mathrm{d}}=\sigma_{1}-\sigma_{3}:$ Tensão de desvio.

Considerando a composição granulométrica, Hicks e Monismith (1971) apud Viana (2007) concluíram que a porcentagem de material que passa na peneira número 200 realmente tem influência no valor do módulo de resiliência. Da igual maneira, Queiroz e Hudson (1994) apud Viana (2007) perceberam que o módulo de resiliência de certas areias naturais é consideravelmente maior do que o dos solos argilosos.

Assim, nos resultados obtidos por Jorenby e Hicks (1986) e por Barksdale e Itani (1989) conforme as Figuras 2.10 e 2.11, respectivamente, confirma-se o fato do módulo de resiliência apresentar valores menores em materiais com maior porcentagem de finos. 


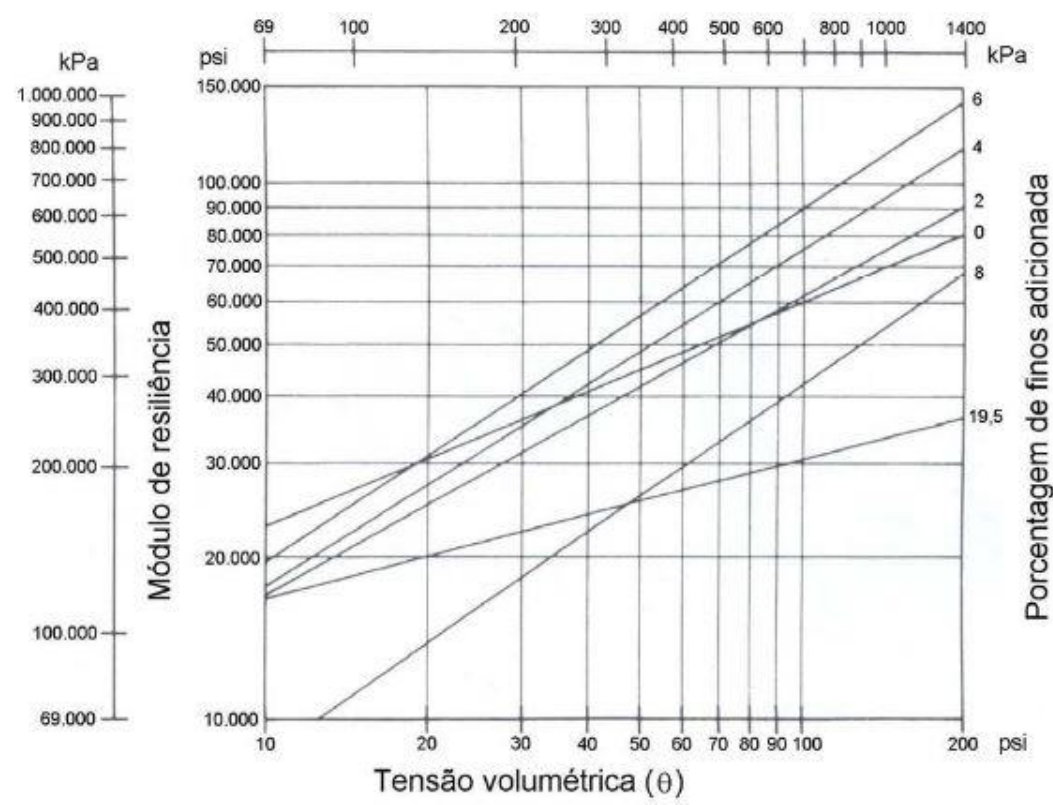

Figura 2.10. Variação do módulo de resiliência com adição de finos num agregado britado de rocha ígnea (Adaptado de Jorenby e Hicks, 1986)

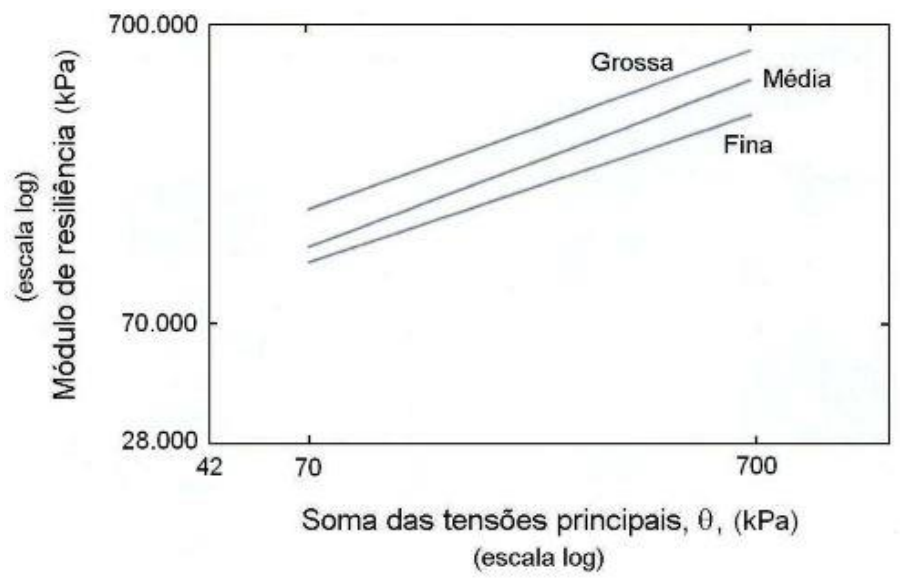

Figura 2.11. Influência da composição granulométrica de um material gnaissegranítico na variação do módulo de resiliência (Adaptado de Barksdale e Itani, 1989)

Sendo que a ação da água é o fator que mais afeta o comportamento mecânico de uma estrada por causa dos problemas que pode gerar, o estudo da variação do módulo de resiliência com a umidade é necessário, pois a sua diminuição contribui para a aparição de deformações excessivas que afetam a funcionalidade e a vida útil do pavimento.

Assim, nas Figuras 2.12 e 2.13 a seguir são mostrados respectivamente os resultados obtidos por Mohammad et al. (1995) respeito à variação do módulo de 
resiliência em função do teor de umidade, numa argila siltosa do tipo A-7-6 e numa areia fina A-3 compactada com energia normal e submetida a três níveis de tensão de confinamento.

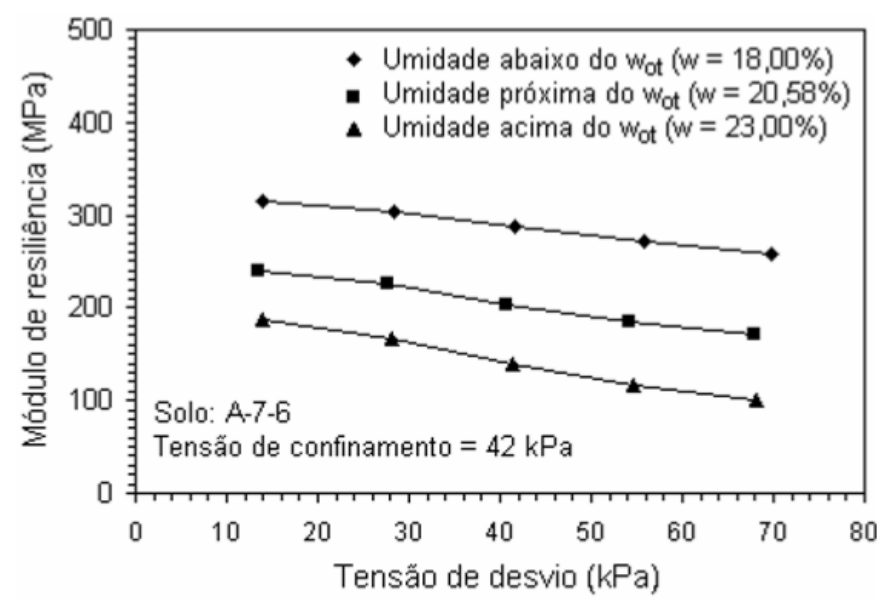

Figura 2.12. Variação do módulo de resiliência com o teor de umidade no solo argiloso siltoso A-7-6 (Adaptado de Mohammad et al., 1995)
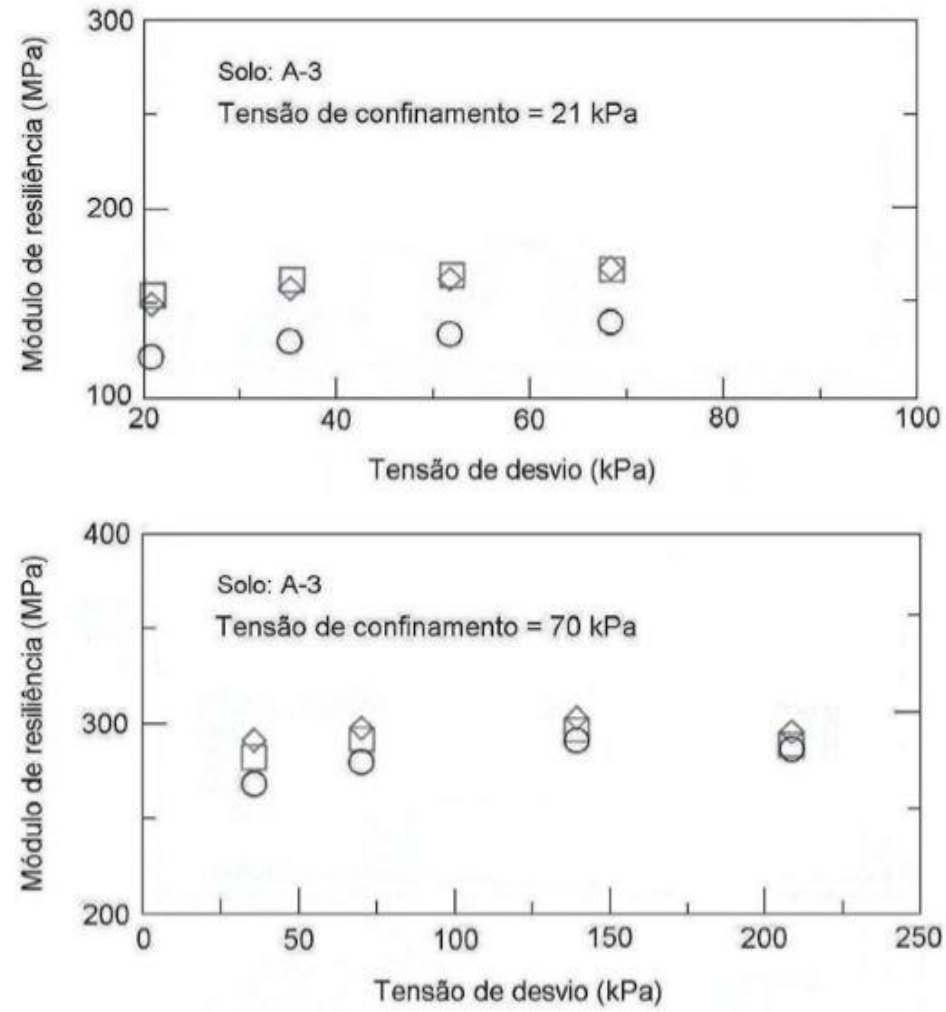


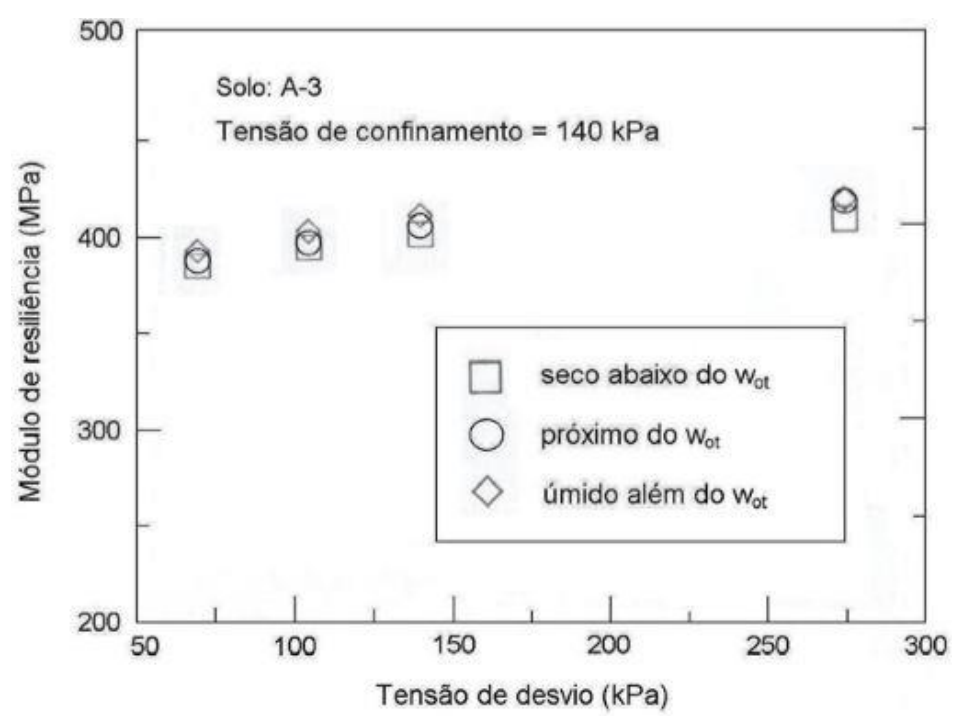

Figura 2.13. Variação do módulo de resiliência com o teor de umidade no solo arenoso A-3 (Adaptado de Mohammad et al., 1995)

Segundo Mohammad et al. (1995), a diminuição dos valores do módulo com o aumento do teor de umidade no solo argiloso deve-se ao aumento da pressão neutra, pois existe uma redução da tensão efetiva e, portanto, da sua resistência ao cisalhamento. Por outro lado, no caso da areia fina o valor do módulo de resiliência cresce com o aumento da tensão de confinamento, independentemente dos teores de umidade analisados.

Assim, Mohammad et al. (1995) concluíram que o teor de umidade tem maior influência no solo argiloso analisado do que no arenoso.

Finalmente, a variação do módulo de resiliência em função da densidade do solo e da energia de compactação tem uma relação muito forte, pois o aumento da energia de compactação implica num aumento da densidade e, portanto, da resistência ao cisalhamento ao se diminuir o índice de vazios (Viana, 2007).

Assim, as pesquisas realizadas por Hicks e Monismith (1971) apud Viana (2007); Rada e Witczak (1981) apud Viana (2007) e Barksdale e Itani (1989) confirmaram o aumento do módulo de resiliência à medida que a densidade do material crescia, sendo que o efeito diminuía com o aumento da porcentagem de finos, como foi comentado anteriormente. 


\subsection{Tipos de geossintéticos utilizados em pavimentação}

Com base nas características físicas e mecânicas dos diferentes tipos de geossintéticos, os mais utilizados para desenvolver funções de reforço em pavimentação são os geotêxteis e as geogrelhas, sendo que as geogrelhas apresentam um melhor desempenho devido à sua geometria, à sua elevada resistência à tração e à boa interação com os materiais nos quais ela é inserida.

\subsubsection{Geotêxtil}

O geotêxtil é um produto têxtil bidimensional permeável, composto por fibras cortadas, filamentos contínuos, monofilamentos, laminetes ou fios, formando estruturas que podem ser tecidas ou não-tecidas, cujas propriedades mecânicas e hidráulicas permitem que desempenhe diferentes funções em uma obra geotécnica, tais como reforço, filtração e separação (Vertematti 2004).

Este tipo de geossintético é comumente utilizado na restauração de pavimentos flexíveis e também para desempenhar funções de separação e filtração das camadas que compõem a estrutura do pavimento. No primeiro caso, os geotêxteis devem apresentar resistência à tração superior a 7 kN/m (NBR ISO 10319, 2013), capacidade de retenção de ligante betuminoso maior do que $0,91 / \mathrm{m} 2$ e ponto de amolecimento acima de $180^{\circ} \mathrm{C}$ (Kakuda, 2010).

No caso da função de separação e filtração, os geotêxteis devem ter a capacidade de prevenir a interpenetração do material de base na camada inferior (Kakuda, 2010). Holtz et al. (1995) recomendam usar os geotêxteis em solos de subleitos com baixa capacidade de suporte, isto é, com CBR menor a 3\% ou com módulo de resiliência menor a $30 \mathrm{MPa}$.

\subsubsection{Geogrelha}

Segundo Vertematti (2004), a geogrelha é um tipo de geossintético cuja função predominante é o reforço. Este material está constituído por elementos resistentes à tração, cuja geometria forma aberturas que permitem a sua interação com o meio em que ela é inserida, como mostrado na Figura 2.14 a seguir. 


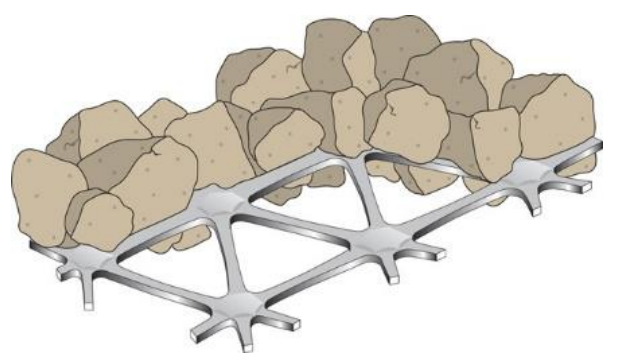

Figura 2.14. Esquema de interação da geogrelha com um material granular (http://www.mathworks.com/matlabcentral/answers/uploaded_files/23014/gt2.jpg em Julho de 2014)

Além disso, dependendo das características e da distribuição dos elementos longitudinais e transversais, as geogrelhas podem ser consideradas uniaxiais quando apresentam elevada resistência à tração apenas em uma direção, ou também biaxiais, quando a resistência à tração é a mesma nas duas direções ortogonais entre si, como mostrado na Figura 2.15 a seguir.

Por outro lado, as geogrelhas podem ser fabricadas por meio da perfuração de mantas poliméricas que são posteriormente tracionadas em uma ou duas direções, ou a partir de cordões trançados em duas direções, sendo urdume no sentido longitudinal e trama no sentido transversal à direção de fabricação. Adicionalmente, a união dos elementos pode ser realizada por meio de extrusão no caso das geogrelhas extrudadas, colagem quando se trata das soldadas ou entrelaçamento no caso das geogrelhas tecidas (Kakuda, 2005).

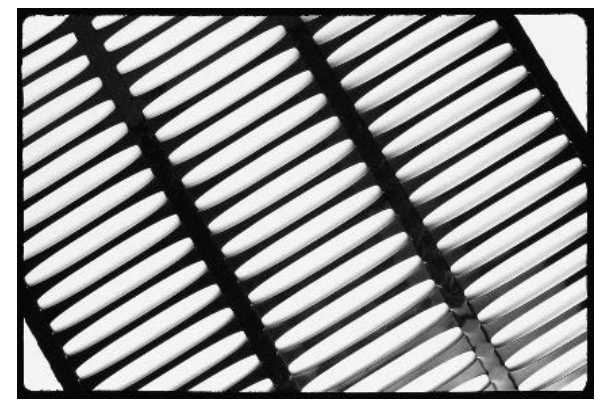

Geogrelha uniaxial extrudada

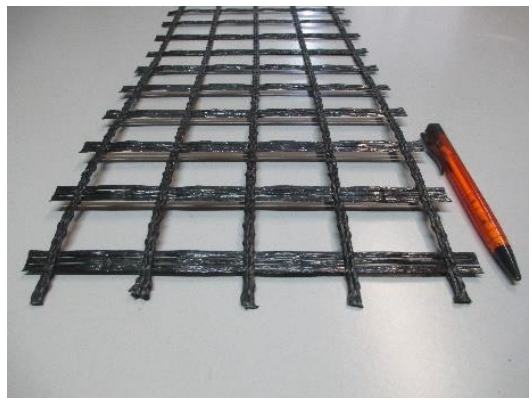

Geogrelha biaxial tecida

Figura 2.15. Tipos de geogrelha de acordo a sua geometria

Com relação aos polímeros que são normalmente utilizados na fabricação das geogrelhas, tem-se o Polietileno de Alta Densidade (PEAD), o Polipropileno (PP) e o Poliéster (PET), cujas características são mostradas na Tabela 2.1 a seguir. 
Tabela 2.1. Características dos principais polímeros utilizados na fabricação de geogrelhas (Vertematti, 2004)

\begin{tabular}{|c|c|c|}
\hline Polímero & Sigla & Características \\
\hline $\begin{array}{l}\text { Polietileno de } \\
\text { Alta Densidade }\end{array}$ & PEAD & $\begin{array}{l}\text { Polímero termoplástico bastante alcalino, } \\
\text { resultante da polimerização de monômeros } \\
\text { de etileno. Apresenta alta resistência } \\
\text { química e densidade entre } 0,941 \text { e } 0,959 \\
\mathrm{~g} / \mathrm{cm}^{3} \text {. Para aumentar a sua longevidade } \\
\text { quando exposto ao sol, incorpora o aditivo } \\
\text { de negro de fumo. }\end{array}$ \\
\hline Polipropileno & PP & $\begin{array}{l}\text { Polímero termoplástico semicristalino. Os } \\
\text { seus principais são estabilizantes térmicos, } \\
\text { negro de fumo (proteção aos raios UV), } \\
\text { plastificantes e antioxidantes. }\end{array}$ \\
\hline Poliéster & PET & $\begin{array}{l}\text { O poliéster resulta da polimerização de } \\
\text { etilonoglicol e dimetiltereftalato ou ácido } \\
\text { tereftálico. Adicionalmente, apresenta alta } \\
\text { resistência à tração e aditivos para combater } \\
\text { a degradação térmica e UV. }\end{array}$ \\
\hline
\end{tabular}

Adicionalmente, estes materiais podem ser também utilizados, além de reforço de base de pavimento, como reforço de capa asfáltica quando pretende-se restaurar pavimentos flexíveis degradados. Neste caso, as geogrelhas devem apresentar uma resistência à tração superior a $50 \mathrm{kN} / \mathrm{m}$ para uma deformação inferior a $12 \%$ (NBR ISO 10319, 2013); a resistência à fadiga deve ser maior que 90\% da resistência retida após 100.000 ciclos de carregamento; a relação entre a abertura da malha e o diâmetro máximo do agregado deve estar dentro do intervalo de 2 a 10 e o ponto de amolecimento deve ser superior a $180^{\circ} \mathrm{C}$ (Kakuda, 2010).

\subsection{Efeitos dos geossintéticos como reforço de base de pavimentos}

Por meio das pesquisas desenvolvidas por Perkins e Ismeik (1997); Perkins (1999); Hoe e Zeng (2001); Perkins et al. (2002) e Al-Qadi (2002), foi analisada a 
influência de algumas variáveis dos geossintéticos quando utilizados como materiais de reforço de camadas de pavimentos flexíveis, sendo estas: a espessura da camada granular a ser reforçada; a posição da inclusão na camada granular; a capacidade de suporte do subleito e as propriedades mecânicas dos geossintéticos (Kakuda, 2010).

\subsubsection{Espessura da camada granular e posicionamento do geossintético}

O posicionamento do geossintético em uma camada de material granular está relacionado com a espessura da camada que pretende ser reforçada. Assim, Al. Qadi et al. (1998) concluíram que quanto menor for a espessura da base granular, a efetividade da geogrelha é maior. Outros pesquisadores, como por exemplo Hass et al. (1988), concluíram que para pavimentos de bases granulares espessas, a geogrelha deve ser inserida no meio da camada, enquanto que para bases granulares de pequena espessura, o reforço deve ser instalado na interface base-subleito.

Por meio da TBR (Traffic Benefit Ratio), que corresponde à taxa de benefício de tráfego, pode-se quantificar a melhoria do desempenho de um pavimento reforçado com geossintético. Esta taxa é definida matemáticamente através da Equação (2.9) (Kakuda, 2010).

$$
\mathrm{TBR}=\frac{\mathrm{N}_{\text {geo }}}{\mathrm{N}}
$$

Onde:

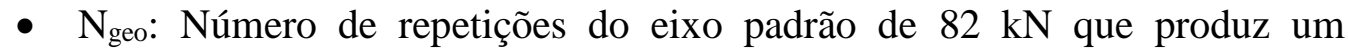
determinado afundamento em trilha de roda $\left(T_{R}\right)$ no pavimento reforçado com geossintético;

- $\mathrm{N}$ : Número de repetições do eixo padrão de $82 \mathrm{kN}$ que produz um determinado afundamento em trilha de roda $\left(T_{R}\right)$ no pavimento sem reforço.

Assim, Collin et al. (1996) concluíram a partir de resultados experimentais que o máximo valor de TBR foi obtido para uma base cuja espessura é de $250 \mathrm{~mm}$. Além disso, na Figura 2.16 pode-se observar que para espessuras maiores que $250 \mathrm{~mm}$, o valor 
de TBR diminui e, acima de $300 \mathrm{~mm}$, o TBR mantem-se constante, evidenciando um benefício mínimo da geogrelha correspondente a um TBR de 2 .

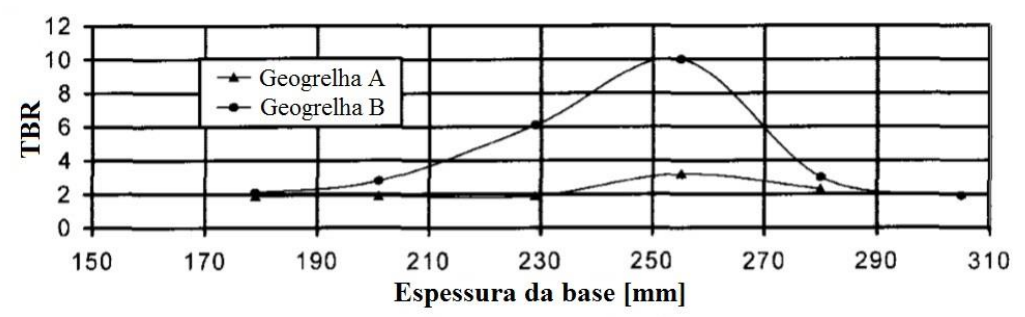

Figura 2.16. Variação do TBR para diferentes espessuras de base granular em uma deflexão de 25 mm (Adaptado de Collin et al., 1996)

Por outro lado, Perkins e Cuelho (1999) verificaram a partir dos ensaios realizados num equipamento de grandes dimensões que quando a geogrelha foi colocada $100 \mathrm{~mm}$ acima da interface base-subleito, a estrutura do pavimento apresentou um melhor desempenho se comparada com a geogrelha colocada na interface; isto para uma base cuja espessura era de $300 \mathrm{~mm}$.

Adicionalmente, Beretta et al. (1994) apud Miranda (2013) analisaram a influência da posição da geogrelha quando instalada na interface base-subleito e na parte central da camada de base granular, verificando que quando o reforço esteve posicionado na interface das duas camadas, o desempenho das estruturas ensaiadas foi bem superior, aumentando a vida útil dos pavimentos ensaiados em $30 \%$.

\subsubsection{Capacidade de suporte do subleito}

A capacidade de suporte do solo de subleito tem relação direta com os Afundamentos de Trilhas de Rodas (ATR) na superfície do pavimento, onde o ATR vai depender da deformação ocorrida no subleito. Assim, em rodovias com revestimento primário, afundamentos de trilha de roda da ordem de dezenas de milímetros de profundidade não vão afetar seriamente o desempenho do pavimento. Entretanto, é necessário adotar um estado limite de utilização da estrutura (Miranda, 2013).

Assim, na Figura 2.17 a seguir pode-se observar o efeito do tráfego em pavimentos sem reforço e em pavimentos reforçados com geossintéticos, onde os afundamentos são menores no segundo caso devido à melhor distribuição das tensões. 

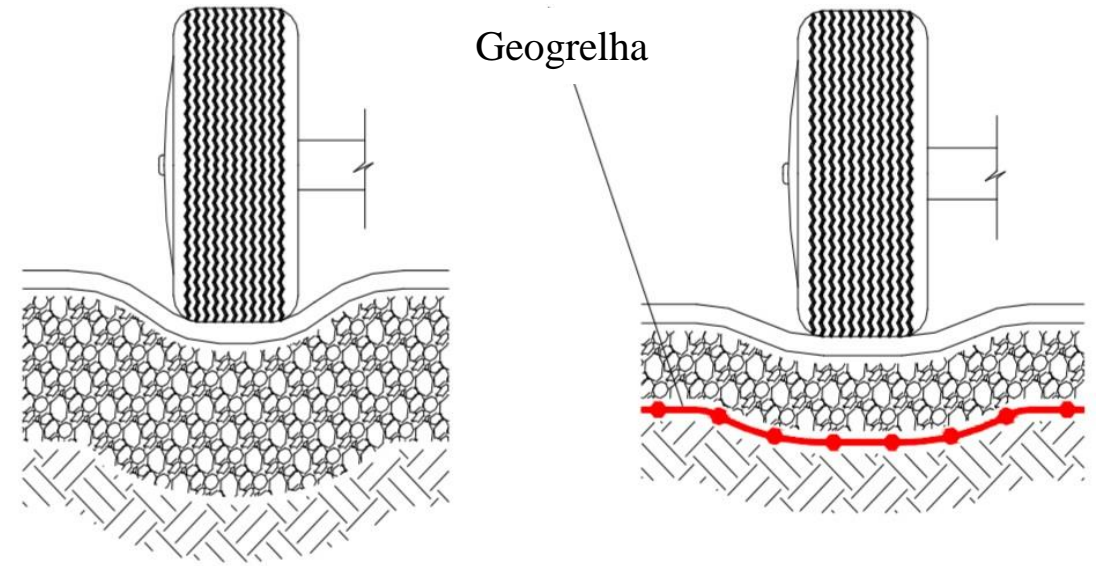

Figura 2.17. Afundamento de trilha de roda (ATR) - (a) Pavimento sem reforço e (b) pavimento reforçado com geogrelha na interface base-subleito (Modificado de Maccaferri, 2012)

Por outro lado, Giroud e Han (2004) mencionam a existência de quatro mecanismos responsáveis pelo surgimento de deformações na superfície do pavimento:

- Compactação da camada de base e/ou subleito por causa das solicitações dinâmicas do tráfego;

- Ruptura por baixa capacidade de suporte na camada de base ou subleito por causa das tensões normais e cisalhantes induzidas pelo tráfego;

- Ruptura por deterioração progressiva do material da base após repetidas solicitações do tráfego, redução da espessura efetiva das camadas granulares por contaminação com os finos do subleito, redução da capacidade da base granular para distribuir as tensões induzidas pelo tráfego no subleito ou por diminuição da resistência do subleito devida à aparição de pressões neutras durante a construção do pavimento;

- Deslocamento lateral dos materiais da base e do subleito por causa da acumulação de deformações plásticas induzidas pelo carregamento dinâmico.

Assim, Kakuda (2010) propõe que quando o subleito apresenta boa resistência, o benefício gerado pelo geossintético ao ser utilizado como reforço em uma estrutura de 
pavimento é menor. Dessa maneira, quando aumentar o valor de CBR no subleito, a taxa de benefício gerada pela inclusão diminui.

Adicionalmente, Perkins e Cuelho (1999) demonstraram que o desempenho do pavimento reforçado com geossintético mostrou-se mais significativo quando foi utilizado um subleito argiloso com CBR de 1,5\% ao invés de um subleito de areia siltosa com CBR de $15 \%$. Sendo assim, a bibliografia existente ressalta que a efetividade de um reforço geossintético será maior quando o subleito apresentar um CBR menor ou igual a 3\% (Miranda, 2013).

\subsubsection{Propriedades mecânicas do geossintético}

As pesquisas desenvolvidas têm demonstrado a grande influência dos geossintéticos quando utilizados como materiais de reforço de base granular, pois melhoram o desempenho e aumentam a vida útil do pavimento. Desse modo, na maioria das pesquisas as geogrelhas têm apresentado o melhor comportamento como reforço de base de pavimentos por causa do tipo de geometria que apresenta e da sua elevada rigidez.

No caso dos geotêxteis, a melhoria do comportamento estrutural do pavimento tem a ver com a função de separação que eles podem desempenhar, sendo que se ocorrer mistura dos materiais das diferentes camadas, isto pode resultar em sérios problemas estruturais para o pavimento. Assim, uma vez que é definida a estrutura do pavimento, é fundamental que ela permaneça íntegra para manter a sua resistência.

Por outro lado, o benefício gerado pelo geossintético utilizado como reforço de base de pavimento é refletido na redução do afundamento em trilha de roda (Kakuda, 2010). Assim, na pesquisa desenvolvida por Brown et al. (1983), concluiu-se que a utilização de uma geogrelha de polipropileno como reforço de base granular gerou uma redução de $20 \%$ a $58 \%$ no afundamento em trilha de roda.

Devido à grande diversidade de geogrelhas, têm-se desenvolvido pesquisas com o objetivo de determinar qual o tipo de geogrelha mais apropriado para desempenhar funções de reforço em estruturas de pavimento.

Assim, na pesquisa desenvolvida por Ling et al. (1998) foram avaliadas as resistências à tração de geogrelhas de diferentes polímeros submetidas a carregamento cíclico, cujos ensaios foram realizados seguindo a norma ASTM D4595. Dos resultados obtidos observou-se que a resistência à tração da geogrelha de polipropileno não foi 
afetada significativamente pelo carregamento cíclico, enquanto que as de poliéster e polietileno apresentaram um aumento na resistência com o carregamento dinâmico. Para isso, os autores propuseram um modelo hiperbólico para expressar as tensões induzidas pelos ciclos de carga nas geogrelhas analisadas.

Por outro lado, Perkins (1999) analisou o efeito gerado por geogrelhas com diferentes módulos de rigidez, mas com o mesmo tipo de polímero e tamanho de aberturas, podendo assim concluir que aquelas que tinham o maior módulo de rigidez contribuíram melhor no comportamento mecânico do pavimento.

De maneira similar, Collin et al. (1996) avaliaram duas geogrelhas de polipropileno com diferentes módulos de rigidez, obtendo valores de TBR de 2,2 para a geogrelha de menor rigidez e TBR de 4,8 para a geogrelha de maior rigidez.

Assim, os melhores desempenhos do reforço em camadas granulares ocorrem quando as inclusões apresentam um maior módulo de rigidez, permitindo concluir que as geogrelhas flexíveis precisam atingir uma certa deformação para mobilizar a sua resistência e dessa maneira diminuir o afundamento em trilha de roda (Kakuda, 2010).

\subsection{Interação solo-geossintético}

Segundo DeMerchant et al. (2002), uma elevada resistência à tração não garante necessariamente o melhor comportamento do reforço no pavimento. $\mathrm{O}$ bom desempenho de uma base granular reforçada depende mais da rigidez da geogrelha e do nível de carregamento sob o qual a estrutura de pavimento está submetida.

Desse modo, DeMerchant et al. (2002) ressaltou a importância da interação entre o geossintético e o solo no comportamento de solos reforçados com estes materiais.

Perkins (1999) também chegou à conclusão de que a função do reforço de base de pavimentos é desenvolvida pela interação entre o geossintético e o material no qual é inserido, podendo ser no interior ou na parte inferior da camada de base.

Assim, as solicitações dinâmicas devidas à passagem dos veículos sobre a estrutura de pavimento geram tensões laterais na base, induzindo ao mesmo tempo movimentos laterais que afetam o desempenho e a durabilidade do projeto rodoviário.

Sendo que o tráfego veicular induz ciclos de carga e descarga, a melhor maneira de avaliar a interação entre o solo e o geossintético em estruturas de pavimento reforçado é por meio de ensaios de arrancamento cíclico (Figura 2.18). 
Para realizar estes ensaios é necessário avaliar antes a interação sologeossintético por meio de ensaios de arrancamento monotônico sob uma taxa de deslocamento constante, pois a partir da resistência obtida para um determinado estado de tensões, é possível definir as amplitudes de carga cíclica sem que ocorra o arrancamento da inclusão.

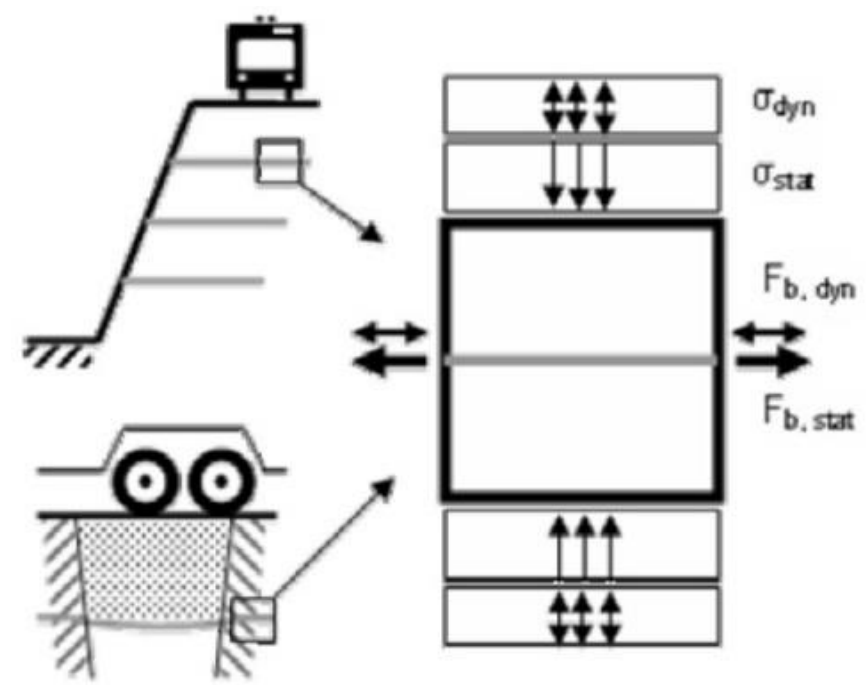

Figura 2.18. Tensões laterais induzidas no geossintético devidas ao tráfego veicular (Meyer et al., 2004)

Ainda, a pesquisa desenvolvida por Teixeira (2003), onde foi estudada a interação solo-geogrelha por meio de testes de arrancamento para a análise e dimensionamento de maciços reforçados, influenciou as pesquisas desenvolvidas por Napa G. (2011) e Campos (2013). Nestes trabalhos foi avaliada a interação dinâmica solo-geossintético por meio de ensaios de arrancamento cíclico, onde o geossintético foi inserido no interior de um mesmo material.

Segundo Kakuda (2005), os ensaios de arrancamento são preferidos pela maioria dos projetistas pois reproduzem fielmente as condições reais da obra no sentido da interação solo-reforço.

No caso da pavimentação, o emprego da geogrelha como material de reforço de base de pavimento, gera um aumento na capacidade estrutural da camada granular, o qual está associado ao intertravamento dos grãos, à inibição dos movimentos laterais, ao confinamento e à separação, como mostrado na Figura 2.19 a seguir. 


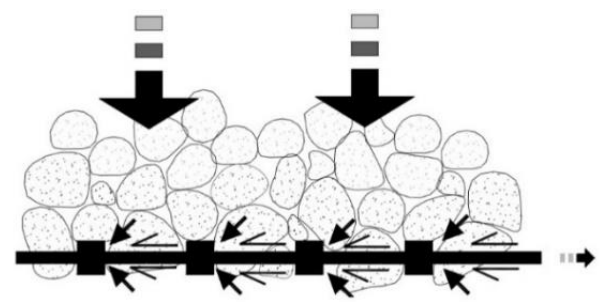

Figura 2.19. Detalhe da interação solo-geogrelha (Kakuda, 2005)

\subsubsection{Ensaios de arrancamento monotônico}

Segundo Teixeira (2003), o ensaio de arrancamento monotônico foi desenvolvido com o intuito de avaliar o comportamento de inclusões inseridas no solo quando submetidas a uma solicitação de tração que possa levá-las à perda de aderência com o material circundante.

Além disso, este ensaio é considerado o mais apropriado quando pretende-se avaliar a interação solo-geogrelha pois considera as parcelas de atrito de superfície e a resistência passiva que os elementos transversais proporcionam, tal como pode-se observar na Figura 2.20.

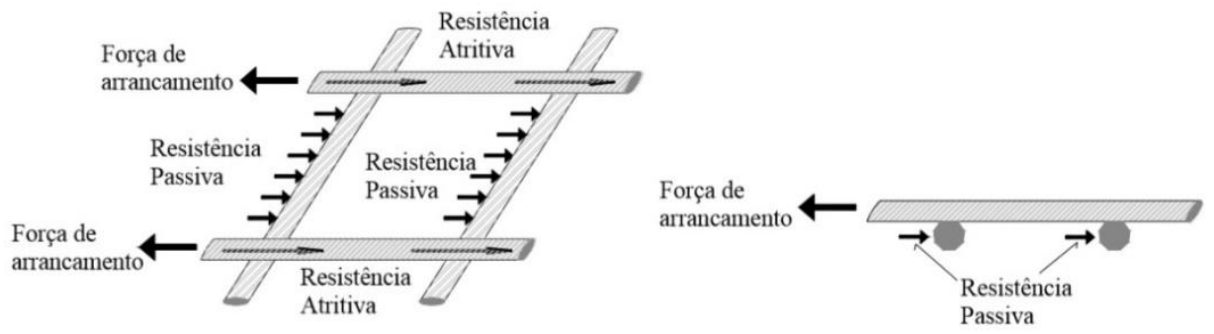

Figura 2.20. Resistências atritiva e passiva na interface solo-geogrelha (Voottipruex et $a l ., 2000)$

Além disso, Jewell et al. (1984) e Bergado et al. (1996) avaliaram o mecanismo de transferência de carga solo-geogrelha por meio da execução de ensaios de arrancamento utilizando inclusões inextensíveis (grelhas de aço), demonstrando que as cargas impostas foram primeiramente transferidas aos elementos longitudinais, sendo mobilizados com deslocamentos pequenos (de aproximadamente $2 \mathrm{~mm}$ ), seguindo com a mobilização da resistência passiva através dos elementos transversais. Assim, chegouse a concluir também que cerca de $10 \%$ da resistência total ao arrancamento é provida pela parcela atritiva e o restante, pela parcela passiva. 
Adicionalmente, a distribuição e separação dos elementos transversais também influencia a transferência de carga na inclusão durante um ensaio de arrancamento. Dessa maneira, Kakuda (2005) menciona que quanto maior for o espaçamento entre elementos transversais, a tensão de arrancamento fica distribuída igualmente entre eles. Por outro lado, quando apresentarem menores separações entre si, os elementos mais próximos do ponto de aplicação da carga serão os mais solicitados e, portanto, apresentarão os maiores deslocamentos.

Em complemento, Ochiai et al. (1996) e Sugimoto et al. (2001) afirmaram que o fato dos elementos transversais das geogrelhas (inclusões extensíveis) apresentarem baixa rigidez à flexão, influencia o decrescimento dos deslocamentos sucessivos entre si com o afastamento do ponto de aplicação da força de arrancamento.

Dessa maneira, Kakuda (2005) faz uma comparação entre as inclusões extensíveis e inextensíveis com enfoque no comportamento durante os ensaios de arrancamento, onde as inclusões inextensíveis deslocam-se como um corpo rígido em relação ao solo envolvente, mobilizando a resistência ao longo do reforço simultaneamente em todas as barras transversais. Por outro lado, quanto às inclusões extensíveis destaca-se a deformabilidade dos seus elementos, a qual implica a diminuição dos deslocamentos ao longo do comprimento da amostra ensaiada e por causa disso, apresenta-se uma mobilização desigual das tensões tangenciais na geogrelha.

Com relação à influência do número de elementos longitudinais e transversais de uma geogrelha na resistência ao arrancamento, Alagiyawanna et al. (2001) e Teixeira (2003) analisaram diferentes configurações e mostraram que a resistência obtida não é tão discrepante quando é variada a porcentagem de elementos transversais do que quando a variação corresponde aos elementos longitudinais.

Finalmente, Kakuda (2005) menciona que os resultados dos ensaios de arrancamento são geralmente utilizados, não só para a avaliação da interação entre o solo e o geossintético, mas também para projetos e análises do comportamento de estruturas reais de solo reforçado.

Por causa disso, as condições em que são realizados os ensaios tornam-se de grande importância para a determinação dos parâmetros desejados. Dessa maneira, dependendo das condições do projeto ou da finalidade requerida, os ensaios de arrancamento podem ser realizados tanto no laboratório quanto no campo (Kakuda, 2005). 


\subsubsection{Ensaios de arrancamento em campo}

Estes ensaios são geralmente realizados em aterros e necessitam de uma grande quantidade de solo, equipamentos pesados para locomoção e compactação do material e, de um anteparo resistente para servir de reação ao equipamento de aplicação do carregamento. Além disso, um controle de umidade e de compactação faz-se necessário durante a construção do aterro.

Adicionalmente, para a execução do ensaio precisam-se de instrumentos de medição dos deslocamentos da face e dos recalques. No entanto, apesar de serem ensaios complicados e custosos, podem fornecer resultados muito mais confiáveis do comportamento da estrutura de solo reforçado. Mesmo assim, a maioria dos pesquisadores escolhe a investigação por meio de ensaios de laboratório (Kakuda, 2005).

\subsubsection{Ensaios de arrancamento no laboratório}

Para a realização dos ensaios de arrancamento no laboratório podem ser utilizados equipamentos tanto de grande como de pequeno porte, onde os primeiros podem fornecer resultados com maior grau de confiabilidade.

Segundo Kakuda (2005), um equipamento de arrancamento típico está constituído por uma caixa rígida de aço com seção transversal retangular, a qual é preenchida com o material desejado devidamente compactado, contendo o reforço no seu interior que será tracionado pelo sistema de aplicação de carga utilizado.

A força de tração no elemento de reforço é aplicada na maioria das vezes por um sistema hidráulico, cuja taxa de deslocamento pode ser controlada durante o ensaio. Adicionalmente, a tensão de confinamento sobre o material de preenchimento da caixa é geralmente aplicada por uma bolsa de ar comprimido.

\subsection{Equipamento de pequenas dimensões}

As vantagens do equipamento de pequenas dimensões têm a ver mais com o tempo de execução do ensaio, o qual é muito menor; com o custo relativamente baixo 
e, com o melhor controle que se tem da umidade e do grau de compactação do material ensaiado.

Assim, pesquisas como as de Nakamura et al. (2003) e Teixeira (1999) utilizaram caixas cujas dimensões eram de $500 \mathrm{~mm}$ de comprimento, $220 \mathrm{~mm}$ de largura e $200 \mathrm{~mm}$ de profundidade e; $250 \mathrm{~mm}$ de comprimento, $300 \mathrm{~mm}$ de largura e $150 \mathrm{~mm}$ de altura, respectivamente.

Segundo Kakuda (2005), a aplicação da força de arrancamento neste tipo de equipamento é feita através de uma máquina universal e, tanto a resistência ao arrancamento quanto os deslocamentos de pontos da superfície da geogrelha, são obtidos através de aquisição automática de dados.

Utilizando este tipo de equipamento, pode-se imaginar que os resultados obtidos não estão tão próximos da realidade. Nesse caso, Teixeira (2003) confirma o contrário, pois apresentou um modelo numérico que permite utilizar os resultados obtidos com o equipamento de pequenas dimensões na avaliação do comportamento de inclusões extensíveis de qualquer comprimento.

Ao comparar os resultados obtidos por meio do modelo numérico proposto com os resultados dos ensaios realizados em equipamentos de grandes dimensões, Teixeira (2003) concluiu que apesar dos resultados em equipamentos de grandes dimensões serem mais precisos, os ensaios em equipamentos de pequeno porte mostraram resultados parecidos no caso dos solos finos, ainda com a vantagem de serem realizados em menor tempo.

Com relação ao efeito da relação entre o tamanho da inclusão e a área interna do equipamento de pequeno porte, Kakuda (2005) realizou uma série de ensaios de arrancamento onde variou-se o número de elementos longitudinais e transversais para um mesmo tipo de geogrelha, com o intuito de definir qual o tamanho do corpo de prova a partir do qual a resistência não é mais afetada pelas dimensões da amostra ensaiada.

Dessa maneira, na Figura 2.21 a seguir mostram-se os valores de resistência ao arrancamento para dez corpos de prova da geogrelha Fortrac 55/30-20 da Huesker, onde foi variado o número de elementos longitudinais de 3 até 12, todos ensaiados no equipamento de pequeno porte da EESC-USP, cujas dimensões são $245 \mathrm{~mm}$ de comprimento, $300 \mathrm{~mm}$ de largura e $150 \mathrm{~mm}$ de altura. 


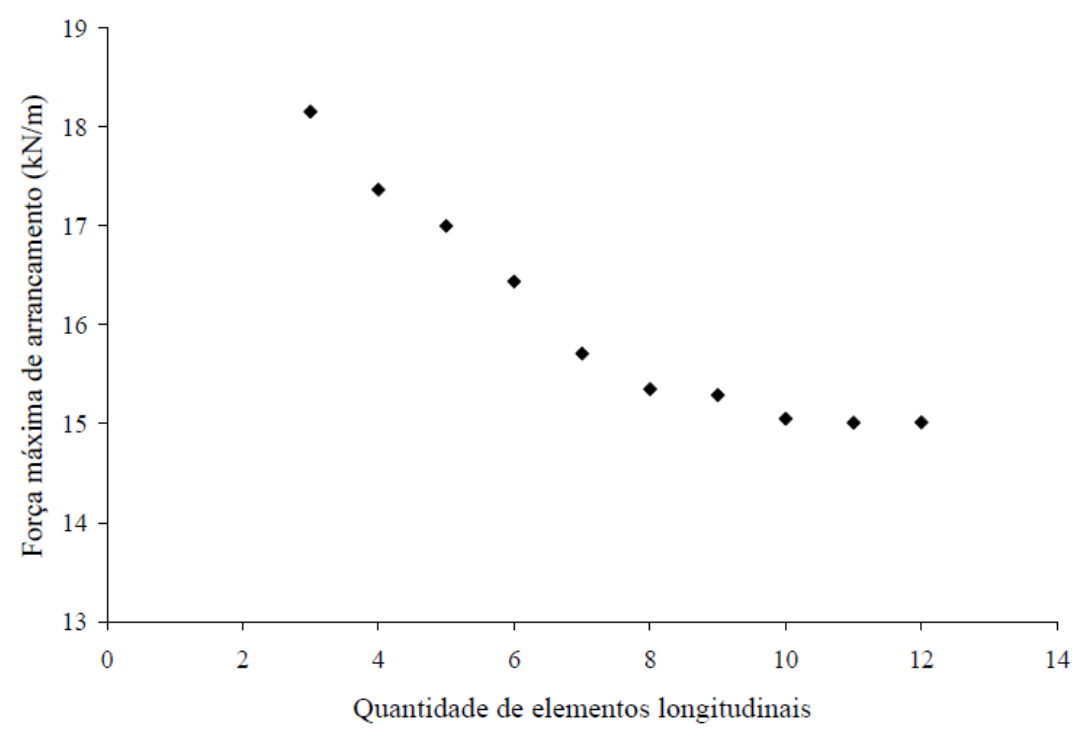

Figura 2.21. Quantidade de elementos longitudinais $v s$. Força máxima de arrancamento (Kakuda, 2005)

Com o gráfico mostrado na Figura 2.21 percebe-se que os valores de resistência ao arrancamento, obtidos por Kakuda (2005) no equipamento de pequenas dimensões da EESC-USP, apresentam uma tendência a se estabilizarem à medida que aumenta o número de elementos longitudinais.

Assim, Kakuda (2005) conclui que à medida que a largura da amostra aproximase à dimensão interna da caixa, a força de arrancamento tende a um valor constante, permitindo atingir um estado plano de tensões. De igual maneira, Sugimoto et al. (2001) realizaram ensaios de arrancamento monotônico num equipamento de pequenas dimensões, utilizando corpos de prova com largura equivalente à dimensão interna do equipamento.

Sendo a largura mais adequada do corpo de prova a correspondente à dimensão interna do equipamento de pequenas dimensões, nos ensaios deve-se garantir uma excelente lubrificação das paredes internas da caixa para evitar o correspondente efeito de atrito, assim como uma correta fixação da amostra na garra para poder distribuir uniformemente o carregamento aplicado na inclusão (Kakuda, 2005).

Por outro lado, Kakuda (2005) também avaliou o efeito do comprimento da amostra nos valores de resistência ao arrancamento, ensaiando corpos de prova com $8 \mathrm{e}$ 12 elementos longitudinais mas variando o número de elementos transversais no mesmo equipamento de pequeno porte da EESC, apresentando coeficientes de variação de 3,6\% e $0,57 \%$, respectivamente. 
Dessa maneira, na Figura 2.22 a seguir é mostrada a variação da resistência ao arrancamento com relação ao número de elementos transversais, onde é evidenciado que o comprimento da amostra não afeta significativamente a resistência ao arrancamento, mas a variabilidade é menor quando a largura aproxima-se à dimensão interna do equipamento.

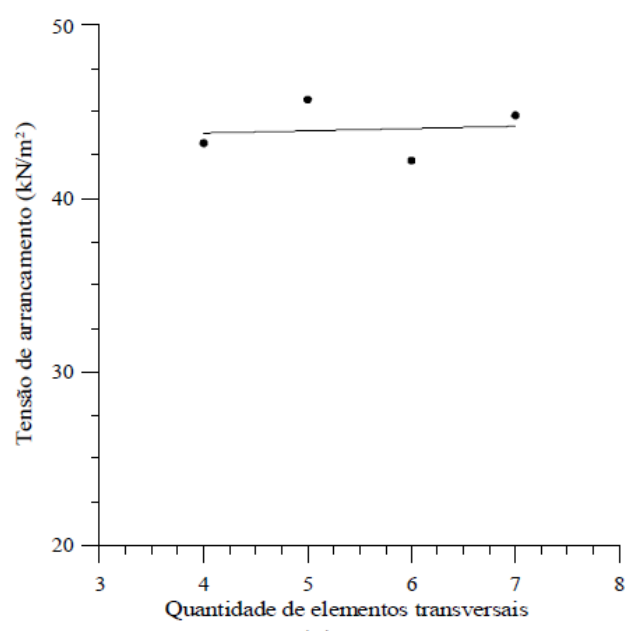

(a)

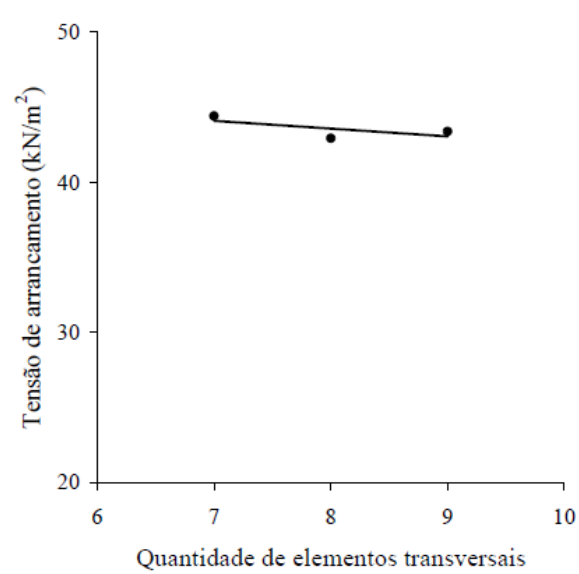

(b)

Figura 2.22. Quantidade de elementos transversais vs. Tensão máxima de arrancamento para (a) 8 elementos longitudinais e (b) 12 elementos longitudinais (Kakuda, 2005)

Sendo assim, apesar do comprimento da inclusão não ter afetado em grande parte a resistência ao arrancamento, Kakuda (2005) também recomenda que este se aproxime aos $245 \mathrm{~mm}$ do equipamento de pequenas dimensões da EESC-USP.

\subsection{Equipamento de grandes dimensões}

Tal como foi mencionado anteriormente, os ensaios realizados neste tipo de equipamento fornecem resultados mais precisos, mas envolvem maior tempo de execução implicando custos mais elevados.

Segundo Raju e Fannin (1998), os equipamentos de grandes dimensões são mais utilizados na maioria dos laboratórios para ensaios de arrancamento e, apresentam dimensões superiores a 1,0 $\mathrm{m}$ de comprimento e 0,50 $\mathrm{m}$ de largura.

Com relação à altura da caixa rígida de arrancamento, Farrag et al. (1993) sugerem que se utilizem $30 \mathrm{~cm}$ de solo tanto acima quanto abaixo do geossintético, 
porém não informam que se com mudanças nas dimensões da caixa e na granulometria do solo, será mantida a mesma espessura.

Por outro lado, para reduzir o efeito de borda durante o ensaio de arrancamento, Johnston (1985) apud Teixeira (2003) recomenda manter um espaço entre a inclusão e as paredes internas da caixa.

Adicionalmente, Teixeira (2003) afirmou que os estudos realizados com relação à interação entre o solo e o geossintético por meio de ensaios de arrancamento, não recomendavam uma altura mínima do equipamento para diminuir a interferência das condições de contorno. Porém, Teixeira (2003) considera que uma altura mínima que apresenta bons resultados corresponde a uma espessura de solo tanto acima quanto abaixo da inclusão de ao menos 50 vezes o diâmetro médio das partículas de solo ( $\left.\mathrm{D}_{50}\right)$.

No entanto, as dimensões mínimas do equipamento de arrancamento exigidas pela norma ASTM D6706 - 01 correspondem a $610 \mathrm{~mm}$ de comprimento, $460 \mathrm{~mm}$ de largura e $305 \mathrm{~mm}$ de altura. Por outro lado, para diminuir o efeito de atrito entre o solo e as paredes laterais da caixa, também recomenda-se deixar um espaço livre de ao menos $150 \mathrm{~mm}$ medidos a partir do contorno da inclusão.

Similarmente, para minimizar o efeito do atrito gerado pela parede frontal do equipamento, a norma ASTM D6706 - 01 também sugere o uso de uma manga metálica no nível do reforço, pois a sua implementação faz com que o ponto de aplicação da força de arrancamento seja transferido no interior da massa de solo (Kakuda, 2005).

\subsubsection{Efeitos a considerar nos ensaios de arrancamento}

\subsection{Efeito da tensão de confinamento}

Segundo Kakuda (2005), a tensão de confinamento aplicada tem grande influência tanto no valor de resistência ao arrancamento como nos deslocamentos relativos dos nós da inclusão. Nesse sentido, Alfaro et al. (1995) e Ochiai et al. (1996) verificaram que o aumento da tensão de confinamento provoca um aumento na resistência ao arrancamento e uma diminuição do deslocamento relativo entre os nós da geogrelha e a parede frontal do equipamento. 
Dessa maneira, nas Figuras 2.23 e 2.24 a seguir são mostrados respectivamente os resultados obtidos por Alfaro et al. (1995) e Ochiai et al. (1996), onde evidencia-se o comportamento mencionado anteriormente.

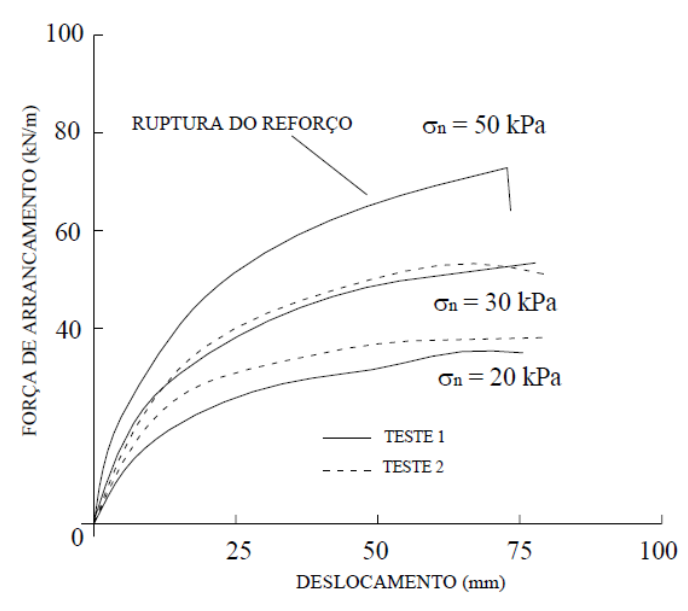

a.

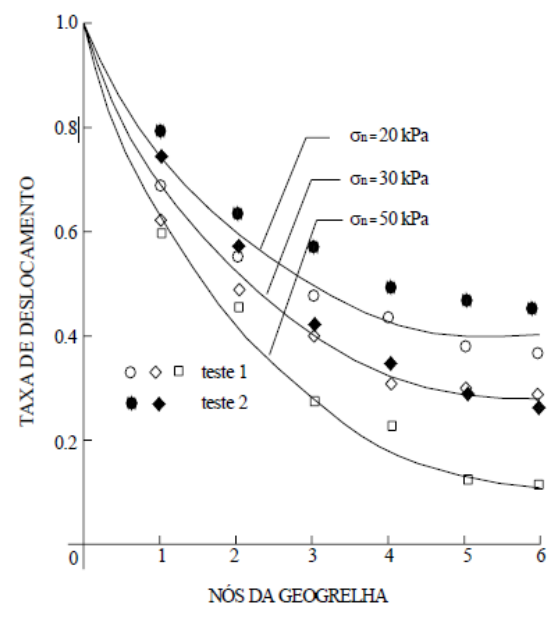

b.

Figura 2.23. Influência da tensão de confinamento na (a) Resistência a arrancamento e na (b) Taxa de deslocamento relativo dos nós da geogrelha (Alfaro et al., 1995)

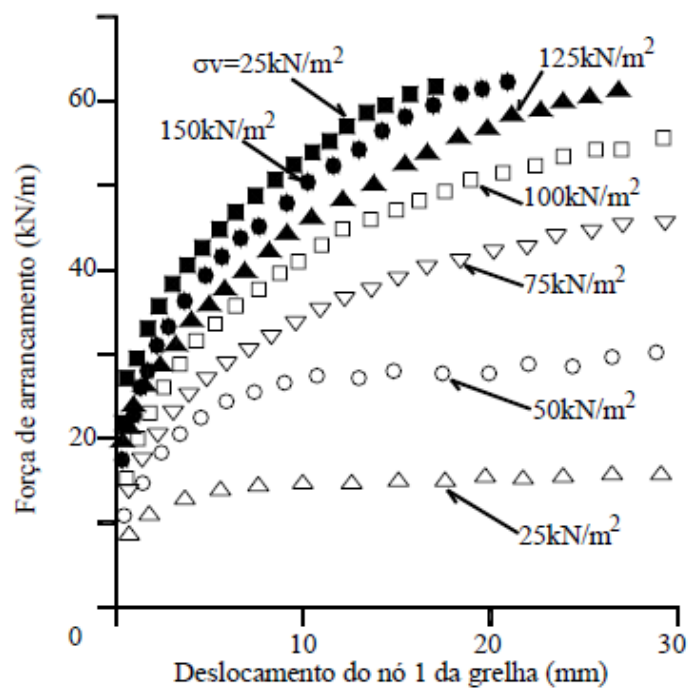

Figura 2.24. Comportamento da força de arrancamento e do deslocamento da inclusão para diferentes tensões de confinamento (Ochiai et al., 1996)

Com base nos resultados mostrados anteriormente, Kakuda (2005) complementa a análise citando um caso prático, onde menciona que o comportamento mostrado nas Figuras 2.23 e 2.24 justifica os deslocamentos diferenciais que se apresentam num maciço de solo reforçado, pois existem maiores deslocamentos nas inclusões mais 
próximas à superfície pelo fato de estarem submetidas a menores tensões de confinamento, e menores deslocamentos nos níveis de reforço mais profundos por causa da presença de tensões mais elevadas.

\subsection{Efeito da dilatância}

Segundo Kakuda (2005), a resistência ao cisalhamento das areias envolve um comportamento muito particular relacionado à parcela de resistência estrutural por causa do efeito da dilatância, a qual é devida a um rolamento de uns grãos sobre outros (Figura 2.25).

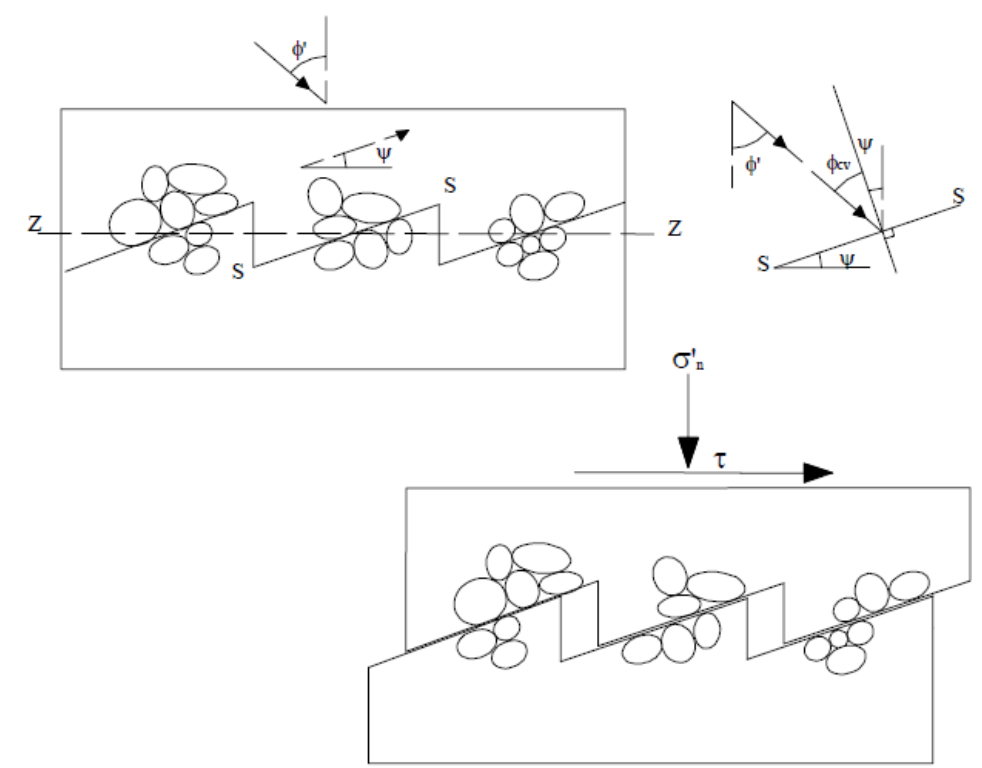

Figura 2.25. Modelo do dente de serra para representar o fenômeno de dilatância

(Bolton, 1986 apud Kakuda, 2005)

No caso dos ensaios de arrancamento ocorre um comportamento diferente se comparado com os ensaios de resistência ao cisalhamento, pois o fenômeno da dilatância é impedido. Segundo Hayashi et al. (1999), ao estar impedido tal efeito por causa da ação dos elementos transversais da geogrelha, provoca-se um aumento da tensão normal na interface solo-geossintético, provocando assim um aumento na resistência ao arrancamento. 


\subsection{Efeito do tipo de solo}

Com relação ao efeito do tipo de solo nos ensaios de arrancamento, Kakuda (2005) menciona que as geogrelhas podem apresentar mudanças no seu comportamento mecânico dependendo do material no qual esteja inserida.

Desse modo, Chang et al. (1995) avaliou o comportamento de geogrelhas inseridas tanto em solos coesivos como não coesivos, chegando a concluir que quando o material é arenoso apresentam-se valores de resistência ao arrancamento mais elevados do que quando o solo ao redor da inclusão é argiloso.

Por outro lado, Bauer e Chang (1993) realizaram ensaios de arrancamento utilizando quatro tipos de solo (arenosos, argilosos, areias argilosas e agregados), percebendo que à medida que o diâmetro das partículas aumentava, a resistência era cada vez maior. Dessa maneira, a explicação dada esteve relacionada ao bom entrosamento das partículas nas aberturas da geogrelha.

Em complemento ao explicado anteriormente, Jewell et al. (1984) analisaram a influência da relação entre o tamanho das aberturas da geogrelha e o diâmetro dos grãos e partículas de solo por meio de ensaios de cisalhamento direto, chegando nas seguintes conclusões com relação à resistência de interface para diferentes configurações:

a. Nos solos finos, a zona de plastificação pode ser ondulada e se adapta à geometria da geogrelha (Figura 2.26.a);

b. À medida que o diâmetro dos grãos de areia aumentam, a zona de plastificação torna-se cada vez mais plana, tangenciando os elementos transversais da geogrelha (Figura 2.26.b);

c. Quando o tamanho dos grãos do material iguala as dimensões da abertura da geogrelha, alguns desses grãos ficam presos nas aberturas. Ao existir uma quantidade suficiente de grãos nessas condições, o deslizamento do material ao longo dos elementos transversais é inibido, fazendo com que a zona de plastificação ocorra dentro da massa de solo (Figura 2.26.c);

d. A situação mais desfavorável ocorre quando as dimensões dos grãos superam o tamanho da abertura da geogrelha, pois ao ser impedida a penetração dos grãos nas aberturas, a resistência de interface acaba sendo muito baixa devido ao leve contato que existe entre os grãos e o reforço (Figura 2.26.d). 


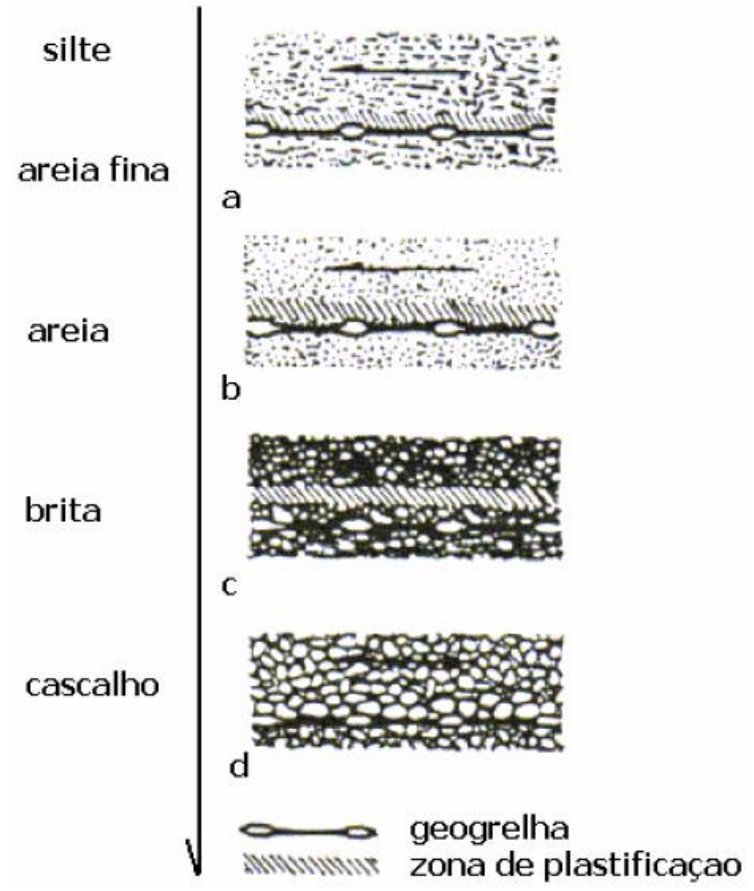

Figura 2.26. Influência qualitativa do aumento da dimensão dos grãos de solo reforçado com geogrelha em condição de cisalhamento direto (Jewell et al., 1984)

\subsection{Efeito da rugosidade da parede interna da caixa}

Segundo Palmeira e Milligan (1989), o efeito de atrito gerado pela rugosidade da parede frontal do equipamento pode alterar o valor de resistência ao arrancamento, provocando um acréscimo no ângulo de atrito de interface entre o solo e a parede frontal da caixa, e portanto, no valor da resistência.

Com o intuito de avaliar tal efeito, Palmeira e Milligan (1989) realizaram uma série de ensaios de arrancamento variando a rugosidade da parede frontal do equipamento, utilizando grelhas de aço de 12,5 x 12,5 mm inseridas numa areia densa $\left(D_{50}=0,80 \mathrm{~mm}\right.$ e $\left.\gamma=16,98 \mathrm{kN} / \mathrm{m}^{3}\right)$. Assim, nas Figuras 2.27 e 2.28 a seguir mostra-se respectivamente a disposição das diferentes rugosidades na parede frontal da caixa e a variação da razão $\tau_{a} / \sigma_{y}$ em função do deslocamento. 

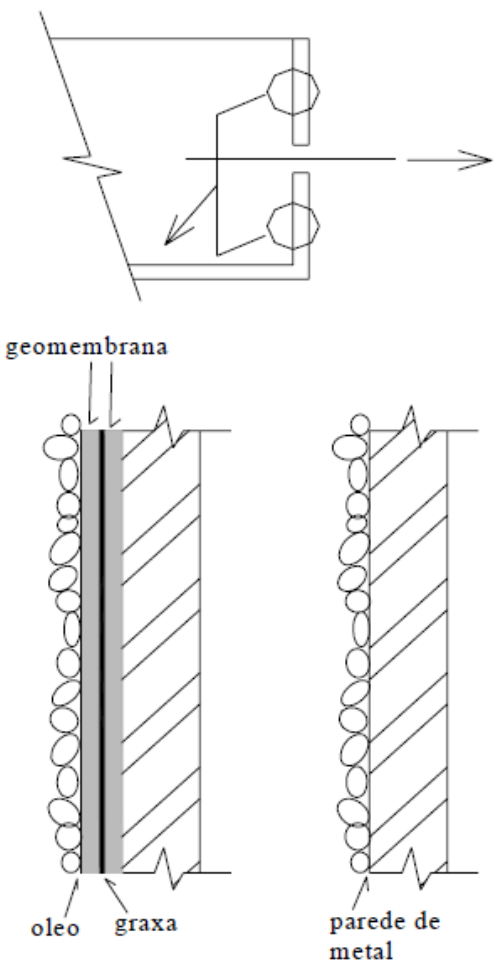
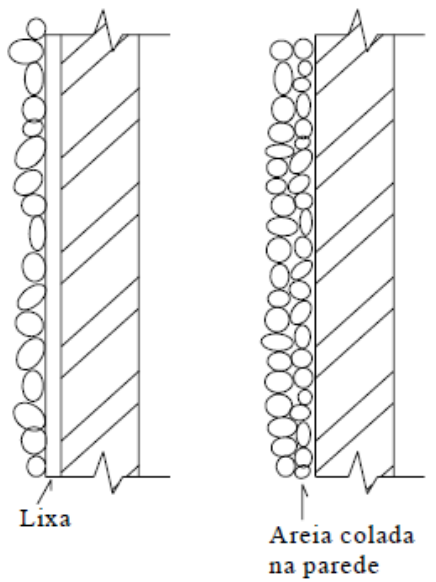

Figura 2.27. Rugosidades avaliadas na parede frontal do equipamento (Palmeira e Milligan, 1989)

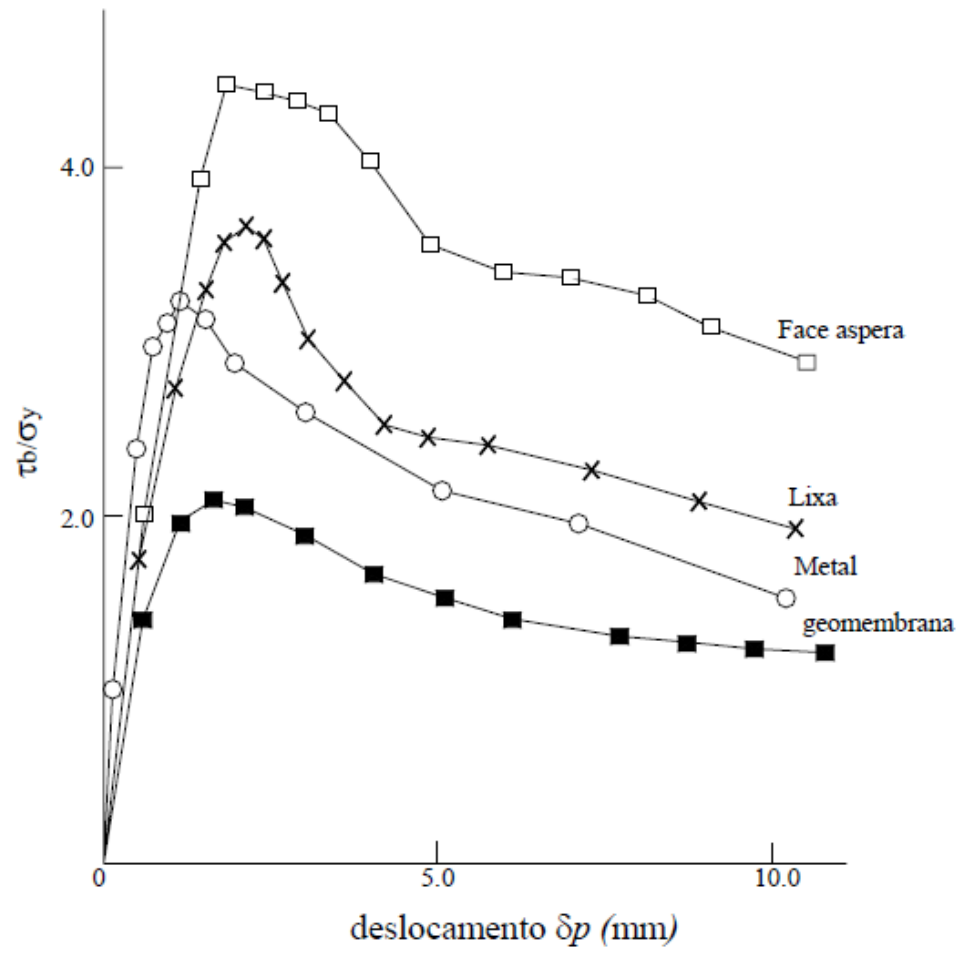

Figura 2.28. Relação entre a tensão cisalhante e normal vs. Deslocamento nos ensaios de arrancamento para diferentes rugosidades (Palmeira e Milligan, 1989) 
A partir dos resultados obtidos, observa-se que nos gráficos da Figura 2.28 a resistência ao arrancamento evidentemente aumenta à medida que a rugosidade da parede frontal do equipamento crescia. Por causa disso, Palmeira e Milligan (1989) recomendam a colocação de duas geomembranas intercaladas com um material lubrificante em cada parede interna do equipamento para minimizar os efeitos de atrito na interface solo-face interna.

Por outro lado, os efeitos de atrito gerados pela parede frontal do equipamento também podem ser reduzidos com a utilização de uma manga instalada no nível do reforço, tal como recomenda a norma ASTM D6706 - 01.

A influência da manga na resistência ao arrancamento e nos empuxos horizontais na parede frontal do equipamento foi avaliada por Farrag et al. (1993) por meio da realização de ensaios sem manga, com manga de $20 \mathrm{~cm}$ e de $30,5 \mathrm{~cm}$ de comprimento, onde foi verificado que à medida que o comprimento da manga aumenta, tanto a resistência ao arrancamento quanto os empuxos diminuem, sendo que estes últimos apresentam uma tendência a se estabilizarem a partir do maior comprimento $(30,5 \mathrm{~cm})$, como mostrado na Figura 2.29 a seguir.

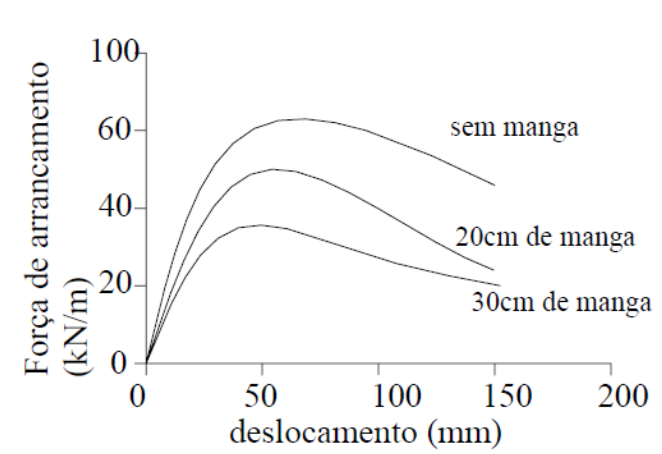

(a)

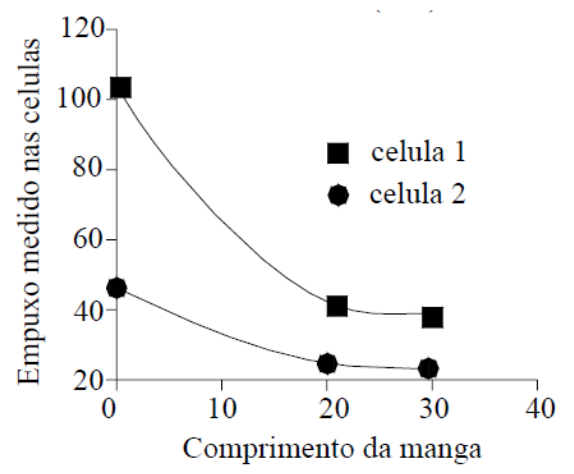

(b)

Figura 2.29. Efeito do comprimento da manga na (a) Resistência ao arrancamento e nos (b) Empuxos horizontais na parede frontal do equipamento (Farrag et al., 1993)

Sendo assim, Kakuda (2005) menciona que a utilização da manga minimiza os efeitos de atrito devido a que a força de arrancamento é transferida para o interior da massa de solo, afastando-se assim da parede frontal do equipamento. 


\subsection{Efeito da espessura da camada de solo acima e abaixo da inclusão}

Com relação ao efeito da espessura de solo tanto acima quanto abaixo do reforço, Brand e Duffy (1987) apud Kakuda (2005) analisaram a sua influência na resistência ao arrancamento de uma geogrelha inserida em argila, chegando a concluir que ao aumentar tais espessuras, a resistência decresce até um valor mínimo, passando ser constante.

Similarmente, Farrag et al. (1993) analisaram o mesmo efeito mas inserindo uma geogrelha dentro de uma areia com espessuras totais de 20, 40, 60 e $70 \mathrm{~cm}$ (considerando as camadas localizadas acima e abaixo da inclusão).

Assim, por meio dos resultados mostrados na Figura 2.30 a seguir, evidencia-se que espessuras de solo com $30 \mathrm{~cm}$ tanto acima quanto abaixo do reforço são suficientes para minimizar os efeitos de contorno, pois a partir daí o valor de resistência ao arrancamento tende a apresentar valores constantes.

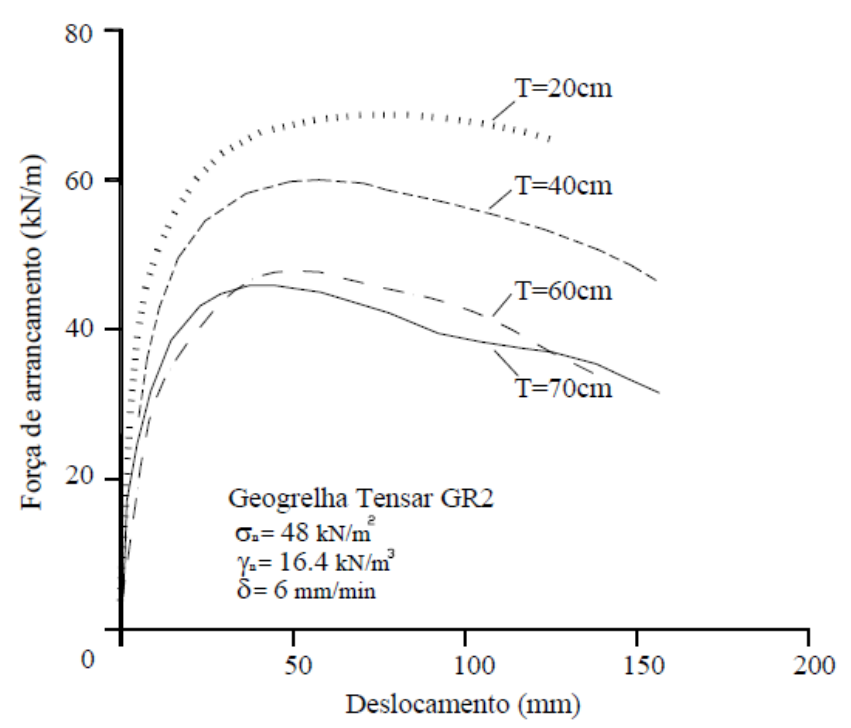

Figura 2.30. Resultados de arrancamento para diferentes espessuras de solo arenoso (Farrag et al., 1993)

Com base nos resultados obtidos por parte dos pesquisadores citados acima, Kakuda (2005) afirma que a resistência ao arrancamento tende a aumentar com a diminuição das espessuras das camadas tanto acima quanto abaixo do reforço, pois o fato do acréscimo de tensão de confinamento estar mais próximo da inclusão impede a dilatância do solo. 


\subsection{Influência da velocidade de ensaio}

Respeito à influência da taxa de deslocamento do pistão responsável pela aplicação do carregamento cisalhante, Lopes e Ladeira (1996) realizaram ensaios de arrancamento numa areia reforçada com geogrelha de PEAD aplicando carregamentos com velocidades de 1,$8 ; 5,4 ; 11,8$ e 22,0 mm/min, onde foi evidenciado que a resistência obtida aumenta seu valor em cerca de $30 \%$ com relação ao incremento de $20,2 \mathrm{~mm} / \mathrm{min}$ na taxa de deslocamento aplicada $(1,8$ para $22,0 \mathrm{~mm} / \mathrm{min})$, como mostrado na Figura 2.31 a seguir.

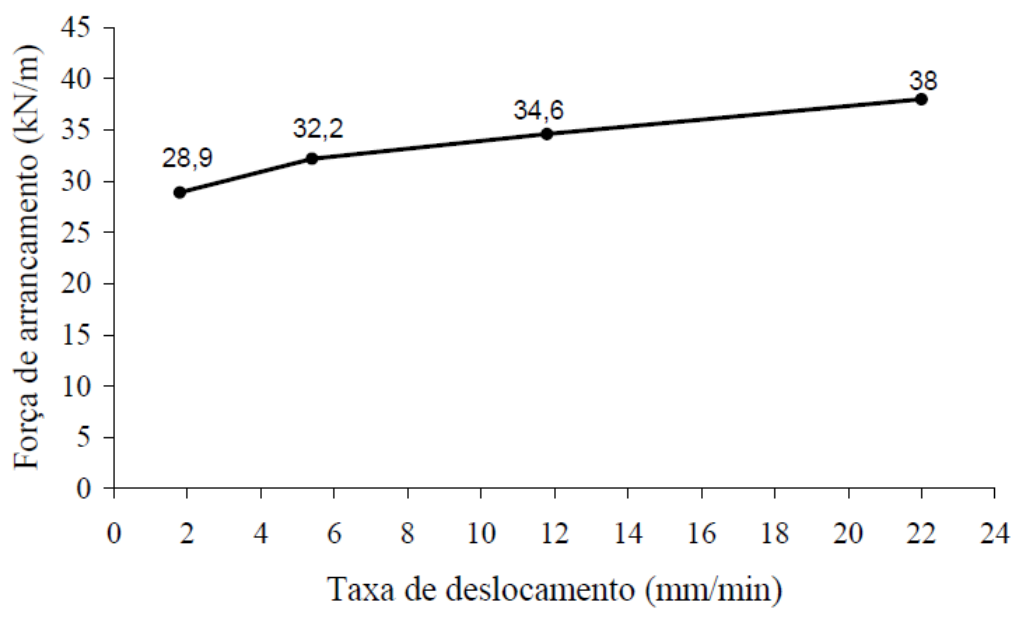

Figura 2.31. Variação da resistência ao arrancamento em função da taxa de deslocamento aplicada (Lopes e Ladeira, 1996)

Assim, os autores puderam concluir que o aumento da resistência ao arrancamento com o incremento da taxa de deslocamento utilizada deve-se ao aumento da rigidez do sistema solo-reforço e à capacidade de rearranjo dos grãos de solo.

Por outro lado, Kakuda (2005) também analisou o efeito da taxa de deslocamento do pistão na variação da resistência ao arrancamento, inicialmente por meio de ensaios com velocidades de 2,$0 ; 4,6 ; 8,0$ e $100,0 \mathrm{~mm} / \mathrm{min}$, obtendo os resultados mostrados na Figura 2.32 a seguir. 


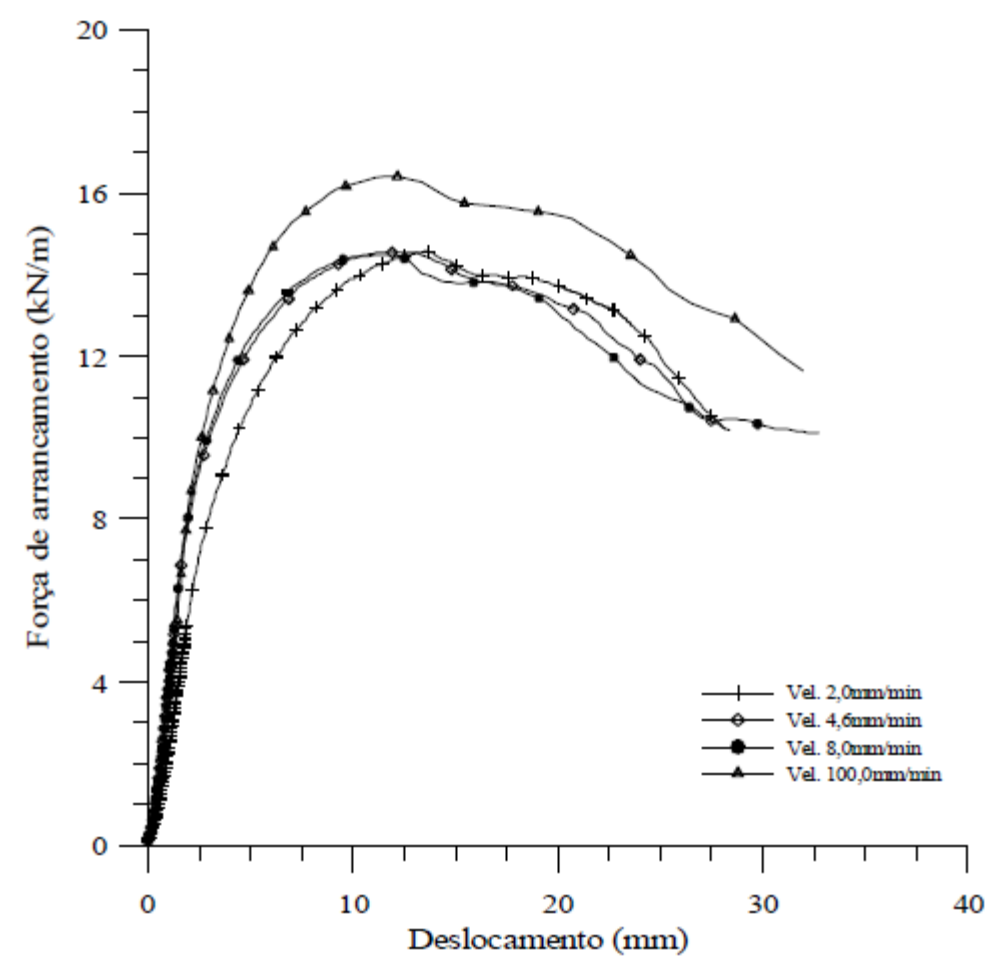

Figura 2.32. Variação da resistência ao arrancamento em função da taxa de deslocamento aplicada (Kakuda, 2005)

Dessa maneira, Kakuda (2005) percebeu que para os ensaios com velocidades de 2,0 $\mathrm{mm} / \mathrm{min}, 4,6 \mathrm{~mm} / \mathrm{min}$ e $8,0 \mathrm{~mm} / \mathrm{min}$, a resistência ao arrancamento não apresentou grande variabilidade entre si, mas no caso do ensaio com velocidade de 100 $\mathrm{mm} / \mathrm{min}$, a resistência teve um acréscimo de aproximadamente $12 \%$ com relação às outras condições. Além disso, também foi observado que à medida que a velocidade aumentava, as curvas apresentaram um leve deslocamento para a esquerda.

Sendo que a norma ASTM D6706 - 01 recomenda a utilização de uma taxa de deslocamento constante de $1,0 \mathrm{~mm} / \mathrm{min}$ para reduzir o excesso de pressão neutra gerada no solo, Kakuda (2005) realizou ensaios adicionais com velocidades de 1, 2 e 5 mm/min para verificar se a utilização da velocidade de $4,6 \mathrm{~mm} / \mathrm{min}$ afetaria o valor de resistência ao arrancamento.

Assim, com base nos resultados obtidos e mostrados na Figura 2.33 a seguir, Kakuda (2005) confirmou as pequenas variações nos valores de resistência e deslocamento, optando dessa maneira pela utilização da velocidade de 4,6 $\mathrm{mm} / \mathrm{min}$ para a realização dos demais ensaios correspondentes à sua pesquisa, a qual foi a mesma taxa utilizada por Teixeira (2003). 


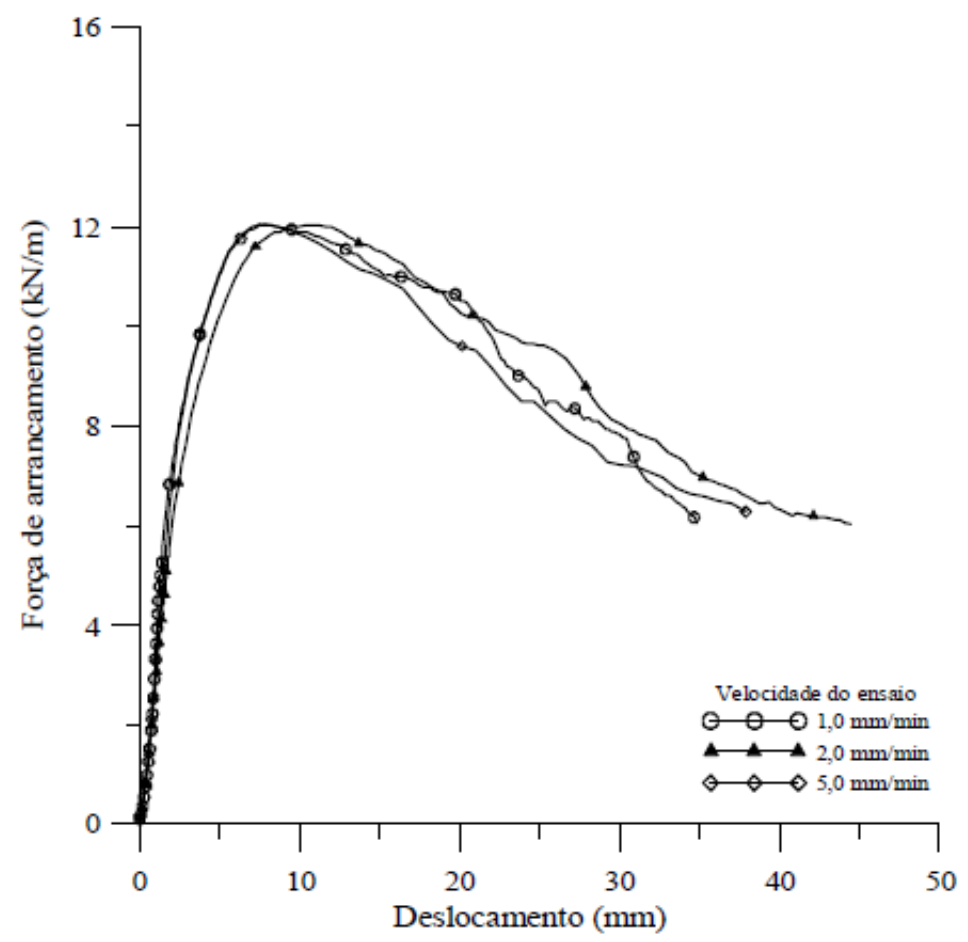

Figura 2.33. Variação da resistência ao arrancamento para taxas de deslocamento de 1,2 e $5 \mathrm{~mm} / \mathrm{min}$ (Kakuda, 2005)

\subsubsection{Ensaios de arrancamento cíclico}

Os ensaios de arrancamento cíclico, além de serem a melhor opção para avaliar a interação entre o solo e o material de reforço, podem simular ciclos de carga e descarga associados ao tráfego dos veículos sobre uma estrutura de pavimento, considerando tanto o acúmulo de deformações plásticas quanto a sua recuperação por meio das deformações elásticas (módulo de resiliência).

Segundo Leng (2002), quando um solo é submetido a um carregamento cíclico, inicialmente promove a melhoria de suas propriedades mecânicas por causa da compactação que experimenta, mas com a persistência dos ciclos de carga e descarga, surge uma diminuição progressiva do valor destas propriedades em função do espalhamento lateral do material da camada de base granular; da contaminação da camada de base com os finos do subleito quando este apresenta uma baixa capacidade de suporte $(\mathrm{CBR}<3 \%)$, e da ruptura dos agregados da base granular causada pelo carregamento cíclico.

Assim, com o intuito de avaliar o comportamento da estrutura de pavimento reforçada quando submetida a um carregamento cíclico de interface, inicialmente faz- 
se necessário conhecer a resposta da estrutura sob a ação de um arrancamento monotônico, de tal maneira que a partir da resistência obtida, possam-se definir e aplicar os ciclos de carga e descarga de amplitude constante e variável.

Desse modo, uma ciclagem convencional tem como característica principal que as amplitudes dos carregamentos cíclicos aplicados são uma parcela porcentual da resistência ao arrancamento monotônico do reforço inserido, podendo ser variáveis tanto a amplitude quanto a frequência e o número de ciclos (Napa G., 2011).

Com base na norma ASTM D7499 - 09, devem-se cumprir certas condições a respeito das dimensões do equipamento e ao tempo do pulso de carga e período de descanso para cada ciclo. Dessa maneira, a norma ASTM D7499 - 09 recomenda que o equipamento a ser utilizado nos ensaios de arrancamento cíclico tenha como mínimo $457 \mathrm{~mm}$ de comprimento, $457 \mathrm{~mm}$ de largura e $305 \mathrm{~mm}$ de altura se o efeito de atrito é minimizado. Caso contrário, a largura mínima deveria ser de $760 \mathrm{~mm}$.

Para minimizar os efeitos de atrito, a norma ASTM D6706 - 01 recomenda deixar no mínimo uma distância de $150 \mathrm{~mm}$ entre a inclusão e as paredes laterais do equipamento, assim como também faz-se necessário o uso da manga metálica à altura do reforço para diminuir o efeito de atrito entre a parede frontal e o solo.

Com relação ao sistema de aplicação de carga, a norma ASTM D7499 - 09 menciona que o equipamento deve ter a capacidade de aplicar múltiplas repetições de carga no mesmo nível da inclusão por meio de uma função de carga sinusoidal padronizada conhecida como "onda haversine" (Figura 2.34), cujo ciclo é constituído por um pulso de carga com duração de 0,2 segundos e por um período de descanso de 0,8 segundos, totalizando assim um período de um segundo, correspondente a uma frequência de $1 \mathrm{~Hz}$.

Por outro lado, já com um enfoque mais voltado para a pavimentação, o Programa Nacional de Pesquisa Cooperativa de Rodovias (NCHRP, 2004) recomenda que cada ciclo de carga esteja composto por um pulso de carga de 0,1 segundos e um período de descanso de 0,9 segundos, correspondendo também a uma frequência de 1 $\mathrm{Hz}$. 


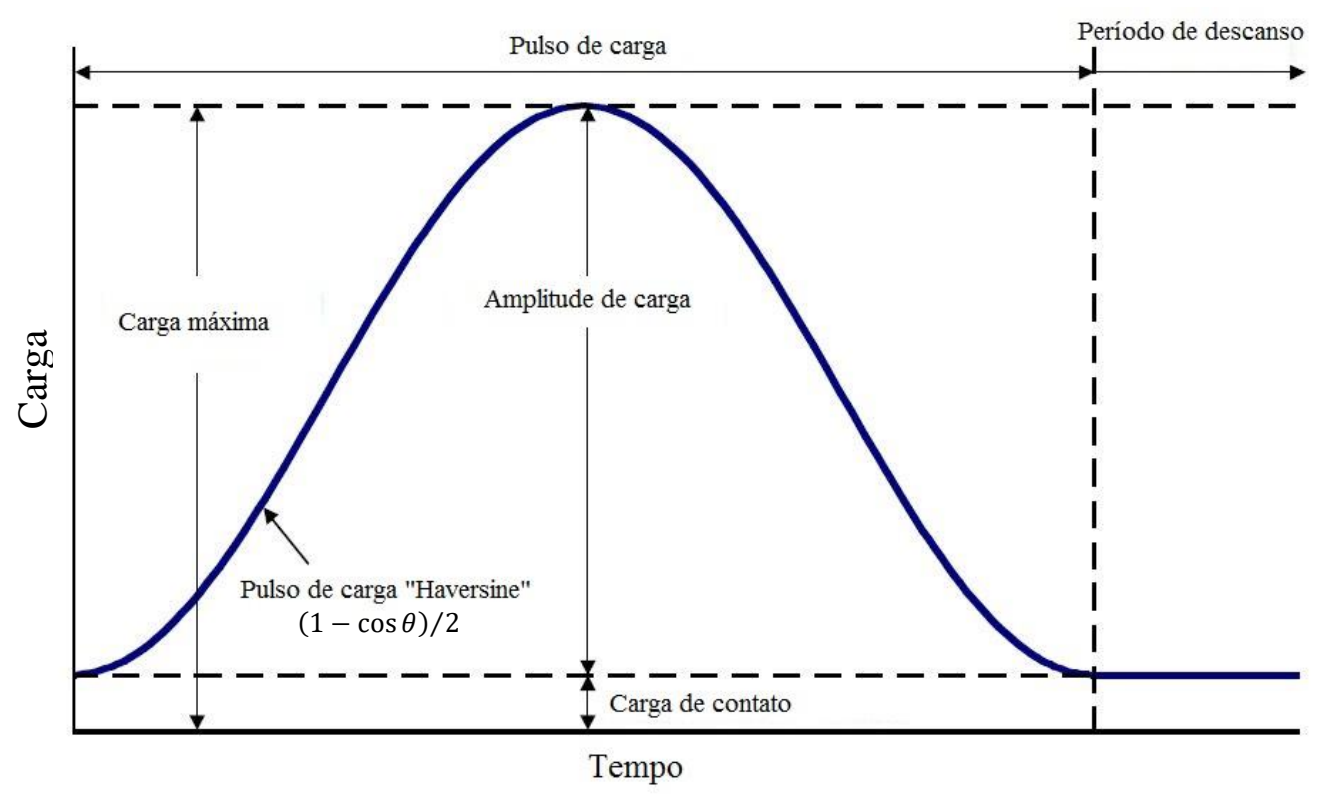

Figura 2.34. Onda Haversine (Adaptado de NCHRP, 2004)

Considerando as modalidades de ensaios de arrancamento cíclico, é preciso especificar que existem duas formas de executar tais ensaios dependendo do tipo de avaliação que pretenda-se realizar. Uma delas é submeter a estrutura de solo reforçado a carregamento cíclico de interface até atingir a falha do sistema, identificando assim o número de ciclos que levou a tal condição (Duckword, 2000; Meyer et al., 2004; Raju e Fannin, 1998).

A outra forma de realizar os ensaios de arrancamento cíclico consiste na aplicação de um carregamento monotônico imediatamente após ter submetido a estrutura reforçada a um determinado número de ciclos de carga (Figura 2.35).

Assim, é possível determinar a influência do carregamento dinâmico na resistência pós-ciclagem, podendo ser comparada com a resistência ao arrancamento inicial do sistema, tal como fizeram Moraci e Cardile (2009), Nayeri e Fakharian (2009), Napa G. (2011) e Ferreira (2015). 
a $\longmapsto_{\text {TCD Ensaio de arrancamento para comparação }}$

$(\mathrm{v}=1 \mathrm{~mm} / \mathrm{min})$

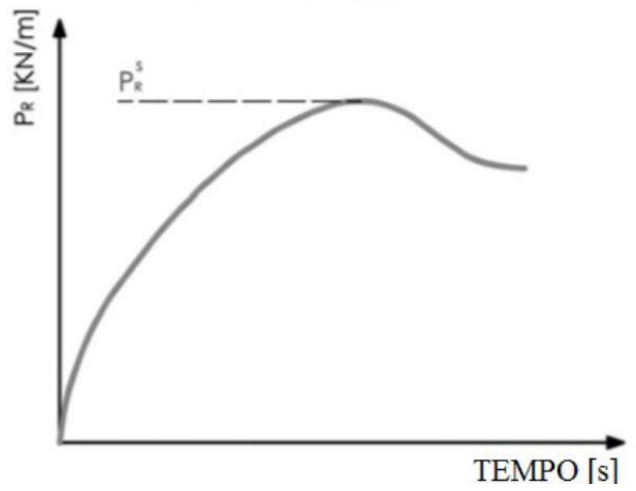

b $\quad \stackrel{\text { Primeira }}{\text { etapa }} \longleftarrow$ Segunda

$\mathrm{Pi} \quad$ Inicio da etapa ciclica

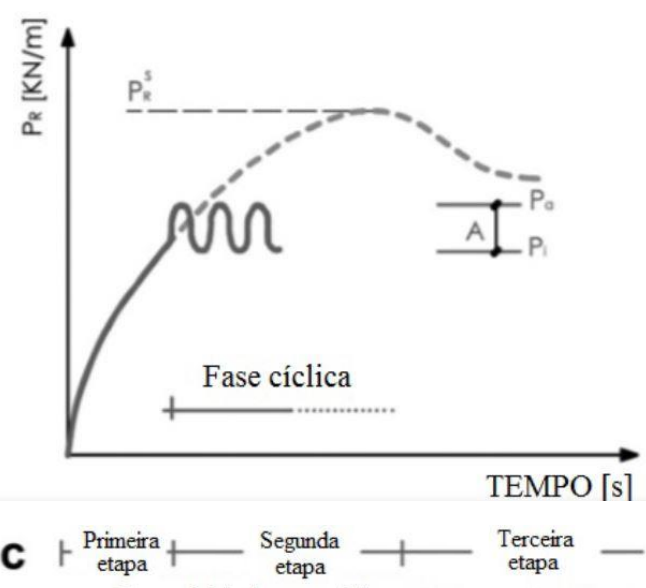

$\mathrm{Pi} \quad$ Início da etapa cíclica Verificação da influência

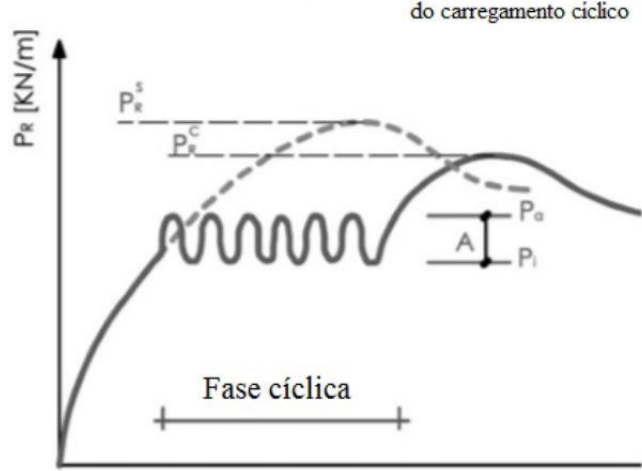

Figura 2.35. Representação esquemática da resistência pós-ciclagem de uma geogrelha inserida em um solo granular (Adaptado de Moraci e Cardile, 2009)

Segundo Leng (2002), o carregamento dinâmico aplicado gera inicialmente um efeito de compactação e uma leve melhoria das propriedades mecânicas do material, seguido de uma degradação progressiva das suas propriedades iniciais e uma diminuição da espessura efetiva das respectivas camadas. 
Moraci e Cardile (2009) puderam verificar o comportamento mencionado no parágrafo anterior por meio da realização de ensaios de arrancamento cíclico e de resistência pós-ciclagem, onde analisaram o comportamento de uma geogrelha uniaxial extrudada $\left(\mathrm{J}_{2} \%=1800 \mathrm{kN} / \mathrm{m}\right.$ e $\left.\mathrm{J}_{5} \%=1440 \mathrm{kN} / \mathrm{m}\right)$ e outra biaxial tecida $\left(\mathrm{J}_{2 \%}=1630 \mathrm{kN} / \mathrm{m}\right.$ e $\mathbf{J}_{5 \%}=1078 \mathrm{kN} / \mathrm{m}$ ) quando submetidas a solicitações de carregamento cíclico de interface com frequência de $0,1 \mathrm{~Hz}$ e tensões de confinamento de 10, 25 e $50 \mathrm{kPa}$. Dessa maneira, os resultados obtidos são mostrados nas Figuras 2.36, 2.37 e 2.38 a seguir.
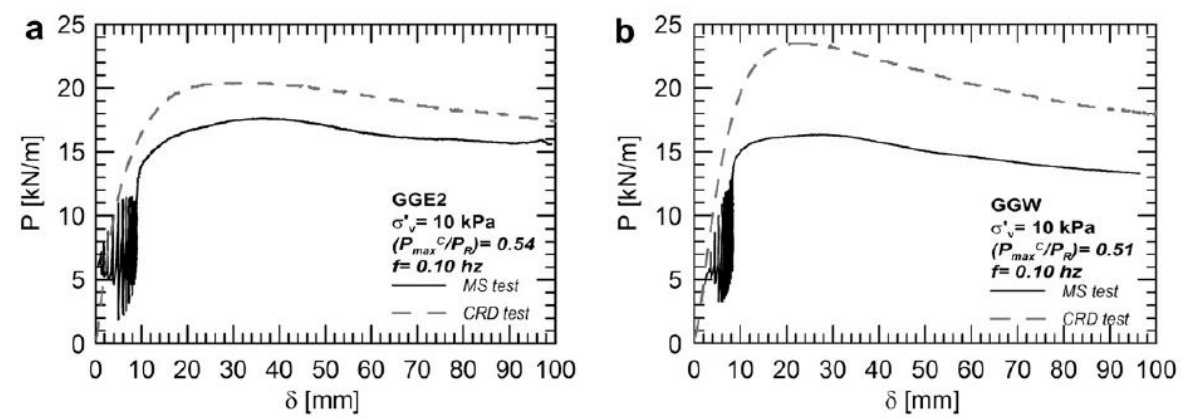

Figura 2.36. Resultados de arrancamento monotônico e resistência pós-ciclagem sob tensão de confinamento de $10 \mathrm{kPa}$ e frequência de $0,10 \mathrm{~Hz}$. (a) Geogrelha extrudada e (b) Geogrelha tecida (Moraci e Cardile, 2009)
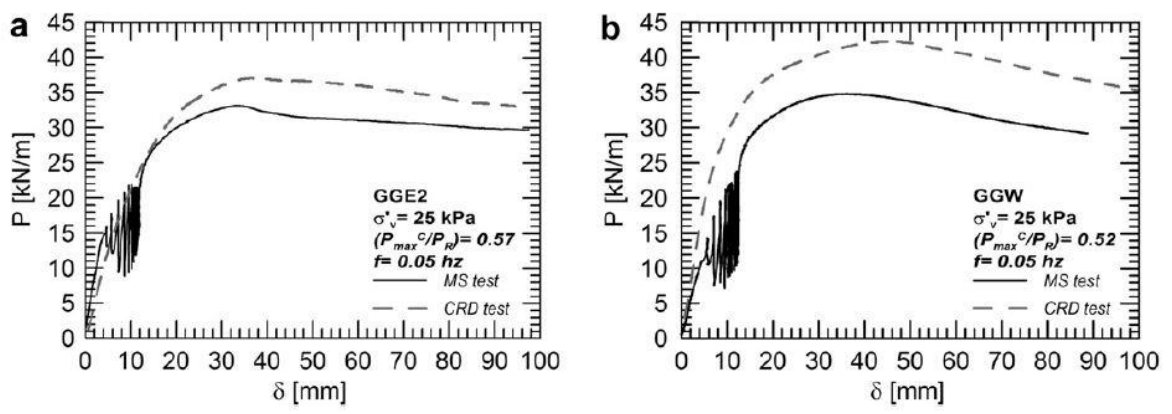

Figura 2.37. Resultados de arrancamento monotônico e resistência pós-ciclagem sob tensão de confinamento de $25 \mathrm{kPa}$ e frequência de $0,10 \mathrm{~Hz}$. (a) Geogrelha extrudada e (b) Geogrelha tecida (Moraci e Cardile, 2009) 

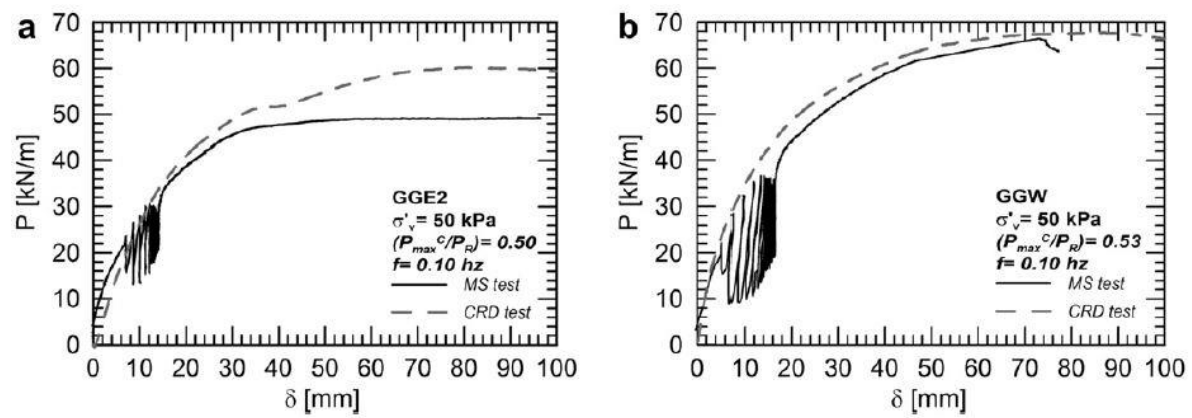

Figura 2.38. Resultados de arrancamento monotônico e resistência pós-ciclagem sob tensão de confinamento de $50 \mathrm{kPa}$ e frequência de 0,10 Hz. (a) Geogrelha extrudada e (b) Geogrelha tecida (Moraci e Cardile, 2009)

Com base nos resultados mostrados anteriormente nas Figuras 2.36, 2.37 e 2.38, Moraci e Cardile (2009) concluíram que o aumento da rigidez no reforço implica maiores resistências ao arrancamento monotônico após a aplicação dos ciclos de carga.

Por outro lado, nos resultados obtidos por Moraci e Cardile (2009) também é possível observar que à medida que a tensão de confinamento aumenta, o efeito do carregamento dinâmico na resistência ao arrancamento é cada vez menor, pois as duas curvas ficam cada vez mais próximas entre si, mas mantendo-se a superioridade da resistência inicial sobre a resistência pós-ciclagem.

Nayeri e Fakharian (2009) também avaliaram o efeito do arrancamento cíclico na resistência pós-ciclagem de uma geogrelha uniaxial de PEAD inserida em areia densa e fofa, obtendo os resultados mostrados na Figura 2.39 a seguir. 


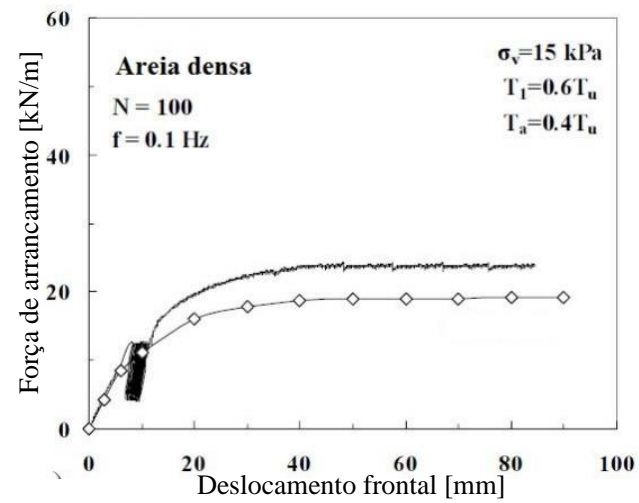

a. Areia densa $-\sigma_{\mathrm{v}}=15 \mathrm{kPa}$

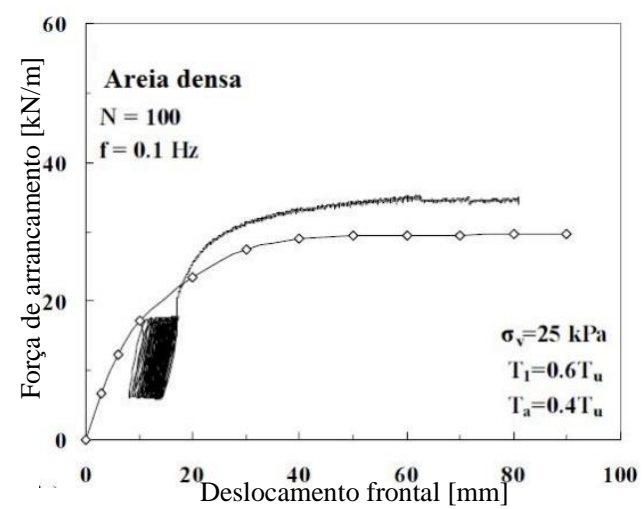

b. Areia densa $-\sigma_{\mathrm{v}}=25 \mathrm{kPa}$

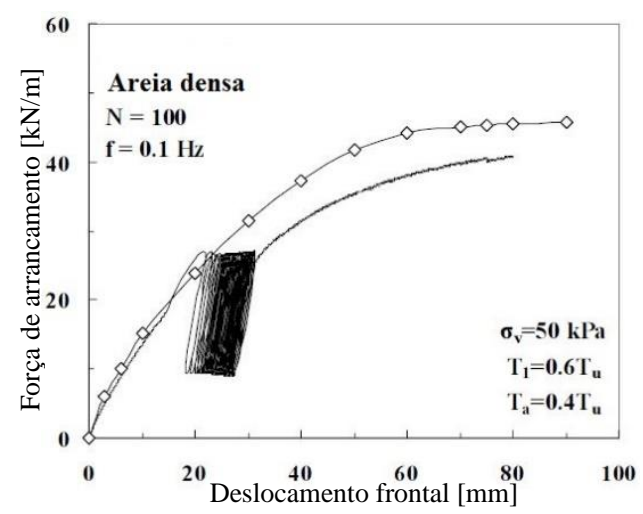

c. Areia densa $-\sigma_{\mathrm{v}}=50 \mathrm{kPa}$

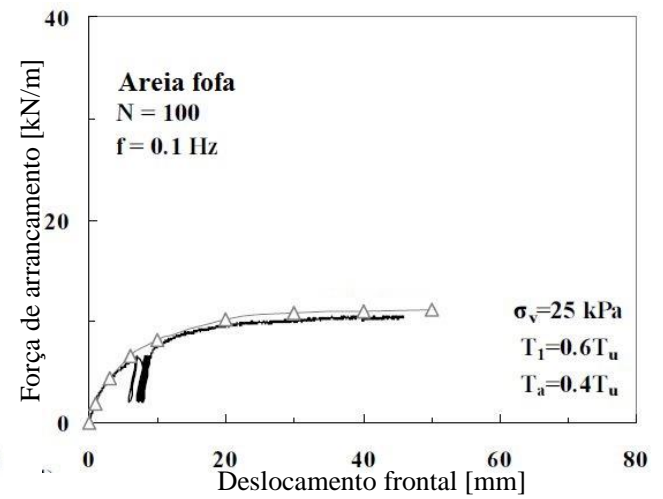

d. Areia fofa $-\sigma_{v}=25 \mathrm{kPa}$

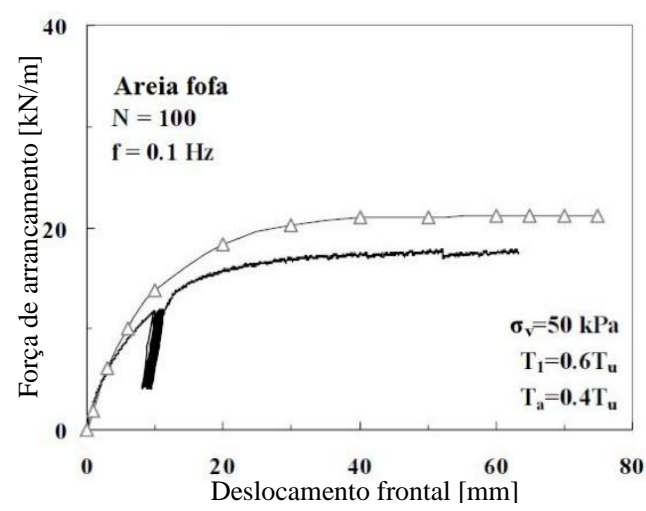

e. Areia fofa $-\sigma_{v}=50 \mathrm{kPa}$

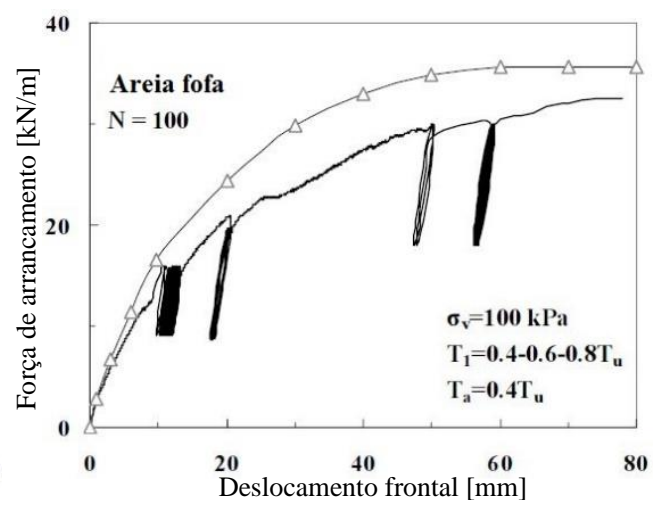

f. Areia fofa $-\sigma_{\mathrm{v}}=100 \mathrm{kPa}$

Figura 2.39. Influência do arrancamento cíclico na resistência ao arrancamento monotônico (Adaptado de Nayeri e Fakharian, 2009)

Com base nos resultados anteriores, Nayeri e Fakharian (2009) puderam concluir que a resposta monotônica pós-ciclagem exibe algum incremento na resistência inicial após os ciclos de carga, a qual é provavelmente atribuída à densificação da areia com o carregamento dinâmico.

Adicionalmente, Nayeri e Fakharian (2009) também concluíram que com o incremento da tensão de confinamento, a amplitude dos ciclos de carga também aumenta, implicando assim o surgimento de grandes deslocamentos frontais no começo 
dos ciclos de carga e levando à mobilização de uma parcela significativa do atrito e da capacidade de carga.

Portanto, durante o carregamento monotônico pós-ciclagem, a resistência ao arrancamento é menor que o carregamento monotônico inicial, sendo também observados maiores deslocamentos acumulados durante os 100 ciclos de carga.

Também, para baixas amplitudes de carga cíclica os grãos de areia não são rearranjados; por isso, são observados valores de resistência ao arrancamento iguais a, ou aproximadamente 10\% maiores que os valores monotônicos iniciais (Nayeri e Fakharian, 2009).

Por outro lado, Perkins et al. (2004), Cuelho e Perkins (2005) e Holley (2009) analisaram a interação entre o solo e o geossintético a partir do comportamento resiliente do sistema, chegando a estimar o módulo de cisalhamento de interface $G_{i}$ a partir de ensaios de arrancamento cíclico.

O módulo de cisalhamento de interface pode ser estimado a partir dos ciclos de carga e descarga mostrados num gráfico de tensão cíclica de cisalhamento $\left(\tau_{\mathrm{i}}\right)$ em $\mathrm{kPa}$ versus o deslocamento da inclusão ( $\delta$ ) em metros, como mostrado na Figura 2.40 a seguir.

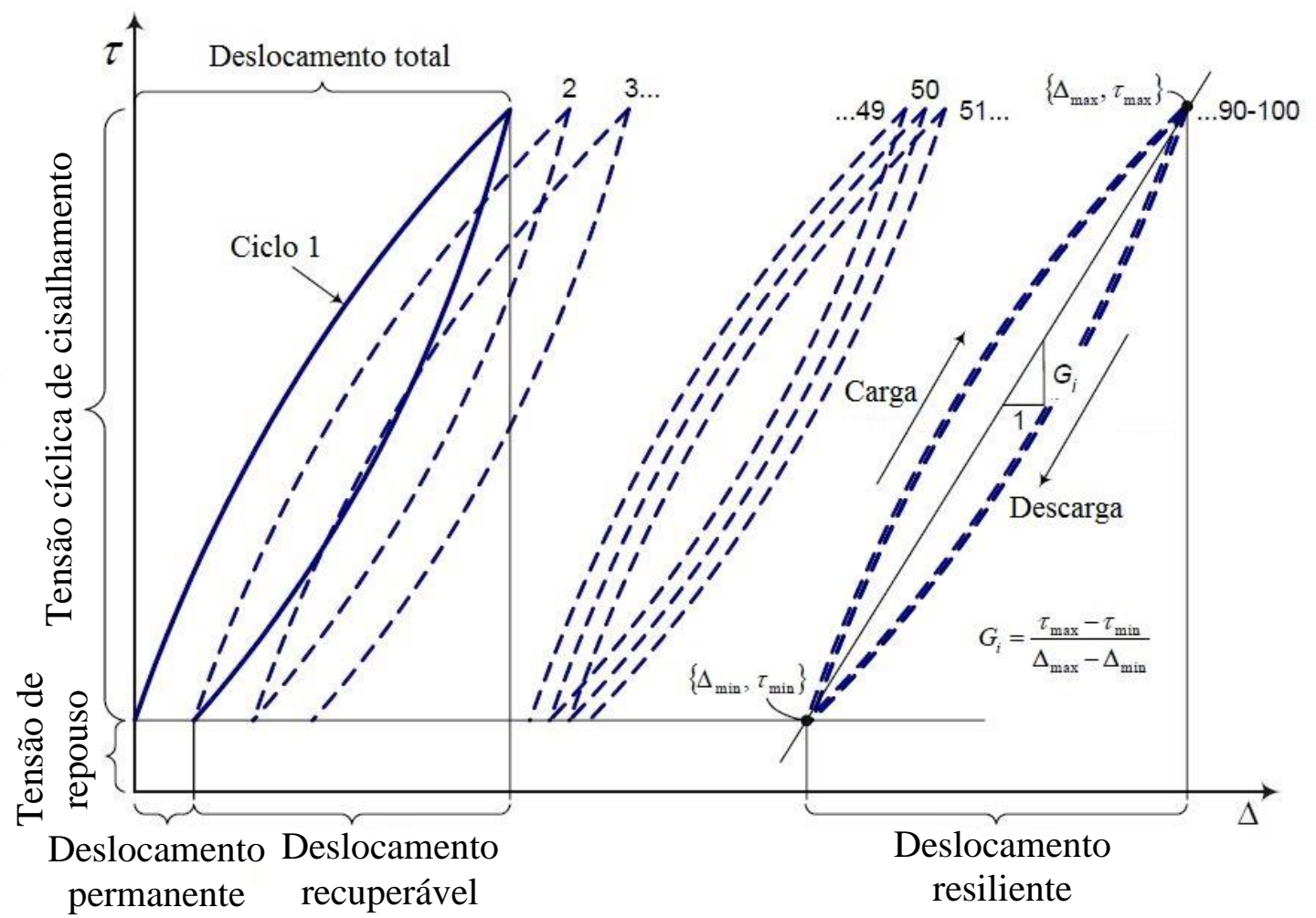

Figura 2.40. Ilustração do cálculo do módulo de cisalhamento de interface (Adaptado de Cuelho e Perkins, 2005) 
Como foi mostrado no gráfico da Figura 2.40, o módulo de cisalhamento de interface $G_{i}$ é calculado como a razão entre a diferença das tensões de cisalhamento cíclico e a diferença dos deslocamentos médios do geossintético para um determinado ciclo de carga (ASTM D7499 - 09), como mostrado na Equação (2.10) a seguir.

$$
G_{i}=\frac{\tau_{\text {imáx }}-\tau_{i \min }}{\delta_{\operatorname{máx}}-\delta_{\min }}
$$

Onde:

- $\tau_{\text {i máx }}$ : Tensão máxima de cisalhamento cíclico, [kPa];

- $\tau_{i \text { mín }}$ : Tensão mínima de cisalhamento cíclico, $[\mathrm{kPa}]$;

- $\delta_{\text {máx }}$ : Deslocamento máximo médio do geossintético para um determinado ciclo de carga, $[\mathrm{m}]$;

- $\delta_{m i ́ n}$ : Deslocamento mínimo médio do geossintético para um determinado ciclo de carga, $[\mathrm{m}]$;

Por outro lado, o cálculo das tensões de cisalhamento cíclico deve levar em consideração a perda de área que acontece na inclusão durante o seu arrancamento (Perkins et al., 2004). Dessa maneira, as tensões de cisalhamento devem ser calculadas conforme a Equação (2.11) a seguir.

$$
\tau=\frac{F}{2 w\left(l-\Delta_{b}\right)}
$$

Onde:

- $F$ : Carga aplicada à geogrelha, $[\mathrm{kN}]$;

- 2: Representa os dois lados da geogrelha;

- $\quad w$ : Largura da amostra, $[\mathrm{m}]$;

- $\quad l$ : Comprimento inicial confinado da amostra, [m];

- $\Delta_{b}$ : Deslocamento médio acumulado permanente na amostra por causa do arrancamento, $[\mathrm{m}]$; 
Finalmente, na Tabela 2.2 a seguir, é mostrada uma relação das características dos equipamentos para realizar ensaios de arrancamento cíclico no mundo, assim como as características dos ensaios realizados.

Tabela 2.2. Equipamentos de arrancamento cíclico no mundo (Modificada de Napa

$$
\text { G., 2011) }
$$

\begin{tabular}{|c|c|c|}
\hline $\begin{array}{c}\text { Centro de } \\
\text { pesquisa - } \\
\text { Universidade }\end{array}$ & Dimensões do equipamento & Tipo de ensaio \\
\hline $\begin{array}{l}\text { Universidade de } \\
\text { British Columbia - } \\
\text { Duckword, 2000; } \\
\text { Raju, } 1995\end{array}$ & $\begin{array}{l}1300 \text { x } 640 \text { x } 600 \mathrm{~mm} \text { - Paredes } \\
\text { frotal e posterior de alumínio; } \\
\text { paredes laterais revestidas com } \\
\text { lámina de vidro; medidor de } \\
\text { pressão na parede frontal; sistema } \\
\text { de garra exterior à caixa. }\end{array}$ & $\begin{array}{l}\text { Taxa constante de } \\
\text { deslocamento; ensaios } \\
\text { cíclicos com diferentes } \\
\text { amplitudes e frequências } \\
(0,1 \text { a } 0,01 \mathrm{~Hz})\end{array}$ \\
\hline $\begin{array}{l}\text { Universidade } \\
\text { Kyushu - Ochiai et } \\
\text { al., } 1996\end{array}$ & $\begin{array}{l}600 \times 400 \times 400 \mathrm{~mm} \text { - Paredes } \\
\text { interiores } \\
\text { membranas } \\
\text { engraxadas. } \\
600 \times 200 \times 300 \mathrm{~mm} \text { - Paredes } \\
\text { lubrificadas. }\end{array}$ & $\begin{array}{l}\text { Taxa constante de } \\
\text { deslocamento; ensaio } \\
\text { cíclico. Carregamentos } \\
\text { monotônicos e cargas de } \\
\text { tração repetitivas }(0,1 \text { a } 0,5 \\
\text { Hz) }\end{array}$ \\
\hline $\begin{array}{l}\text { Universidade } \\
\text { Técnica de } \\
\text { Clausthal - Meyer; } \\
\text { Nernheim e Köhler, } \\
\text { 2004; Nernheim; } \\
\text { Meyer, 2006 }\end{array}$ & $\begin{array}{l}1500 \text { × } 600 \text { × } 600 \mathrm{~mm} \text { - Mangas } \\
\text { metálicas nas paredes frontais; } \\
\text { sistema de garras interior à caixa. }\end{array}$ & $\begin{array}{l}\text { Taxa constante de } \\
\text { deslocamento; ensaios } \\
\text { cíclicos de fadiga (até } 4 \\
\mathrm{~Hz} \text { ) }\end{array}$ \\
\hline $\begin{array}{l}\text { Universidade } \\
\text { Mediterrânea de } \\
\text { Reggio Calabria - } \\
\text { Moraci e Recalcati, } \\
\text { 2006; Moraci e } \\
\text { Cardile, } 2009\end{array}$ & $\begin{array}{l}1700 \text { x } 600 \text { x } 680 \mathrm{~mm} \text { - Mangas na } \\
\text { parede frontal, sistema de garra } \\
\text { interior à caixa, paredes interiores } \\
\text { lubrificadas através de películas de } \\
\text { teflon. }\end{array}$ & $\begin{array}{l}\text { Taxa constante de } \\
\text { deslocamento; ensaios } \\
\text { cíclicos multiestágio }(0,1 \mathrm{e} \\
0,05 \mathrm{~Hz})\end{array}$ \\
\hline
\end{tabular}




\begin{tabular}{|c|c|c|}
\hline $\begin{array}{c}\text { Centro de } \\
\text { pesquisa - } \\
\text { Universidade }\end{array}$ & Dimensões do equipamento & Tipo de ensaio \\
\hline $\begin{array}{l}\text { Universidade de } \\
\text { Montana State - } \\
\text { Cuelho; Perkins, } \\
\text { 2005; Holley, } 2009\end{array}$ & $\begin{array}{l}650 \text { x } 900 \text { x } 300 \text { mm (900 x } 1250 \text { x } \\
1100 \mathrm{~mm}) \text { - Mangas metálicas na } \\
\text { parede frontal. Caixa de madeira } \\
\text { reforçada, blocos espaçadores de } \\
\text { estirofoam e blocos de construção } \\
\text { para reduzir o volume de solo. }\end{array}$ & $\begin{array}{l}\text { Taxa constante de } \\
\text { deslocamento; ensaios } \\
\text { cíclicos de módulo de } \\
\text { resiliência da interface }\end{array}$ \\
\hline $\begin{array}{l}\text { Universidade de São } \\
\text { Paulo - Escola de } \\
\text { Engenharia de São } \\
\text { Carlos - Napa G., } \\
2011 \text {; Campos, } \\
2013\end{array}$ & $\begin{array}{l}1500 \text { x } 700 \text { x } 480 \mathrm{~mm} \text { - Caixa rígida } \\
\text { de aço; sistema hidráulico de } \\
\text { aplicação de carga com } 50 \mathrm{kN} \text { de } \\
\text { capacidade; velocidade de } \\
\text { deslocamento do pistão variando de } \\
1 \text { a } 53 \mathrm{~mm} / \mathrm{s} \text {, com precisão de } 1 \\
\mathrm{~mm} / \mathrm{s} \text {; tempo de carga máxima do } \\
\text { ciclo com precisão de } 0,01 \mathrm{~s} \text {. }\end{array}$ & $\begin{array}{l}\text { Taxa constante de } \\
\text { deslocamento com } \\
\text { velocidade de } 3,6 \mathrm{~mm} / \mathrm{s}, \\
\text { equivalente a } 1 \% \text { de } \\
\text { deformação do corpo de } \\
\text { prova; pressão hidráulica } \\
\text { de } 50 \text { bar para os ensaios } \\
\text { cíclicos; amplitudes de } \\
\text { cargas cíclicas com cerca } \\
\text { de } 40 \text { kg para mais e para } \\
\text { menos, em relação à } \\
\text { amplitude desejada; tempo } \\
\text { de pulso de } 0,4 \text { s e } \\
\text { descanso entre pulsos de } \\
0,6 \quad \text { s, totalizando } \\
\text { frequência de } 1 \text { Hz; } \\
\text { velocidade do pistão } \\
\text { variável de acordo com o } \\
\text { nível de carregamento, } \\
\text { variando entre } 20 \text { e } 37 \\
\text { mm/s, (Campos, } 2013 \text { ). }\end{array}$ \\
\hline
\end{tabular}




\section{Capítulo 3}

\section{MATERIAIS E MÉTODOS}

Neste capítulo são descritas as propriedades dos materiais a serem utilizados nos ensaios propostos, as quais foram obtidas a partir dos ensaios de caracterização realizados nos laboratórios de Mecânica dos Solos (Departamento de Geotecnia), de Estradas (Departamento de Transportes) e de Geossintéticos (Departamento de Geotecnia), todos pertencentes à Escola de Engenharia de São Carlos da Universidade de São Paulo.

De igual maneira, tem-se também uma descrição dos equipamentos utilizados na realização dos ensaios de arrancamento monotônico e cíclico, assim como dos instrumentos de medição destinados para o registro das tensões, da força e dos deslocamentos de forma contínua durante cada ensaio.

Finalmente, é desenvolvido um guia detalhado com todo o procedimento para a preparação do solo e para a montagem dos equipamentos utilizados na etapa experimental, os quais serão de grande utilidade para futuros trabalhos onde sejam executados ensaios de arrancamento monotônico e cíclico.

\subsection{Solos}

Para o desenvolvimento da pesquisa procurou-se utilizar solos da região que pudessem representar uma estrutura de pavimento, escolhendo assim um solo argiloso para a camada inferior da estrutura e um material arenoso para a camada superior, com jazidas localizadas respectivamente nas abscissas km153+900 e km154+800 da rodovia Luiz Augusto de Oliveira (SP-215), no sentido São Carlos - Ribeirão Bonito (lado direito). 
Na Figura 3.1 a seguir são mostradas as fotografias das jazidas dos materiais utilizados, fazendo a aclaração que a coleta do solo foi realizada com autorização da empresa responsável pelas obras de pavimentação que estavam sendo desenvolvidas nesse momento no local.

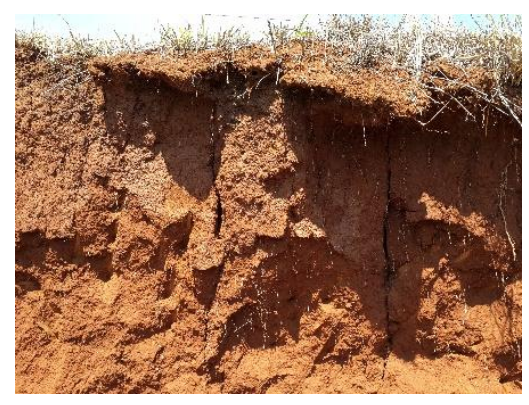

a. Jazida do solo argiloso

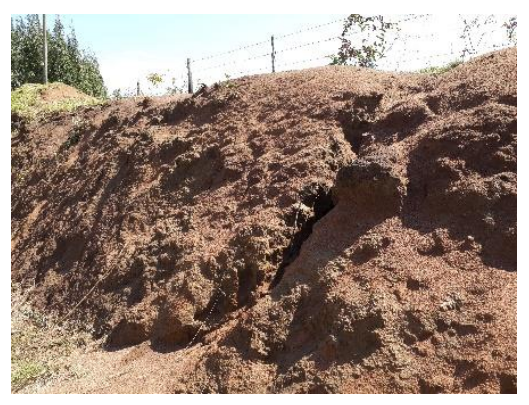

b. Jazida do solo arenoso

Figura 3.1. Jazidas do solo utilizado na pesquisa

Adicionalmente, na Figura 3.2 a seguir é mostrado o aspecto visual do solo utilizado nos ensaios realizados, onde é possível observar diferenças entre um solo coesivo e não coesivo, mesmo que no solo arenoso é possível ver uns pequenos torrões que evidenciam a presença de argila.

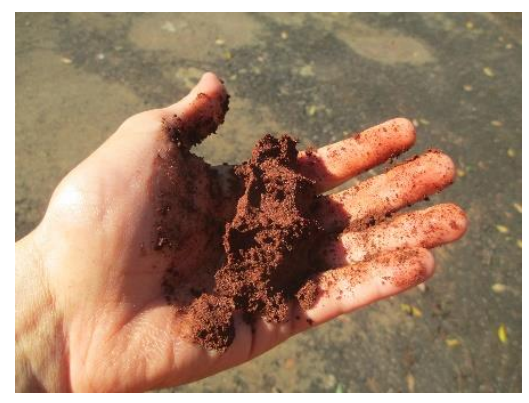

a. Solo argiloso

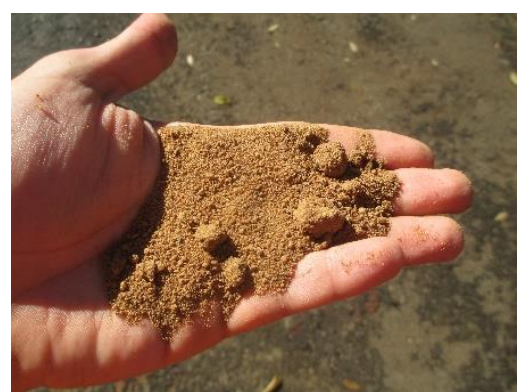

b. Solo arenoso

Figura 3.2. Aspecto visual do solo utilizado na pesquisa

Com relação à estocagem do material, o solo utilizado na pesquisa foi disposto nas baias que fazem parte do Laboratório de Geossintéticos, sendo protegido de intempéries com uma lona, como mostrado na Figura 3.3 a seguir. 


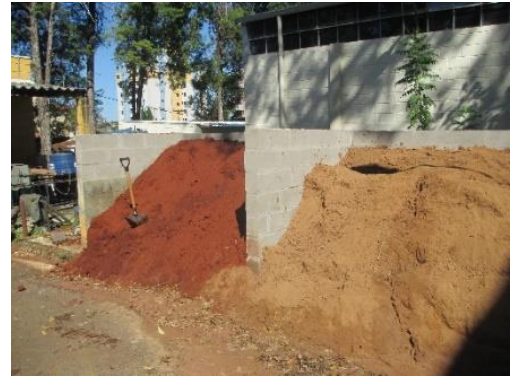

a. Material sem cobertura

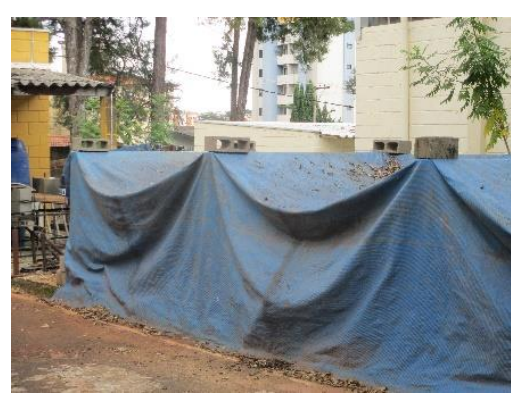

b. Material com cobertura

Figura 3.3. Estocagem do solo utilizado

Sobre a classificação dos materiais, o solo da camada inferior da estrutura (solo de subleito) é classificado como um silte de alta plasticidade (MH) e como uma argila areno-siltosa, segundo o Sistema Unificado de Classificação de Solos (SUCS) e a norma brasileira NBR 6502/95, respectivamente. No caso do solo da camada superior (solo de base), sua classificação corresponde a uma areia argilosa (SC) e a uma areia argilosa com vestígio de silte, segundo o Sistema Unificado de Classificação de Solos (SUCS) e a norma brasileira NBR 6502/95, respectivamente.

Para a caracterização completa dos materiais foram realizados os ensaios propostos na mecânica dos solos, como também foi realizado o ensaio do Índice de Suporte Califórnia (CBR), cujos corpos de prova foram compactados com um grau de compactação de $100 \%$ e teor de umidade ótimo.

Pensando numa futura simulação numérica, também foram realizados ensaios triaxiais do tipo CU (Consolidated Undrained) e CD (Consolidated Drained) sem saturação à contrapressão, e assim poder determinar os parâmetros de resistência ao cisalhamento e os módulos de deformabilidade do solo argiloso e arenoso, respectivamente.

Com o intuito de representar as mesmas condições de compactação do solo nos ensaios de arrancamento monotônico e cíclico, nos ensaios triaxiais utilizaram-se amostras deformadas, onde cada corpo de prova foi compactado com um grau de compactação de $98 \%$ e teor de umidade ótimo.

Assim, nas Figuras 3.4, 3.5 e 3.6, são mostradas respectivamente as curvas de distribuição granulométrica, de compactação e de tensão de desvio versus deformação axial para cada material. 


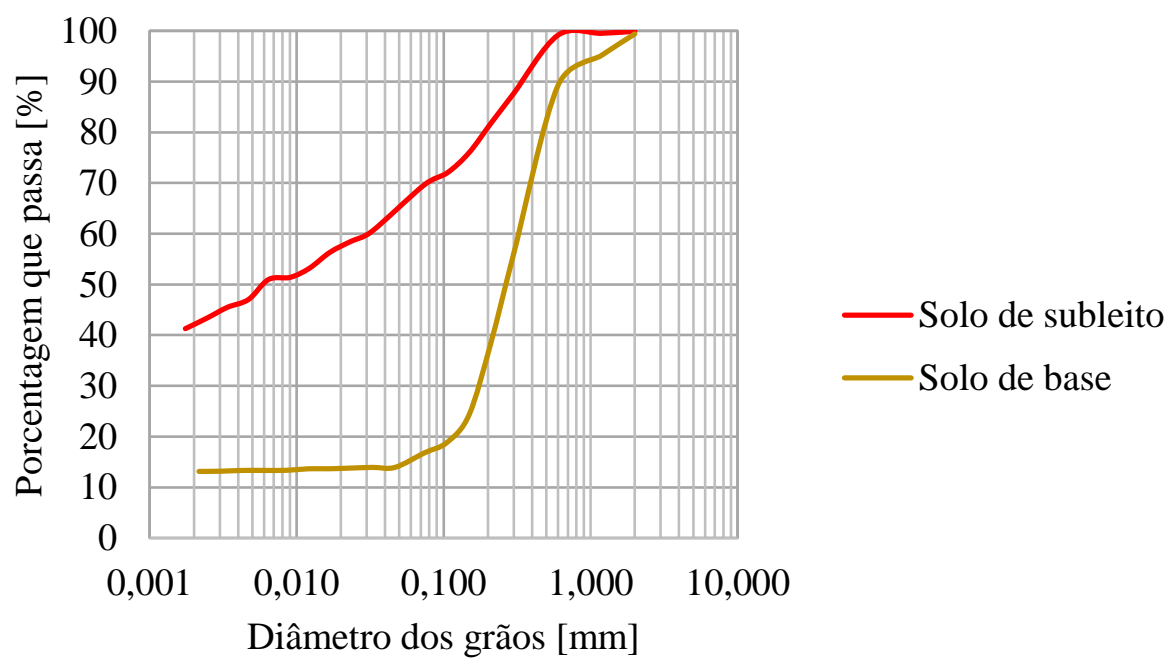

Figura 3.4. Distribuição granulométrica dos solos

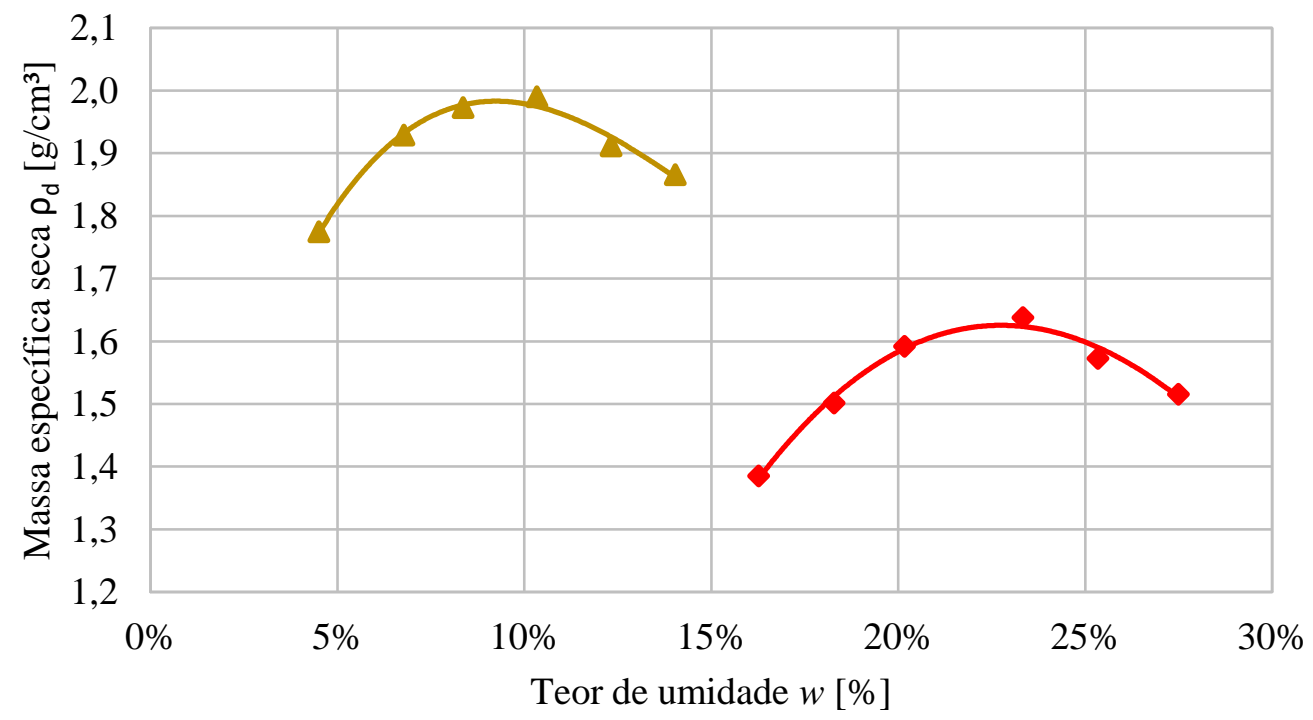

• "Solo de base" • "Solo de subleito"

- Solo de base $\quad$ Solo de subleito

Figura 3.5. Curvas de compactação dos solos 


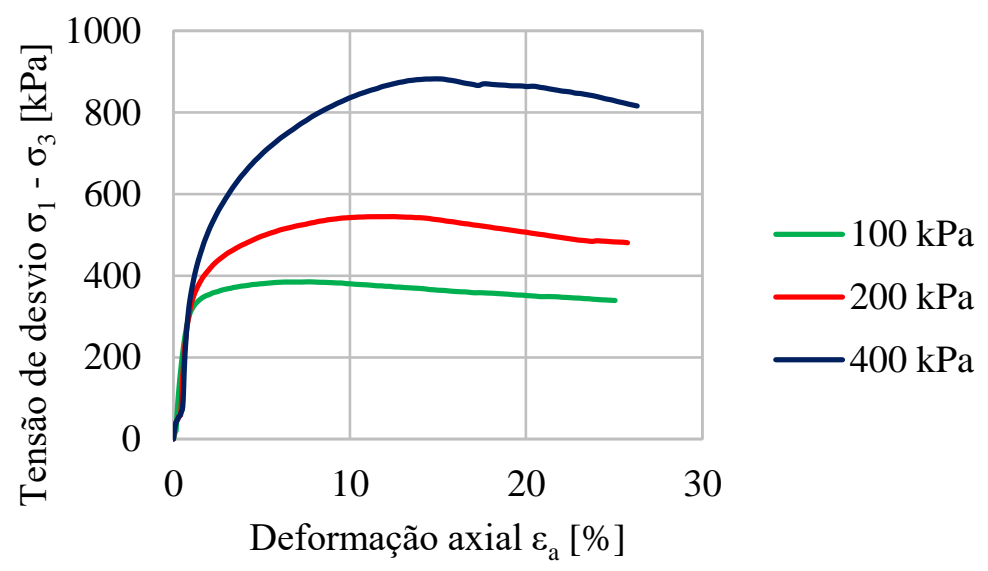

a. Solo argiloso - Ensaio triaxial CU

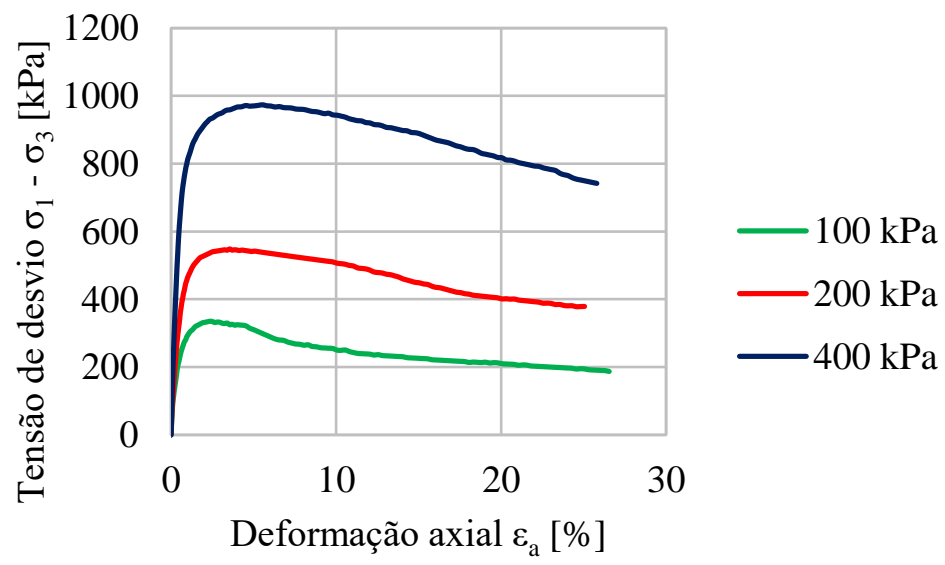

b. Solo arenoso - Ensaio triaxial CD

Figura 3.6. Curvas de tensão de desvio versus deformação axial

Com base nos resultados dos ensaios triaxiais mostrados anteriormente na Figura 3.6, os parâmetros de resistência ao cisalhamento de cada material são determinados a partir das trajetórias de tensões, as quais são constituídas a partir dos lugares geométricos dos pontos correspondentes à máxima tensão de cisalhamento para cada estado de tensões no círculo de Mohr (Vilar, S/D).

Assim, as trajetórias de tensões mostradas no gráfico da Figura 3.7 a seguir, cujos eixos $\left(\mathrm{s}^{\prime}, \mathrm{t}^{\prime}\right)$ representam as coordenadas dos pontos mencionados anteriormente (Tabela 3.1), são obtidas com base nas seguintes equações:

$$
\begin{aligned}
s^{\prime} & =\frac{\sigma_{1}+\sigma_{3}}{2} \\
t^{\prime} & =\frac{\sigma_{1}-\sigma_{3}}{2}
\end{aligned}
$$


Onde $\sigma_{1}$ e $\sigma_{3}$ correspondem respectivamente à tensão principal maior e menor.

Tabela 3.1. Coordenadas dos pontos de máxima tensão de cisalhamento no círculo de Mohr

\begin{tabular}{|c|c|c|c|c|c|c|}
\hline \multirow[b]{2}{*}{$\begin{array}{c}\sigma 3 \\
{[\mathrm{kPa}]}\end{array}$} & \multicolumn{2}{|c|}{$\sigma_{1}[\mathrm{kPa}]$} & \multicolumn{2}{|c|}{$\mathbf{t}^{\prime}[\mathrm{kPa}]$} & \multicolumn{2}{|c|}{$s^{\prime}[\mathrm{kPa}]$} \\
\hline & $\begin{array}{c}\text { Solo } \\
\text { argiloso }\end{array}$ & $\begin{array}{c}\text { Solo } \\
\text { arenoso }\end{array}$ & $\begin{array}{c}\text { Solo } \\
\text { argiloso }\end{array}$ & $\begin{array}{c}\text { Solo } \\
\text { arenoso }\end{array}$ & $\begin{array}{c}\text { Solo } \\
\text { argiloso }\end{array}$ & $\begin{array}{c}\text { Solo } \\
\text { arenoso }\end{array}$ \\
\hline 100 & & & 192,52 & & & 267 \\
\hline 200 & 7 & 748,39 & 272 & 27 & 472 & 474,20 \\
\hline 400 & 1282,36 & 1373,74 & 441,18 & 486,87 & 841,18 & 886,87 \\
\hline
\end{tabular}

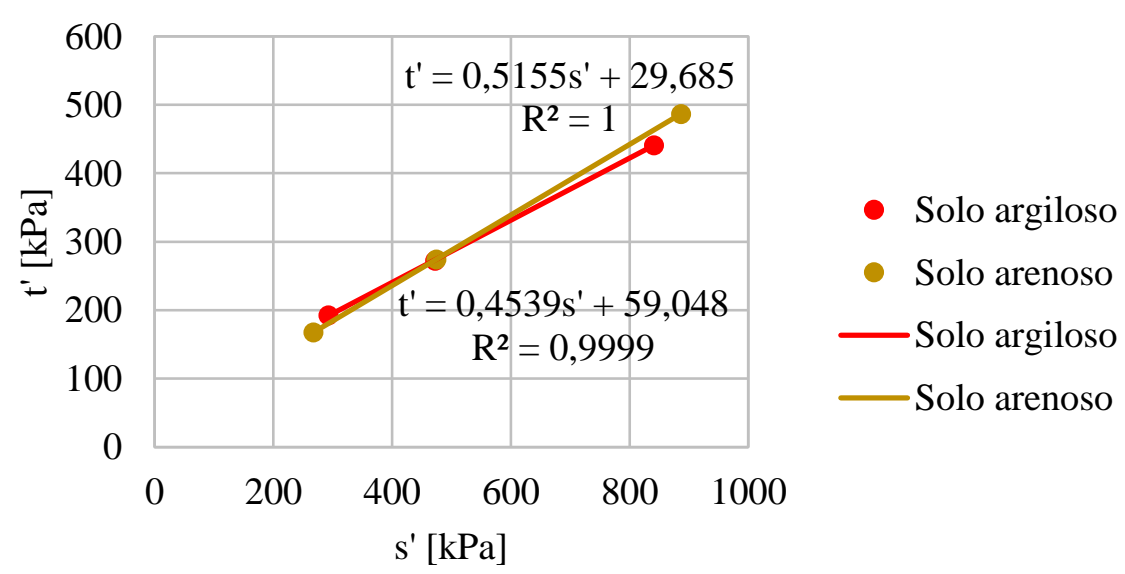

Figura 3.7. Trajetórias de tensões obtidas a partir dos ensaios triaxiais

Com base nas envoltórias de resistência obtidas das trajetórias de tensões para cada tipo de solo (Figura 3.7), Vilar (S/D) mostra que é possível obter os parâmetros de resistência ao cisalhamento a partir da relação que existe com a envoltória de resistência de Mohr-Coulomb aplicando as equações a seguir:

$$
t^{\prime}=a^{\prime}+s^{\prime} \tan \alpha^{\prime}
$$

Onde,

$$
\begin{gathered}
a^{\prime}=c^{\prime} \cos \phi^{\prime} \\
\tan \alpha^{\prime}=\sin \phi^{\prime}
\end{gathered}
$$


Dessa maneira, na Tabela 3.2 a seguir é mostrado um resumo das propriedades geotécnicas dos solos utilizados, obtidas a partir dos ensaios de caracterização realizados nos laboratórios de Mecânica dos Solos e de Estradas, pertencentes aos Departamentos de Geotecnia e de Transportes da EESC-USP, respectivamente.

Tabela 3.2. Propriedades geotécnicas dos solos

\begin{tabular}{|c|c|c|c|c|}
\hline \multirow[t]{2}{*}{ Ensaio } & \multirow[t]{2}{*}{ Parâmetro } & \multicolumn{2}{|c|}{ Tipo de solo } & \multirow[t]{2}{*}{ Especificação } \\
\hline & & Solo do subleito & Solo da base & \\
\hline \multirow{3}{*}{ Classificação } & SUCS & MH & $\mathrm{SC}$ & ASTM D2488 \\
\hline & ABNT & $\begin{array}{l}\text { Argila areno- } \\
\quad \text { siltosa }\end{array}$ & $\begin{array}{c}\text { Areia argilosa } \\
\text { com vestígio de } \\
\text { silte }\end{array}$ & $\begin{array}{c}\text { ABNT NBR } \\
7181\end{array}$ \\
\hline & AASHTO & $A-7-5$ & $A-2-4$ & $\begin{array}{l}\text { AASHTO } \\
\text { M145-87 }\end{array}$ \\
\hline $\begin{array}{c}\text { Massa } \\
\text { específica dos } \\
\text { sólidos }\end{array}$ & $\rho_{\mathrm{s}}\left[\mathrm{g} / \mathrm{cm}^{3}\right]$ & 2,913 & 2,646 & $\begin{array}{c}\text { ABNT NBR } \\
6508\end{array}$ \\
\hline \multirow{3}{*}{$\begin{array}{l}\text { Limites de } \\
\text { consistência }\end{array}$} & $w_{\mathrm{L}}[\%]$ & 55 & 16 & $\begin{array}{c}\text { ABNT NBR } \\
6459\end{array}$ \\
\hline & $w_{\mathrm{P}}[\%]$ & 32 & NP & $\begin{array}{c}\text { ABNT NBR } \\
7180\end{array}$ \\
\hline & $\mathrm{I}_{\mathrm{P}}[\%]$ & 23 & NP & \\
\hline \multirow{3}{*}{ Proctor normal } & $\rho_{\mathrm{d} \text { máx }}\left[\mathrm{g} / \mathrm{cm}^{3}\right]$ & 1,626 & 1,983 & \multirow{3}{*}{$\begin{array}{c}\text { ABNT NBR } \\
7182\end{array}$} \\
\hline & $w_{\mathrm{ot}}[\%]$ & 22,75 & 9,24 & \\
\hline & $\mathrm{S}_{\mathrm{r}}[\%]$ & 84 & 73 & \\
\hline \multirow{2}{*}{$\begin{array}{l}\text { Índice de } \\
\text { Suporte } \\
\text { California } \\
\end{array}$} & CBR [\%] & 22 & 51 & \multirow{2}{*}{$\begin{array}{c}\text { DER/SP-M53- } \\
71\end{array}$} \\
\hline & $\begin{array}{c}\text { Expansão } \\
{[\%]}\end{array}$ & 0,02 & 0,20 & \\
\hline \multirow{3}{*}{ Triaxial } & $\phi^{\prime}\left[{ }^{\circ}\right]$ & 27,0 & 31,0 & \\
\hline & $\mathrm{c}^{\prime}[\mathrm{kPa}]$ & 66,27 & 34,64 & \\
\hline & $\mathrm{E}[\mathrm{kPa}]$ & $922,41(\mathrm{CU})$ & $1414,86(\mathrm{CD})$ & \\
\hline
\end{tabular}

Adicionalmente, com o intuito de conhecer as propriedades resilientes dos solos, também foram realizados ensaios triaxiais cíclicos para cada material com base na norma AASHTO T 307-99, onde cada corpo de prova foi compactado com as mesmas condições dos ensaios de compressão triaxial CD (Consolidated Drained) e CU (Consolidated Undrained).

Assim, na Figura 3.8 a seguir é mostrada a variação do módulo de resiliência em função da tensão de desvio para cada tipo de solo, onde é possível observar que com o 
aumento da tensão de desvio apresenta-se um comportamento diferente na variação do módulo de resiliência em cada material, sendo de diminuição no solo argiloso e de aumento no arenoso, tal como foi mostrado por Mohammad et al. (1995).
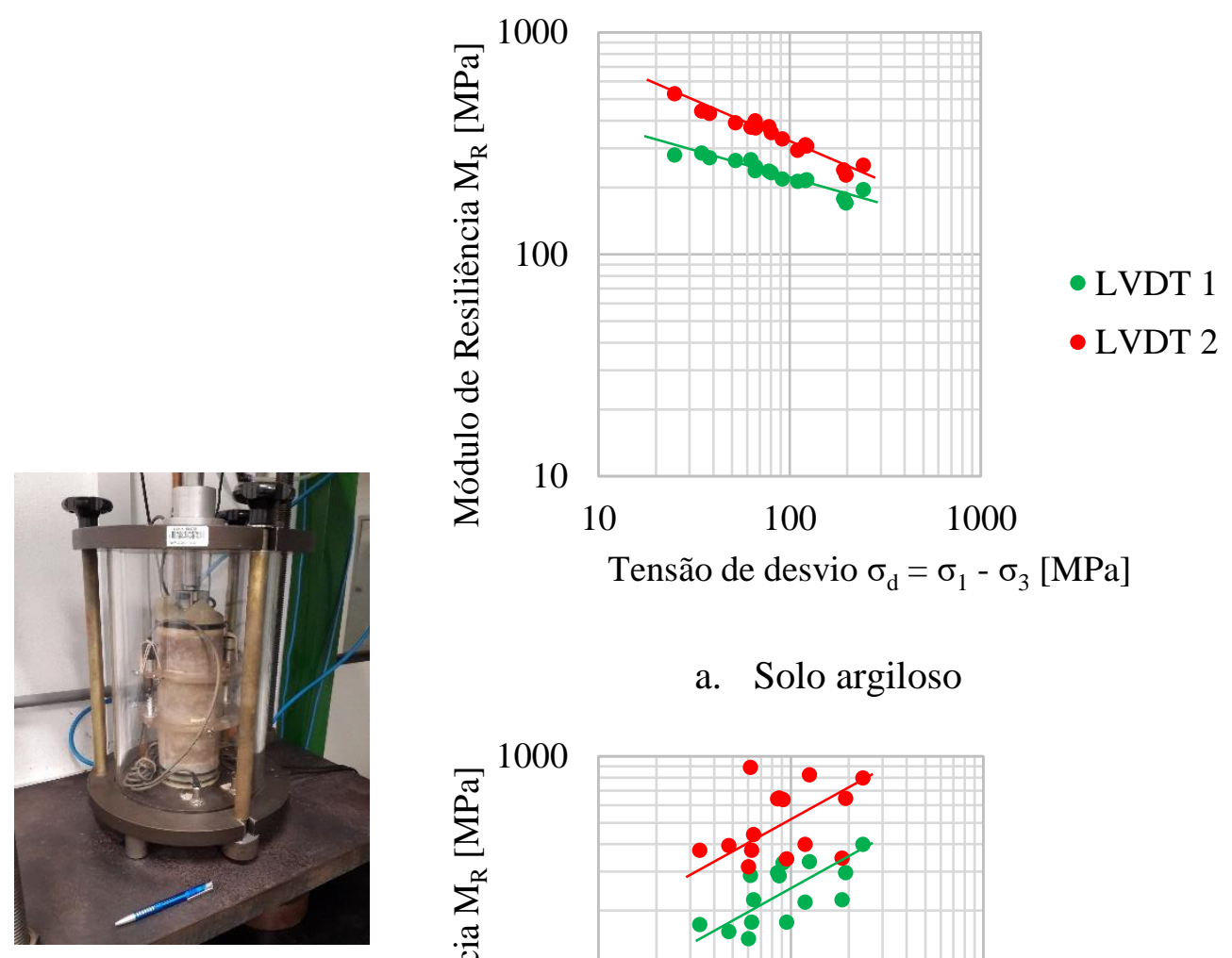

a. Solo argiloso

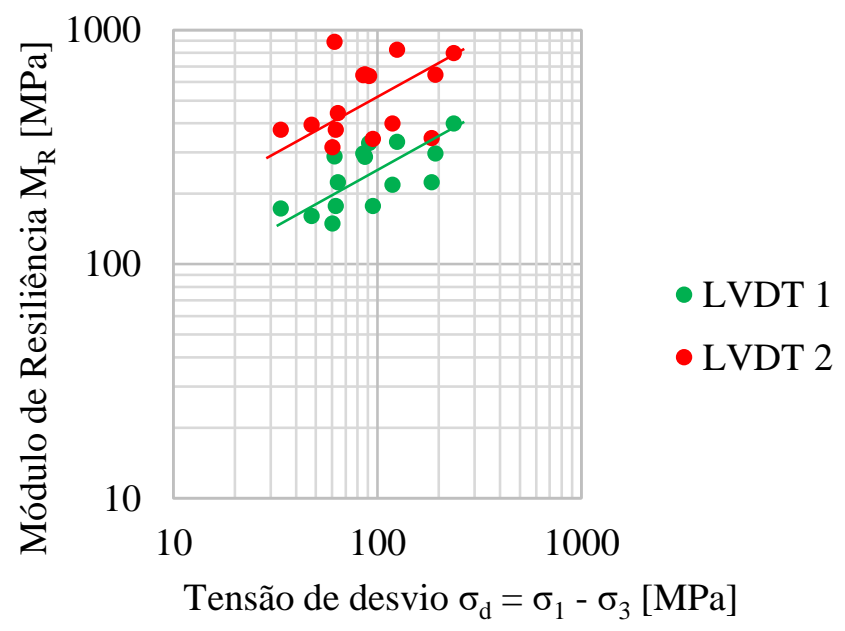

b. Solo arenoso

Figura 3.8. Variação do módulo de resiliência em função da tensão de desvio

Por outro lado, segundo o Guia de Dimensionamento Mecanicista e Empírico de Estruturas de Pavimento Novas e Reabilitadas (NCHRP 1-37A, 2004), o módulo de resiliência é influenciado pelo estado de tensão atuante no solo. Por causa disso, o ensaio triaxial cíclico tem tanta importância na estimativa do módulo de resiliência, pois permite a determinação das constantes de regressão para calibrar os modelos que representam o seu comportamento em função do estado de tensões (Viana, 2007). 
Sendo assim, na Tabela 3.3 a seguir são mostradas as constantes de regressão dos modelos mais representativos para estimar o módulo de resiliência, obtidas a partir dos ensaios triaxiais cíclicos realizados no Laboratório de Estradas da EESC-USP.

Tabela 3.3. Constantes de regressão dos modelos mais representativos na estimativa do módulo de resiliência

\begin{tabular}{|c|c|c|c|c|c|c|}
\hline & Modelo & Tipo de solo & k1 & k2 & k3 & $\mathbf{R}^{2}$ \\
\hline \multirow{2}{*}{ Composto } & \multirow{2}{*}{$M_{R}=k_{1} \cdot \sigma_{3}^{k_{2}} \cdot \sigma_{d}^{k_{3}}$} & Argiloso & 1056,712 & 0,038 & $-0,332$ & 0,959 \\
\hline & & Arenoso & 22,610 & 0,330 & 0,314 & 0,895 \\
\hline \multirow{2}{*}{$\begin{array}{c}\text { Tensão de } \\
\text { desvio }\end{array}$} & \multirow{2}{*}{$M_{R}=k_{1} \cdot \sigma_{d}^{k_{2}}$} & Argiloso & 1084,896 & $-0,302$ & & 0,950 \\
\hline & & Arenoso & 62,433 & 0,396 & & 0,819 \\
\hline
\end{tabular}

\subsection{Preparação do solo}

Para a execução dos ensaios de arrancamento monotônico e cíclico, o solo precisa de um processo de preparação baseado nos seguintes passos:

- Peneiramento para tirar a fração grossa correspondente aos pedregulhos e desfazer os torrões de solo;

- Secagem ao ar;

- Homogeneização da umidade higroscópica através de uma betoneira;

- Ajuste da umidade ótima de compactação e homogeneização na betoneira.

\subsubsection{Peneiramento}

Com o intuito de tirar a fração grossa correspondente ao pedregulho e desfazer os torrões de solo, utilizaram-se duas peneiras comumente usadas em agricultura, cujas aberturas correspondiam à peneira número $4(4,80 \mathrm{~mm})$. Para facilitar o processo de destorroamento do solo, cada peneira foi apoiada sobre um tubo rígido utilizado em obras de esgoto, como mostrado na Figura 3.9 a seguir. 


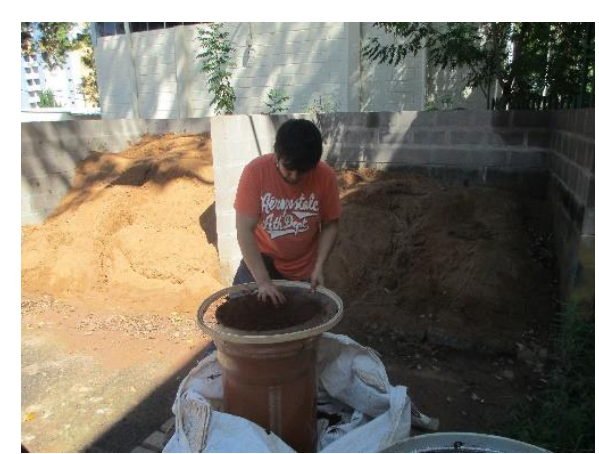

a. Destorroamento do solo

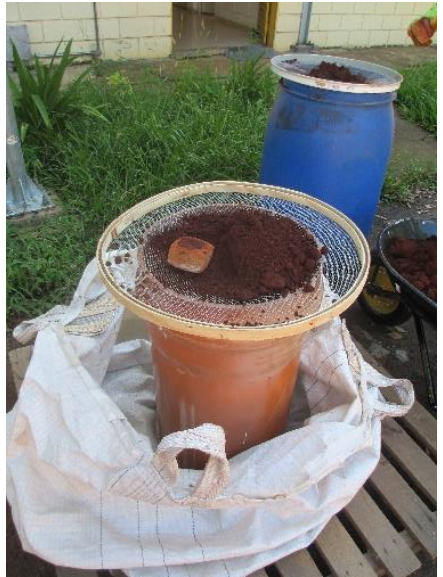

b. Apoio das peneiras nos tubos rígidos

Figura 3.9. Peneiramento do solo

Finalmente, utilizaram-se bags com capacidade de meia tonelada para guardar o solo já peneirado dentro do Laboratório de Geossintéticos (Figura 3.10), os quais eram apoiados sobre pallets para evitar o seu contato com algum líquido.

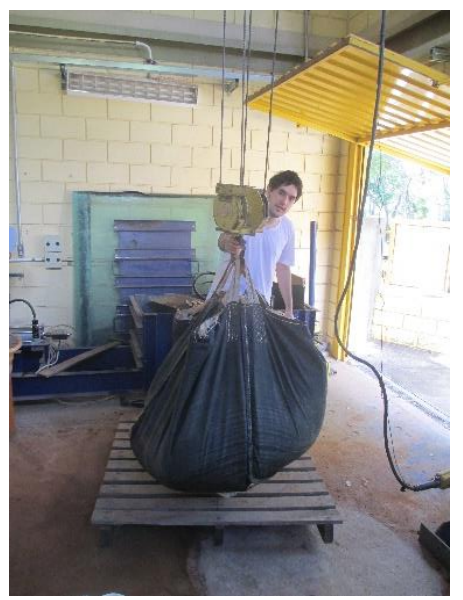

Figura 3.10. Conservação do solo peneirado dentro do Laboratório de Geossintéticos

\subsubsection{Secagem ao ar}

Como o solo encontrava-se com um teor de umidade superior ao ótimo, foi necessário secar o material (Figura 3.11). Para isso, foi espalhado sobre uma lona e deixou-se ali até atingir aproximadamente a umidade higroscópica. Em razão do solo não apresentar o mesmo teor de umidade, posteriormente foi necessário homogeneizálo com o auxílio de uma betoneira (Figura 3.12.a), sendo dividido a seguir em sacos 
plásticos com capacidade de aproximadamente $35 \mathrm{~kg}$. Finalmente, os sacos de solo foram guardados dentro de uma sala com condições de temperatura e umidade controladas (Figura 3.12.b).

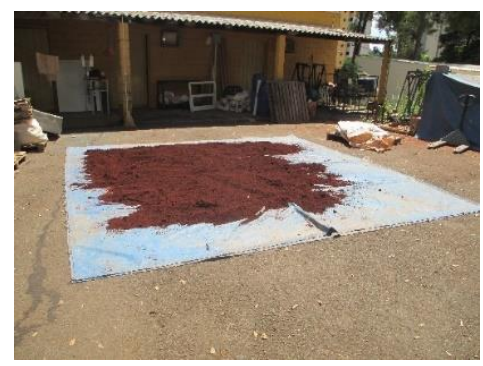

a. Solo argiloso

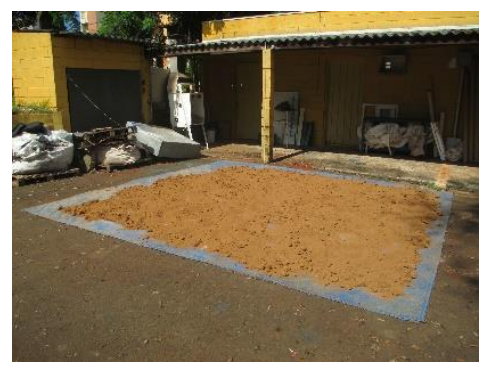

b. Solo arenoso

Figura 3.11. Processo de secagem do solo

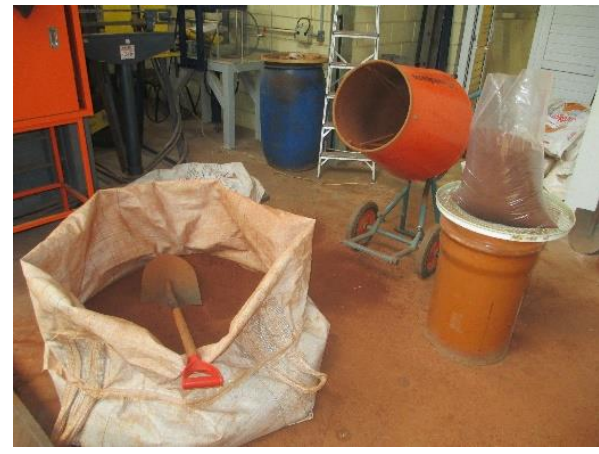

a. Homogeneização da umidade higroscópica

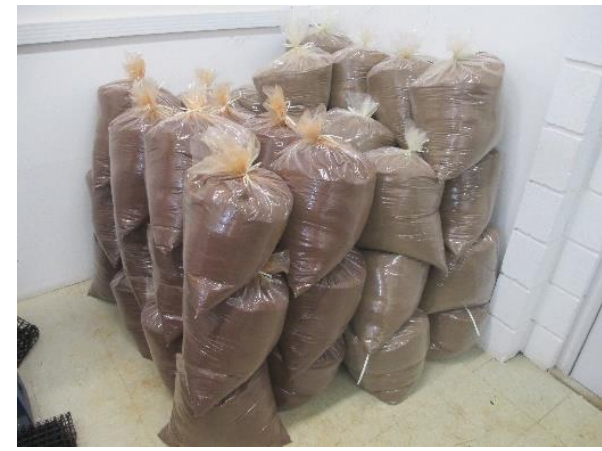

b. Armazenamento do solo

Figura 3.12. Homogeneização e conservação do solo em ambiente controlado

\subsubsection{Ajuste da umidade ótima e homogeneização na betoneira}

Sendo que o solo deve estar na condição de umidade ótima no momento da sua compactação nos equipamentos de pequenas e grandes dimensões, foi necessário calcular a quantidade de água a ser acrescentada para atingir tal condição. Tendo a quantidade desejada, adicionou-se uma quantidade de $10 \mathrm{ml}$ a mais por causa da perda de umidade que poderia ocorrer durante o processo. Posteriormente, à medida que o solo girava dentro da betoneira, a quantidade de água calculada era despejada dentro dela por meio de um regador, deixando a betoneira ligada até que o solo apresentasse uma consistência homogênea (Figura 3.13). 
A seguir, com o intuito de verificar o teor de umidade do solo, foi retirada uma pequena quantidade do material homogeneizado numa cápsula de alumínio e finalmente, o material foi guardado em sacos plásticos fechados para manter tal condição. Dessa maneira, o procedimento foi repetido para cada saco de solo na condição de umidade higroscópica.
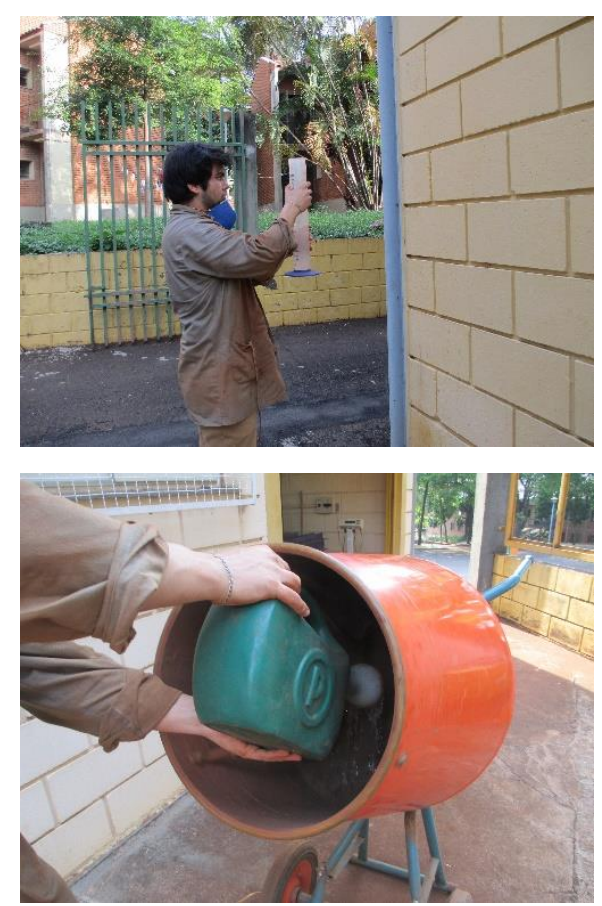

a. Adição da água necessária para atingir o teor de umidade ótimo
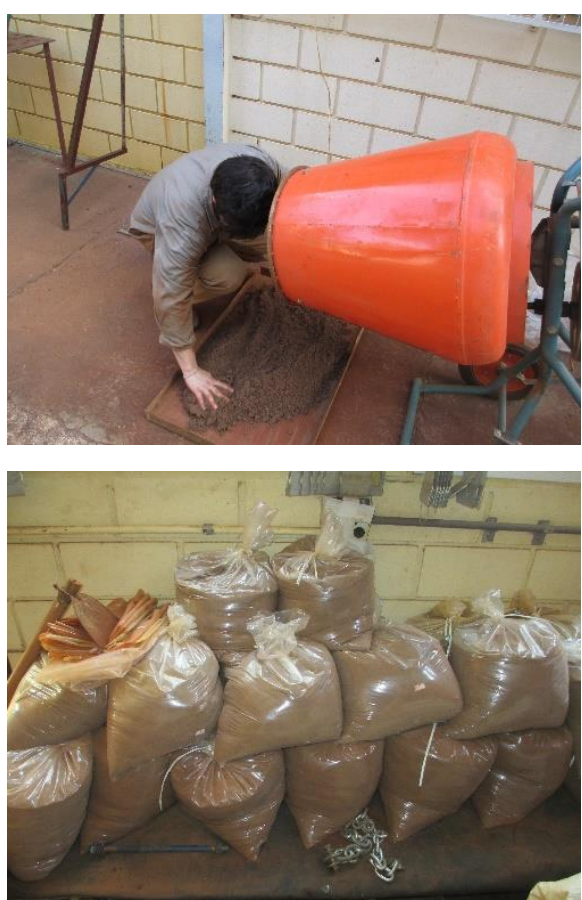

b. Solo homogeneizado na condição de umidade ótima

Figura 3.13. Ajuste da umidade ótima do solo

\subsection{Material de reforço}

Por causa das baixas deformações que se apresentam numa estrutura de pavimento, procurou-se uma geogrelha que mobilizasse toda a sua resistência com deformações inferiores a 10\%. Assim, nos ensaios de arrancamento monotônico e cíclico foi utilizada uma geogrelha biaxial tecida de polipropileno (PP) recoberta com Policloreto de Vinila (PVC), projetada principalmente para desempenhar funções de reforço de bases e sub-bases de pavimentos submetidos a solicitações dinâmicas.

A sua caracterização foi realizada na Máquina Universal de Ensaios Instron® do Laboratório de Geossintéticos da EESC-USP, cuja capacidade é de 25 toneladas, utilizando uma garra do tipo rolete para a fixação da amostra. Dessa maneira, nas 
Figuras 3.14 e 3.15, assim como na Tabela 3.4 a seguir, mostram-se respectivamente a geogrelha utilizada nos ensaios de arrancamento monotônico e cíclico, as curvas de resistência à tração não confinada para corpos de prova com 5 elementos e as suas respectivas propriedades.

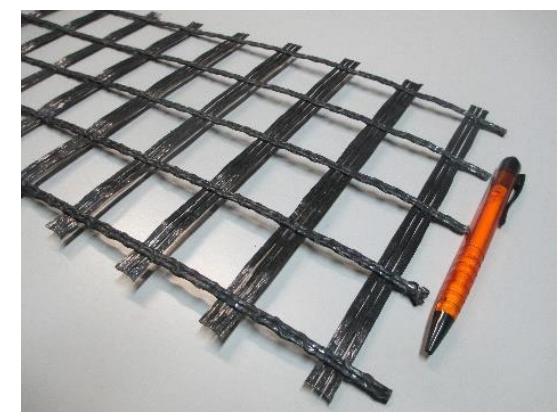

a. Geogrelha utilizada nos ensaios

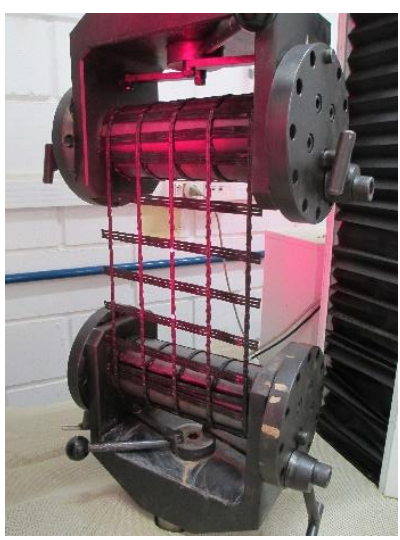

b. Caracterização da geogrelha no sentido longitudinal

Figura 3.14. Material de reforço utilizado nos ensaios de arrancamento monotônico e cíclico

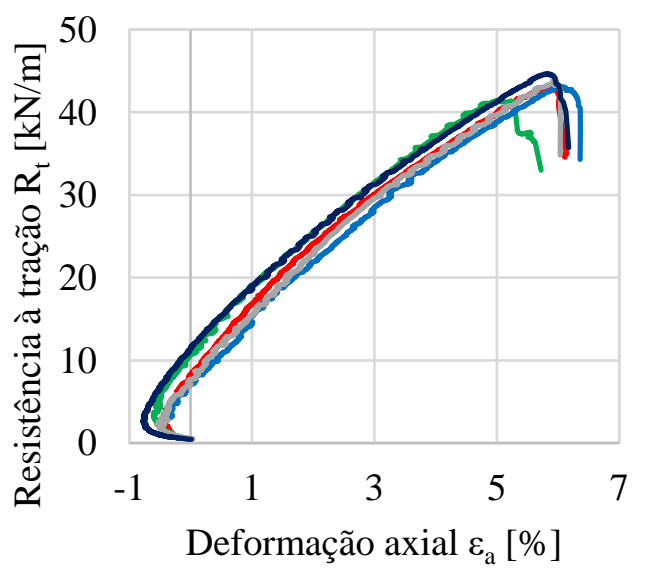

a. Sentido longitudinal

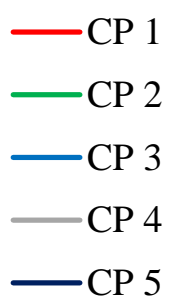
- $\mathrm{CP} 5$

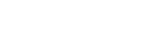


Tabela 3.4. Propriedades da geogrelha Fornit D30/30-40T utilizada nos ensaios de arrancamento monotônico e cíclico

\begin{tabular}{|c|c|c|}
\hline \multirow{2}{*}{$\begin{array}{l}\text { Resistência média à } \\
\text { tração }[\mathrm{kN} / \mathrm{m}]\end{array}$} & Longitudinal & 43,24 \\
\hline & Transversal & 42,16 \\
\hline \multirow{2}{*}{$\begin{array}{l}\text { Deformação média na } \\
\text { ruptura [\%] }\end{array}$} & Longitudinal & 5,75 \\
\hline & Transversal & 5,40 \\
\hline \multirow{2}{*}{$\begin{array}{l}\text { Resistência média à } \\
\text { tração para } \varepsilon_{\mathrm{a}}=3 \% \\
{[\mathrm{kN} / \mathrm{m}]}\end{array}$} & Longitudinal & 30,15 \\
\hline & Transversal & 29,72 \\
\hline \multirow{2}{*}{$\begin{array}{l}\text { Resistência média à } \\
\text { tração para } \varepsilon_{\mathrm{a}}=4 \% \\
{[\mathrm{kN} / \mathrm{m}]}\end{array}$} & Longitudinal & 35,38 \\
\hline & Transversal & 35,25 \\
\hline \multirow{2}{*}{$\begin{array}{l}\text { Módulo de rigidez } \mathrm{J} \\
{[\mathrm{kN} / \mathrm{m}]}\end{array}$} & Longitudinal & 523,00 \\
\hline & Transversal & 553,00 \\
\hline \multirow{2}{*}{$\begin{array}{l}\text { Largura do elemento } \\
{[\mathrm{mm}]}\end{array}$} & Longitudinal & 5,50 \\
\hline & Transversal & 11,25 \\
\hline \multirow{2}{*}{$\begin{array}{l}\text { Espaçamento entre os } \\
\text { eixos dos elementos } \\
{[\mathrm{mm}]}\end{array}$} & Longitudinais & 45,00 \\
\hline & Transversais & 45,00 \\
\hline $\begin{array}{l}\text { Espessura do elemento } \\
\text { transversal }[\mathrm{mm}]\end{array}$ & & 1,05 \\
\hline
\end{tabular}

Adicionalmente, também foram realizados ensaios de resistência à tração não confinada para corpos de prova com 2, 3 e 4 elementos longitudinais com o intuito de avaliar a variação da resistência e do módulo de rigidez $\mathbf{J}$ em função do número de elementos.

Assim, na Tabela 3.5 e nas Figuras 3.16 e 3.17 a seguir são mostrados respectivamente os valores de resistência à tração não confinada e do módulo de rigidez no sentido longitudinal obtidos nos ensaios realizados, com as suas respectivas curvas de variação em função do número de elementos.

Tabela 3.5. Resistência à tração não confinada no sentido longitudinal e módulo de rigidez em função do número de elementos

\begin{tabular}{ccc}
\hline $\begin{array}{c}\text { Número de } \\
\text { elementos }\end{array}$ & $\begin{array}{c}\text { Resistência à tração } \\
{[\mathbf{k N} / \mathbf{m}]}\end{array}$ & $\begin{array}{c}\text { Módulo de rigidez J } \\
{[\mathbf{k N} / \mathbf{m}]}\end{array}$ \\
\hline 2 & 71,30 & 859,75 \\
3 & 52,69 & 650,30 \\
4 & 46,62 & 547,35 \\
5 & 43,24 & 523,28 \\
\hline
\end{tabular}




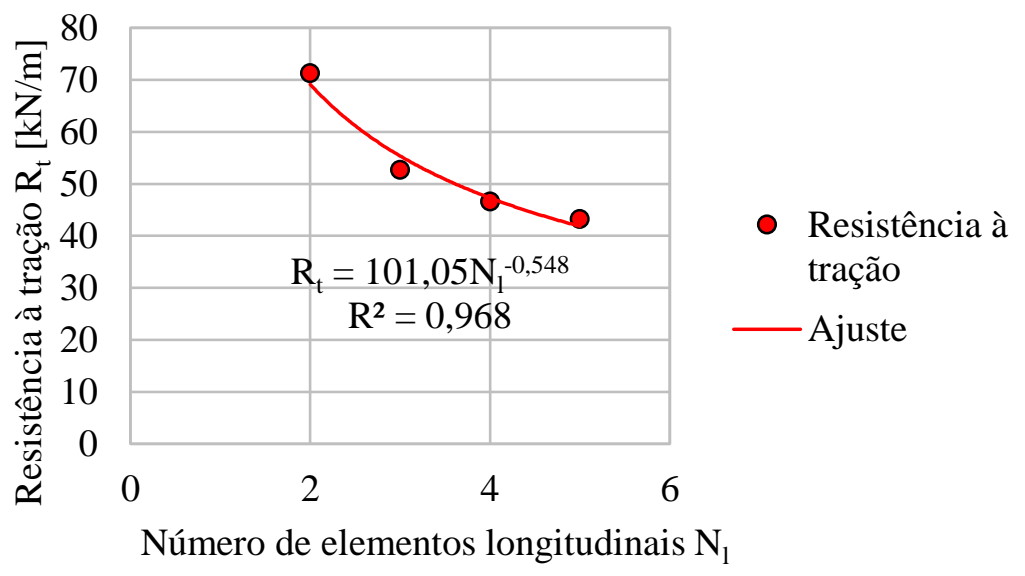

Figura 3.16. Variação da resistência à tração com o número de elementos

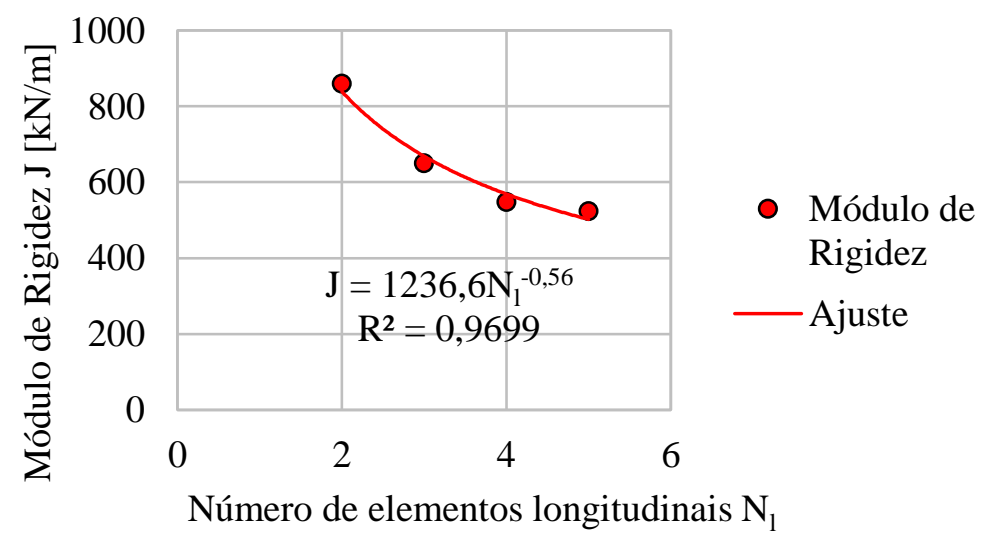

Figura 3.17. Variação do módulo de rigidez com o número de elementos

Como foi mostrado nos gráficos anteriores, é possível perceber uma diminuição nos valores da resistência à tração não confinada e do módulo de rigidez com o aumento do número de elementos longitudinais, apresentando ainda uma tendência a se estabilizarem devido à redistribuição das tensões atuantes.

\subsection{Equipamentos e procedimentos de montagem}

De acordo com os objetivos da pesquisa, os ensaios de arrancamento monotônico e cíclico foram executados nos equipamentos de grandes e pequenas dimensões pertencentes ao Laboratório de Geossintéticos da EESC-USP, mostrados respectivamente nas Figuras 3.18 e 3.19 a seguir. 


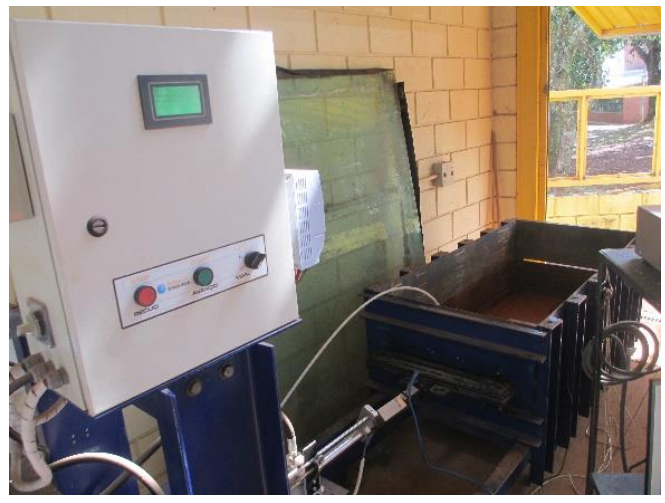

a. Caixa aberta

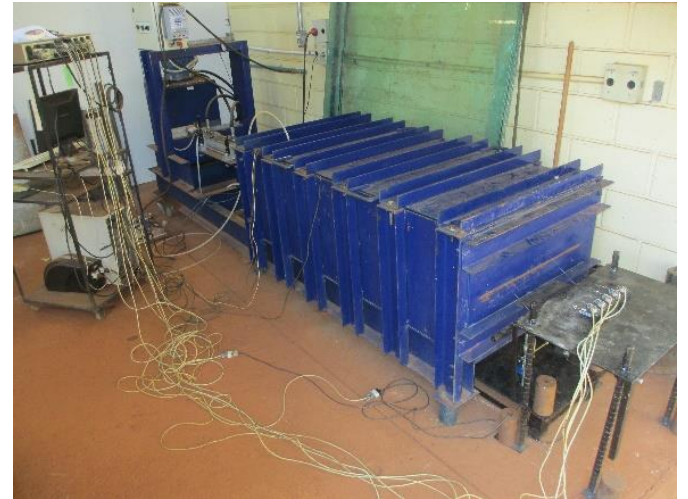

b. Caixa fechada

Figura 3.18. Equipamento de grandes dimensões (1,50 $\mathrm{m}$ de comprimento, 0,70 $\mathrm{m}$ de largura e $0,48 \mathrm{~m}$ de altura)

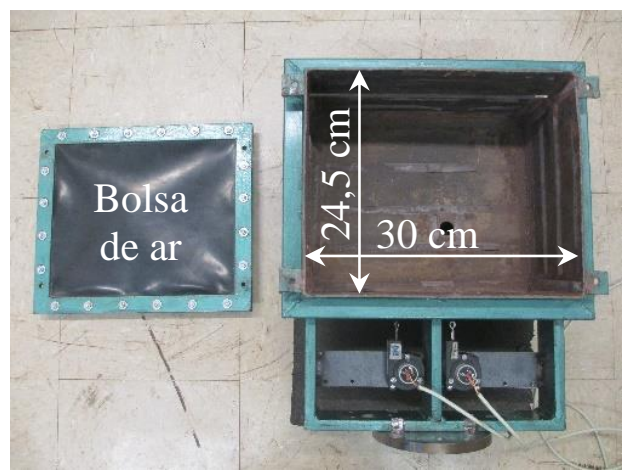

a. Caixa aberta

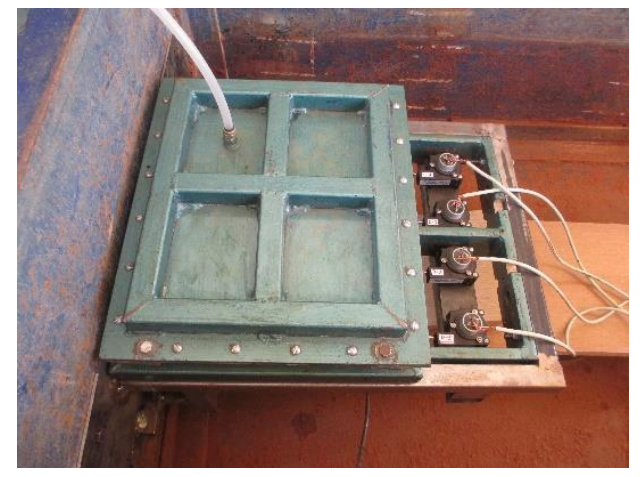

b. Caixa fechada

Figura 3.19. Equipamento de pequenas dimensões $(24,5 \mathrm{~cm}$ de comprimento, $30 \mathrm{~cm}$ de largura e $14,5 \mathrm{~cm}$ de altura)

O equipamento de grandes dimensões da EESC-USP possui dimensões superiores às mínimas recomendadas pela norma ASTM D6706 - 01 para a medição da resistência ao arrancamento de um geossintético $(0,61 \mathrm{~m}$ de comprimento, 0,46 m de largura e 0,305 $\mathrm{m}$ de atura). Por outro lado, sendo que os efeitos de atrito lateral gerado pelas paredes interiores da caixa podem alterar o valor da resistência ao arrancamento, como comentado por Palmeira e Milligan (1989), uma das opções recomendadas pela norma ASTM D6706 - 01 para reduzir tais efeitos baseia-se em deixar um espaço livre de $150 \mathrm{~mm}$ entre o geossintético e cada parede da caixa de arrancamento.

Além disso, faz-se necessária a utilização de uma manga metálica no nível do reforço para minimizar os efeitos de atrito entre o solo e a parede frontal, pois a sua implementação faz com que o ponto de aplicação da força de arrancamento seja transferido no interior da massa de solo (Kakuda, 2005). 
No caso do equipamento de pequenas dimensões, ao possuir $24,5 \mathrm{~cm}$ de comprimento, $30 \mathrm{~cm}$ de largura e $14,5 \mathrm{~cm}$ de altura, não dispõe-se do espaço mínimo entre a inclusão e as paredes da caixa exigido pela norma ASTM D6706 - 01, nem é possível utilizar uma manga metálica para minimizar o efeito de atrito gerado pelas paredes laterais e frontal, respectivamente.

Por causa disso, é preciso adotar uma solução diferente às do equipamento de grandes dimensões para minimizar os efeitos de atrito entre o solo e as paredes internas da caixa. Dessa maneira, foi adotada a solução proposta por Palmeira e Milligan (1989), onde é recomendada a instalação de duas geomembranas em cada parede, lubrificadas no seu interior com graxa de cálcio grafitada, como mostrado Figuras 3.20 e 3.21 a seguir.
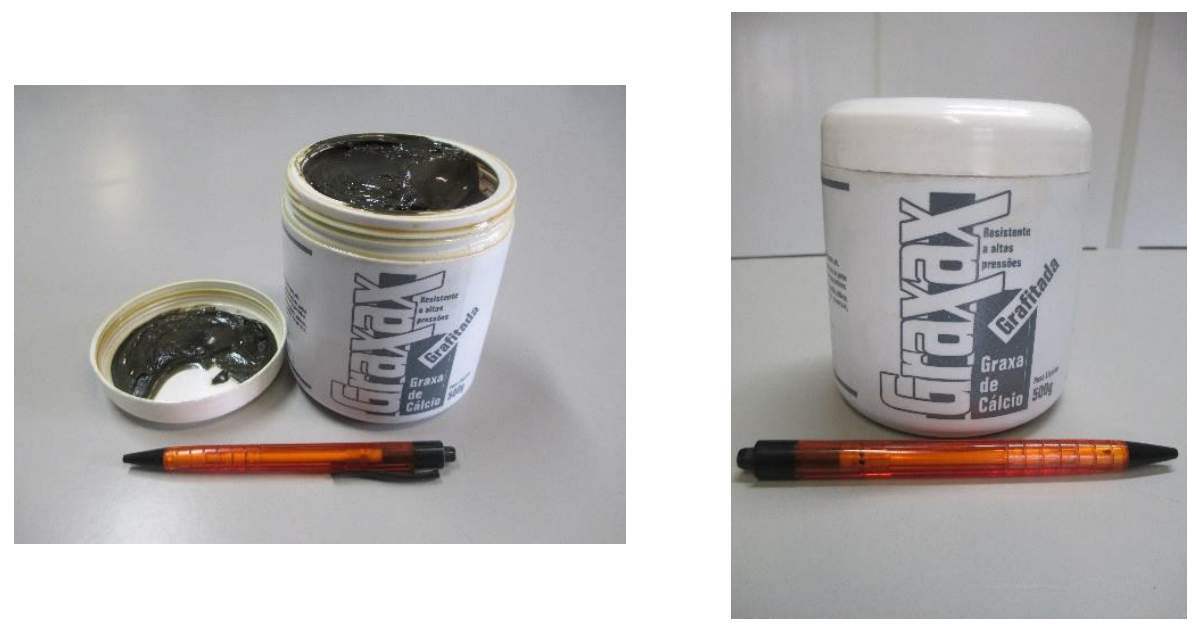

Figura 3.20. Graxa de cálcio grafitada

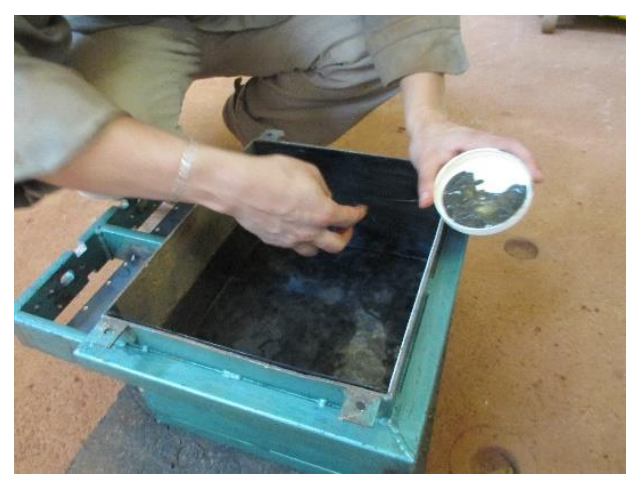

a. Aplicação da graxa na primeira geomembrana

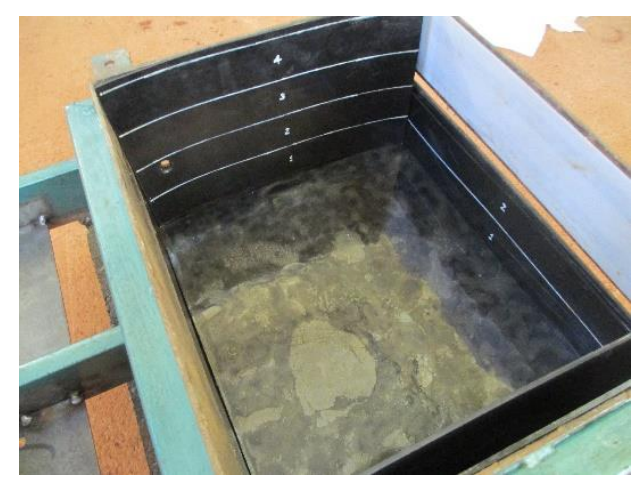

b. Instalação da segunda geomembrana

Figura 3.21. Lubrificação das geomembranas em cada parede interna do equipamento de pequeno porte 
Com relação ao sistema de aplicação do carregamento cisalhante em cada equipamento, foi levada em consideração a descrição realizada por Campos (2013), onde é especificado o pistão hidráulico externo à caixa de grandes dimensões que é alimentado por uma bomba elétrica cuja capacidade de tração no geossintético é de até cinco toneladas.

Além disso, o equipamento possui um sistema de controle da velocidade da bomba e sistemas que controlam o deslocamento do pistão, os quais funcionam por meio de um controlador lógico programável (Figura 3.22), onde podem ser inseridos dados da velocidade do pistão, da carga de cisalhamento e configurações do pulso correspondente ao carregamento cíclico.

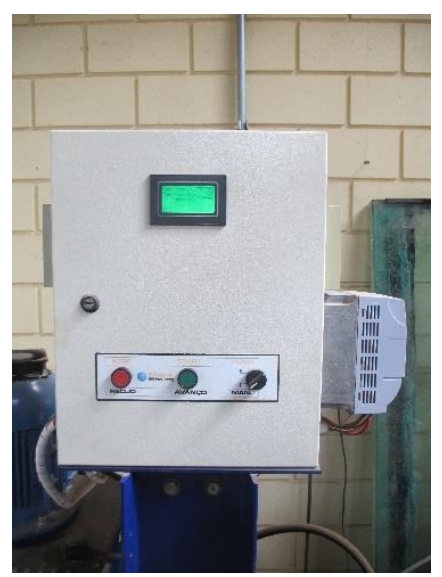

a. CLP - Controlador Lógico Programável

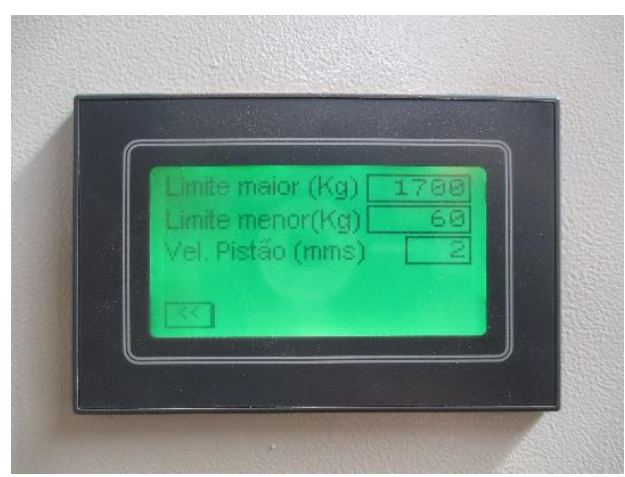

b. Detalhe da tela do CLP

Figura 3.22. Painel de controle do sistema de aplicação de carga

Por outro lado, com a válvula que controla a passagem de óleo no sistema hidráulico totalmente aberta não é possível atingir taxas de deslocamento da ordem de 1,0 mm/min (ASTM D6706 - 01), mesmo fixando tal valor no CLP. Dessa maneira, é preciso realizar testes de velocidade de deslocamento do pistão com a estrutura de solo reforçado já pronta para a execução do ensaio, com a respectiva regulação da válvula mostrada na Figura 3.23 a seguir, até atingir a condição de ensaio desejada. 


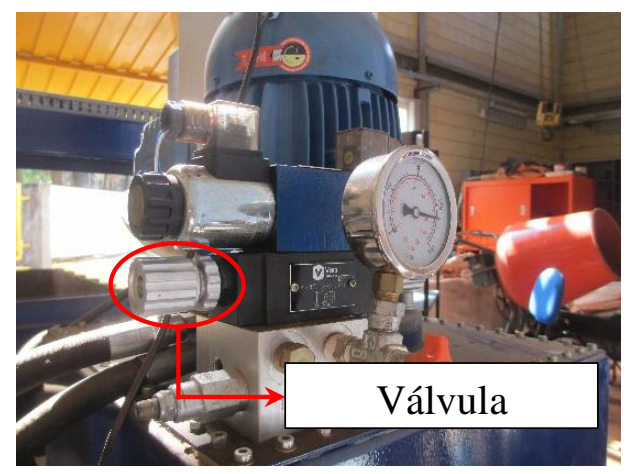

Figura 3.23. Sistema de válvulas para o controle da passagem de óleo no sistema hidráulico

Com o intuito de utilizar o mesmo sistema de aplicação de carga em ambos os equipamentos e poder realizar assim as respectivas comparações, foi necessário projetar um suporte de adaptação do equipamento de pequenas dimensões na caixa de grande porte, o qual é mostrado na Figura 3.24 a seguir.

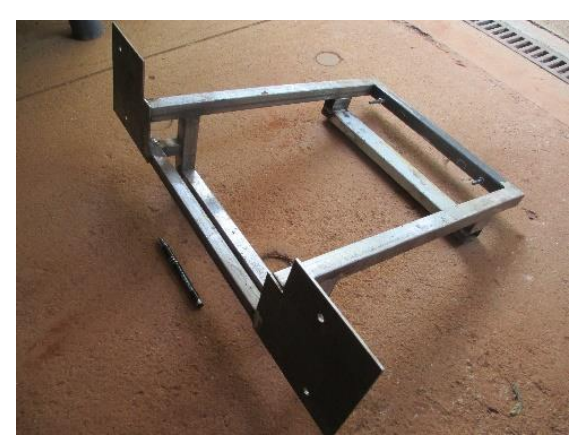

a. Suporte de adaptação do equipamento de pequenas dimensões na caixa de grande porte

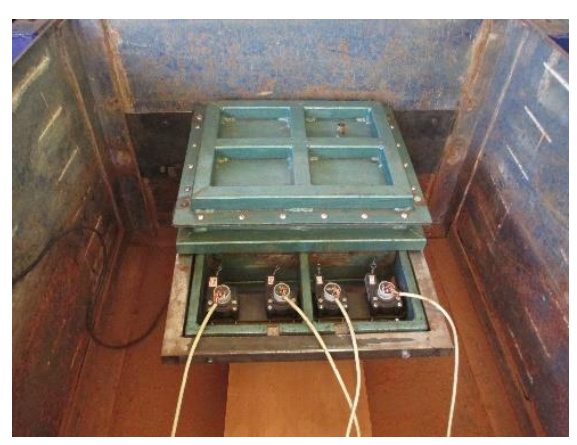

b. Fixação do equipamento de pequenas dimensões na parede frontal da caixa de grande porte

Figura 3.24. Adaptação do equipamento de pequenas dimensões na caixa de grande porte

Adicionalmente, nas Figuras 3.25 e 3.26 a seguir são mostrados respectivamente o sistema de controle da pressão de ar para a aplicação das tensões de confinamento, e a garra responsável pela distribuição homogênea da tração no reforço geossintético em ambos os equipamentos. 


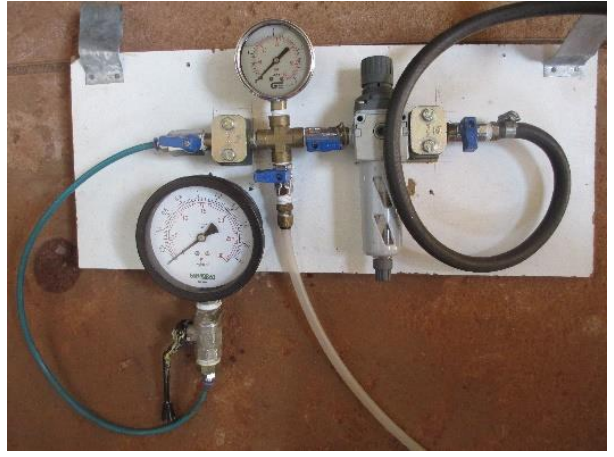

a. Painel de controle da pressão de ar comprimido no sistema

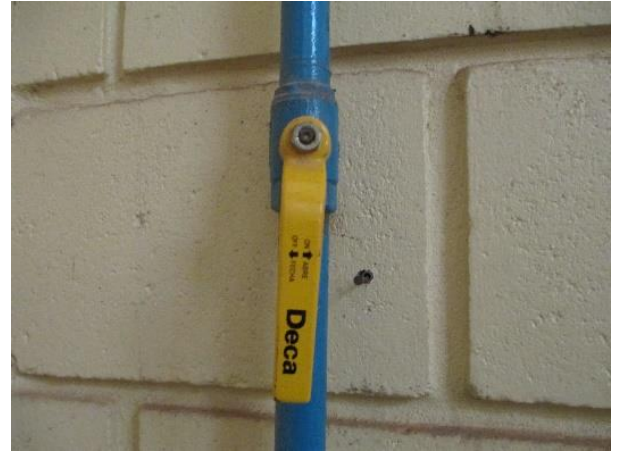

b. Válvula de liberação do ar comprimido na rede de distribuição do laboratório

Figura 3.25. Sistema de controle do ar comprimido para a aplicação das tensões de confinamento

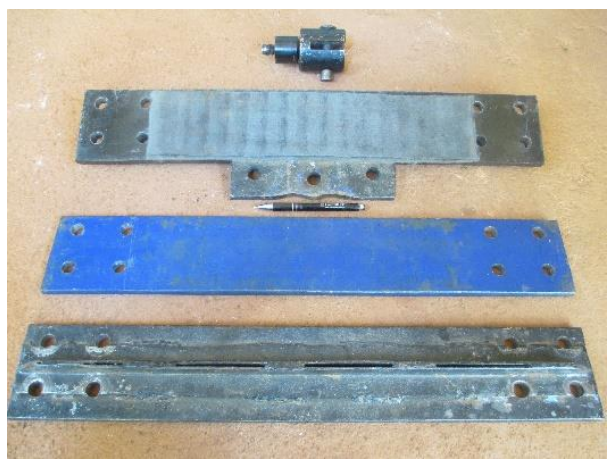

a. Componentes da garra de fixação da geogrelha

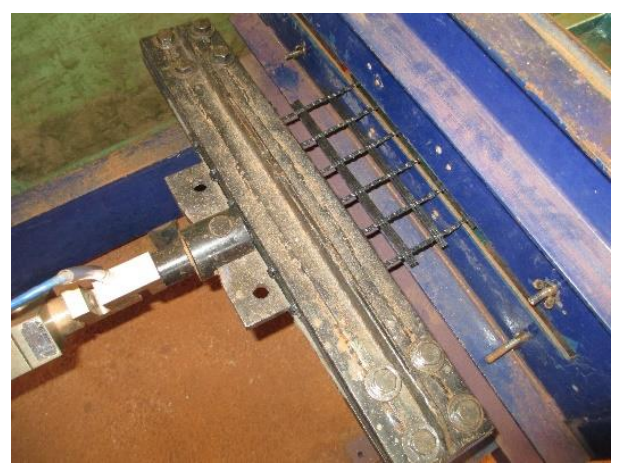

b. Garra de fixação instalada no sistema de aplicação de carga

Figura 3.26. Garra responsável pela distribuição homogênea da tração na geogrelha

Por outro lado, para a enrolação da geogrelha no componente intermediário da garra de fixação, deve-se considerar um comprimento adicional de aproximadamente $60 \mathrm{~cm}$ medidos a partir da parede frontal da caixa. Além disso, para evitar a degradação mecânica do geossintético durante a aplicação do carregamento, no componente inferior da garra deve ser colada uma amostra de geotêxtil não tecido para cumprir a função de proteção do mesmo, como mostrado na Figura 3.26.a.

Já com relação ao tamanho dos corpos de prova e às tensões de confinamento a serem aplicadas em cada equipamento, levou-se em consideração uma relação constante entre a largura e o comprimento do corpo de prova na região confinada para cada 
equipamento, assim como o efeito do acréscimo de tensões de cada camada de solo acima da inclusão, respectivamente.

Sendo que a relação entre a largura e o comprimento do corpo de prova na região confinada era limitada pelo tamanho do equipamento de pequeno porte, as dimensões foram definidas deixando um espaço livre de $2 \mathrm{~cm}$ entre as paredes laterais da caixa e a geogrelha, assim como um espaço de $3 \mathrm{~cm}$ entre a parede posterior da caixa e a inclusão.

Dessa maneira, o tamanho do corpo de prova no equipamento de pequeno porte foi definido com um comprimento de $215 \mathrm{~mm}$ e uma largura de $260 \mathrm{~mm}$, ficando numa relação $y_{1} / x_{1}=1,21$, como mostrado na Figura 3.27 a seguir.

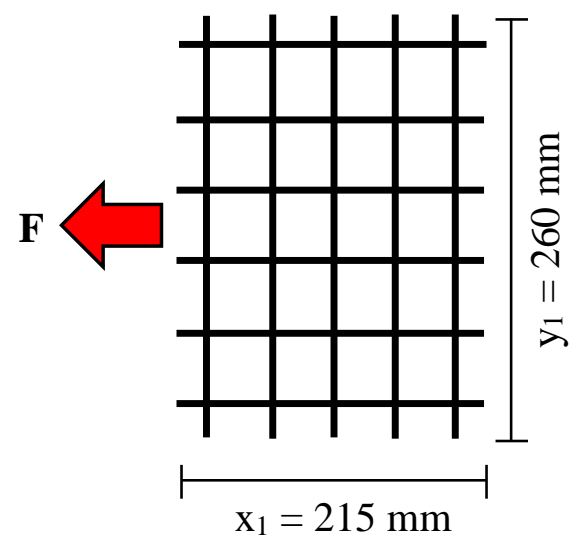

$$
\frac{y_{1}}{x_{1}}=\frac{260 \mathrm{~mm}}{215 \mathrm{~mm}}=1,21
$$

Figura 3.27. Definição da relação do tamanho dos corpos de prova a partir das dimensões da inclusão no equipamento de pequenas dimensões

Com base na constante obtida anteriormente a partir do tamanho do corpo de prova no equipamento de pequeno porte, no de grandes dimensões leva-se em consideração tal constante, assim como as recomendações dadas na norma ASTM D6706 - 01 com relação ao espaço livre entre as paredes laterais da caixa e a inclusão com o intuito de minimizar os efeitos de atrito.

Dessa maneira, na Figura 3.28 a seguir é mostrada a determinação das dimensões do corpo de prova no equipamento de grandes dimensões, considerando um espaço de $200 \mathrm{~mm}$ entre o corpo de prova e cada parede lateral da caixa. 
Levando em consideração:

$$
\frac{y_{1}}{x_{1}}=\frac{y_{2}}{x_{2}}=1,21
$$

Para $y_{2}=300 \mathrm{~mm}$, tem-se:

$$
x_{2}=\frac{300 \mathrm{~mm}}{1,21} \cong 250 \mathrm{~mm}
$$

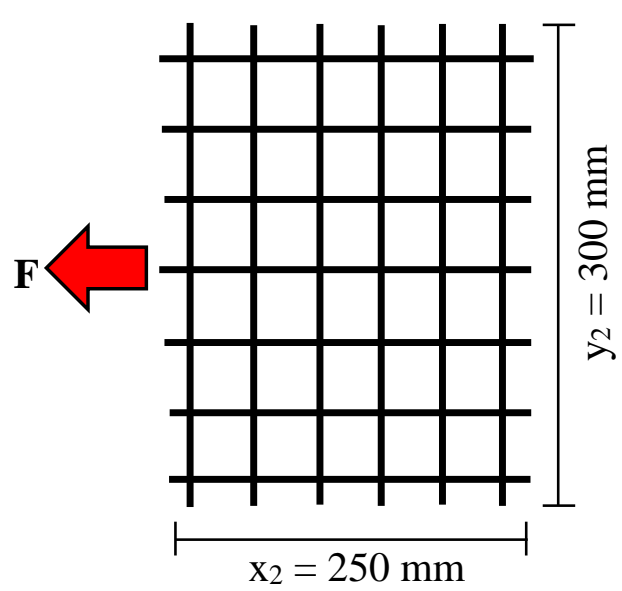

Figura 3.28. Definição do tamanho do corpo de prova no equipamento de grandes dimensões

Por outro lado, a definição das tensões de confinamento a serem aplicadas em cada equipamento levou em consideração o acréscimo de tensões de cada camada de solo acima da inclusão, o efeito da capa asfáltica e o do trem tipo para o caso mais crítico.

Assim, considerando um peso específico típico de $26 \mathrm{kN} / \mathrm{m} 3$ para o concreto asfáltico usinado à quente, o local de instalação da geogrelha em cada equipamento (na metade da altura de cada caixa, especificamente na interface dos solos argiloso e arenoso) e o espaço ocupado pela bolsa de ar em cada equipamento $(0,5 \mathrm{~cm}$ no equipamento de pequeno porte e $3 \mathrm{~cm}$ no de grandes dimensões), na Tabela 3.6 a seguir mostra-se o acréscimo de tensões sobre a inclusão devido ao peso dos materiais que comporiam uma estrutura de pavimento flexível em cada equipamento.

Tabela 3.6. Efeito do peso próprio de uma estrutura de pavimento sobre a inclusão em cada equipamento

\begin{tabular}{cccccc}
\hline Equipamento & Material & $\begin{array}{c}\text { Peso } \\
\text { específico } \\
{\left[\mathbf{k N} / \mathbf{m}^{3}\right]}\end{array}$ & $\begin{array}{c}\text { Espessura } \\
\text { da camada } \\
{[\mathbf{m}]}\end{array}$ & $\begin{array}{c}\text { Tensão } \\
\text { vertical } \\
{[\mathbf{k P a}]}\end{array}$ & $\begin{array}{c}\text { Acréscimo } \\
\text { de tensão } \\
{[\mathbf{k P a}]}\end{array}$ \\
\hline $\begin{array}{c}\text { Pequenas } \\
\text { dimensões }\end{array}$ & $\begin{array}{c}\text { Concreto } \\
\text { asfáltico }\end{array}$ & 26,0 & 0,05 & 1,30 & \\
& $\begin{array}{c}\text { Solo } \\
\text { arenoso }\end{array}$ & 20,8 & 0,07 & 1,46 & 2,76 \\
\hline $\begin{array}{c}\text { Grandes } \\
\text { dimensões }\end{array}$ & $\begin{array}{c}\text { Concreto } \\
\text { asfáltico } \\
\text { Solo } \\
\text { arenoso }\end{array}$ & 26,0 & 0,05 & 1,30 & 6,08 \\
\hline
\end{tabular}


Com base nos parâmetros mostrados anteriormente na Tabela 3.6, tem-se que para a condição menos crítica (peso próprio do pavimento), no equipamento de pequenas dimensões a bolsa de ar teria que aplicar um acréscimo de tensão de 4,63 $\mathrm{kPa}$ sobre a estrutura de solo reforçado, o qual corresponde ao efeito da capa asfáltica e da diferença de tensão causada pelos $16 \mathrm{~cm}$ de solo arenoso a mais presentes no equipamento de grandes dimensões.

Com relação ao equipamento de grandes dimensões, a bolsa de ar teria que aplicar somente o acréscimo de tensão de $1,30 \mathrm{kPa}$ correspondente ao efeito da capa asfáltica, pois é o único material que não faz parte da estrutura de solo reforçado simulada dentro da caixa.

A simulação da condição mais crítica leva em consideração a carga máxima legal para o eixo simples de rodas duplas no Brasil, a qual é de 10 toneladas (100 kN). Dessa maneira e, considerando a área interna de cada equipamento, o efeito do trem tipo no equipamento de pequenas dimensões estaria relacionado a uma tensão vertical de 1360,5 $\mathrm{kPa}$, enquanto que no equipamento de grandes dimensões seria de 95,2 kPa. Por causa disso, a bolsa de ar teria que aplicar respectivamente tensões de $1365,1 \mathrm{kPa}$ e de 96,5 $\mathrm{kPa}$, considerando já o peso próprio do pavimento.

Devido a que o manômetro disponível no Laboratório de Geossintéticos da EESC-USP tem uma precisão de $0,02 \mathrm{kgf} / \mathrm{cm}^{2}$, que equivale aproximadamente a $2 \mathrm{kPa}$, e a capacidade das bolsas de ar em cada equipamento é de $150 \mathrm{kPa}$, decidiram-se aplicar tensões de confinamento de 25, 50 e $100 \mathrm{kPa}$ com as bolsas de ar em ambos os equipamentos, cujo motivo principal foram as limitações apresentadas e também as considerações realizadas por Kakuda (2005) para comparar os seus resultados com os de Teixeira (2003).

Finalmente, a seguir são mostrados de maneira geral os procedimentos de montagem de cada equipamento para a realização dos ensaios de arrancamento monotônico e cíclico. 


\subsubsection{Procedimento de montagem do equipamento de pequenas dimensões}

1. Limpeza e preparação da caixa:
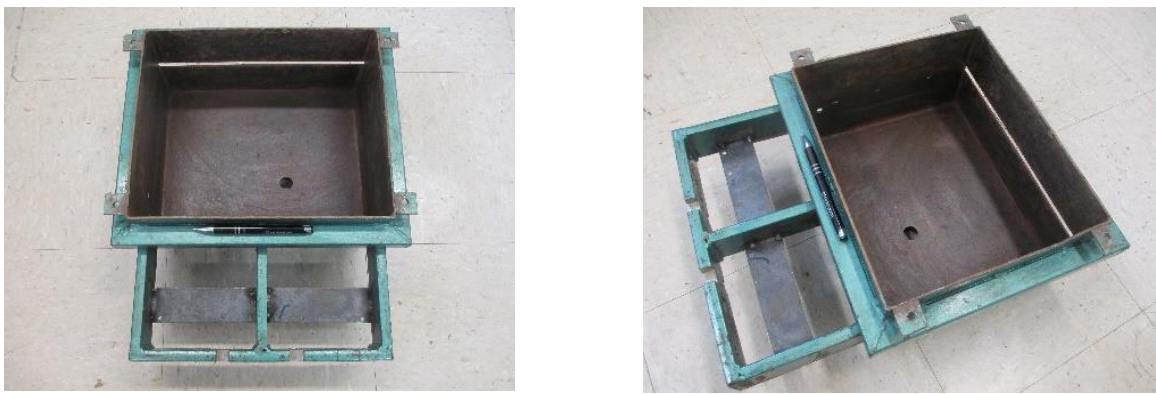

2. Fixação da primeira camada de geomembranas em cada uma das paredes internas da caixa com o uso de fita dupla face:
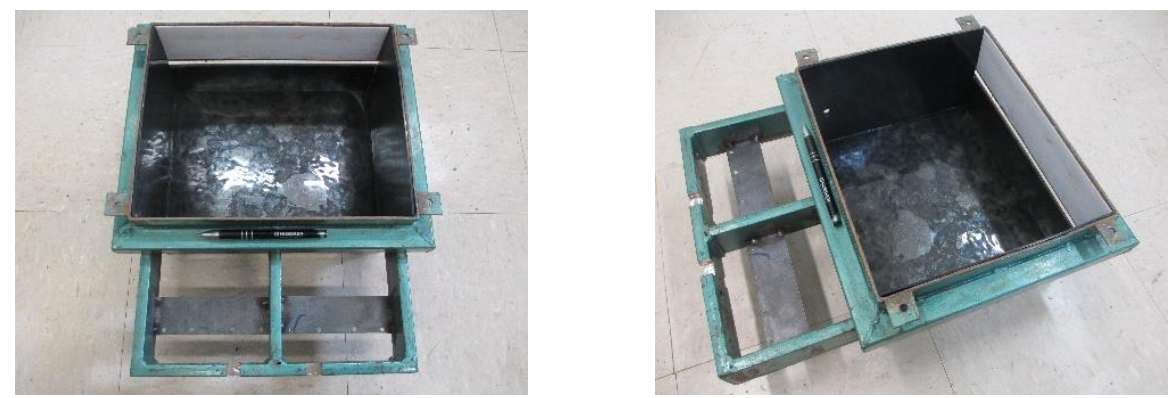

3. Lubrificação das geomembranas com graxa de cálcio grafitada, instalação da segunda camada de geomembranas e marcação das camadas de compactação:
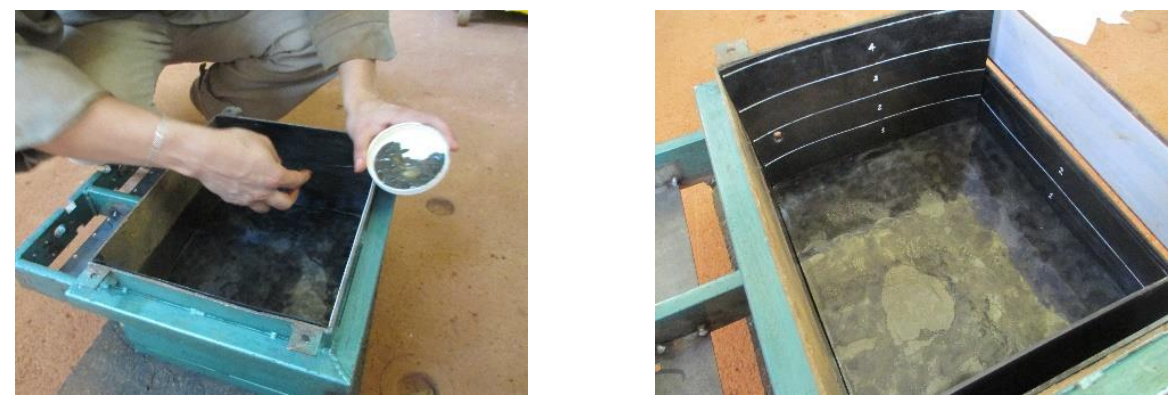

4. Colocação de fita adesiva na abertura da caixa para evitar perda de material durante o processo de compactação:
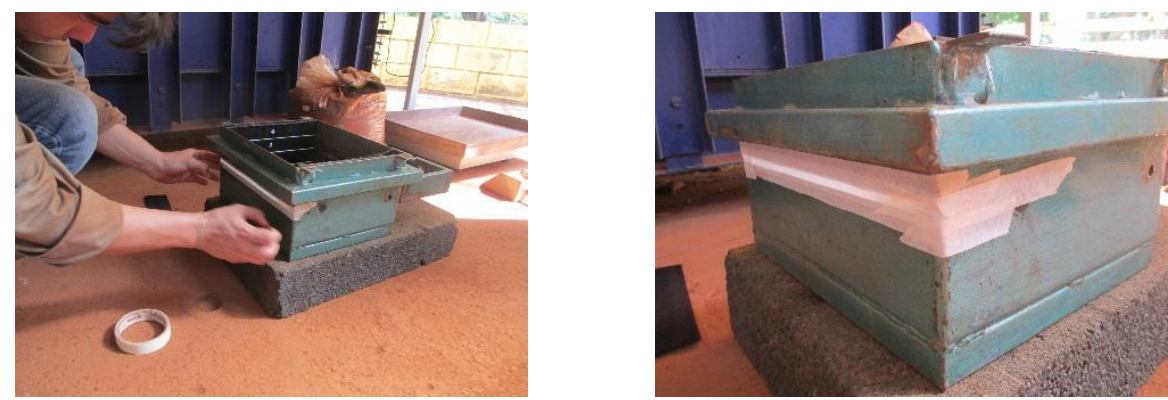

5. Pesagem do material já preparado, compactação do solo e escarificação 
de cada camada:
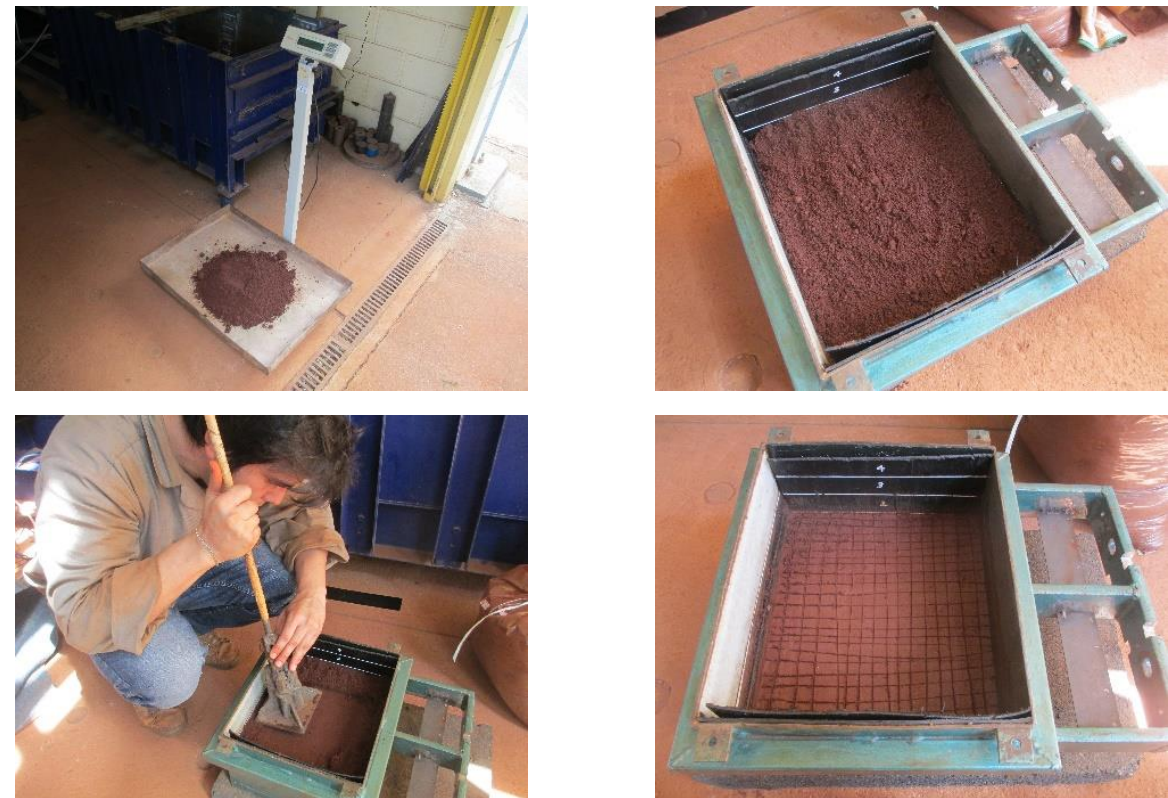

6. Instalação da célula de tensão total, escarificação da camada e colocação da geogrelha já instrumentada com os fios de aço:
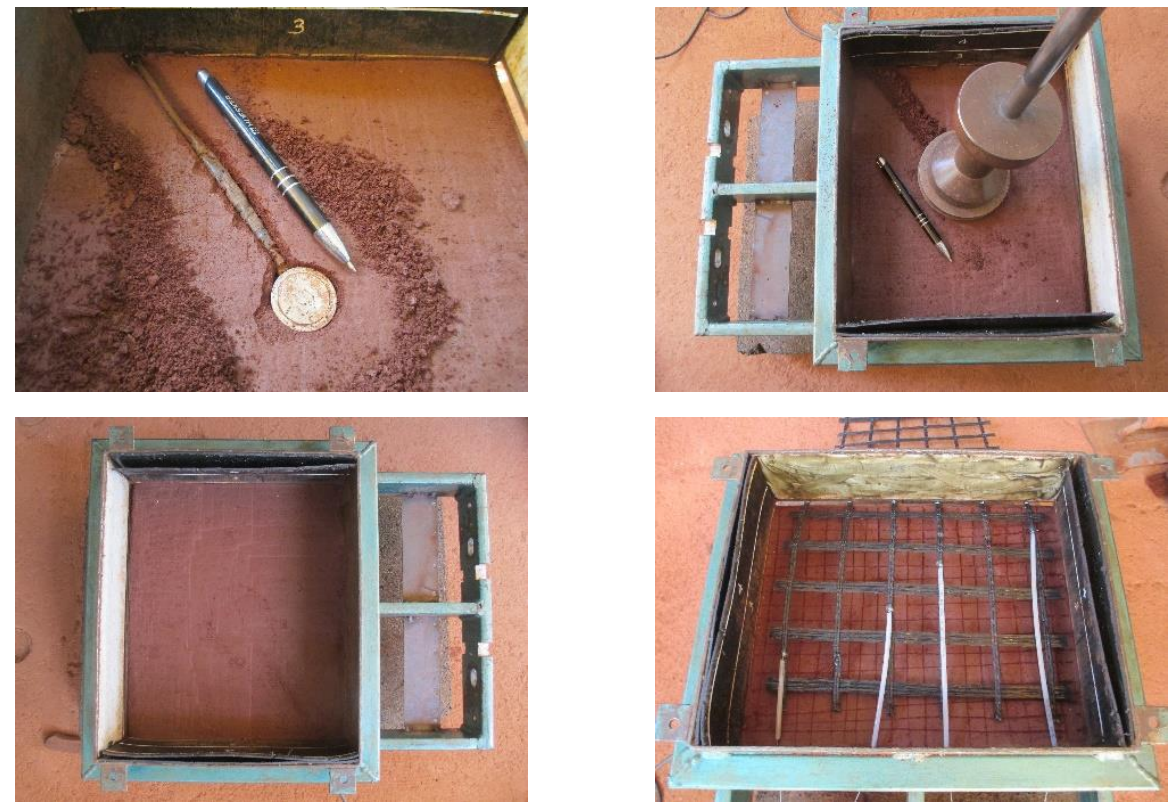

7. Compactação das camadas de solo arenoso acima da geogrelha:
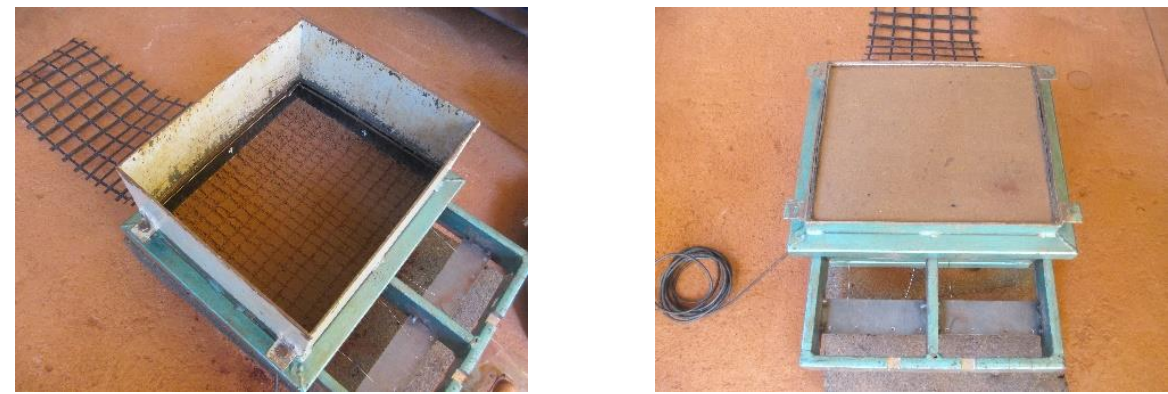

8. Fixação da tampa de reação da caixa e instalação dos transdutores de 
deslocamento (Tell-tales):
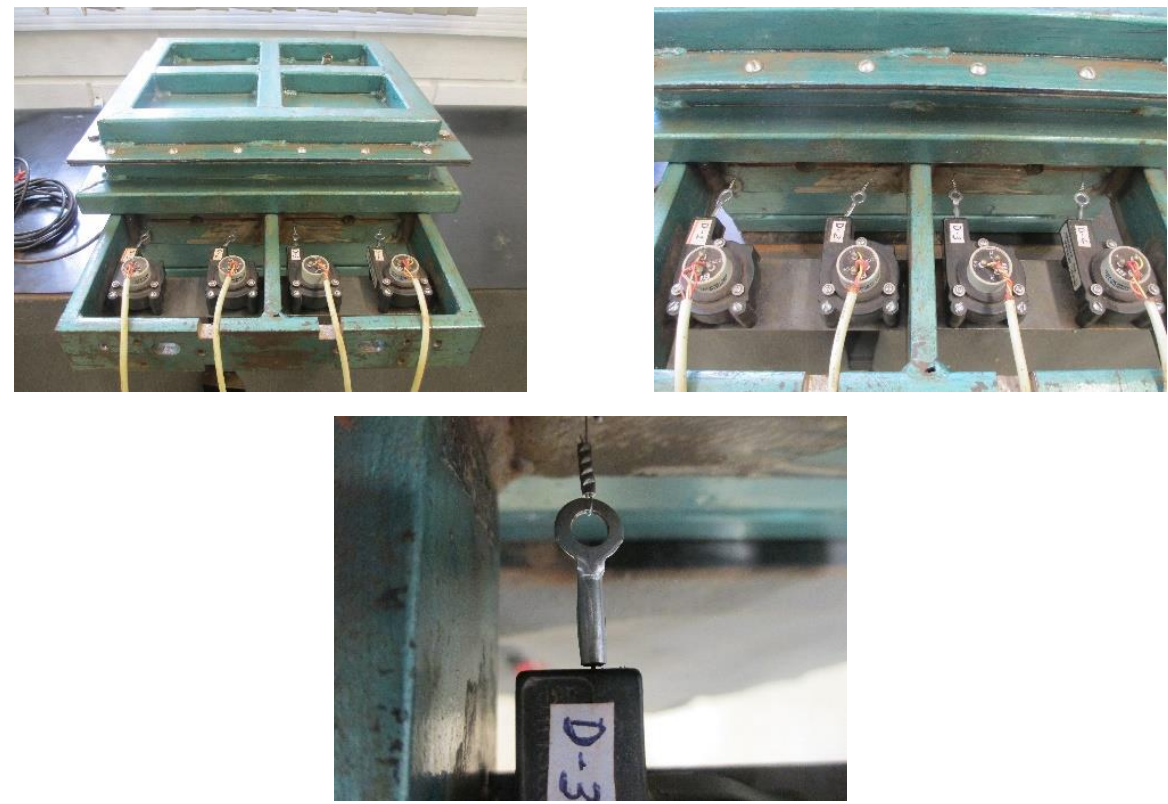

9. Instalação da caixa de pequeno porte no suporte de adaptação e posterior fixação na parede frontal da caixa de grandes dimensões:
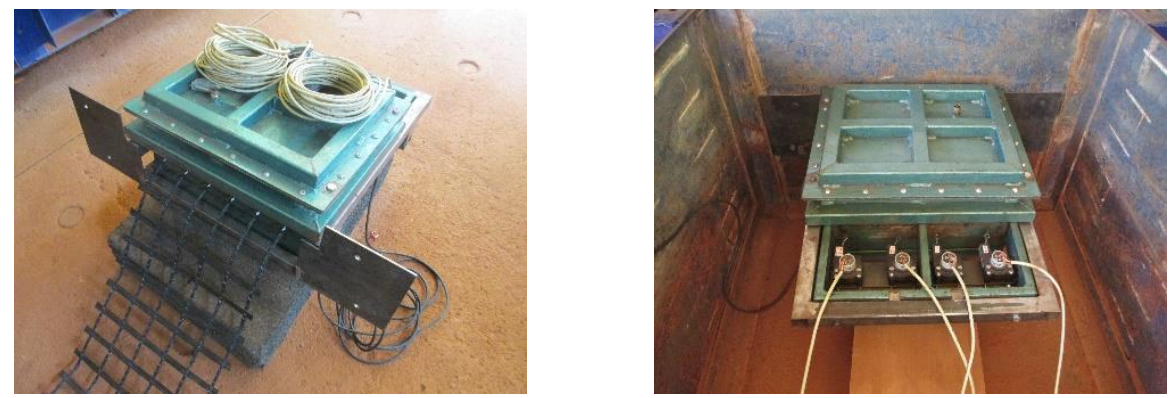

10. Instalação da garra, conexão dos instrumentos de medição no sistema de aquisição de dados, fixação da mangueira de ar comprimido na tampa de reação e habilitação da passagem de ar por meio da válvula:
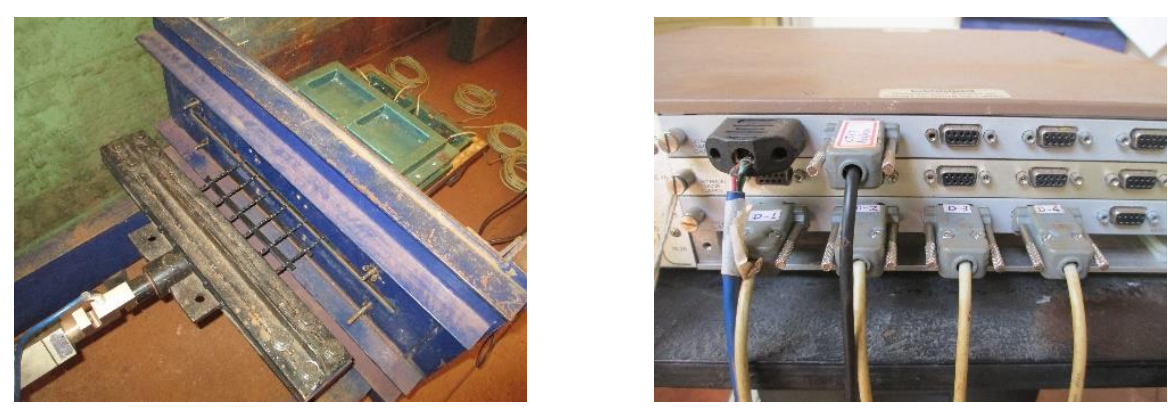

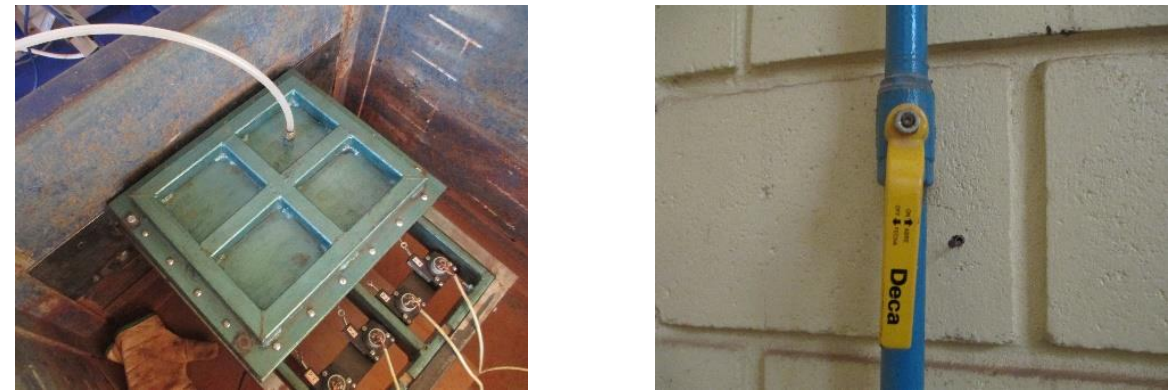

\subsubsection{Procedimento de montagem do equipamento de grandes dimensões}

1. Limpeza da caixa e marcação das camadas de compactação:
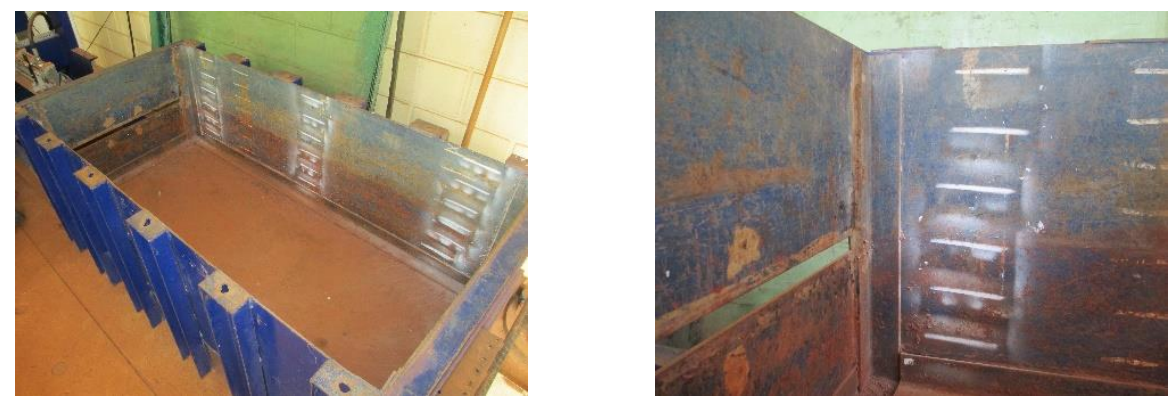

2. Instalação dos enrijecedores para evitar deformações nas paredes laterais da caixa durante o processo de compactação:
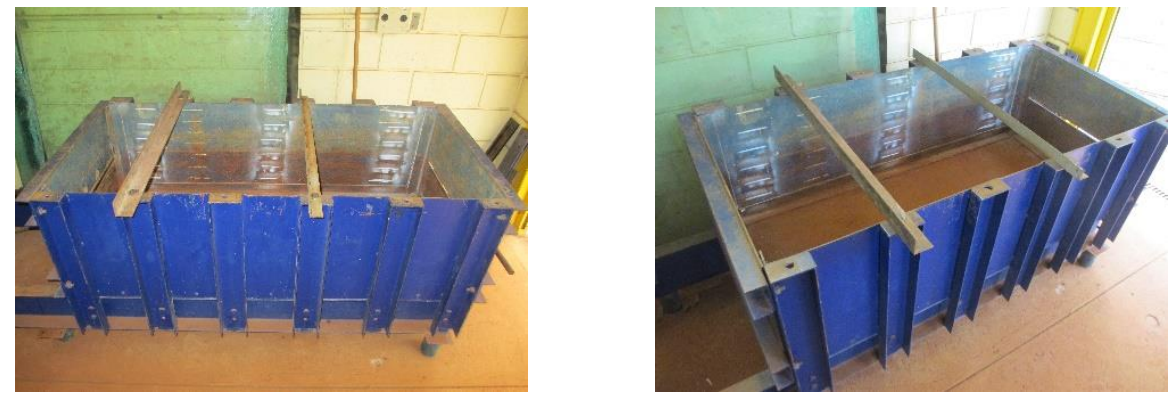

3. Colocação de fita adesiva nas aberturas frontal e posterior da caixa para evitar perda de material durante o processo de compactação:
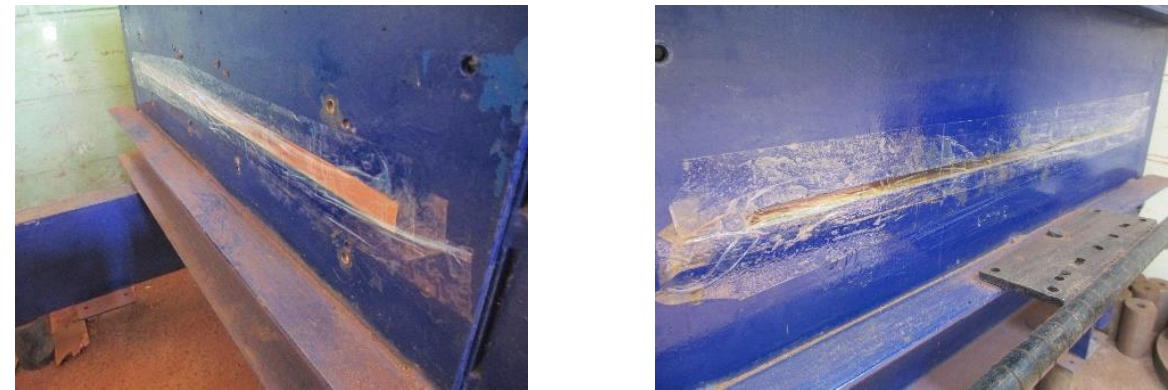

4. Pesagem do material já preparado, compactação do solo e escarificação de cada camada: 

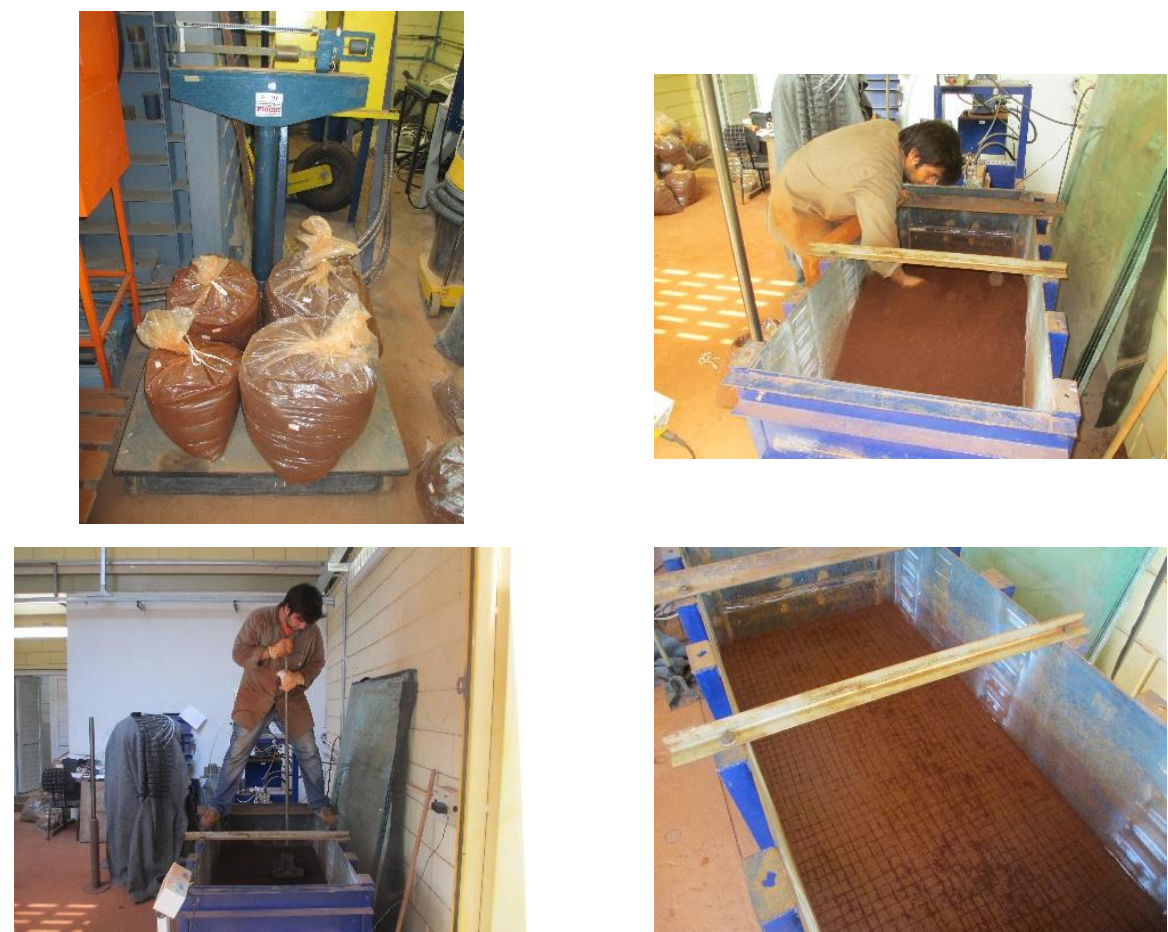

5. Fixação da manga na parede frontal da caixa e instalação da geogrelha na posição adequada, levando em consideração a distância mínima recomendada pelas normas ASTM D6706 - 01 e ASTM D7499 M - 09 para minimizar o efeito de atrito das paredes laterais:
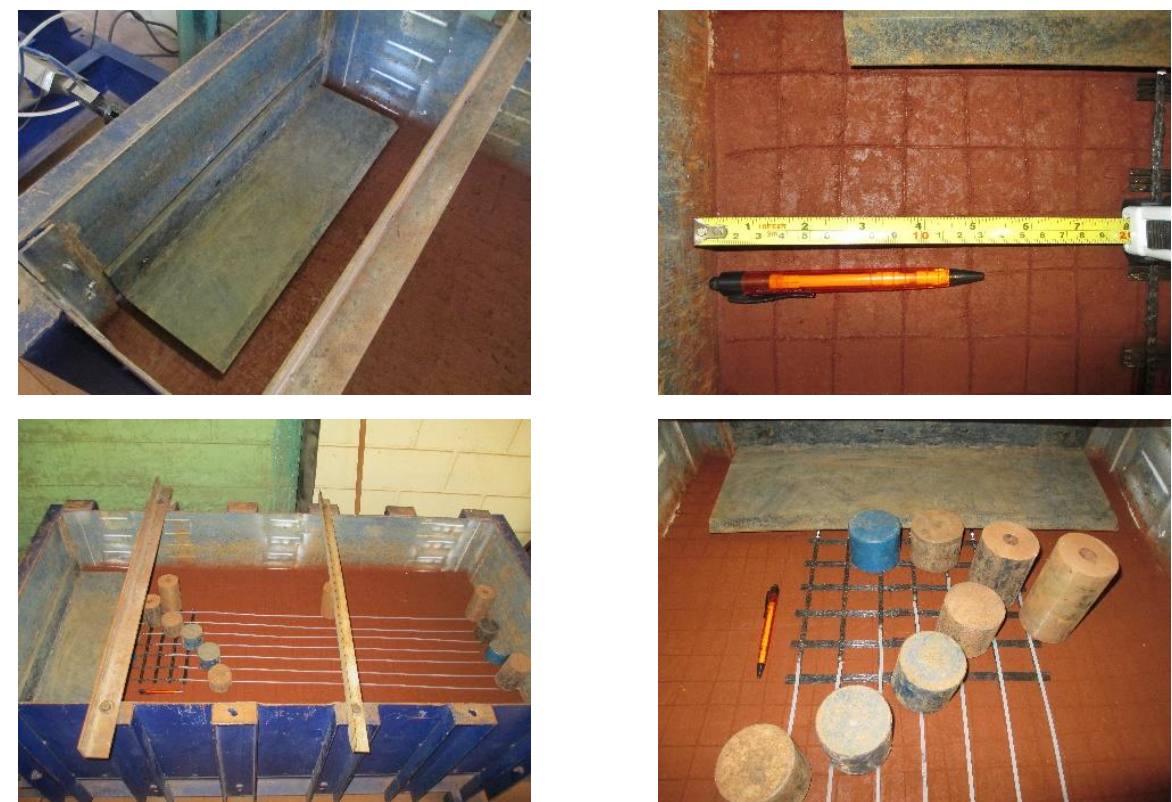

6. Instalação das células de tensão total, escarificação da camada, compactação das camadas superiores e remoção dos enrijecedores após o processo de compactação: 

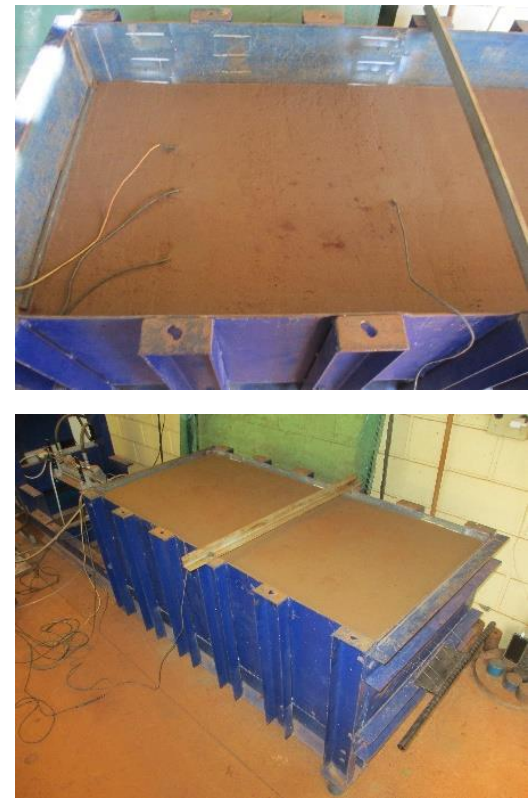
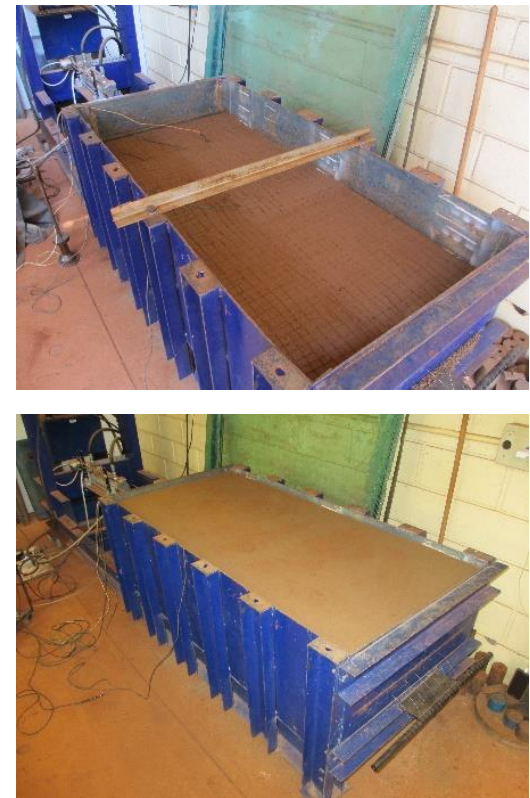

7. Colocação da bolsa de ar, fixação da tampa de reação com os respectivos parafusos e instalação da garra:
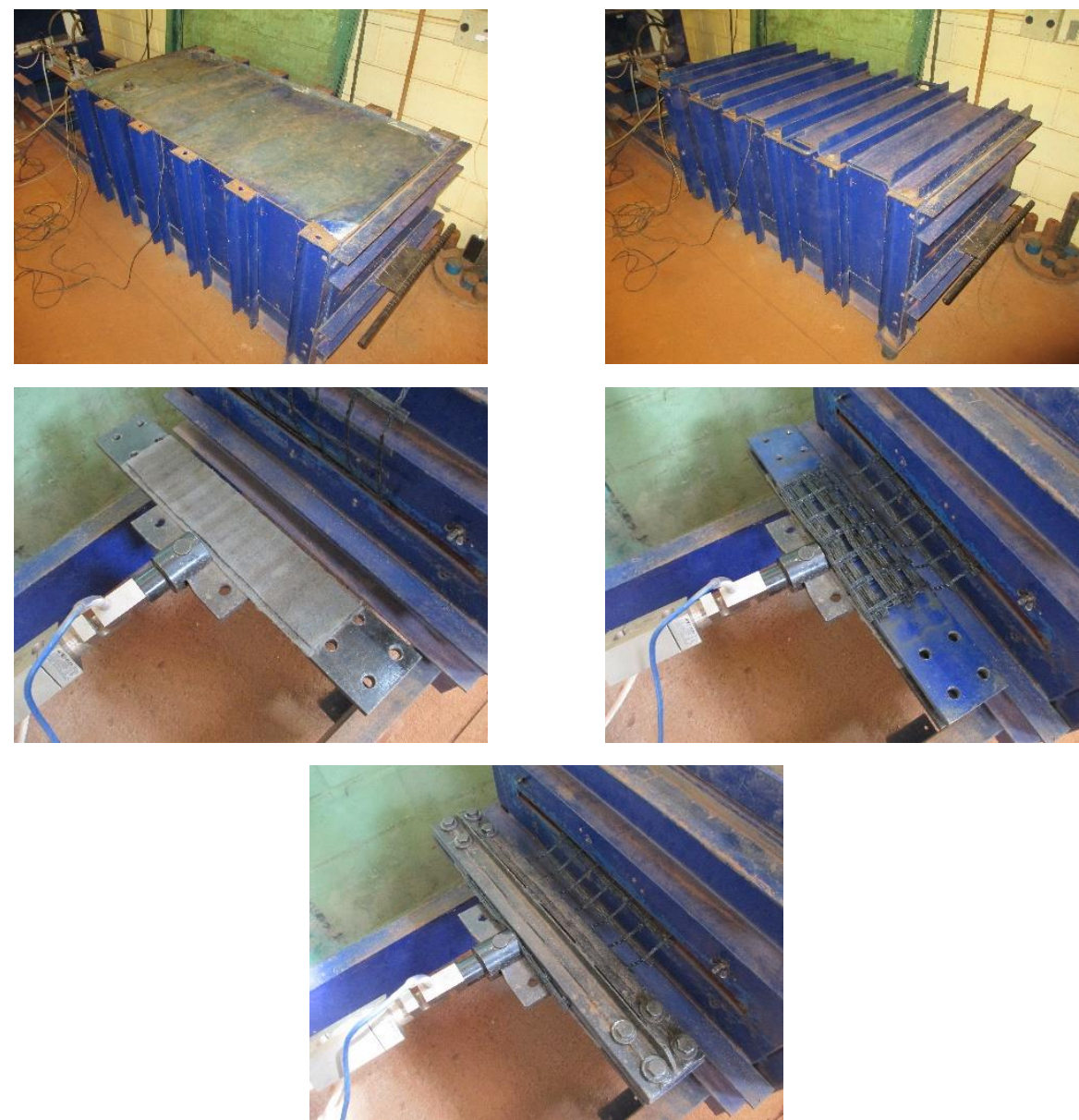

8. Instalação dos instrumentos de medição dos deslocamentos (LVDTs e Tell-tales), conexão dos mesmos no sistema de aquisição de dados, fixação da mangueira de ar comprimido na boca da bolsa e habilitação 
da passagem de ar por meio da válvula:
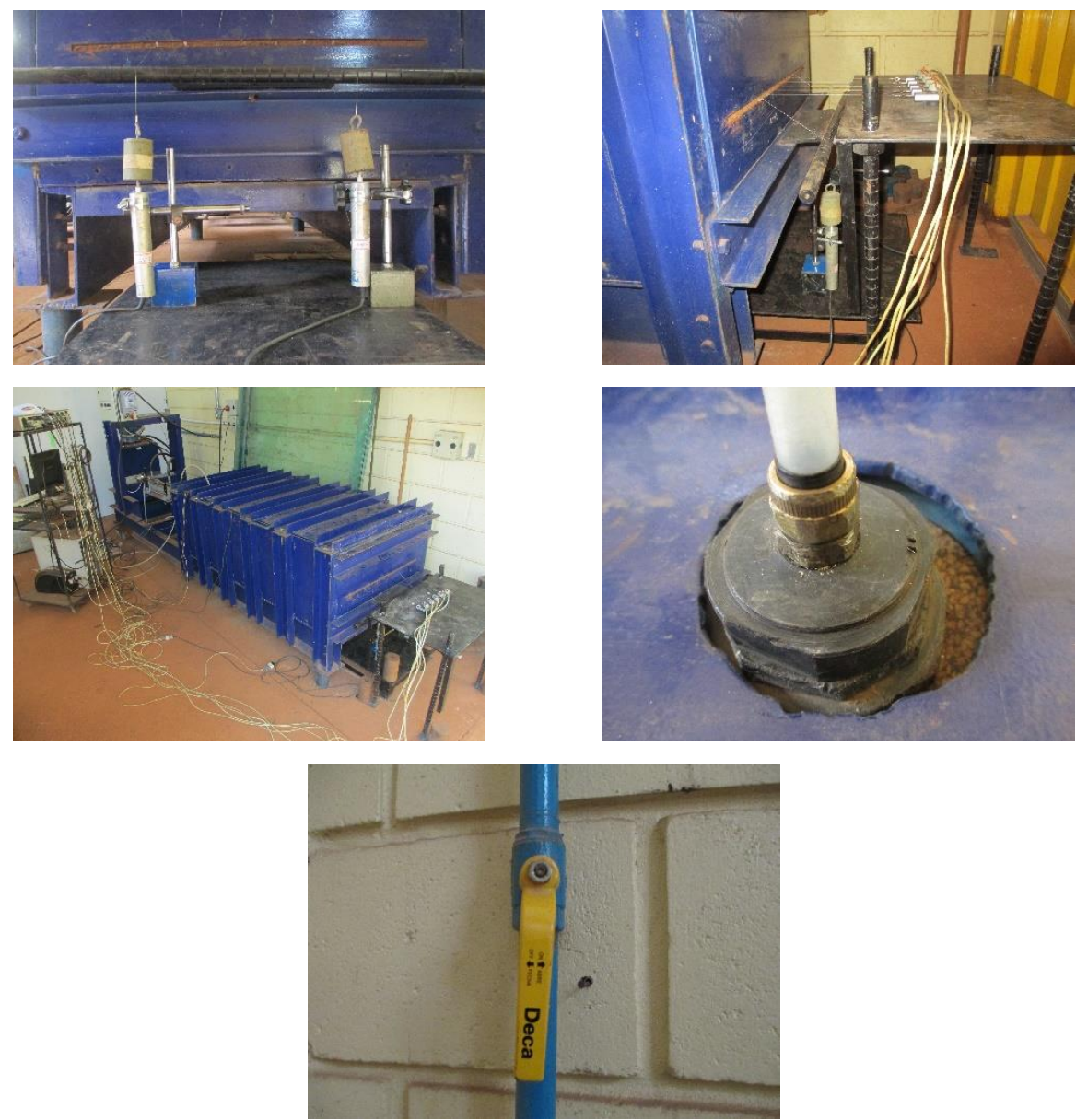

\subsection{Instrumentação e aquisição de dados}

Para o registro dos deslocamentos, das tensões e dos carregamentos aplicados durante os ensaios de arrancamento monotônico e cíclico a serem realizados em ambos os equipamentos, dispõe-se dos seguintes instrumentos de medição:

- 5 células de tensão total da empresa Kyowa® com capacidade de $200 \mathrm{kPa}$ e precisão de $0,001 \mathrm{kPa}$;

- 2 sensores de deslocamento do tipo LVDT com faixa de leitura de $50 \mathrm{~mm}$ e precisão de $0,001 \mathrm{~mm}$;

- 5 transdutores de deslocamento (Tell-tales) LX-PA 2.8 da empresa UniMeasure ${ }^{\circledR}$ com faixa de leitura de $29 \mathrm{~mm}$ e precisão de $0,001 \mathrm{~mm}$;

- 1 célula de carga com capacidade de 2 toneladas e precisão de 0,25 kgf; 
Por outro lado, a medição dos deslocamentos da geogrelha foi realizada por meio de fios de aço inextensível fixados na região confinada dos corpos de prova conforme as Figuras 3.29 e 3.30 a seguir, os quais são protegidos por uma mangueira de nylon com diâmetro externo de $4 \mathrm{~mm}$ e diâmetro interno de $2 \mathrm{~mm}$ para evitar alterações nas leituras por causa do atrito com o solo durante os ensaios.

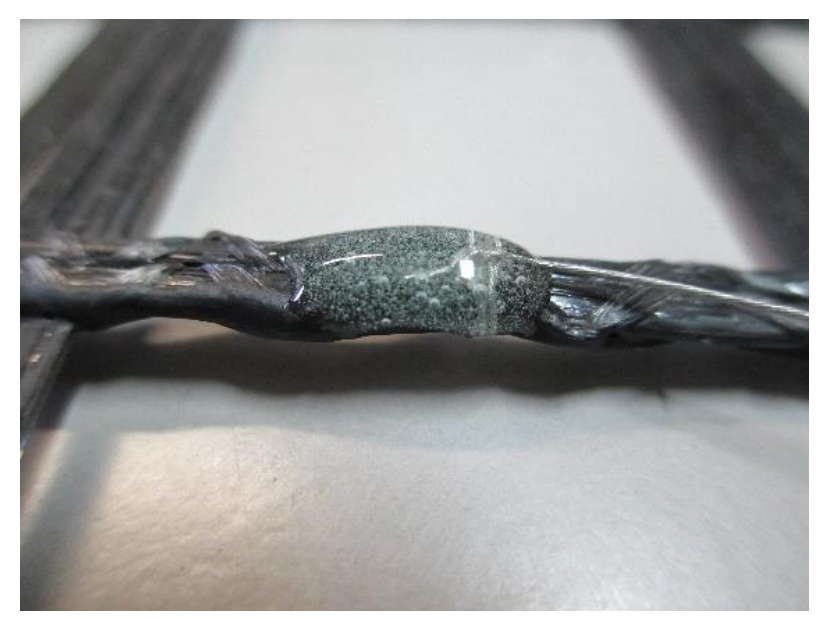

Figura 3.29. Detalhe da fixação do fio de aço inextensível nos elementos longitudinais instrumentados

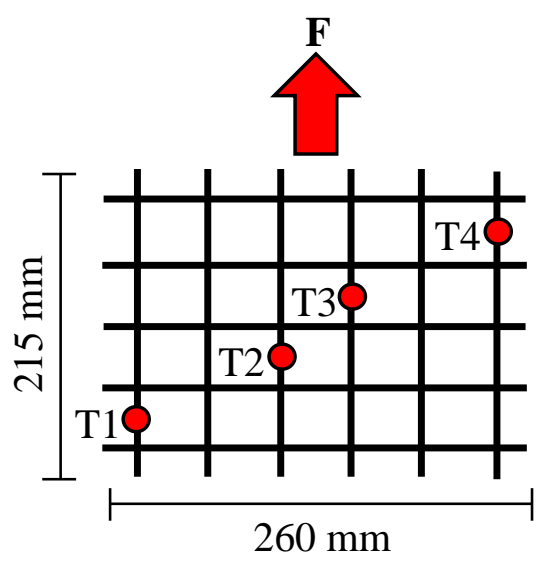

a. Equipamento de pequenas dimensões

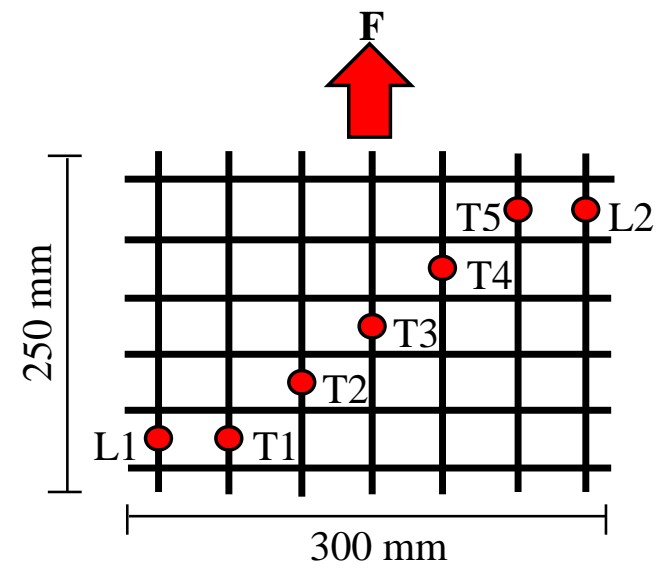

b. Equipamento de grandes dimensões

Figura 3.30. Localização dos pontos de medição dos deslocamentos na região confinada dos corpos de prova

Com relação à instrumentação instalada no interior do solo, nas Figuras $3.31 \mathrm{e}$ 3.32 a seguir é mostrada a localização das células de tensão total em ambos os equipamentos, tanto em planta como em perfil, para registrar a variação das tensões 
verticais (ambos equipamentos) e horizontais (equipamento de grandes dimensões) durante os ensaios realizados.

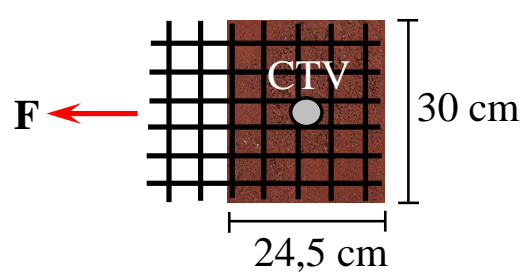

a. Planta

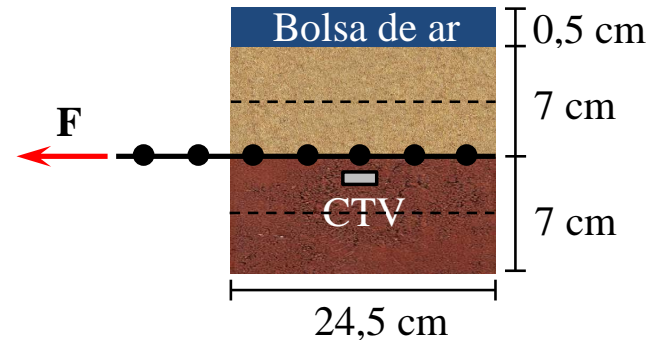

b. Perfil

Figura 3.31. Localização da célula de tensão total no equipamento de pequenas dimensões

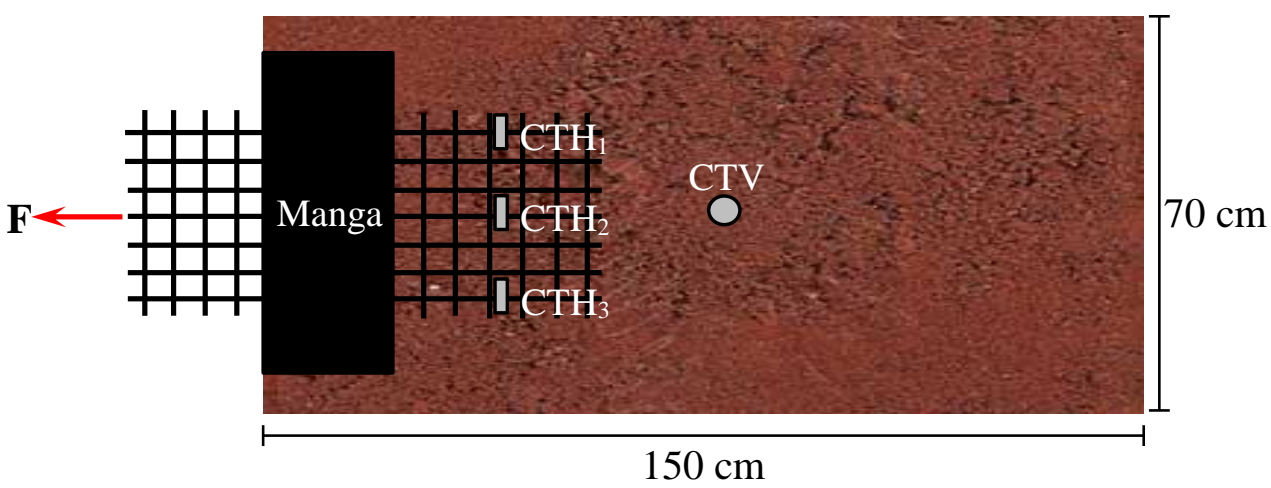

a. Planta

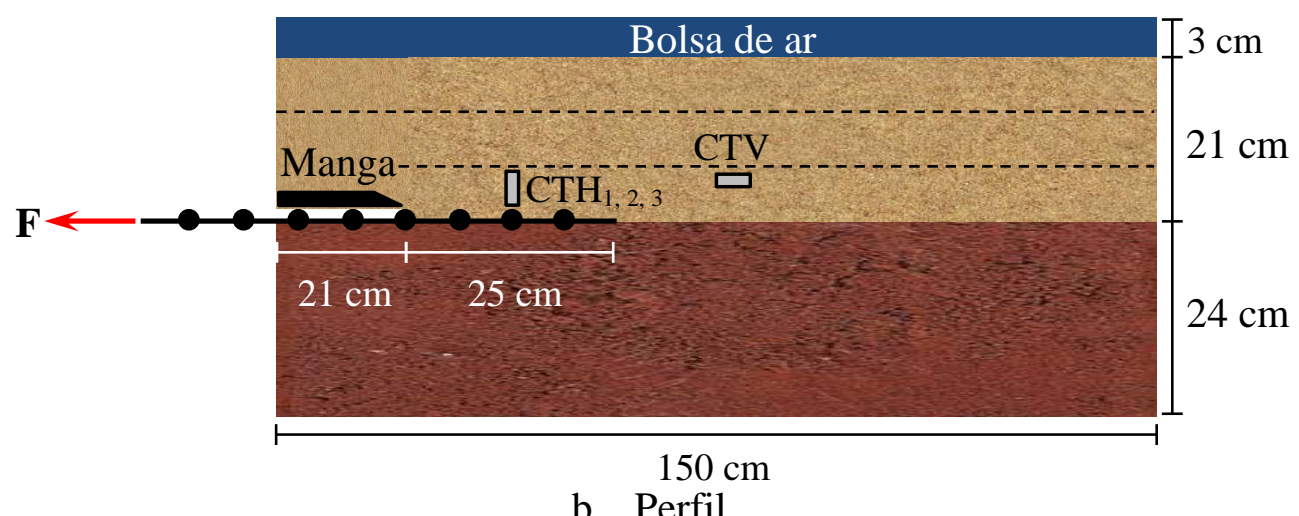

Figura 3.32. Localização das células de tensão total no equipamento de grandes dimensões

Finalmente, para o registro dos dados de força, deslocamento e tensão durante 
os ensaios de arrancamento monotônico e cíclico nos dois equipamentos, na Figura 3.33 a seguir mostra-se o sistema de aquisição utilizado, que corresponde ao SYSTEM 5000 (modelo 5100B Scanner), fabricado pela companhia VISHAY MEASUREMENTS GROUP INC., que permite o registro contínuo e simultâneo de até 20 instrumentos de medição com frequências de aquisição de até $100 \mathrm{~Hz}$.

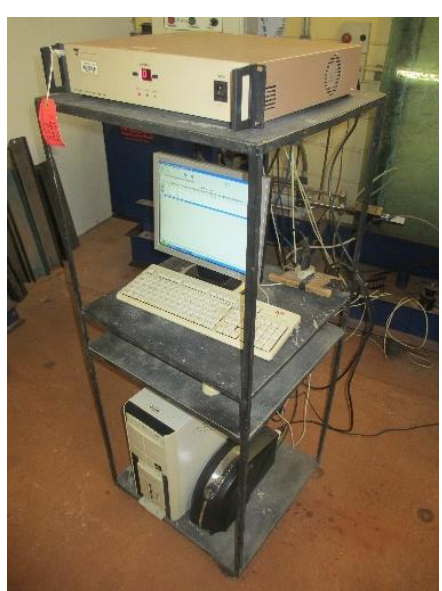

a. Equipamentos utilizados para o registro dos dados

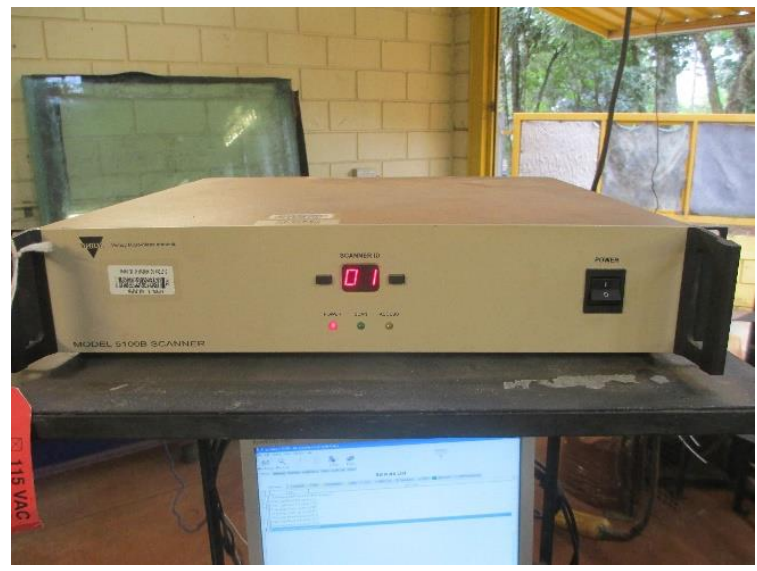

b. Detalhe do sistema de aquisição de dados SYSTEM 5000 (Modelo 5100B Scanner)

Figura 3.33. Sistema de aquisição de dados 


\section{Capítulo 4}

\section{RESULTADOS E DISCUSSÃO}

Neste capítulo são apresentados os resultados obtidos durante os ensaios de arrancamento monotônico e cíclico, todos realizados nos equipamentos de pequenas e grandes dimensões pertencentes ao Laboratório de Geossintéticos da Escola de Engenharia de São Carlos - Universidade de São Paulo.

Apesar dos ensaios de arrancamento cíclico serem o foco principal da pesquisa, foi necessária a realização de ensaios de arrancamento monotônico em ambos os equipamentos, pois as amplitudes de carga de cada ciclo dependem da resistência ao arrancamento monotônico, sendo elas uma parcela de tal valor. Dessa maneira, foram executados tais ensaios sob três tensões de confinamento, de 25,50 e $100 \mathrm{kPa}$, o que possibilitou a obtenção de uma envoltória de resistência para cada caso.

Além disso, nos ensaios de arrancamento cíclico foram utilizadas duas tensões de confinamento, onde levaram-se em consideração as condições menos e mais crítica referentes à solicitação de uma estrutura de pavimento, com alguns ajustes devidos às limitações de precisão dos manômetros, às capacidades das bolsas de ar responsáveis pela aplicação da tensão de confinamento nos dois equipamentos, e também, ao grau de confinamento da geogrelha na estrutura de solo reforçado, como foi exposto no capítulo anterior.

Com base nas pequenas deformações que ocorrem nas estruturas de pavimento em decorrência do tráfego, na sensibilidade dos instrumentos de medição disponíveis no laboratório e nos critérios adotados por Napa G. (2011) e Campos (2013), a amplitude de carga foi definida em $20 \%$ do valor da resistência ao arrancamento monotônico para cada tensão de confinamento, e o limite inferior, ou tensão de repouso, foi estimado de acordo ao descrito na norma ASTM D 7499 M - 09, sendo eles de 0,9 $\mathrm{kPa}$ para a tensão de confinamento de $25 \mathrm{kPa}$, e de $3,6 \mathrm{kPa}$ para a tensão de 
confinamento de $100 \mathrm{kPa}$.

Durante os ensaios de arrancamento cíclico foi atingida a capacidade do equipamento correspondente a 10.000 ciclos de carga sem ocorrer falha do sistema e nem ruptura da geogrelha por fadiga. Por causa disso, decidiu-se aplicar um carregamento monotônico imediatamente após os 10.000 ciclos de carga, com o intuito de comparar a sua resistência residual com a resistência obtida nos ensaios de arrancamento monotônico, e assim poder verificar o efeito da ciclagem na estrutura de solo reforçado, tal como fizeram Moraci e Cardile (2009) e Nayeri e Fakharian (2009).

Assim, a análise dos resultados experimentais obtidos nos ensaios realizados compõe-se de comparações entre ambos equipamentos com relação ao arrancamento monotônico e cíclico; às envoltórias de resistência do arrancamento monotônico; ao efeito dos ciclos de carga na resistência residual; à variação da tensão de confinamento; à variação das tensões horizontais durante o ensaio de arrancamento monotônico no equipamento de grandes dimensões e, ao módulo de cisalhamento de interface nos ensaios de arrancamento cíclico.

\subsection{Arrancamento monotônico}

Tal como foi mostrado no Capítulo 3, ao se comparar o efeito gerado pelas camadas de solo sobre a geogrelha em ambos os equipamentos, percebe-se que a diferença do acréscimo de tensão no de grandes dimensões com relação ao de pequenas dimensões é pouco significativa. Por causa disso, decidiu-se aplicar as mesmas tensões de confinamento $(25,50$ e $100 \mathrm{kPa})$ em ambos os equipamentos de tal forma que o grau de confinamento do reforço fosse similar nos dois casos, e assim poder obter as envoltórias de resistência ao arrancamento, comparáveis entre si.

Para a escolha da velocidade de arrancamento foram levadas em consideração as recomendações realizadas por Kakuda (2005), pois realizou uma série de ensaios de arrancamento com velocidades de 2,0 $\mathrm{mm} / \mathrm{min}, 4,6 \mathrm{~mm} / \mathrm{min}, 8,0 \mathrm{~mm} / \mathrm{min}$ e 100 $\mathrm{mm} / \mathrm{min}$, podendo avaliar assim a sua influência na resistência ao arrancamento.

Dessa maneira, Kakuda (2005) percebeu que para os ensaios com velocidades de 2,0 $\mathrm{mm} / \mathrm{min}, 4,6 \mathrm{~mm} / \mathrm{min}$ e $8,0 \mathrm{~mm} / \mathrm{min}$, a resistência ao arrancamento não apresentou grande variabilidade entre si, mas no caso do ensaio com velocidade de 100 $\mathrm{mm} / \mathrm{min}$, a resistência teve um acréscimo de aproximadamente $12 \%$ com relação às outras velocidades. Além disso, também foi observado que à medida que a velocidade 
aumentava, as curvas apresentaram um leve deslocamento para a esquerda, como mostrado na Figura 2.32 do Capítulo 2.

Apesar de que a norma ASTM D 6706 - 01 (Medição da resistência ao arrancamento de geossintéticos em solo) recomenda uma taxa de deslocamento constante de $1 \mathrm{~mm} / \mathrm{min}$ para reduzir o excesso de pressão neutra gerada no solo, Kakuda (2005) realizou ensaios adicionais com velocidades de 1,2 e $5 \mathrm{~mm} / \mathrm{min}$ para verificar se a utilização da velocidade de $4,6 \mathrm{~mm} / \mathrm{min}$ afetaria o valor de resistência ao arrancamento. Assim, Kakuda (2005) conseguiu confirmar as pequenas variações nos valores de resistência e deslocamento, como foi mostrado na Figura 2.33 do Capítulo 2.

Com base nas considerações de Teixeira (2003), Kakuda (2005) e Campos (2013) com relação à velocidade do ensaio, e na dificuldade em controlar a taxa de deslocamento do pistão no equipamento de grandes dimensões, decidiu-se utilizar uma velocidade média de 4,0 $\mathrm{mm} / \mathrm{min}$, pois durante os ensaios, conseguiram-se manter taxas de deslocamento próximas de tal valor com a regulação da respectiva válvula.

Assim, a seguir são mostrados os resultados obtidos durante os ensaios de arrancamento monotônico, levando em consideração as curvas de força versus deslocamento, as envoltórias de resistência, a variação da tensão de confinamento durante os ensaios, a variação da tensão horizontal no caso do equipamento de grandes dimensões e finalmente, as respectivas comparações.

\subsubsection{Equipamento de pequenas dimensões}

Tal como foi mostrado no Capítulo 3, para a realização dos ensaios no equipamento de pequenas dimensões foi projetado um suporte metálico que permitisse a adaptação desse equipamento na caixa metálica de grandes dimensões, com o intuito de utilizar o mesmo sistema de aplicação de carga nos dois casos.

Com relação à instrumentação dos ensaios realizados no equipamento de pequenas dimensões, na Figura 4.1 a seguir é mostrada a região confinada da geogrelha no equipamento de pequenas dimensões, com a localização dos pontos de medição de deslocamento, cuja numeração representa os respectivos tell-tales. 


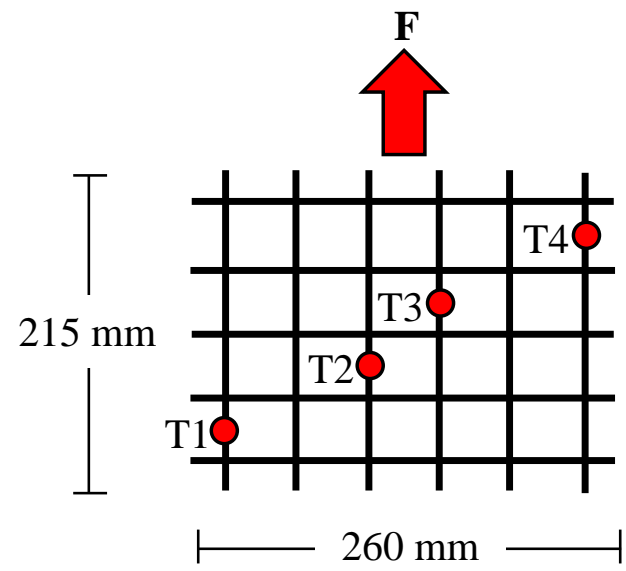

Figura 4.1. Instrumentação da região confinada da geogrelha no equipamento de pequenas dimensões

Ao analisar os resultados de arrancamento monotônico realizados no equipamento de pequenas dimensões, é preciso levar em consideração que pode ou não ocorrer ruptura do reforço geossintético, sendo que em caso de ocorrer, é mais indicado classificar o ensaio como tração confinada.

Dessa maneira, nas Figuras 4.2, 4.3 e 4.5 a seguir é mostrada a variação da força necessária para arrancar a geogrelha em função do deslocamento, a envoltória de resistência para as três tensões de confinamento utilizadas $(25,50$ e $100 \mathrm{kPa})$ e a variação da tensão de confinamento durante os ensaios, respectivamente.

Para a obtenção dos gráficos mostrados na Figura 4.2 a seguir, foi necessário fazer uma média dos deslocamentos obtidos para cada instante de tempo, pois foram registrados quatro valores por meio dos tell-tales utilizados. 


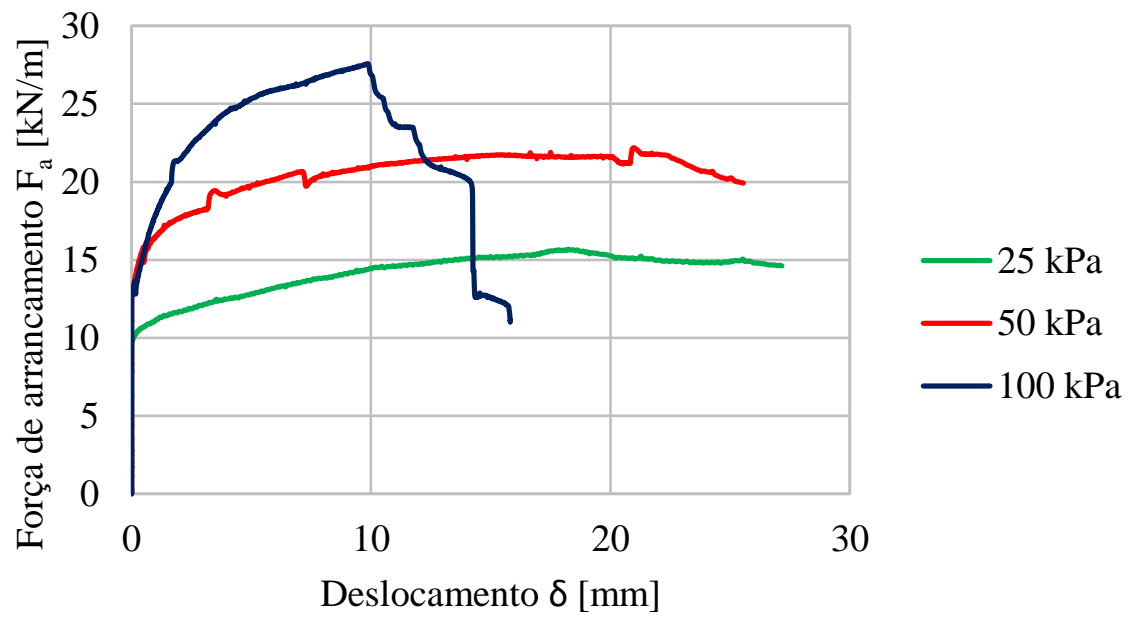

Figura 4.2. Curvas de força de arrancamento vs. deslocamento no equipamento de pequenas dimensões

Adicionalmente, na Tabela 4.1 são mostrados os valores de resistência ao arrancamento para cada tensão de confinamento, necessários para traçar a envoltória de resistência mostrada na Figura 4.3.

Por outro lado, é preciso salientar a importância da correção dos valores das tensões de cisalhamento com base na Equação (2.11) mostrada no Capítulo 2, pois durante o arrancamento existe perda de área da inclusão na região confinada.

Tabela 4.1. Valores de resistência de arrancamento para cada tensão de confinamento - Equipamento de pequenas dimensões

\begin{tabular}{ccc}
\hline $\begin{array}{c}\text { Tensão de confinamento } \\
{[\mathbf{k P a}]}\end{array}$ & $\begin{array}{r}\text { Resistência ao arrancamento } \\
{[\mathbf{k N} / \mathbf{m}]}\end{array}$ & {$[\mathbf{k P a}]$} \\
\hline 25 & 15,68 & 39,85 \\
50 & 22,19 & 57,19 \\
100 & 27,57 & 67,21 \\
\hline
\end{tabular}

Como mostrado na Figura 4.2, percebe-se que para a tensão de confinamento de $100 \mathrm{kPa}$ ocorreu ruptura da geogrelha, observada na queda brusca de resistência para um deslocamento de aproximadamente $10 \mathrm{~mm}$. Por causa disso, é possível afirmar que para as condições de compactação e tipos de solo utilizados, existiu arrancamento do reforço para as menores tensões, enquanto que para a maior, o ensaio pode ser 
classificado como tração confinada por causa do elevado grau de confinamento ao qual a geogrelha estava submetida.

Mesmo que a envoltória de resistência ao arrancamento, mostrada na Figura 4.3 a seguir, tivesse um bom fator de correlação, não é correto afirmar que os parâmetros de resistência de interface ( $a$ e $\delta_{i}$ ) entre o solo e a geogrelha são os verdadeiros (Tabela 4.2), pois ocorreram dois fenômenos diferentes para as três tensões de confinamento aplicadas, sendo de arrancamento para as de 25 e $50 \mathrm{kPa}$ e de ruptura (tração confinada) para a de $100 \mathrm{kPa}$.

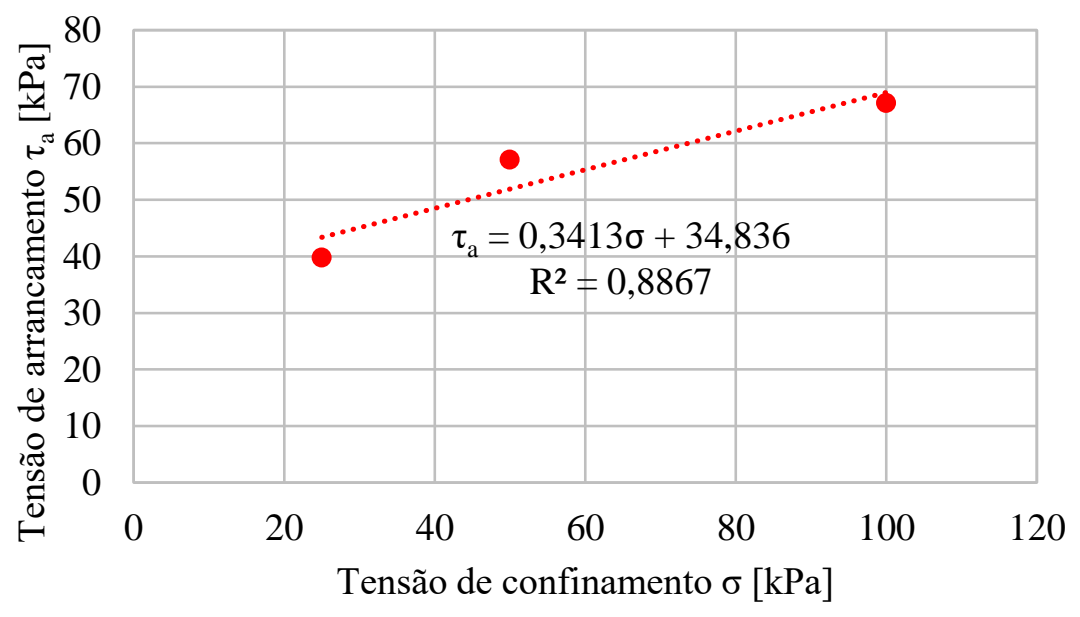

Figura 4.3. Envoltória de resistência ao arrancamento no equipamento de pequenas dimensões

Tabela 4.2. Parâmetros de resistência de interface no equipamento de pequenas dimensões

\begin{tabular}{lc}
\hline Adesão, $a[\mathrm{kPa}]$ & 34,8 \\
\hline Ângulo de atrito de interface, $\delta_{i}\left[^{\circ}\right]$ & 18,8 \\
\hline
\end{tabular}

Com relação à variação da tensão de confinamento durante os ensaios de arrancamento monotônico no equipamento de pequenas dimensões, registrada por meio da célula de tensão total instalada a $1 \mathrm{~cm}$ de profundidade da camada de solo argiloso abaixo da geogrelha (Figura 4.4), foi possível observar a contribuição dos elementos transversais na variação da tensão de confinamento, pois à medida que a geogrelha era 
arrancada, os elementos transversais iam empurrando o solo, alterando assim o seu confinamento (Figura 4.5).

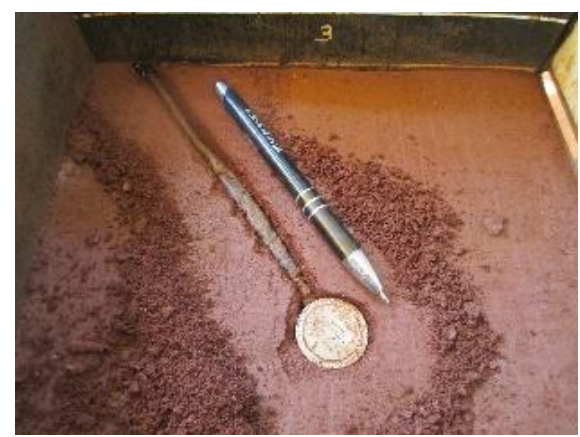

a. Escavação de $1 \mathrm{~cm}$ para a instalação da célula

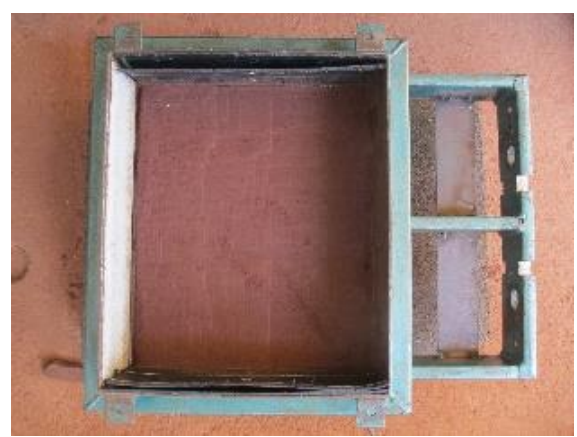

c. Superfície de interface compactada

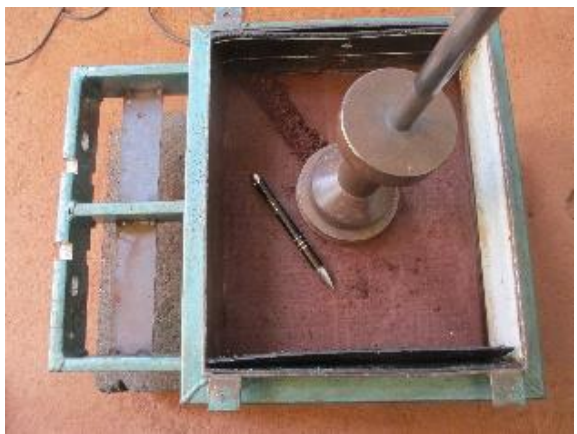

b. Compactação do solo

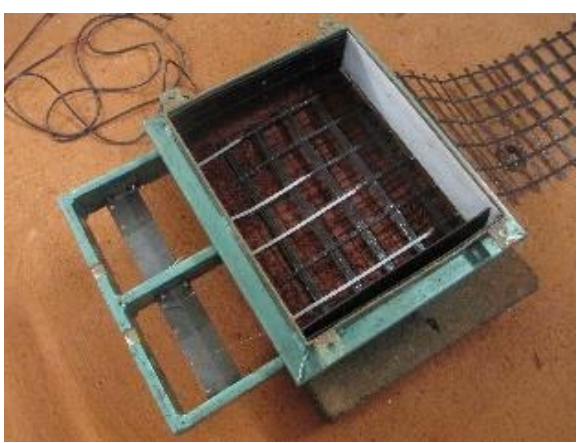

d. Escarificação da superfície de interface e instalação da geogrelha

Figura 4.4. Processo de instalação da célula de tensão total no equipamento de pequenas dimensões

É por causa disso que, no momento em que o ensaio inicia, ocorre um desconfinamento do solo devido ao efeito de dilatância, seguido de um aumento desta tensão por causa do rearranjo das partículas (Figura 4.5), as quais tendem a se juntar novamente. 


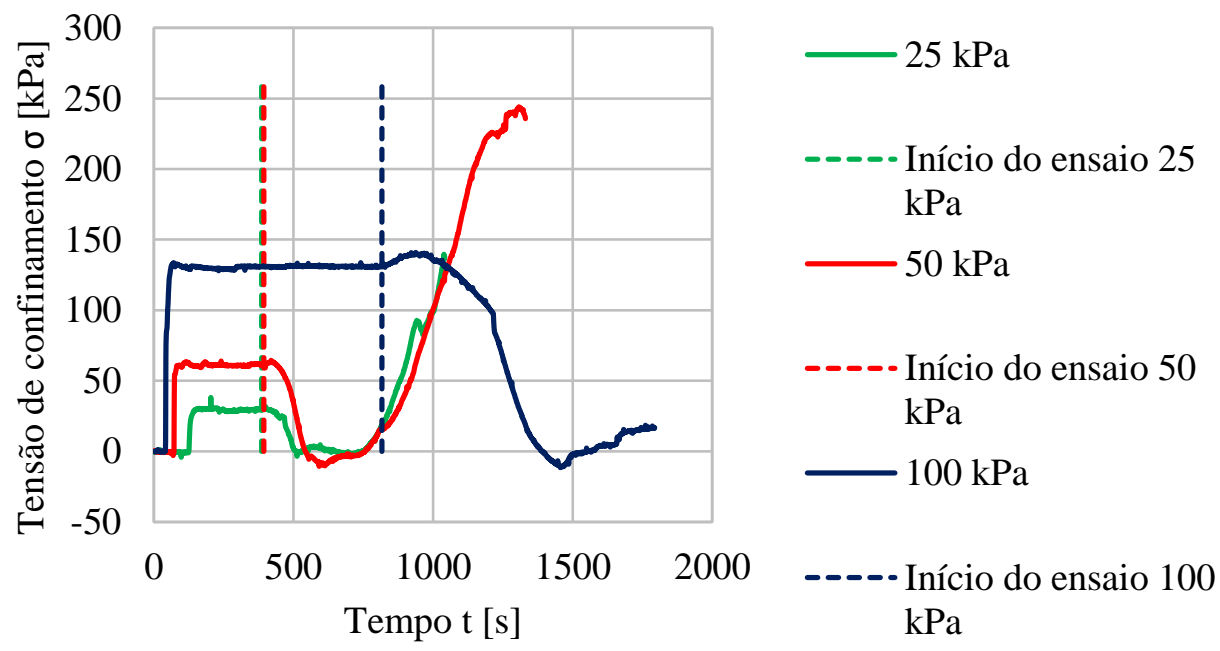

Figura 4.5. Variação da tensão de confinamento nos ensaios de arrancamento monotônico - Equipamento de pequenas dimensões

Em complemento aos resultados anteriores, a seguir é mostrada a variação da força de arrancamento em função do deslocamento para cada tensão de confinamento $(25,50$ e $100 \mathrm{kPa})$, levando em consideração a localização dos pontos de medição de deslocamento na geogrelha, mostrados anteriormente na Figura 4.1.

\subsubsection{Tensão de confinamento de $25 \mathrm{kPa}$}

Analisando os resultados de arrancamento monotônico separadamente para cada tensão de confinamento, observa-se que para o caso da menor tensão aplicada no equipamento de pequenas dimensões apresentou-se arrancamento da inclusão, pois não houve uma queda brusca na força registrada pela célula de carga. Além disso, os deslocamentos registrados pelos quatro tell-tales para cada instante de tempo foram similares, o qual indica que a geogrelha deslocou-se de forma homogênea (Figura 4.6). 


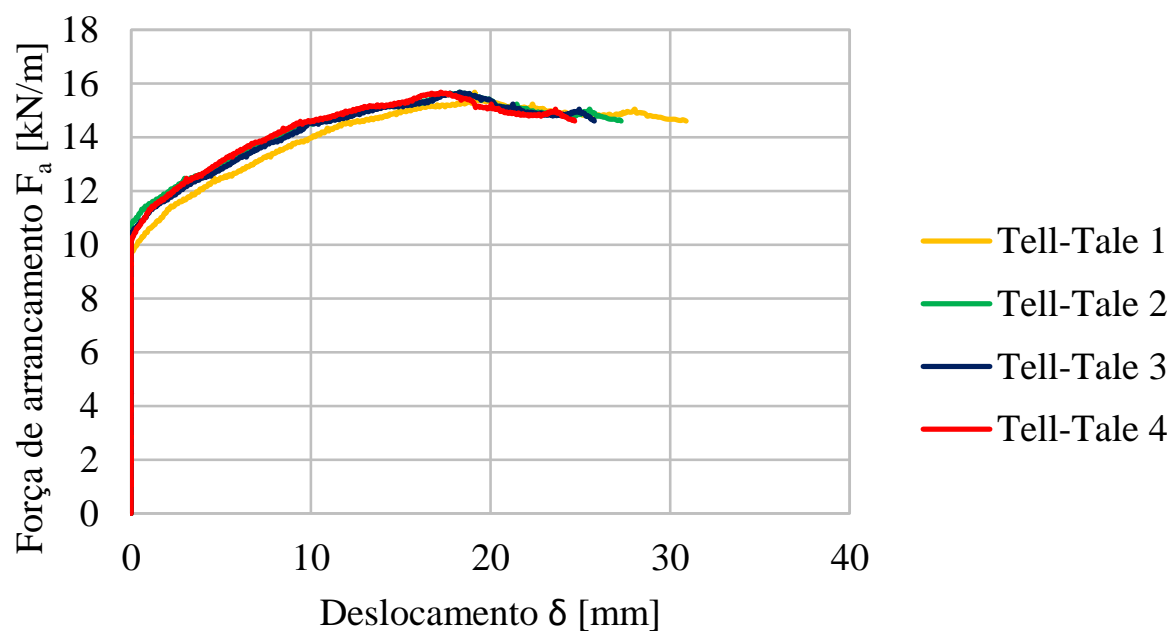

Figura 4.6. Curvas de força de arrancamento vs. deslocamento para uma tensão de confinamento de $25 \mathrm{kPa}$ - Equipamento de pequenas dimensões

Adicionalmente, com a exumação realizada à geogrelha após a execução do ensaio, confirmaram-se os resultados apresentados anteriormente na Figura 4.6, pois pôde-se observar que não ocorreu ruptura de nenhum elemento do corpo de prova. Além disso, apesar da geogrelha ter-se deslocado de forma homogênea, nas fotografias mostradas na Figura 4.7 a seguir, é possível observar um pequeno efeito de borda nos elementos dos extremos laterais, os quais apresentavam um grau de confinamento menor do que os elementos da região central.
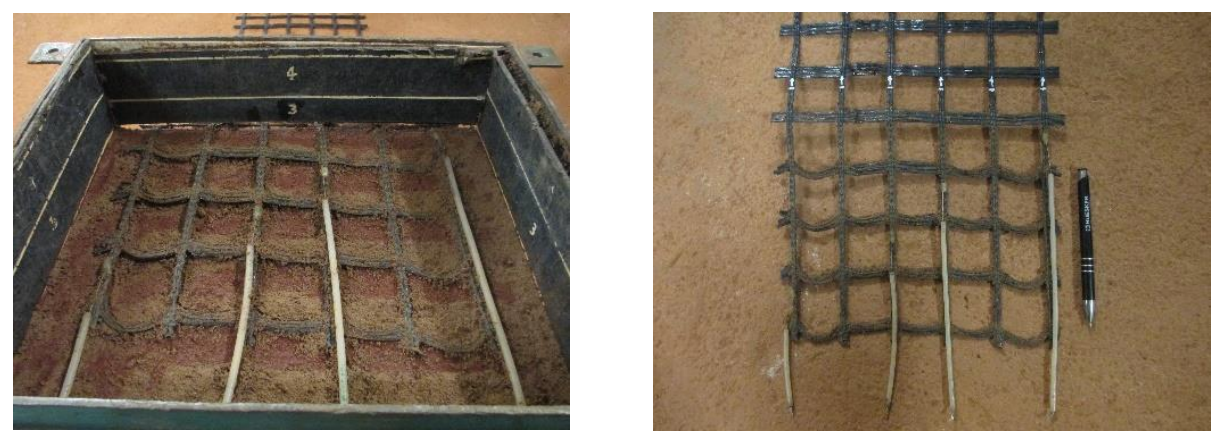

Figura 4.7. Exumação da geogrelha após o ensaio de arrancamento monotônico no equipamento de pequenas dimensões $-25 \mathrm{kPa}$

\subsubsection{Tensão de confinamento de $50 \mathrm{kPa}$}

No caso da tensão de confinamento de $50 \mathrm{kPa}$, o efeito de borda foi ainda mais acentuado do que no ensaio com a menor tensão de confinamento. Por causa disso, nos 
gráficos de força de arrancamento versus deslocamento mostrados na Figura 4.8, é possível observar o início da deformação no elemento longitudinal correspondente ao tell-tale número 4, cujo ponto de medição estava mais próximo da garra (Figura 4.1) e num dos extremos da caixa, onde o grau de confinamento era menor que o da região central.

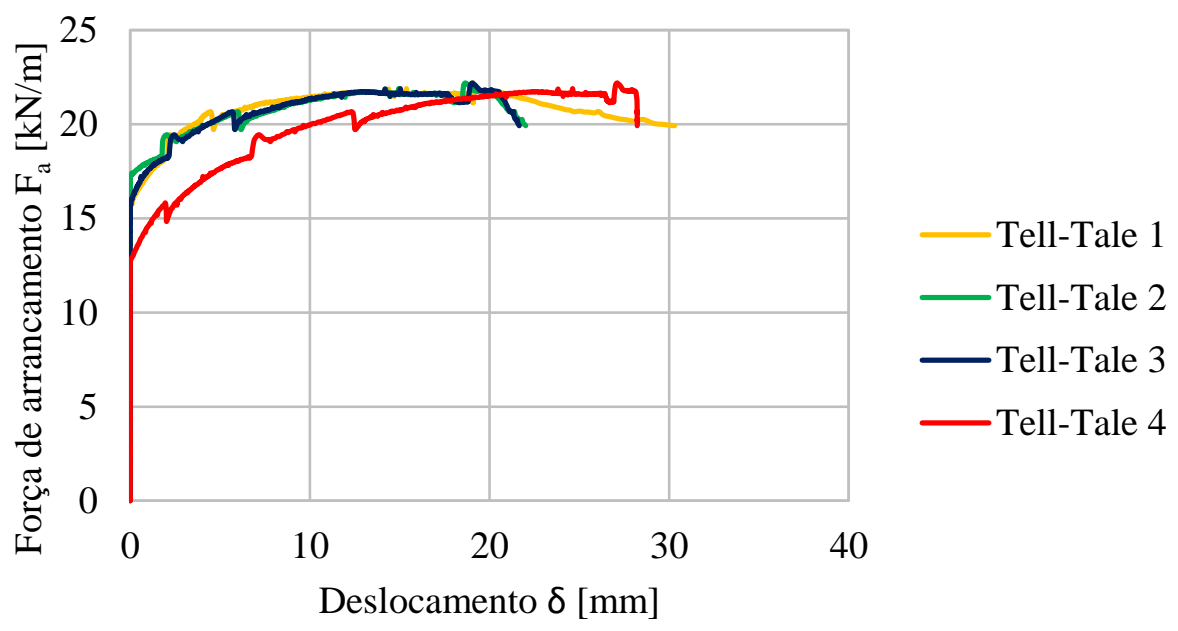

Figura 4.8. Curvas de força de arrancamento vs. deslocamento para uma tensão de confinamento de $50 \mathrm{kPa}$ - Equipamento de pequenas dimensões

Adicionalmente, a análise anterior é complementada com o observado na exumação realizada à geogrelha para este ensaio (Figura 4.9), onde foi confirmada a queda de resistência no trecho final de cada curva devido à falha de alguns nós formados entre elementos transversais e os longitudinais extremos, onde o grau de confinamento era menor que o da região central, e estavam carregados com metade da resistência passiva ao terem um elemento transversal de um lado só.
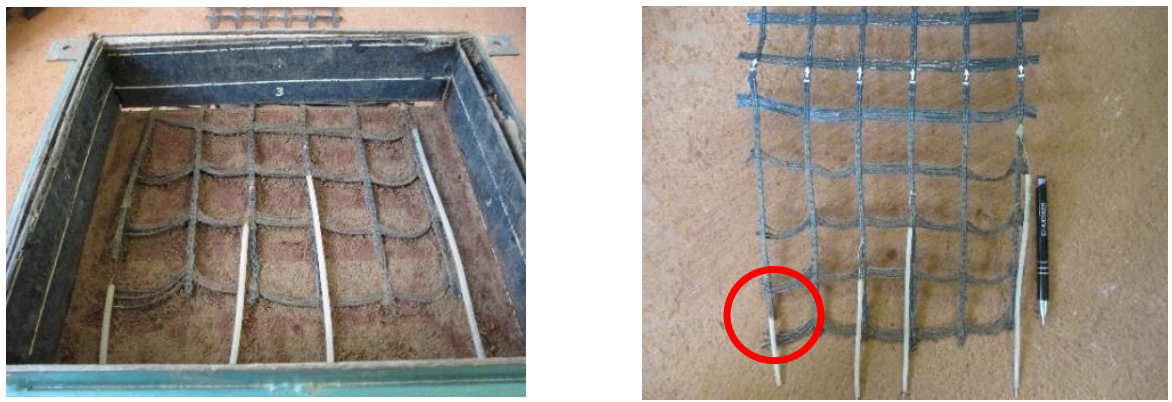

Figura 4.9. Exumação da geogrelha após o ensaio de arrancamento monotônico no equipamento de pequenas dimensões - $50 \mathrm{kPa}$ 


\subsubsection{Tensão de confinamento de $100 \mathrm{kPa}$}

A tendência observada nos resultados obtidos para as tensões de confinamento de 25 e $50 \mathrm{kPa}$ é confirmada no último ensaio de arrancamento monotônico, pois a região central da geogrelha esteve submetida a um grau de confinamento muito mais elevado do que nos casos anteriores, aumentando assim o efeito de borda nos elementos longitudinais extremos.

Dessa maneira, na Figura 4.10 a seguir é possível observar que os elementos que se deformaram primeiro foram os correspondentes aos transdutores 1 e 4, que correspondiam aos elementos longitudinais dos extremos do corpo de prova (Figura 4.1). Além disso, a queda brusca de resistência foi muito mais acentuada do que no caso anterior, confirmando assim que o ensaio não foi propriamente de arrancamento e sim de tração confinada pelo fato da ocorrência de falha em alguns dos nós da geogrelha.

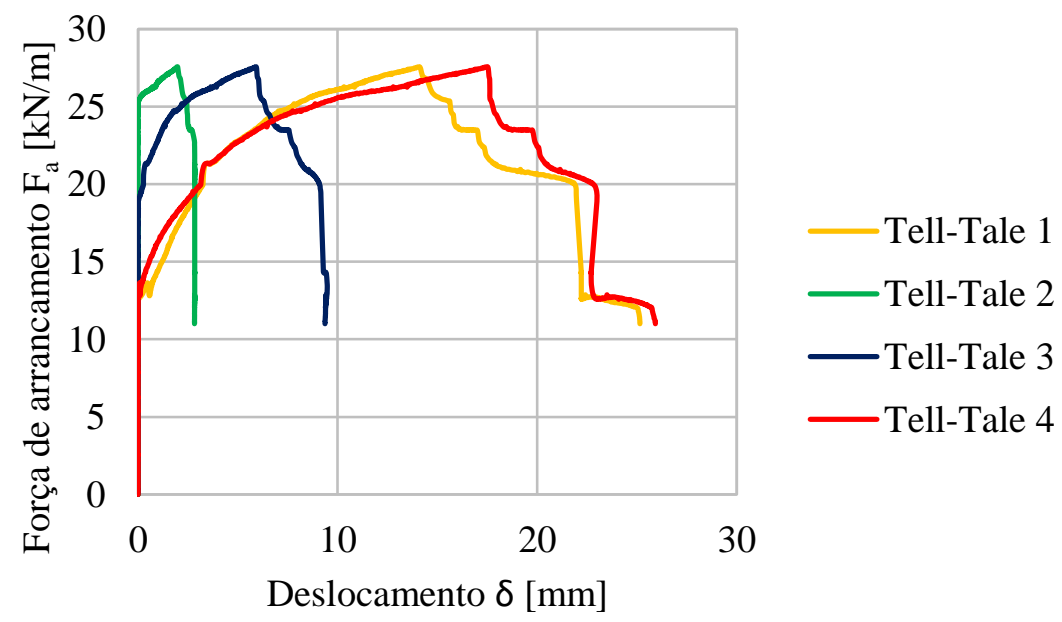

Figura 4.10. Curvas de força de arrancamento vs. deslocamento para uma tensão de confinamento de $100 \mathrm{kPa}$ - Equipamento de pequenas dimensões

Tal como nos casos anteriores, a exumação da geogrelha permitiu confirmar o comportamento das curvas mostradas na Figura 4.11, pois foi possível observar mais uma vez o efeito de borda através da falha dos nós dos extremos, e também, o fato desses elementos apresentarem os maiores deslocamentos devido ao menor grau de confinamento em comparação com o da região central. 

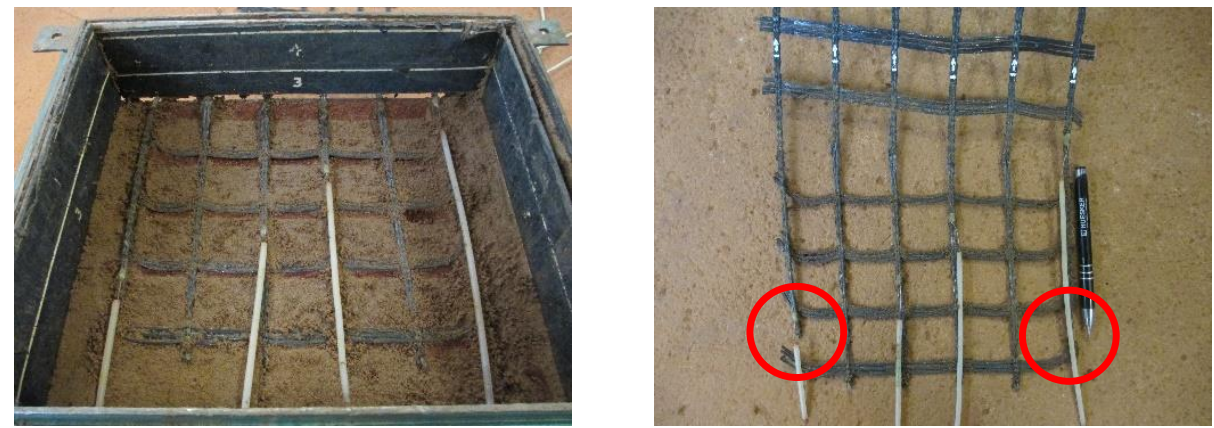

Figura 4.11. Exumação da geogrelha após o ensaio de arrancamento monotônico no equipamento de pequenas dimensões - $100 \mathrm{kPa}$

\subsubsection{Equipamento de grandes dimensões}

No equipamento de grandes dimensões não foi necessário utilizar o método das geomembranas lubrificadas para reduzir do efeito de atrito gerado pelas paredes interiores da caixa, pois o espaço era suficiente para cumprir com as recomendações apresentadas pela norma ASTM D 6706 - 01, onde exige-se um espaço livre de no mínimo $150 \mathrm{~mm}$ entre a geogrelha e as paredes laterais da caixa.

Além disso, é recomendada a utilização de uma manga metálica no nível do reforço para minimizar os efeitos de atrito entre o solo e a parede frontal, pois a sua implementação faz com que o ponto de aplicação da força de arrancamento seja transferido no interior da massa de solo (Kakuda, 2005).

Com relação à instrumentação utilizada nos ensaios de arrancamento realizados no equipamento de grandes dimensões, o número de tell-tales esteve limitado a cinco, sendo assim necessária a implementação de mais dois sensores do tipo LDVT com faixa de leitura de $50 \mathrm{~mm}$ para complementar a medição dos deslocamentos do corpo de prova.

Além disso, foi utilizada a mesma célula de carga de duas toneladas dos ensaios realizados no equipamento de pequenas dimensões, e mais quatro células de tensão total com capacidade de $200 \mathrm{kPa}$, das quais três foram utilizadas para medir tensões horizontais e a outra para o registro da tensão de confinamento durante os ensaios.

Assim, na Figura 4.12 a seguir é mostrada a região confinada da geogrelha no equipamento de grandes dimensões, com a localização dos pontos de medição de deslocamento, cuja nomenclatura representa a instrumentação utilizada. 


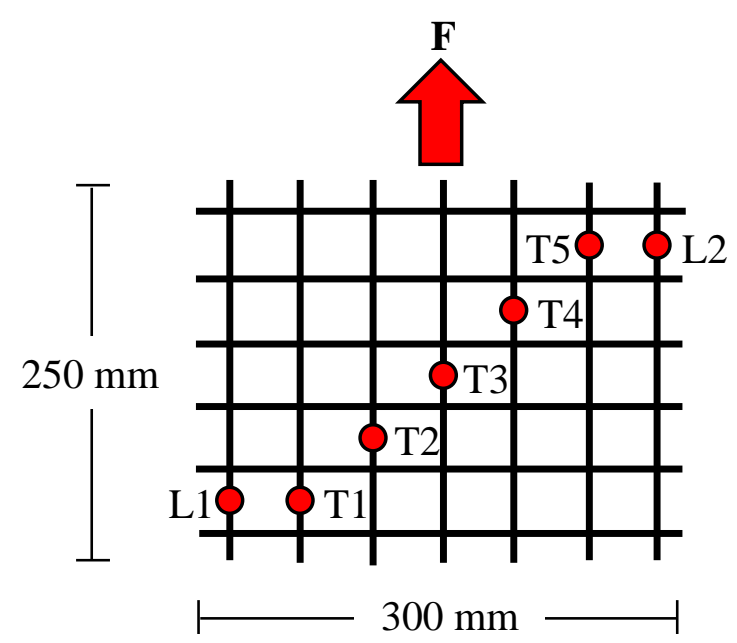

Figura 4.12. Instrumentação da região confinada da geogrelha no equipamento de grandes dimensões

Ao analisar os resultados de arrancamento monotônico realizados no equipamento de grandes dimensões, é preciso levar em consideração que, semelhante ao que aconteceu no equipamento de pequenas dimensões, pode ou não ocorrer ruptura do reforço geossintético, sendo que em caso de ocorrer, seria mais indicado classificar o ensaio de tração confinada e não de arrancamento.

Dessa maneira, nas Figuras 4.13, 4.14 e 4.17 a seguir mostra-se respectivamente a variação da força necessária para arrancar a geogrelha em função do deslocamento, a envoltória de resistência para as três tensões de confinamento utilizadas (25, 50 e 100 $\mathrm{kPa}$ ) e a variação da tensão de confinamento durante os ensaios.

Tal como aconteceu no equipamento de pequenas dimensões, para a obtenção dos gráficos mostrados na Figura 4.13 também foi necessário fazer uma média dos deslocamentos obtidos para cada instante de tempo, pois neste caso foram registrados sete valores por meio dos LVDT e tell-tales utilizados. 


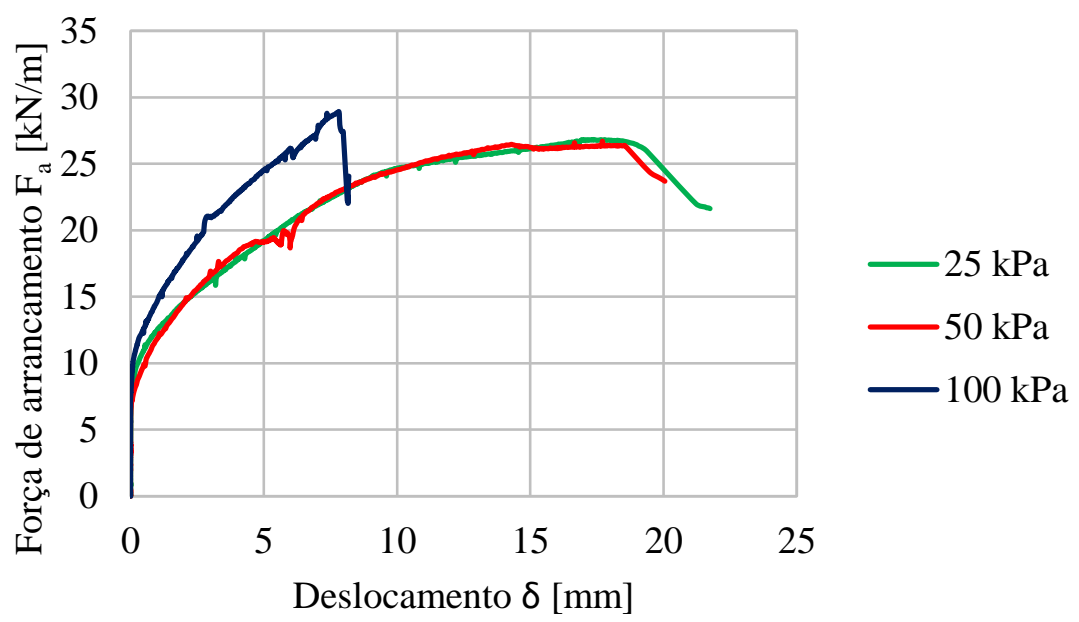

Figura 4.13. Curvas de força de arrancamento vs. deslocamento no equipamento de grandes dimensões

Na Tabela 4.3 a seguir são mostrados os valores de resistência ao arrancamento corrigidos com base na Equação (2.11) para cada tensão de confinamento, os quais são necessários para traçar a envoltória de resistência mostrada na Figura 4.14.

Tabela 4.3. Valores de resistência de arrancamento para cada tensão de confinamento - Equipamento de grandes dimensões

\begin{tabular}{ccc}
\hline $\begin{array}{c}\text { Tensão de confinamento } \\
{[\mathbf{k P a}]}\end{array}$ & $\begin{array}{r}\text { Resistência ao arrancamento } \\
{[\mathbf{k N} / \mathbf{m}]}\end{array}$ & {$[\mathbf{k P a}]$} \\
\hline 25 & 26,83 & 57,75 \\
50 & 26,70 & 57,47 \\
100 & 28,93 & 59,73 \\
\hline
\end{tabular}

Como foi mostrado na Figura 4.13, percebe-se que para as três tensões de confinamento ocorreu ruptura da geogrelha, mas no caso de $100 \mathrm{kPa}$ o fenômeno foi mais acentuado e aconteceu primeiro $(\delta=8 \mathrm{~mm})$ do que para as tensões de 25 e de 50 $\mathrm{kPa}(\delta=18 \mathrm{~mm})$, cujo comportamento foi similar.

Assim, é possível concluir que a geogrelha esteve submetida a um grau de confinamento maior no equipamento de grandes dimensões, mesmo tendo sido considerado o efeito escala com relação ao tamanho do corpo de prova e às tensões sobre o reforço, descrito com mais detalhe no Capítulo 3. 
Dessa maneira, afirma-se que as envoltórias de resistência em ambos os equipamentos não são comparáveis entre si por causa do comportamento mecânico não ter sido o mesmo, sendo que no equipamento de pequenas dimensões ocorreu ruptura só na tensão de $100 \mathrm{kPa}$ e, no de grandes dimensões, nos três valores de tensão de confinamento.

Similar ao caso do equipamento de pequenas dimensões, na Figura 4.14 a seguir é mostrada a envoltória de resistência ao arrancamento no equipamento de grandes dimensões, cujos parâmetros de resistência de interface ( $a$ e $\left.\delta_{i}\right)$ estão relacionados à interação solo-geossintético para um caso propriamente de tração confinada e não de arrancamento.

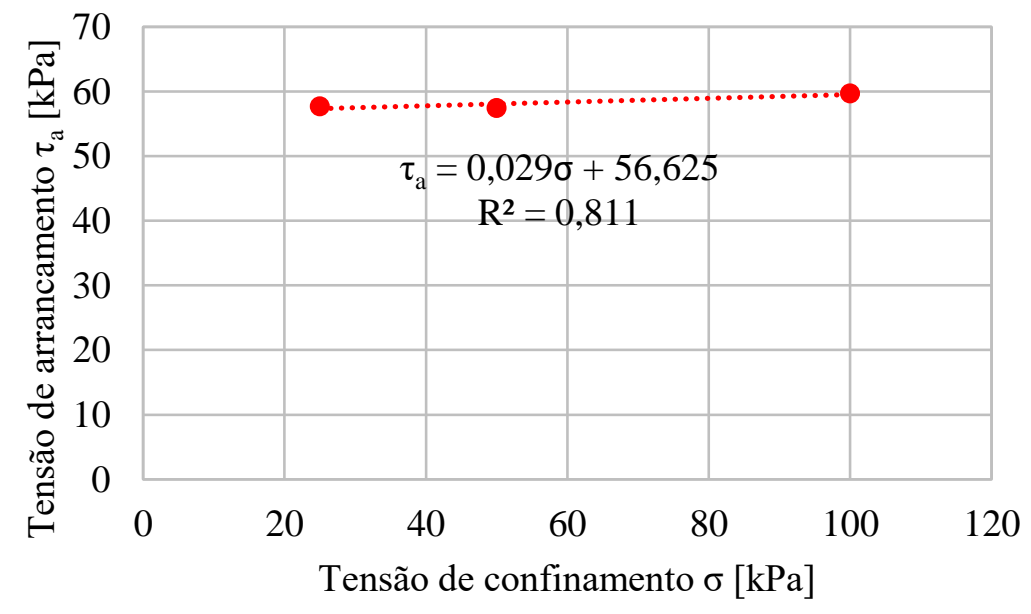

Figura 4.14. Envoltória de resistência ao arrancamento no equipamento de grandes dimensões

Apesar dos parâmetros de resistência de interface mostrados na Tabela 4.4 a seguir estarem relacionados a um caso de tração confinada, como foi comentado anteriormente, permitem ter uma noção da interação entre o solo e a geogrelha no equipamento de grandes dimensões, onde a adesão foi muito maior do que o ângulo de atrito de interface por causa do maior grau de confinamento da geogrelha em comparação ao equipamento de pequenas dimensões. 
Tabela 4.4. Parâmetros de resistência de interface no equipamento de grandes dimensões

\begin{tabular}{lc}
\hline Adesão, $a[\mathrm{kPa}]$ & 56,6 \\
\hline Ângulo de atrito de interface, $\delta_{i}\left[^{\circ}\right]$ & 1,7 \\
\hline
\end{tabular}

Com relação à variação da tensão de confinamento durante os ensaios de arrancamento monotônico no equipamento de grandes dimensões, registrada por meio da célula de tensão total CTV (Figuras 4.15 e 4.16), é possível confirmar a afirmação realizada anteriormente com relação à ação dos elementos transversais na variação da tensão de confinamento, pois neste caso, os valores mantiveram-se constantes devido ao fato da célula CTV estar afastada da geogrelha, e portanto, não ser afetada pelo arrasto do material contido nas aberturas do reforço, como mostrado na Figura 4.17.

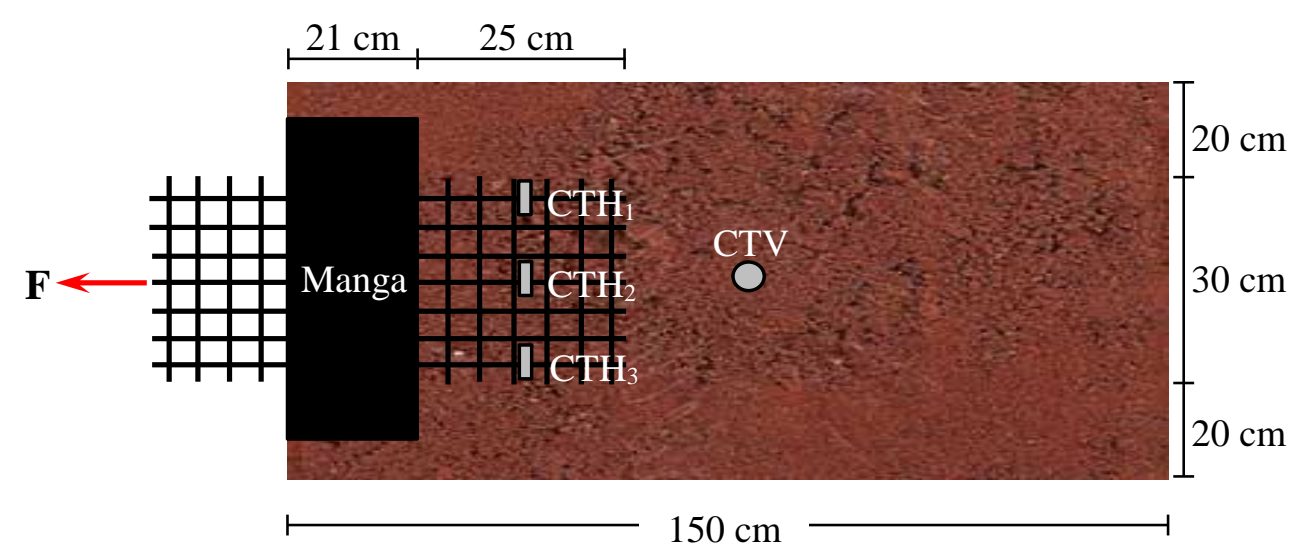

Figura 4.15. Localização em planta das células de tensão total - Equipamento de grandes dimensões

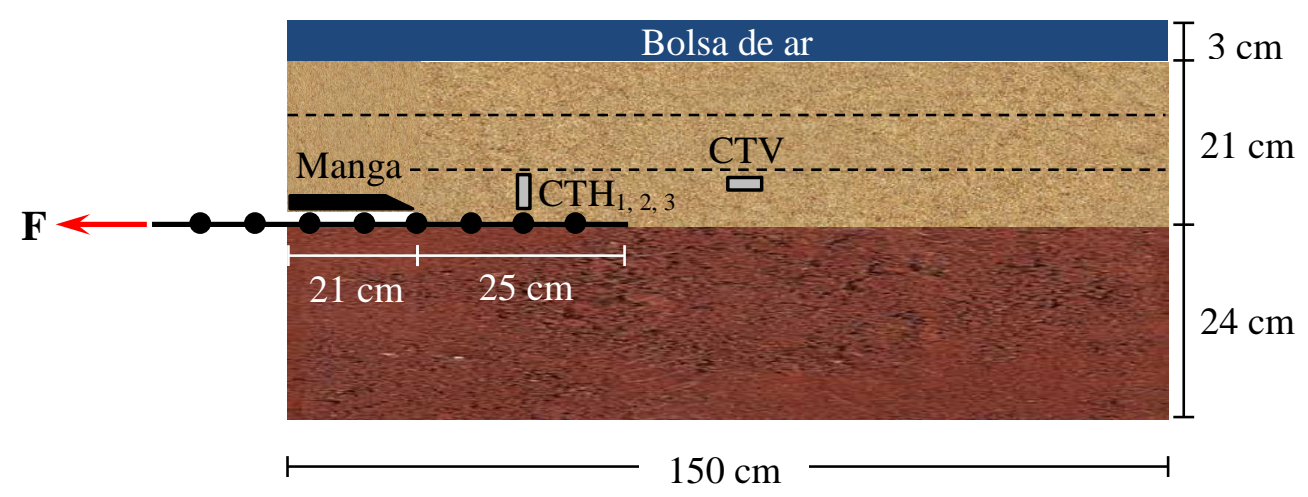

Figura 4.16. Localização em profundidade das células de tensão total - Equipamento de grandes dimensões 

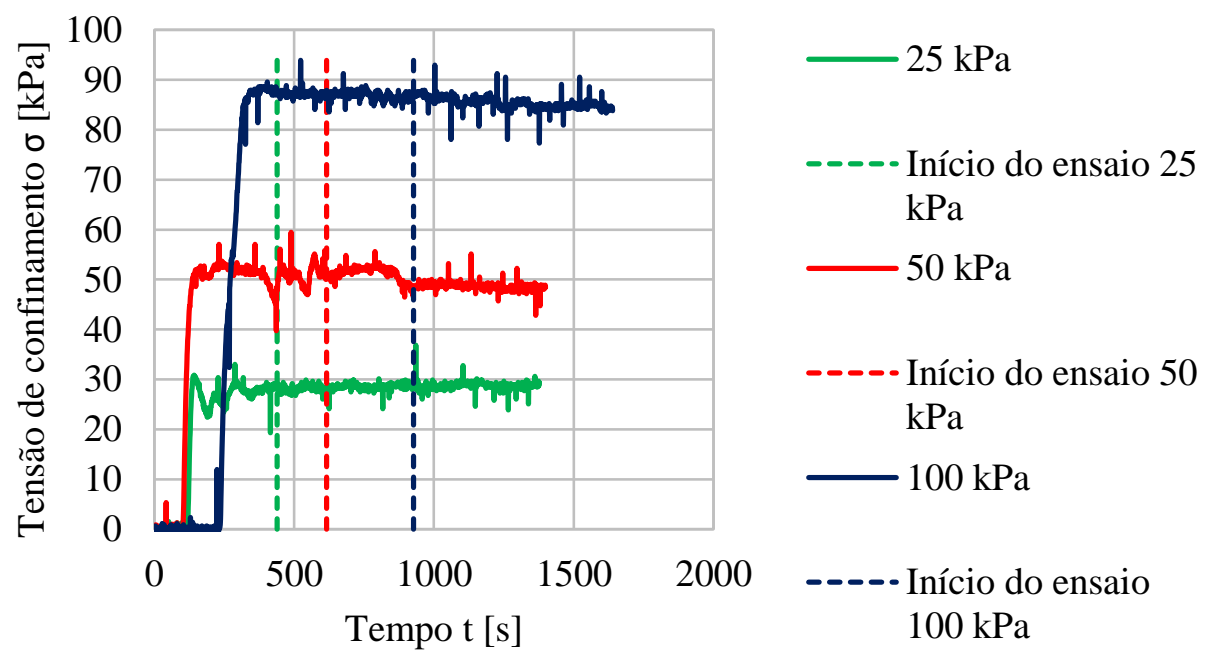

Figura 4.17. Variação da tensão de confinamento nos ensaios de arrancamento monotônico - Equipamento de grandes dimensões

Como no caso do equipamento de pequenas dimensões, a seguir é mostrada a variação da força de arrancamento em função do deslocamento para cada tensão de confinamento $(25,50$ e $100 \mathrm{kPa})$, assim como a variação das tensões horizontais registradas pelas células $\mathrm{CTH}_{1}, \mathrm{CTH}_{2}$ e $\mathrm{CTH}_{3}$.

\subsubsection{Tensão de confinamento de $25 \mathrm{kPa}$}

No caso do equipamento de grandes dimensões, os resultados do ensaio de arrancamento monotônico para a menor tensão de confinamento mostraram uma queda brusca de resistência, o qual indica que, mesmo tendo as mesmas condições de compactação, o grau de confinamento sobre a geogrelha neste caso foi maior do que no equipamento de pequenas dimensões.

Além disso, nas curvas de força de arrancamento versus deslocamento mostradas na Figura 4.18 a seguir, é possível perceber o efeito de borda analisado anteriormente e a influência do local de medição dos deslocamentos na geogrelha (Figura 4.12), onde o primeiro ponto a se deslocar foi o correspondente ao LVDT 2, ponto mais próximo da garra, seguido dos tell-tales 5 e 4, respectivamente.

Seguindo a sequência, os deslocamentos registrados pelo LVDT 1 (ponto do extremo esquerdo) confirmaram o efeito de borda, situação que não aconteceu no 
equipamento de pequenas dimensões para a mesma tensão de confinamento, pois nesse caso os deslocamentos foram similares para cada instante de tempo (Figura 4.6).

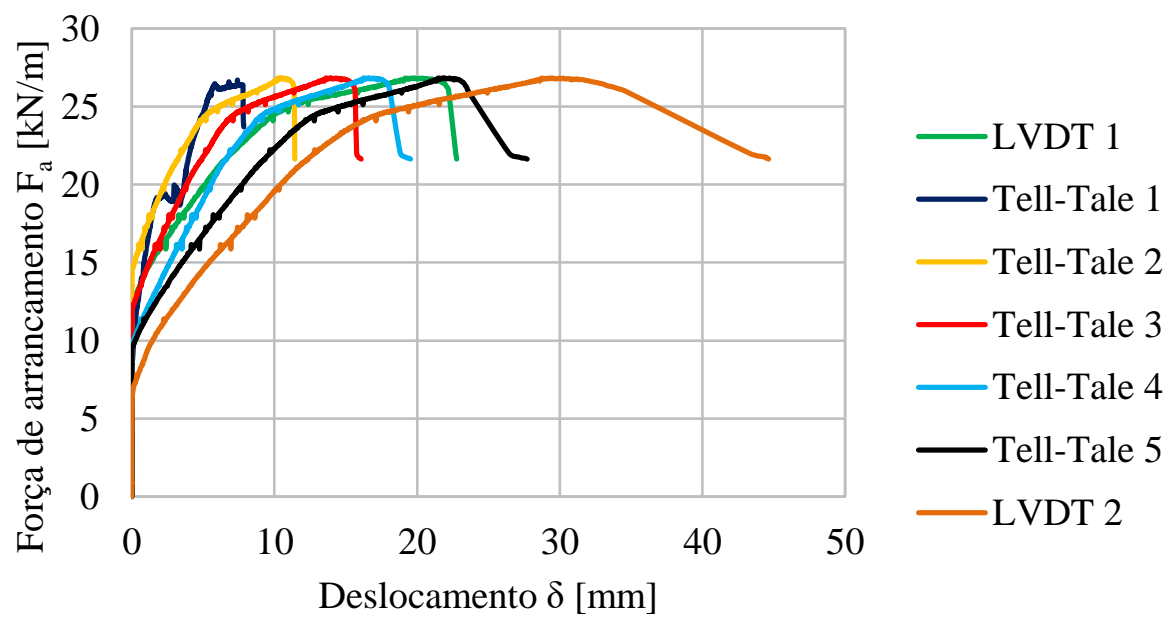

Figura 4.18. Curvas de força de arrancamento vs. deslocamento para uma tensão de confinamento de $25 \mathrm{kPa}$ - Equipamento de grandes dimensões

Adicionalmente, como foi realizado no equipamento de pequenas dimensões, a exumação da geogrelha após a execução do ensaio confirmou os resultados mostrados através da Figura 4.18, onde é possível observar o deslocamento mais acentuado nos extremos do corpo de prova e a falha dos nós do elemento longitudinal da extrema direita, justificando assim a queda brusca de resistência (Figura 4.19).
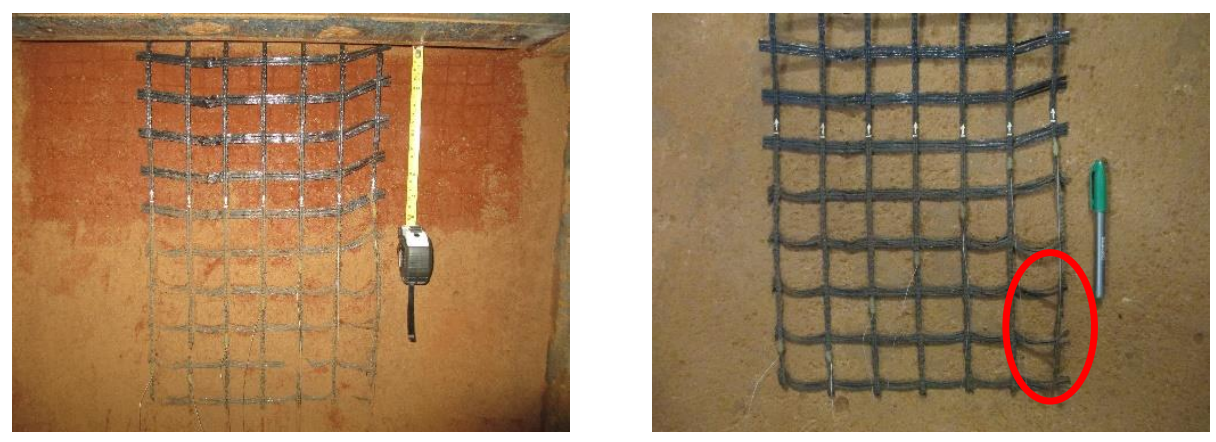

Figura 4.19. Exumação da geogrelha após o ensaio de arrancamento monotônico no equipamento de grandes dimensões $-25 \mathrm{kPa}$

Por outro lado, o tamanho do equipamento de grandes dimensões permitiu a utilização de mais instrumentos de medição, sendo possível analisar a variação da tensão horizontal durante o ensaio por meio dos valores registrados nas células $\mathrm{CTH}_{1}, \mathrm{CTH}_{2} \mathrm{e}$ 
$\mathrm{CTH}_{3}$, localizadas conforme as Figuras 4.15 e 4.16.

Assim, na Figura 4.20 a seguir é mostrado que no instante em que o ensaio inicia, existe uma pequena diminuição nos valores registrados por causa do desconfinamento do solo, o qual é devido ao arrasto de material através dos elementos transversais da geogrelha. Posteriormente, o contínuo movimento do reforço sob a taxa de deslocamento constante, faz com que exista um rearranjo das partículas, evidenciando assim o aumento nos valores das tensões registradas, sendo maior na região central do corpo de prova.

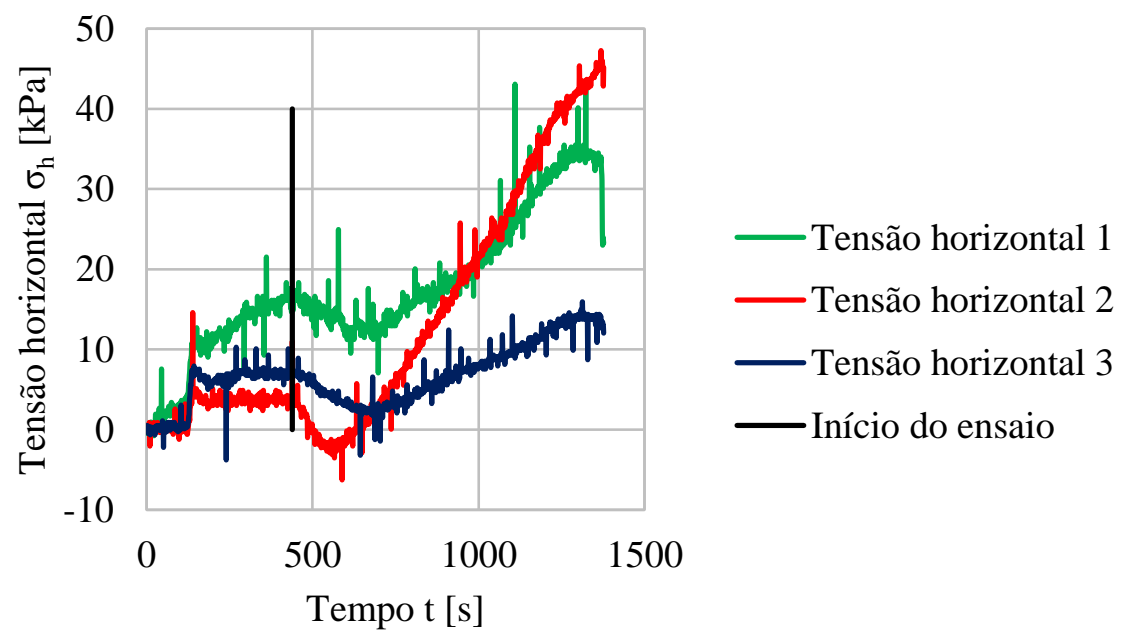

Figura 4.20. Variação da tensão horizontal no ensaio de arrancamento monotônico $25 \mathrm{kPa}$

\subsubsection{Tensão de confinamento de $50 \mathrm{kPa}$}

No caso da tensão de confinamento de $50 \mathrm{kPa}$ também é possível observar o mesmo efeito de borda e sequência de deslocamento nos pontos analisados, pois o primeiro em se deslocar foi o correspondente ao LVDT 2, ponto mais próximo da garra, seguido dos tell-tales 5 e 4, respectivamente (Figura 4.21).

Adicionalmente, o fato dos deslocamentos registrados pelo LVDT 1 (ponto do extremo esquerdo) serem os seguintes na sequência, confirma o efeito de borda causado pelo elevado grau de confinamento na região central da geogrelha, como ocorreu no ensaio mostrado no item anterior (Figura 4.18). 


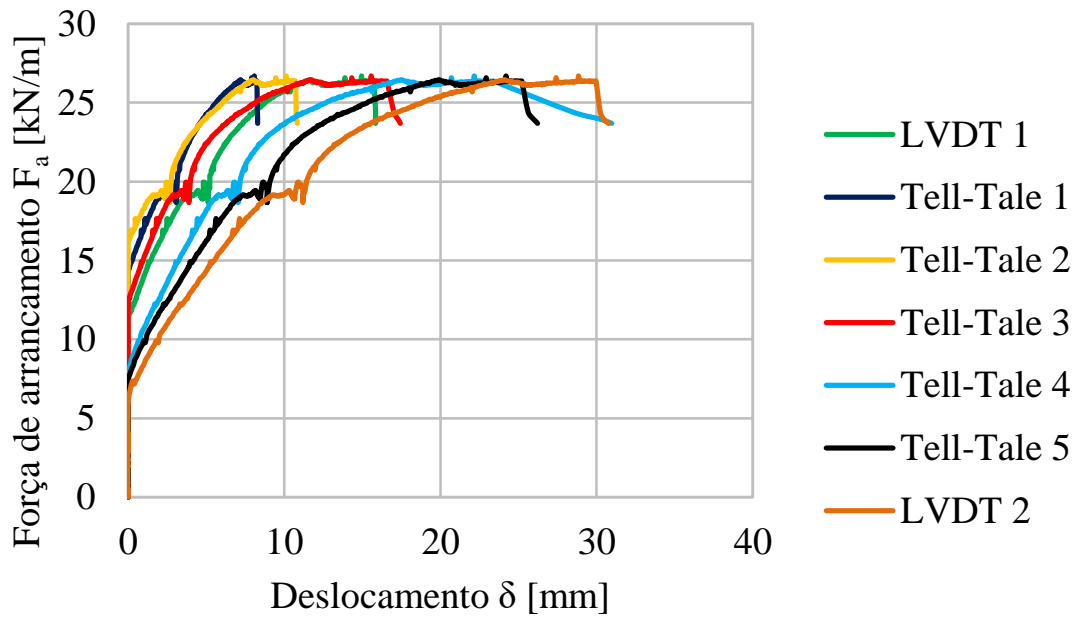

Figura 4.21. Curvas de força de arrancamento $v s$. deslocamento para uma tensão de confinamento de $50 \mathrm{kPa}$ - Equipamento de grandes dimensões

Como complemento ao gráfico anterior, a exumação da geogrelha mostrada na Figura 4.22 a seguir, permite confirmar os resultados obtidos com relação à queda brusca de resistência, pois é possível observar a falha dos nós do elemento longitudinal da extrema direita, como ocorreu no ensaio realizado com a tensão de confinamento de $25 \mathrm{kPa}$.
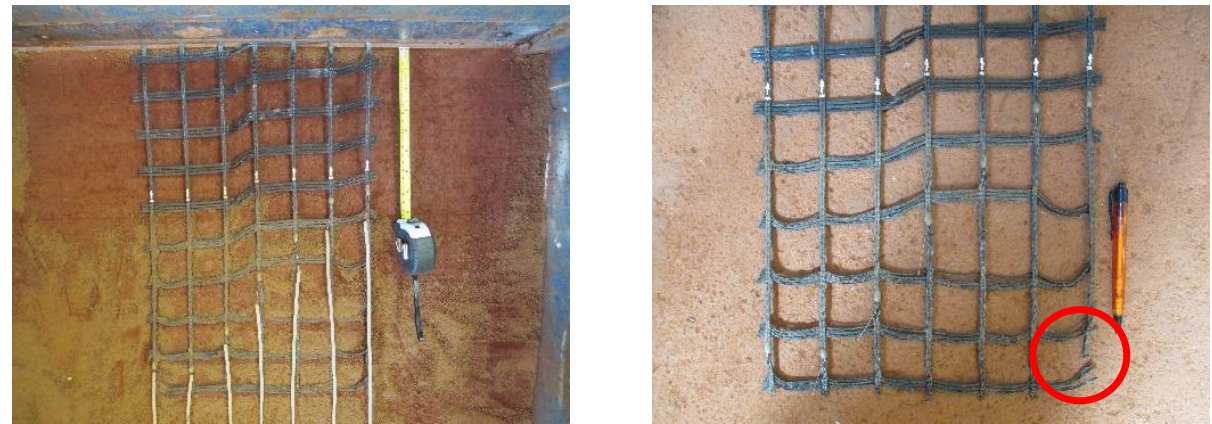

Figura 4.22. Exumação da geogrelha após o ensaio de arrancamento monotônico no equipamento de grandes dimensões - $50 \mathrm{kPa}$

Com relação à variação das tensões horizontais durante este ensaio, é possível afirmar que com relação aos resultados obtidos com a tensão de confinamento de 25 $\mathrm{kPa}$, o comportamento foi o mesmo por causa da ação dos elementos transversais da geogrelha.

Por outro lado, se comparar os gráficos mostrados anteriormente na Figura 4.20 com os da Figura 4.23 a seguir, é possível observar que no trecho final das curvas, 
correspondente ao rearranjo e confinamento das partículas, o efeito tende a ser menos acentuado por causa do solo estar mais confinado no segundo caso (tensão de confinamento de $50 \mathrm{kPa}$ ).

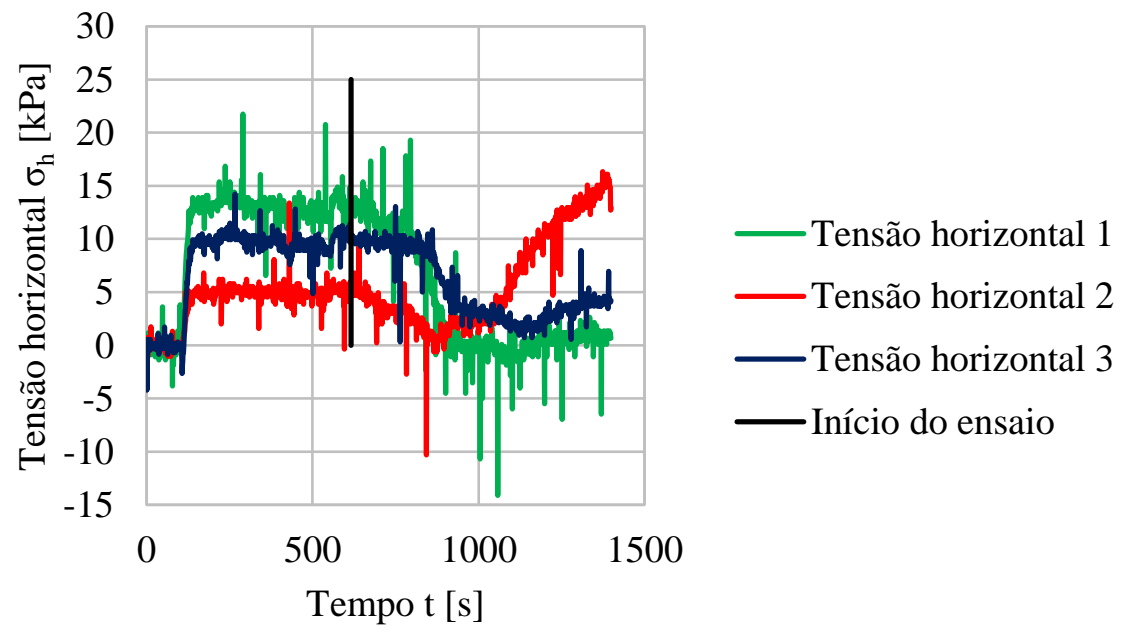

Figura 4.23. Variação da tensão horizontal no ensaio de arrancamento monotônico $50 \mathrm{kPa}$

\subsubsection{Tensão de confinamento de $100 \mathrm{kPa}$}

Ao comparar os resultados mostrados anteriormente (Figuras 4.18 e 4.21 ) com os da tensão de confinamento de $100 \mathrm{kPa}$ (Figura 4.24), percebe-se que no último caso a ruptura ocorreu muito mais rápido do que nos ensaios com tensões de 25 e $50 \mathrm{kPa}$.

Além disso, é possível afirmar que no caso da maior tensão de confinamento, a localização dos pontos de medição (Figura 4.12) tornou-se mais importante na sequência dos deslocamentos registrados, pois os primeiros em aparecer foram os mais próximos da garra e assim sucessivamente até chegar no ponto mais afastado do ponto de aplicação da carga.

Por outro lado, o efeito de borda neste caso não foi tão acentuado como no caso do equipamento de pequenas dimensões, pois o fato de existir um espaço de $20 \mathrm{~cm}$ entre a geogrelha e cada parede da caixa (Figura 4.15), permitiu uma melhor distribuição da maior tensão de confinamento em toda a área do corpo de prova, e não uma concentração de tensões na região central. 


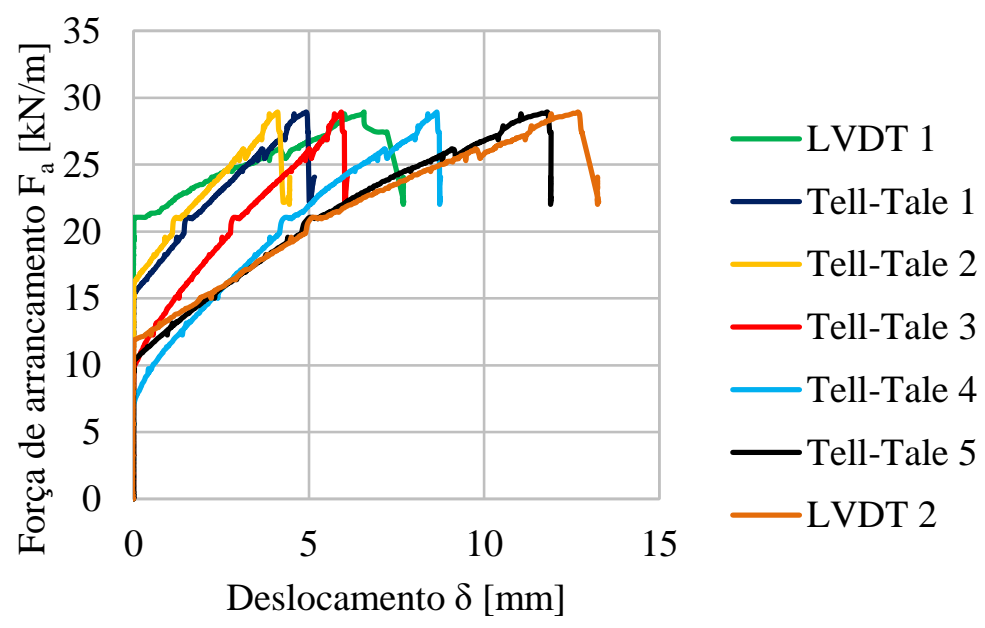

Figura 4.24. Curvas de força de arrancamento $v s$. deslocamento para uma tensão de confinamento de $100 \mathrm{kPa}$ - Equipamento de grandes dimensões

Adicionalmente, com a exumação da geogrelha mostrada na Figura 4.25 a seguir, é confirmada a diminuição do efeito de borda com relação aos resultados obtidos no equipamento de pequenas dimensões, pois a geogrelha apresentou um deslocamento mais homogêneo.

Além disso, o fato da queda de resistência não foi por causa da falha dos nós nos elementos longitudinais extremos, senão pela ruptura de um elemento da região não confinada da geogrelha devido à ação da elevada tensão de confinamento e a sua melhor distribuição em toda a área do corpo de prova, sem existir concentração de tensões na região central.
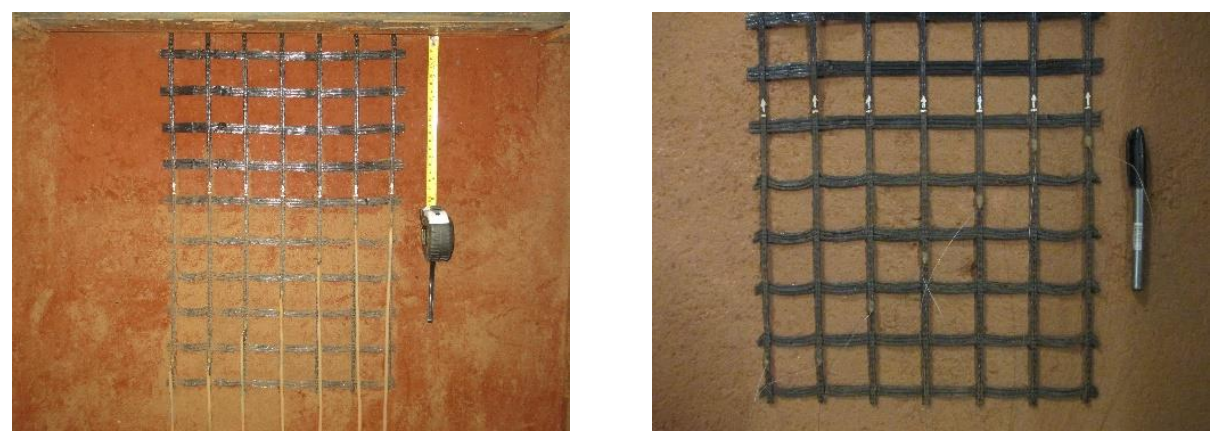


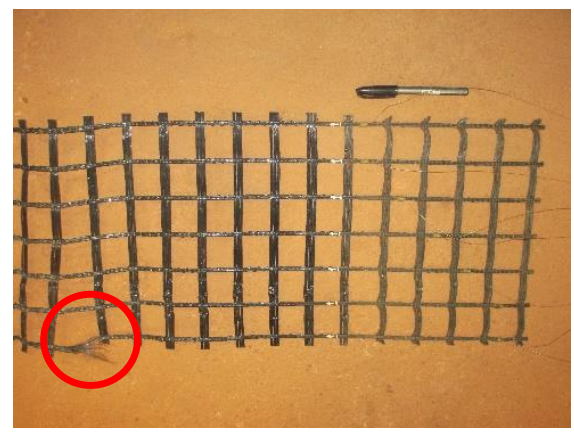

Figura 4.25. Exumação da geogrelha após o ensaio de arrancamento monotônico no equipamento de grandes dimensões - $100 \mathrm{kPa}$

Com relação à variação das tensões horizontais, a partir do início do ensaio com tensão de confinamento de $100 \mathrm{kPa}$, percebe-se a diminuição pronunciada nos valores registrados pelas células de tensão total $\mathrm{CTH}_{1}, \mathrm{CTH}_{2}$ e $\mathrm{CTH}_{3}$, mas, no trecho final das curvas, existe uma pequena tendência de novo aumento, como aconteceu nos casos anteriores.

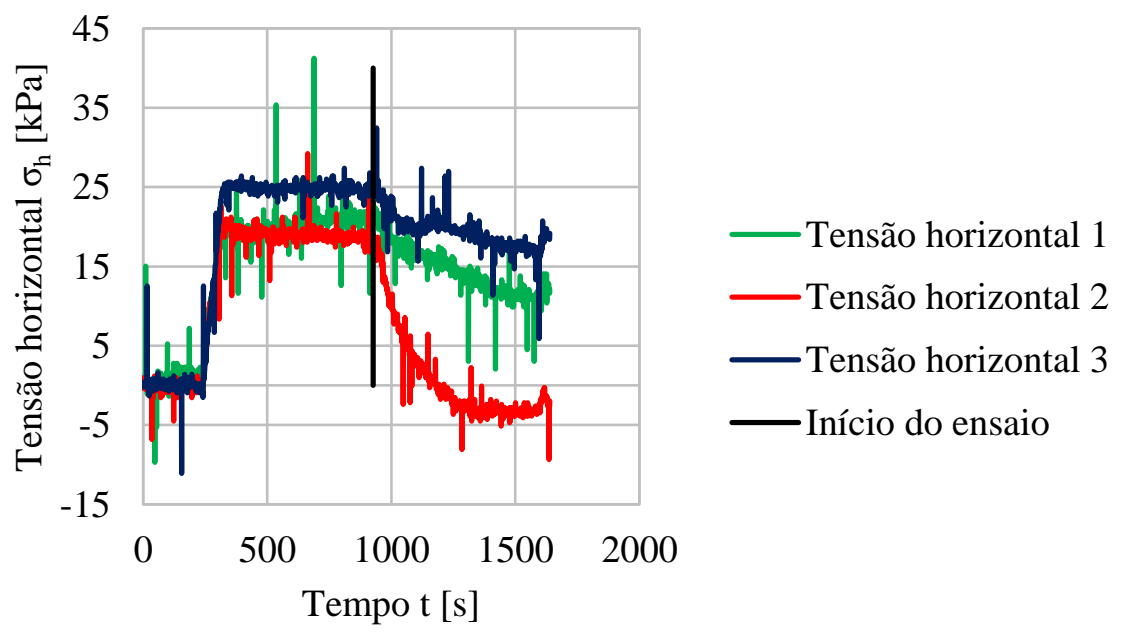

Figura 4.26. Variação da tensão horizontal no ensaio de arrancamento monotônico $100 \mathrm{kPa}$

\subsubsection{Comparação dos resultados obtidos nos dois equipamentos}

Com a recopilação dos resultados de arrancamento monotônico mostrados anteriormente, é possível fazer a respectiva comparação dos fenômenos ocorridos nos dois equipamentos utilizados para a realização dos ensaios. Dessa maneira, a partir dos gráficos da Figura 4.27, onde é mostrada a variação da força de arrancamento versus 
deslocamento para cada tensão de confinamento, percebe-se que à medida que o grau de confinamento aumenta, no equipamento de pequenas dimensões ocorre ruptura só na tensão de $100 \mathrm{kPa}$, enquanto que no equipamento de grandes dimensões, a ruptura é evidenciada nas três tensões $(25,50$ e $100 \mathrm{kPa})$.

Por outro lado, no equipamento de grandes dimensões percebe-se que as curvas obtidas para as tensões de 25 e $50 \mathrm{kPa}$ foram praticamente iguais, caso contrário ao ocorrido no equipamento de pequenas dimensões, onde em ambas ocorreu arrancamento da geogrelha e a curva correspondente à tensão de $50 \mathrm{kPa}$ esteve por cima da obtida para a tensão de $25 \mathrm{kPa}$, o qual seria o esperado para um ensaio de arrancamento.

Assim, o fenômeno ocorrido é justificado por causa da diferença no grau de confinamento do reforço em ambos os equipamentos, sendo maior no de grandes dimensões por causa da melhor distribuição das tensões sobre o corpo de prova, tal como foi comentado anteriormente nas análises realizadas para cada tensão de confinamento.

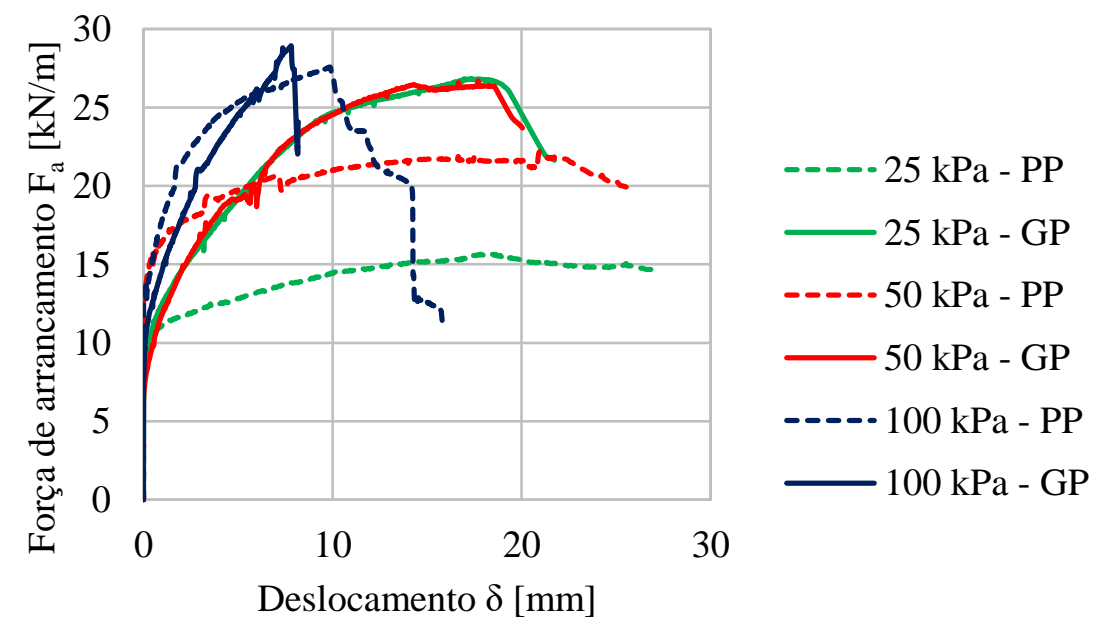

Figura 4.27. Comparação das curvas de força de arrancamento vs. deslocamento, $\mathrm{PP}=$ pequeno porte, $\mathrm{GP}=$ grande porte

Com relação às envoltórias de resistência ao arrancamento obtidas a partir dos ensaios realizados nos dois equipamentos (Figura 4.28), é possível afirmar que a diferença entre as duas deve-se ao grau de confinamento da geogrelha em cada equipamento, o qual foi maior no de grandes dimensões por causa da melhor distribuição das tensões. 
Em complemento ao anterior, apesar dos fenômenos acontecidos em ambos os equipamentos terem sido diferentes, como comentado nas análises realizadas anteriormente para cada tensão de confinamento, as envoltórias de resistência permitem ter uma noção da interação entre o solo e a geogrelha, sendo que em ambos equipamentos o parâmetro mais influente foi a adesão $(a)$, mas foi maior no de grandes dimensões.

Assim, é possível concluir que para as condições de compactação e tipos de solo utilizados, o ideal teria sido utilizar uma geogrelha com maior resistência à tração, pois o fato de não existir ruptura da inclusão, permitiria obter melhores resultados com relação à interação entre o solo e o reforço, e portanto, melhores comparações relacionadas ao efeito escala entre os dois equipamentos disponíveis no Laboratório de Geossintéticos da EESC-USP.

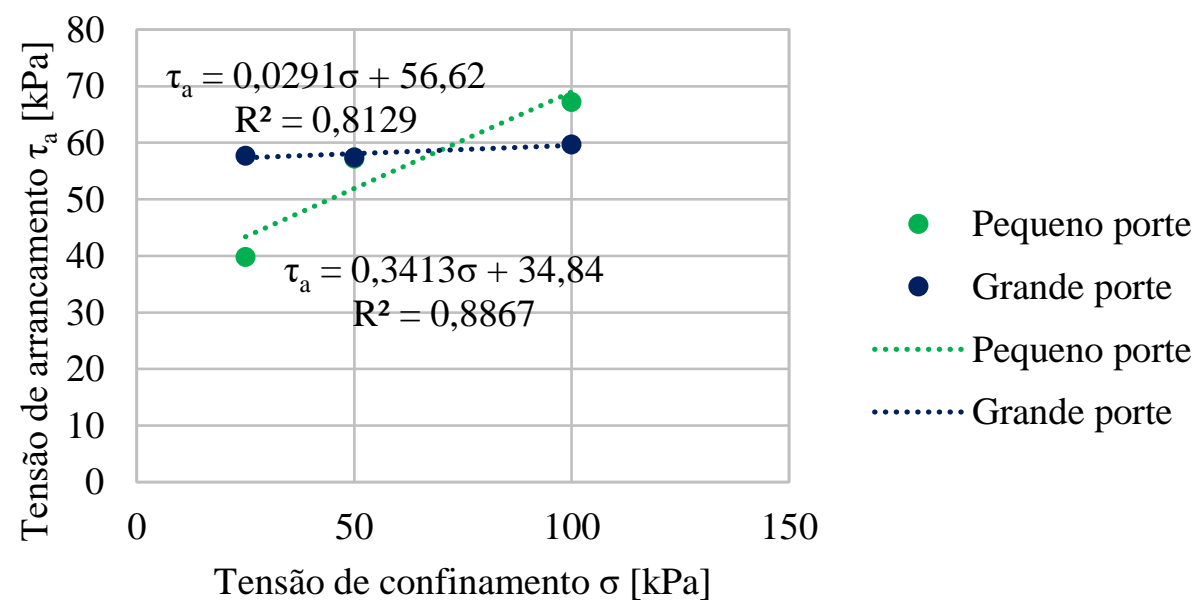

Figura 4.28. Comparação das envoltórias de resistência ao arrancamento

\subsubsection{Tensão de confinamento de $25 \mathrm{kPa}$}

Como complemento às análises realizadas anteriormente de maneira geral, na Figura 4.29 a seguir é mostrada a comparação dos resultados obtidos nos dois equipamentos para a tensão de confinamento de $25 \mathrm{kPa}$, onde é possível observar a diferença na resistência ao arrancamento e a queda brusca no trecho final da curva correspondente ao equipamento de grandes dimensões, evidenciando assim que houve ruptura no equipamento de grandes dimensões e não no de pequenas dimensões. 


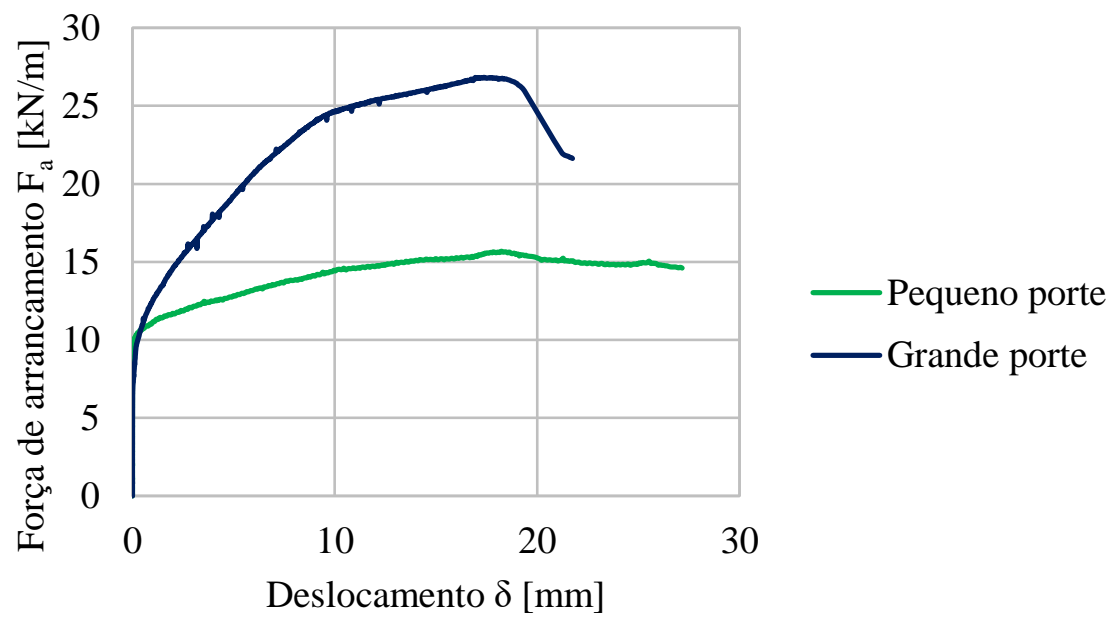

Figura 4.29. Comparação das curvas de força de arrancamento vs. deslocamento Tensão de confinamento de $25 \mathrm{kPa}$

Adicionalmente, com a exumação das geogrelhas utilizadas nos ensaios de arrancamento monotônico com a menor tensão de confinamento (Figura 4.30), confirmam-se as análises realizadas anteriormente, pois $\mathrm{o}$ fato da amostra correspondente ao equipamento de pequenas dimensões ter apresentado maiores deformações do que a do equipamento de grandes dimensões, demonstra uma melhor distribuição das tensões de confinamento no segundo caso.

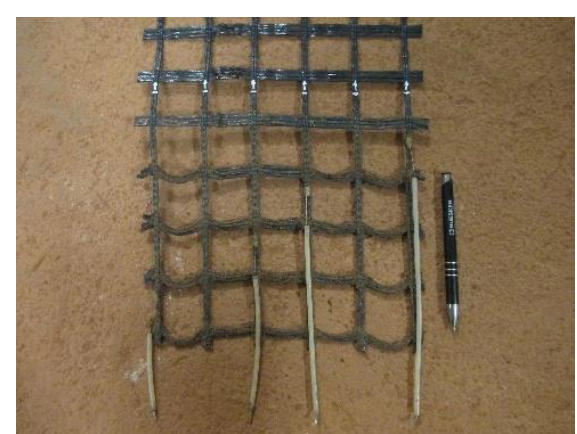

a. Pequenas dimensões

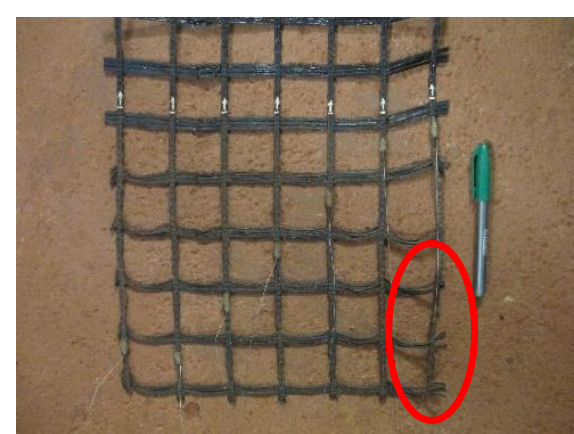

b. Grandes dimensões

Figura 4.30. Exumação das geogrelhas após os ensaios de arrancamento monotônico nos dois equipamentos $-25 \mathrm{kPa}$

Além disso, na Tabela 4.5 a seguir mostra-se que no equipamento de grandes dimensões, o valor da resistência ao arrancamento teve um incremento de $71 \%$ com relação ao obtido no equipamento de pequenas dimensões. 
Tabela 4.5. Comparação dos valores de resistência de arrancamento - $25 \mathrm{kPa}$

\begin{tabular}{ccc}
\hline Equipamento & Resistência ao arrancamento $[\mathbf{k N / m}]$ & $\mathbf{G p / P p}$ \\
\hline Pequeno porte & 15,68 & 1,71 \\
Grande porte & 26,83 & \\
\hline
\end{tabular}

\subsubsection{Tensão de confinamento de $50 \mathrm{kPa}$}

No caso dos resultados obtidos nos dois equipamentos para a tensão de confinamento de $50 \mathrm{kPa}$, observa-se uma tendência das curvas de força de arrancamento versus deslocamento estarem mais próximas entre si (Figura 4.31), confirmando assim que à medida que a tensão de confinamento aumenta, a distribuição de tensões no corpo de prova tende a ser mais homogênea.

Além disso, para esta tensão de confinamento é ainda possível observar o arrancamento da geogrelha no equipamento de pequenas dimensões, pois não houve queda brusca no comportamento da curva respectiva, caso contrário ao acontecido no equipamento de grandes dimensões.

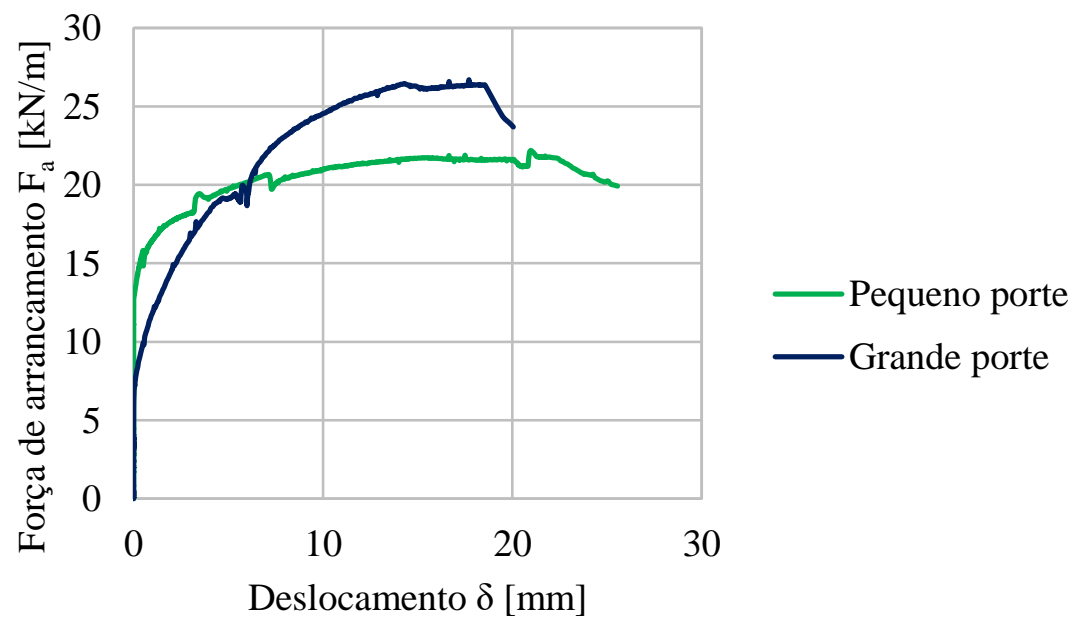

Figura 4.31. Comparação das curvas de força de arrancamento vs. deslocamento Tensão de confinamento de $50 \mathrm{kPa}$

Dessa maneira, ao comparar os valores de resistência ao arrancamento obtidos em ambos os equipamentos para a tensão de confinamento de $50 \mathrm{kPa}$, confirma-se a proximidade dos valores em comparação aos resultados obtidos com a tensão de 
confinamento de $25 \mathrm{kPa}$, pois neste caso o incremento do valor registrado no equipamento de grandes dimensões em relação ao de pequenas dimensões foi de $20 \%$ (Tabela 4.6), sendo 51\% menor em relação ao caso anterior.

Tabela 4.6. Comparação dos valores de resistência de arrancamento - $50 \mathrm{kPa}$

\begin{tabular}{ccc}
\hline Equipamento & Resistência ao arrancamento $[\mathbf{k N} / \mathbf{m}]$ & $\mathbf{G p / P p}$ \\
\hline Pequeno porte & 22,19 & 1,20 \\
Grande porte & 26,70 & \\
\hline
\end{tabular}

Como complemento às análises realizadas anteriormente, a exumação das geogrelhas utilizadas nos ensaios de arrancamento monotônico com tensão de confinamento de $50 \mathrm{kPa}$ (Figura 4.32), confirma os resultados mostrados anteriormente na Figura 4.31, pois a queda brusca observada na curva correspondente ao equipamento de grandes dimensões é evidenciada na falha do nó inferior direito da inclusão, enquanto que a amostra correspondente ao equipamento de pequenas dimensões não apresentou ruptura nem falha em algum elemento ou nó, respectivamente.

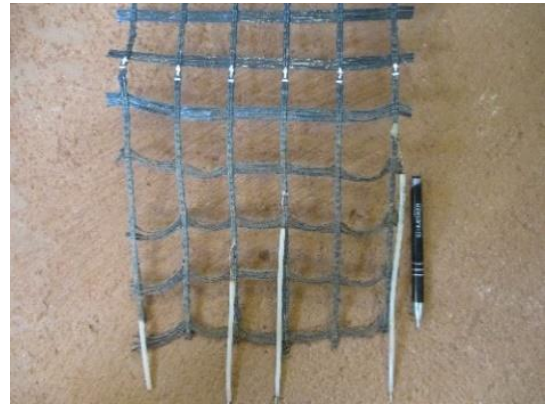

a. Pequenas dimensões

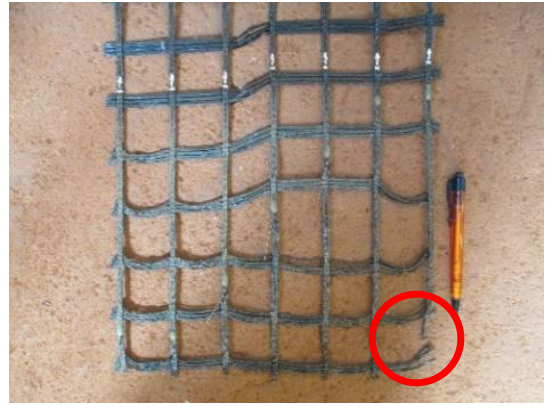

b. Grandes dimensões

Figura 4.32. Exumação das geogrelhas após os ensaios de arrancamento monotônico nos dois equipamentos $-50 \mathrm{kPa}$

\subsubsection{Tensão de confinamento de $100 \mathrm{kPa}$}

Levando em consideração as comparações realizadas anteriormente para as tensões de 25 e $50 \mathrm{kPa}$, no caso da tensão de confinamento de $100 \mathrm{kPa}$ confirma-se a tendência observada, pois a proximidade entre as curvas de força de arrancamento 
versus deslocamento é claramente evidenciada, sendo que em ambas situações ocorreu ruptura da inclusão.

Assim, a anterior afirmação é confirmada pela queda brusca no trecho final das curvas mostradas na Figura 4.33 a seguir.

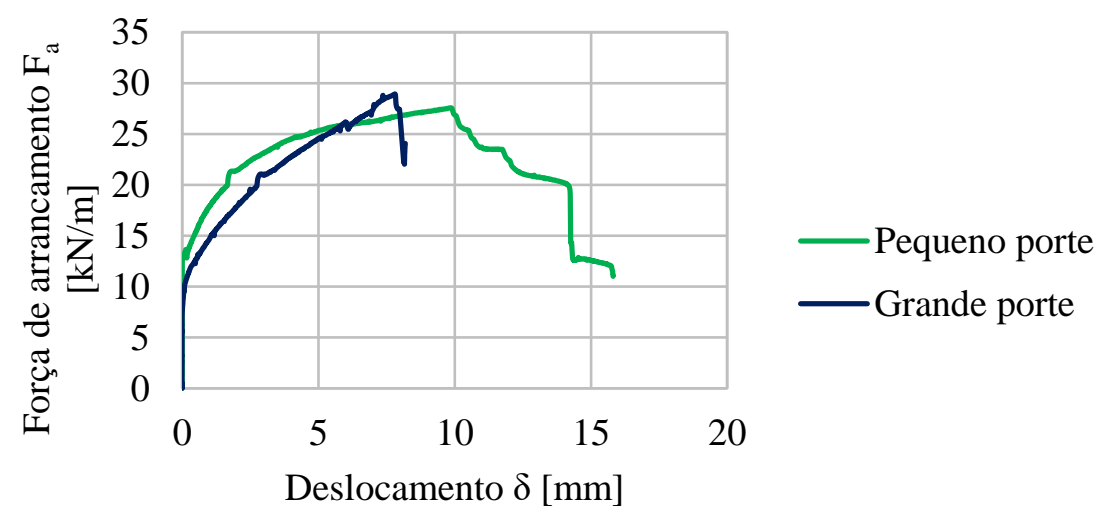

Figura 4.33. Comparação das curvas de força de arrancamento vs. deslocamento Tensão de confinamento de $100 \mathrm{kPa}$

Tal como foi realizado nos casos anteriores, ao comparar os valores de resistência ao arrancamento obtidos em ambos os equipamentos para a tensão de confinamento de $100 \mathrm{kPa}$, confirma-se a proximidade dos valores em comparação aos resultados obtidos com as tensões de confinamento de 25 e $50 \mathrm{kPa}$, pois neste caso, o incremento do valor registrado no equipamento de grandes dimensões em relação ao de pequenas dimensões foi de $5 \%$ (Tabela 4.7), apresentando uma diferença de $15 \%$ em relação aos resultados obtidos com a tensão de $50 \mathrm{kPa}$.

Tabela 4.7. Comparação dos valores de resistência de arrancamento - $100 \mathrm{kPa}$

\begin{tabular}{ccc}
\hline Equipamento & Resistência ao arrancamento [kN/m] & Gp/Pp \\
\hline Pequeno porte & 27,57 & 1,05 \\
Grande porte & 28,93 & \\
\hline
\end{tabular}

Por outro lado, a exumação das geogrelhas utilizadas nos ensaios de arrancamento monotônico com a maior tensão de confinamento (Figura 4.34), confirma a queda brusca de resistência observada anteriormente nas curvas da Figura 4.33, pois a amostra utilizada no equipamento de pequenas dimensões apresentou falha nos nós 
dos extremos inferiores, e a do equipamento de grandes dimensões ruptura em um elemento longitudinal da região não confinada.

Assim, evidencia-se mais uma vez a concentração de tensões na região central da geogrelha do equipamento de pequenas dimensões e a melhor distribuição das tensões no de grandes dimensões, pois o efeito de borda foi mais acentuado no primeiro caso e o elevado grau de confinamento no segundo deixou tão presa a inclusão que ocorreu ruptura de um elemento longitudinal na região não confinada.

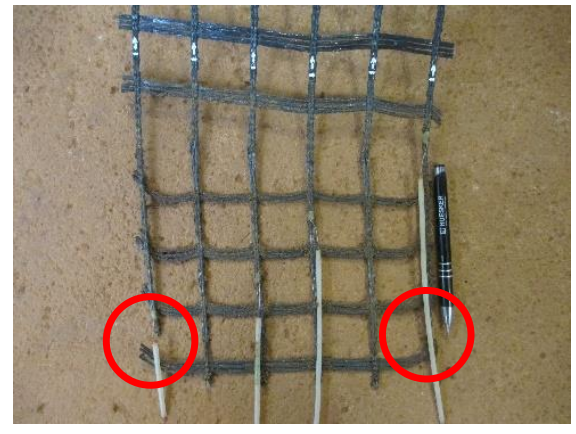

a. Pequenas dimensões

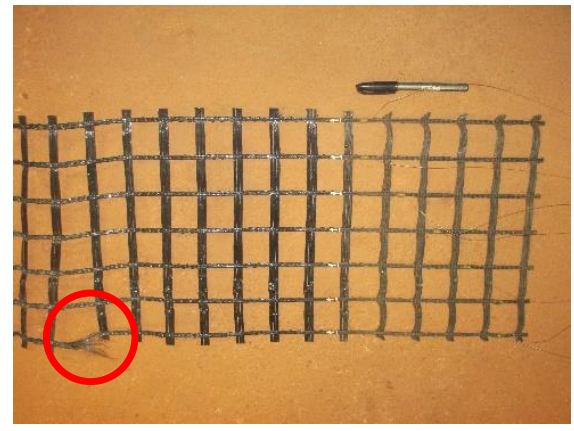

b. Grandes dimensões

Figura 4.34. Exumação das geogrelhas após os ensaios de arrancamento monotônico nos dois equipamentos $-100 \mathrm{kPa}$

\subsection{Arrancamento cíclico}

Como foi comentado no início do capítulo, a realização dos ensaios de arrancamento cíclico dependeu dos resultados obtidos nos ensaios de arrancamento monotônico, pois as amplitudes de carga de cada ciclo correspondiam a uma parcela das resistências obtidas para as tensões de confinamento de 25 e $100 \mathrm{kPa}$ em cada equipamento.

O fato de terem sido utilizadas duas tensões de confinamento nos ensaios de arrancamento cíclico deve-se à consideração das condições menos e mais crítica numa estrutura de pavimento (25 e $100 \mathrm{kPa}$, respectivamente), com alguns ajustes relacionados a limitações de precisão dos manômetros utilizados para o controle da tensão aplicada, às capacidades das bolsas de ar responsáveis pela aplicação da tensão de confinamento, e também, ao grau de confinamento da geogrelha na estrutura de solo reforçado, como foi mostrado no Capítulo 3.

As amplitudes de carga para cada ciclo foram definidas com base nas limitações 
dos equipamentos disponíveis no Laboratório de Geossintéticos da EESC-USP, e nos critérios adotados por Napa G. (2011) e Campos (2013), cujas pesquisas foram desenvolvidas no mesmo laboratório.

Dessa maneira, a amplitude de carga foi definida em $20 \%$ do valor da resistência ao arrancamento monotônico para cada tensão de confinamento, e o limite inferior, ou tensão de repouso, foi estimado de acordo ao descrito na norma ASTM D 7499 M - 09, sendo eles de 0,9 kPa para a tensão de confinamento de $25 \mathrm{kPa}$, e de $3,6 \mathrm{kPa}$ para a tensão de confinamento de $100 \mathrm{kPa}$.

Por outro lado, para a definição da frequência do carregamento cíclico relacionada à passagem dos veiculos, levaram-se em consideração as recomendações do Programa Nacional de Pesquisa Cooperativa de Rodovias (NCHRP, 2004), onde indicase que a determinação do módulo de resiliência para o dimensionamento de pavimentos flexíveis deve ser realizada através da aplicação de uma função de carga sinusoidal padronizada, conhecida como "onda haversine", cujo ciclo é constituído por um pulso de carga com duração de 0,1 segundos e por um período de descanso de 0,9 segundos.

No entanto, o sistema hidráulico de aplicação de carga utilizado não permite chegar nos tempos recomendados pelo Programa Nacional de Pesquisa Cooperativa de Rodovias (NCHRP, 2004) para o pulso de carga e período de descanso. Assim, por causa das limitações do sistema e do controlador lógico programável para a aplicação do carregamento cíclico, foram aplicados pulsos de carga e períodos de descanso de 0,5 segundos para cada ciclo, chegando assim na frequência de $1 \mathrm{~Hz}$ requerida.

Adicionalmente, durante os ensaios de arrancamento cíclico foi atingida a capacidade do equipamento correspondente a 10.000 ciclos de carga sem acontecer falha do sistema nem ruptura da geogrelha por fadiga. Por causa disso, após atingir os 10.000 ciclos de carga, decidiu-se aplicar um carregamento monotônico com o intuito de comparar a sua resistência residual com a resistência ao arrancamento monotônico inicial, e assim poder verificar o efeito da ciclagem na estrutura de solo reforçado, como fizeram Moraci e Cardile (2009) e Nayeri e Fakharian (2009).

Com base no anterior, a seguir são mostrados os resultados obtidos durante os ensaios de arrancamento cíclico em cada um dos equipamentos utilizados, levando em consideração as resistências ao arrancamento monotônico correspondentes às tensões de confinamento de 25 e $100 \mathrm{kPa}$. 


\subsubsection{Equipamento de pequenas dimensões}

Similar aos ensaios de arrancamento monotônico, o equipamento de pequenas dimensões foi adaptado à caixa metálica de grandes dimensões por meio de um suporte metálico, com o intuito de poder utilizar o mesmo sistema de aplicação de cargas.

Tal como foi explicado anteriormente, tanto no equipamento de pequenas como de grandes dimensões, os ciclos de carga foram aplicados com uma frequência de $1 \mathrm{~Hz}$, sendo dividida em pulsos de carga e períodos de descanso de 0,5 segundos por causa das limitações do sistema de aplicação de carga. Além disso, tiveram-se considerações especiais com relação às amplitudes de carga e às cargas de repouso, as quais foram definidas com relação aos resultados de arrancamento monotônico e à norma ASTM D 7499 M - 09, respectivamente.

Com relação ao registro das tensões de confinamento durante os ensaios de arrancamento cíclico, percebeu-se que no momento de execução do primeiro ensaio, a célula de tensão total utilizada não registrou nenhum valor. Por causa disso e, ao ser a única disponível com saída do fio no mesmo plano, não foi possível conhecer a variação da tensão de confinamento durante a aplicação dos ciclos de carga, pois uma célula com saída do fio em sentido perpendicular ao plano de medição das tensões, alteraria o grau de compactação da camada de solo argiloso abaixo da geogrelha, pois precisaria de um furo com uma profundidade equivalente à espessura da camada.

Por outro lado, durante os ensaios de arrancamento cíclico também foi percebido que no momento em que a garra tracionava a geogrelha em cada ciclo de carga, a caixa de pequenas dimensões movimentava-se acompanhando o deslocamento da inclusão enquanto era tracionada, o qual foi por causa de estar fixa só na parede frontal do equipamento de grandes dimensões e não nas paredes laterais, como também pela falta de rigidez da parede frontal do mesmo equipamento.

Como será mostrado nos resultados obtidos para cada tensão de confinamento, não é possível enxergar os ciclos nos gráficos de força versus deslocamento, pois os telltales não conseguiram registrar os deslocamentos da geogrelha durante a ciclagem, sendo assim indispensável uma adequação do suporte para os próximos ensaios a serem realizados com o mesmo equipamento, onde também é preciso fixá-lo às paredes laterais do equipamento de grandes dimensões, além de enrijecer a sua parede frontal e dessa maneira evitar a sua deformação durante a aplicação dos ciclos de carga. 
Assim, na Tabela 4.8 e Figuras 4.35 e 4.36 a seguir, são mostrados respectivamente os parâmetros de carga cíclica, um detalhe da variação da carga aplicada ao longo do tempo e o comportamento do arrancamento cíclico e da resistência pós-ciclagem para as duas tensões de confinamento aplicadas (25 e $100 \mathrm{kPa}$ ), sendo que na Figura 4.36 somente é mostrado o trecho correspondente à resistência pós-ciclagem por causa do problema relacionado à movimentação da caixa durante a aplicação dos ciclos de carga.

Tabela 4.8. Parâmetros de carga cíclica no equipamento de pequenas dimensões

\begin{tabular}{cccc}
\hline $\begin{array}{c}\text { Tensão de } \\
\text { confinamento } \\
{[\mathbf{k P a}]}\end{array}$ & $\begin{array}{c}\text { Resistência ao arrancamento } \\
\text { monotônico } \\
{[\mathbf{k g f}]}\end{array}$ & $\begin{array}{c}\text { Amplitude de } \\
\text { carga por ciclo } \\
{[\mathbf{k g f}]}\end{array}$ & $\begin{array}{c}\text { Carga de } \\
\text { repouso } \\
{[\mathbf{k g f}]}\end{array}$ \\
\hline 25 & 415,58 & 78,12 & 5 \\
100 & 730,77 & 126,15 & 20 \\
\hline
\end{tabular}

No detalhe da variação da carga cisalhante ao longo do tempo mostrado na Figura 4.35 a seguir, mostra-se que as amplitudes de carga aplicadas durante o ensaio foram realmente as especificadas na Tabela 4.8, as quais foram estimadas com base nos resultados obtidos nos ensaios de arrancamento monotônico e na norma ASTM D 7499 M - 09.

Além disso, é ainda possível perceber que o período do carregamento cíclico foi evidentemente de um segundo, como sugerido pelo Programa Nacional de Pesquisa Cooperativa de Rodovias (NCHRP, 2004) para levar em consideração o efeito dinâmico do tráfego. 


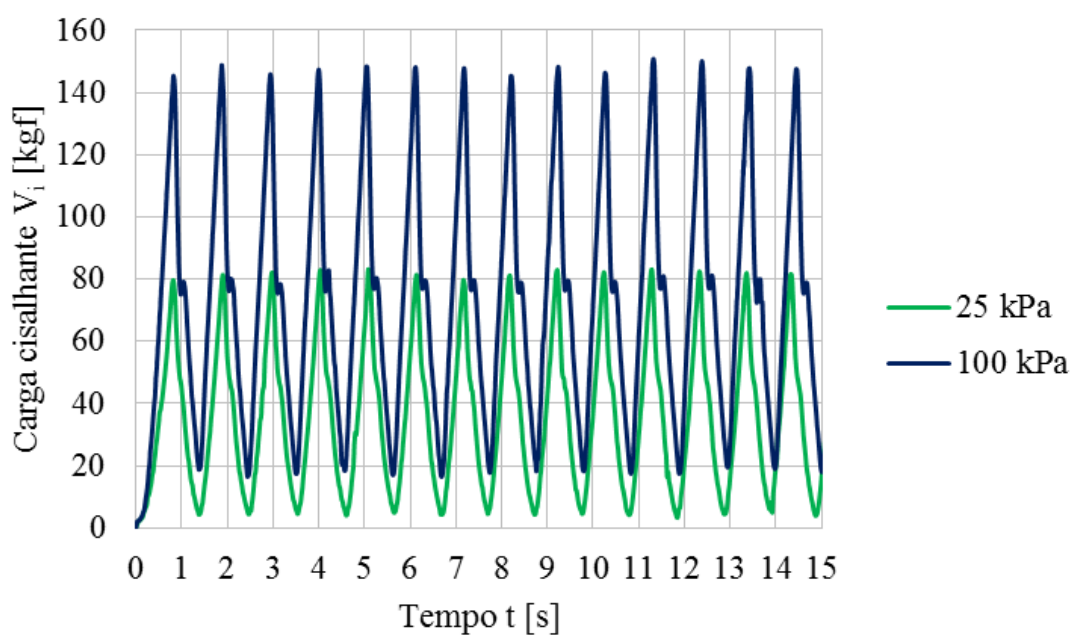

Figura 4.35. Detalhe da variação da carga cisalhante ao longo do tempo no equipamento de pequenas dimensões durante os primeiros 15 segundos

Com relação ao comportamento da força de arrancamento após a aplicação dos 10.000 ciclos de carga, na Figura 4.36 mostrada a seguir percebe-se a ocorrência de ruptura da geogrelha no caso da maior tensão de confinamento, a qual é evidenciada na queda brusca de resistência.

Por outro lado, o comportamento apresentado no caso da menor tensão de confinamento é de arrancamento, mesmo tendo uma pequena queda no trecho final que pode ser por causa de uma eventual compactação do material como consequência do carregamento cíclico.

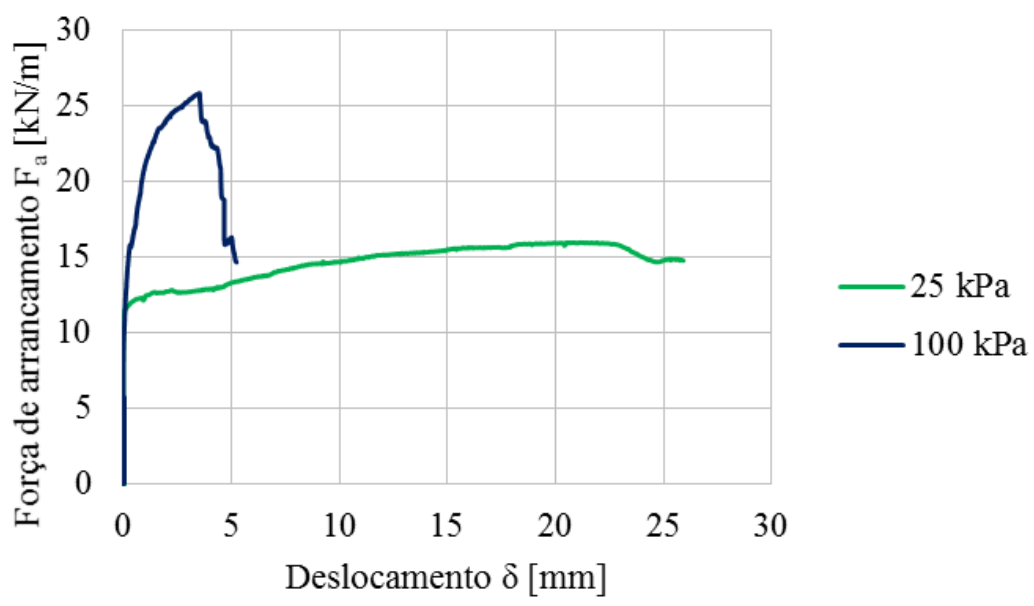

Figura 4.36. Arrancamento cíclico e resistência pós-ciclagem no equipamento de pequenas dimensões 
Em complemento aos resultados anteriores, a seguir é mostrada a variação da força de arrancamento após a aplicação dos ciclos de carga para cada tensão de confinamento (25 e $100 \mathrm{kPa}$ ), assim como a sua respectiva comparação com os resultados obtidos inicialmente nos ensaios de arrancamento monotônico.

\subsubsection{Tensão de confinamento de $25 \mathrm{kPa}$}

Analisando os resultados de arrancamento monotônico e de resistência pósciclagem separadamente para cada tensão de confinamento, observa-se que no caso da menor tensão de confinamento foram bastante similares, ocorrendo arrancamento da inclusão em ambos casos, mas tendo uma leve diferença no trecho inicial e final das curvas (Figura 4.37).

No caso do arrancamento monotônico inicial, observa-se um arrancamento quase perfeito da inclusão, enquanto que a variação da força após a aplicação dos 10.000 ciclos de carga mostra um pequeno aumento nos trechos inicial e final da curva, finalizando numa diminuição um pouco mais acentuada nos valores registrados.

Como foi comentado anteriormente, apesar de ter existido arrancamento da inclusão sem ruptura, essa pequena mudança na curva pode ser por causa de uma leve compactação do material devida ao efeito dinâmico do carregamento, a qual fez que a resistência pós-ciclagem fosse um pouco maior em comparação com a obtida inicialmente no ensaio de arrancamento monotônico.

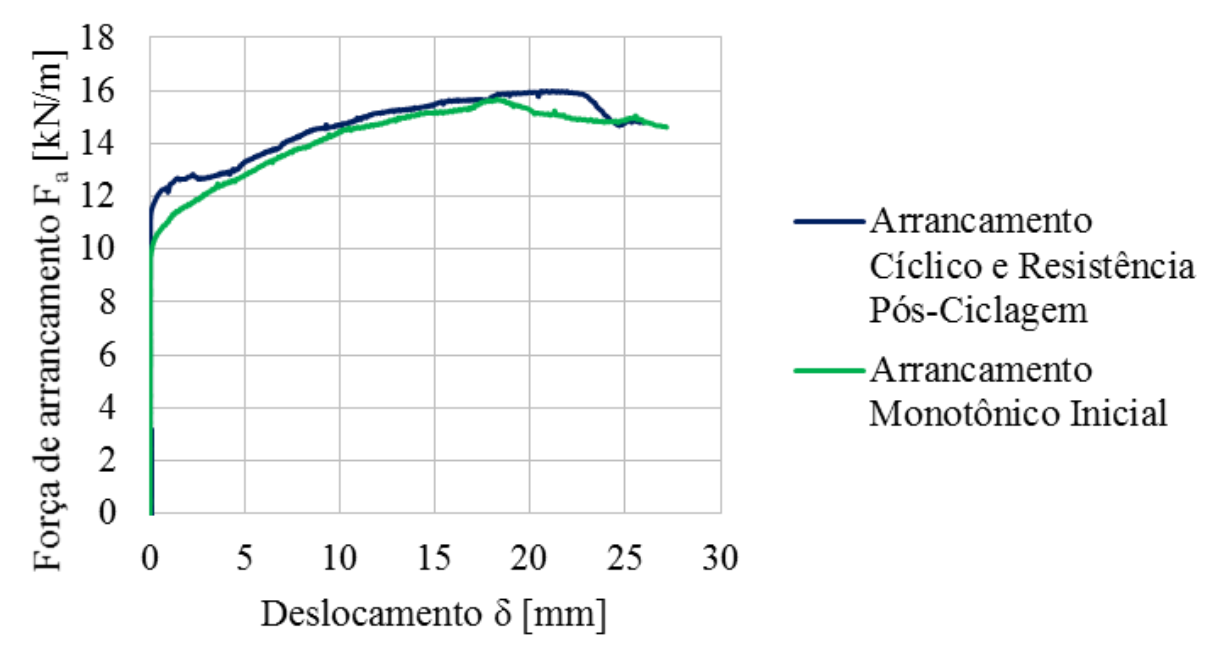

Figura 4.37. Resistência pós-ciclagem e resistência ao arrancamento monotônico no equipamento de pequenas dimensões $-25 \mathrm{kPa}$ 
Dessa maneira, na Tabela 4.9 a seguir confirma-se a afirmação realizada anteriormente, pois o efeito dinâmico do carregamento tornou o material um pouco mais compacto e fez com que a resistência pós-ciclagem fosse levemente maior do que a obtida inicialmente no ensaio de arrancamento, apresentando uma diferença percentual de $1,92 \%$.

Tabela 4.9. Valores de resistência ao arrancamento monotônico inicial e pósciclagem no equipamento de pequenas dimensões $-25 \mathrm{kPa}$

\begin{tabular}{lc}
\hline Resistência ao arrancamento monotônico [kN/m] \\
\hline Inicial & 15,68 \\
Pós-ciclagem & 15,98 \\
Diferença percentual & $1,92 \%$ \\
\hline
\end{tabular}

Adicionalmente, com a exumação da geogrelha após a realização do ensaio de arrancamento cíclico e de resistência pós-ciclagem mostrada na Figura 4.38 a seguir, além da inexistência de ruptura e falha em algum elemento ou nó, respectivamente, foi observado o mesmo efeito de borda apresentado no ensaio de arrancamento monotônico inicial para a tensão de confinamento de $25 \mathrm{kPa}$, onde os elementos transversais apresentaram maiores deformações nos extremos laterais do corpo de prova, correspondentes à região menos confinada.

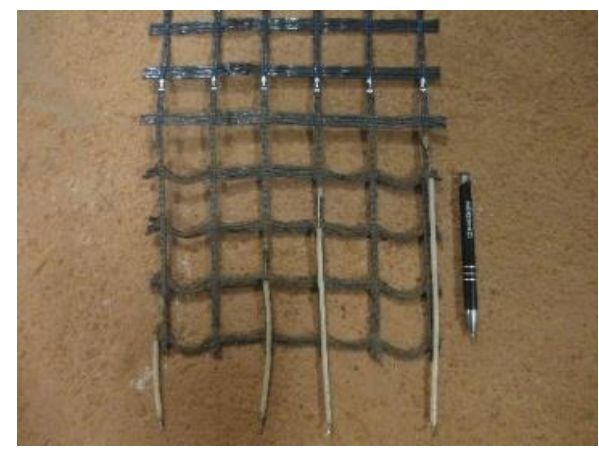

a. Arrancamento monotônico inicial

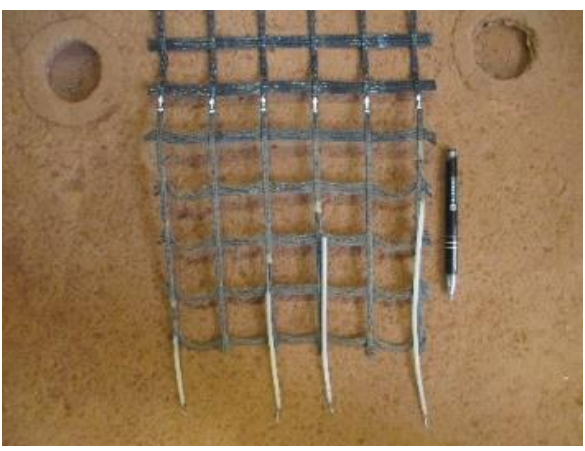

b. Arrancamento cíclico e resistência pós-ciclagem

Figura 4.38. Exumação das geogrelhas após os ensaios de arrancamento monotônico e cíclico no equipamento de pequenas dimensões - $25 \mathrm{kPa}$ 


\subsubsection{Tensão de confinamento de $100 \mathrm{kPa}$}

Considerando que o grau de compactação do solo foi o mesmo nos dois casos $(25$ e $100 \mathrm{kPa})$, e portanto, a estrutura interna do solo dentro da caixa, o comportamento após a aplicação do carregamento dinâmico deve ter uma tendência semelhante ao caso anterior (tensão de confinamento de $25 \mathrm{kPa}$ ), gerando assim um aumento na resistência em comparação à obtida inicialmente nos ensaios de arrancamento monotônico realizados no equipamento de pequenas dimensões.

Dessa maneira, a análise anterior é confirmada com os gráficos mostrados na Figura 4.39 a seguir, pois apesar da resistência obtida após a aplicação dos 10.000 ciclos de carga ter sido menor do que a do ensaio de arrancamento monotônico por causa da ruptura da geogrelha, o comportamento da curva de resistência pós-ciclagem apresenta uma tendência a ser superior e estar por cima da correspondente ao arrancamento monotônico inicial, apresentando também um afastamento um pouco maior do que no caso da menor tensão de confinamento.

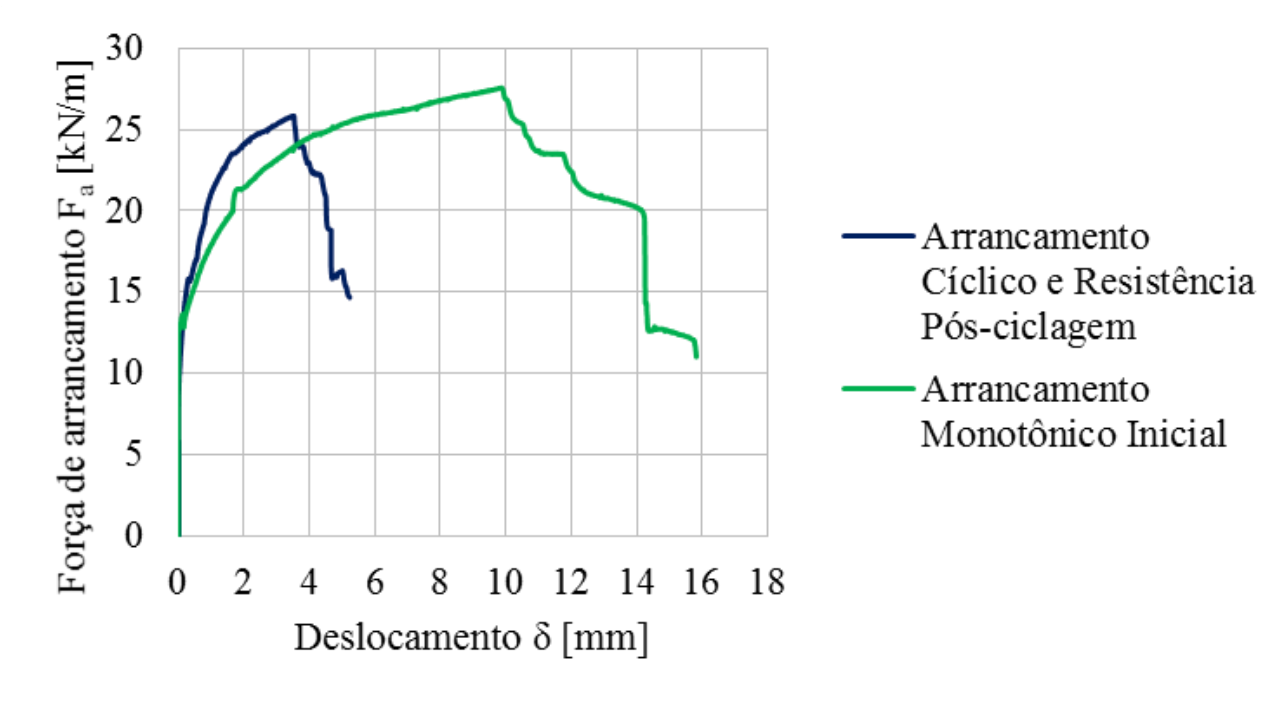

Figura 4.39. Resistência pós-ciclagem e resistência ao arrancamento monotônico no equipamento de pequenas dimensões - $100 \mathrm{kPa}$

Por outro lado, na Tabela 4.10 a seguir são mostrados os valores de resistência obtidos tanto no ensaio de arrancamento monotônico como no de resistência pósciclagem, onde é possível observar que os valores obtidos apresentaram uma diferença percentual de $6,29 \%$ por causa da ruptura da inclusão em ambos casos. 
Tabela 4.10. Valores de resistência ao arrancamento monotônico inicial e pósciclagem no equipamento de pequenas dimensões $-100 \mathrm{kPa}$

\begin{tabular}{lc}
\hline \multicolumn{2}{l}{ Resistência ao arrancamento monotônico [kN/m] } \\
\hline Inicial & 27,57 \\
Pós-ciclagem & 25,84 \\
Diferença percentual & $6,29 \%$ \\
\hline
\end{tabular}

Adicionalmente, com a exumação da geogrelha mostrada na Figura 4.40 a seguir, confirma-se a análise realizada anteriormente com relação aos resultados obtidos no equipamento de pequenas dimensões, pois com a falha de um nó do corpo de prova na região não confinada, evidencia-se a compactação do material e, portanto, o aumento do grau de confinamento do reforço na região central por causa do carregamento dinâmico.

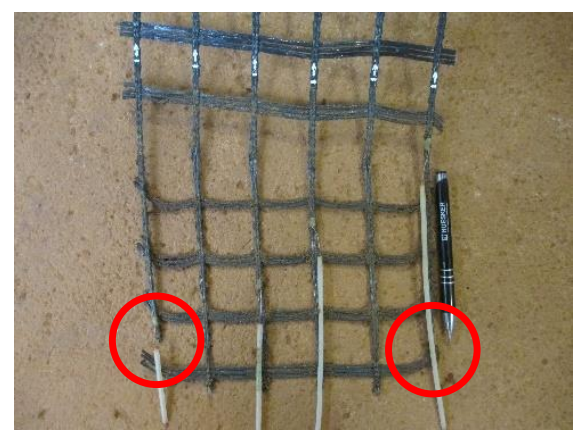

a. Arrancamento monotônico inicial

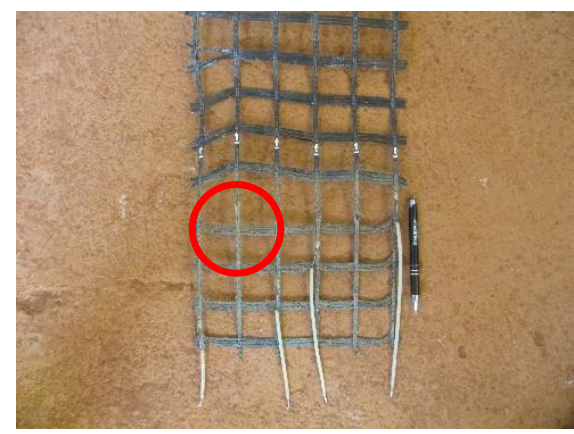

b. Arrancamento cíclico e resistência pós-ciclagem

Figura 4.40. Exumação das geogrelhas após os ensaios de arrancamento monotônico e cíclico no equipamento de pequenas dimensões - $100 \mathrm{kPa}$

\subsubsection{Equipamento de grandes dimensões}

Levando em consideração os resultados obtidos nos ensaios de arrancamento monotônico, o efeito de borda no equipamento de grandes dimensões não foi tão acentuado como no caso do equipamento de pequenas dimensões, pois o fato de ter se apresentado uma melhor distribuição das tensões sobre a geogrelha por causa do espaço, gerou um maior grau de confinamento da inclusão no primeiro caso.

Dessa maneira, se comparar os ensaios de arrancamento cíclico realizados nos dois equipamentos para as tensões de confinamento de 25 e $100 \mathrm{kPa}$, é possível pensar 
que o carregamento dinâmico no equipamento de pequenas dimensões gerou uma compactação do material, como foi evidenciado anteriormente, enquanto que no equipamento de grandes dimensões ocorreu o contrário por causa da melhor distribuição e maior concentração das tensões confinantes sobre toda a área da geogrelha.

Adicionalmente, assim como no caso do equipamento de pequenas dimensões, a instrumentação utilizada nos ensaios de arrancamento cíclico e a localização dos pontos de medição dos deslocamentos no corpo de prova (Figura 4.12), também foi a mesma dos ensaios de arrancamento monotônico para poder realizar as respectivas comparações entre a resistência inicial e residual após a aplicação dos ciclos de carga no equipamento de grandes dimensões.

Por outro lado, no equipamento de grandes dimensões não aconteceu movimentação da caixa durante a aplicação do carregamento dinâmico, permitindo assim o registro dos deslocamentos durante os ciclos de carga e portanto a possibilidade de enxergar os ciclos de carga nos gráficos de força versus deslocamento.

Assim, na Tabela 4.11 e Figuras 4.41 e 4.42 a seguir, são mostrados respectivamente os parâmetros de carga cíclica, um detalhe da variação da carga aplicada ao longo do tempo e o comportamento do arrancamento cíclico e da resistência pós-ciclagem para as duas tensões de confinamento aplicadas (25 e $100 \mathrm{kPa})$ no equipamento de grandes dimensões.

Tabela 4.11. Parâmetros de carga cíclica no equipamento de grandes dimensões

\begin{tabular}{cccc}
\hline $\begin{array}{c}\text { Tensão de } \\
\text { confinamento } \\
{[\mathbf{k P a}]}\end{array}$ & $\begin{array}{c}\text { Resistência ao arrancamento } \\
\text { monotônico } \\
{[\mathbf{k g f}]}\end{array}$ & $\begin{array}{c}\text { Amplitude de } \\
\text { carga por ciclo }\end{array}$ & $\begin{array}{c}\text { Carga de } \\
\text { repouso } \\
{[\mathbf{k g f}]}\end{array}$ \\
\hline 25 & 820,50 & 159,10 & 5 \\
100 & 884,75 & 156,95 & 20 \\
\hline
\end{tabular}

Assim como no caso do equipamento de pequenas dimensões, no detalhe da variação da carga cisalhante ao longo do tempo apresentado na Figura 4.41 a seguir, mostra-se que as amplitudes de carga aplicadas durante o ensaio foram realmente as especificadas na Tabela 4.11, as quais foram estimadas com base nos resultados obtidos nos ensaios de arrancamento monotônico e na norma ASTM D 7499 M - 09. Além disso, é ainda possível perceber que o período do carregamento cíclico foi de um segundo, 
como sugerido pelo Programa Nacional de Pesquisa Cooperativa de Rodovias (NCHRP, 2004) para levar em consideração a ação do tráfego.

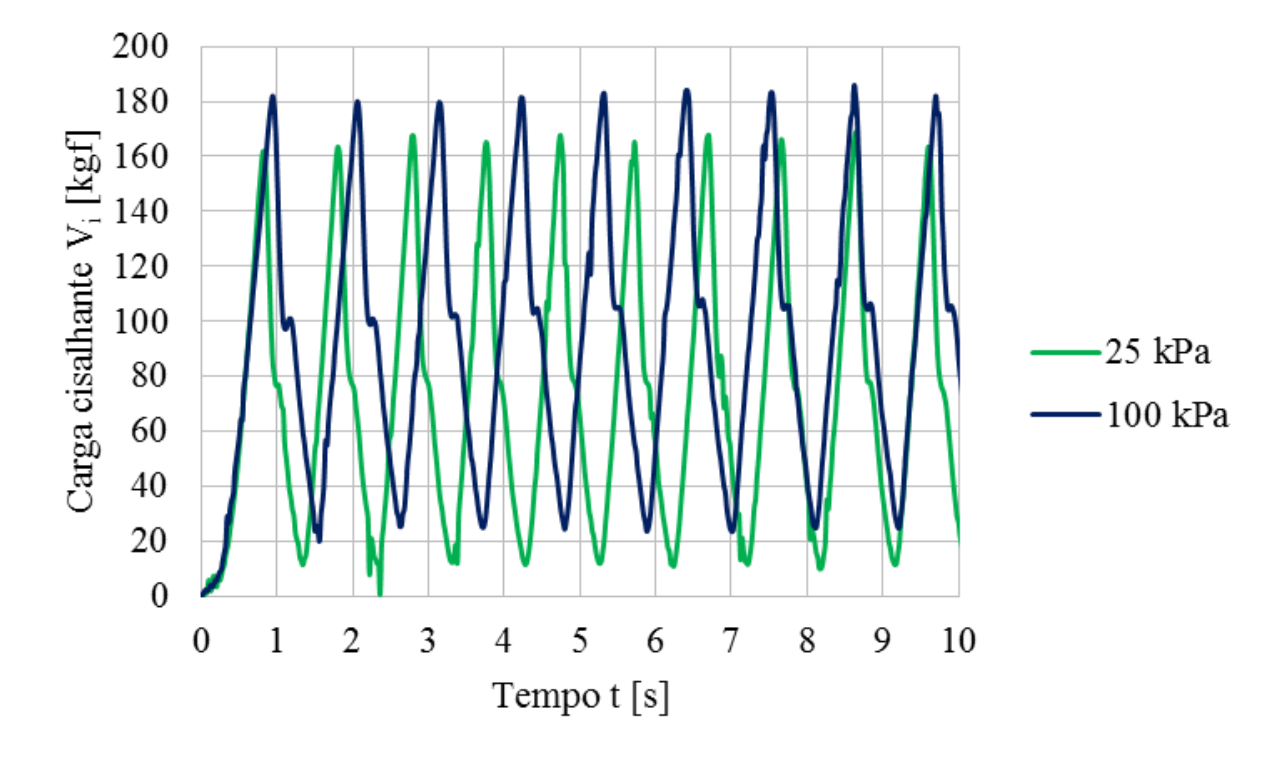

Figura 4.41. Detalhe da variação da carga cisalhante ao longo do tempo no equipamento de grandes dimensões durante os primeiros 10 segundos

Com relação ao comportamento da força de arrancamento após a aplicação do carregamento cíclico, na Figura 4.42 a seguir percebe-se a ocorrência de ruptura da geogrelha no caso da maior tensão de confinamento, a qual é evidenciada na queda brusca de resistênca no trecho final da curva. Por outro lado, o comportamento apresentado no caso da menor tensão de confinamento é de arrancamento, pois a força registrada aumentou e se estabilizou com o tempo. 


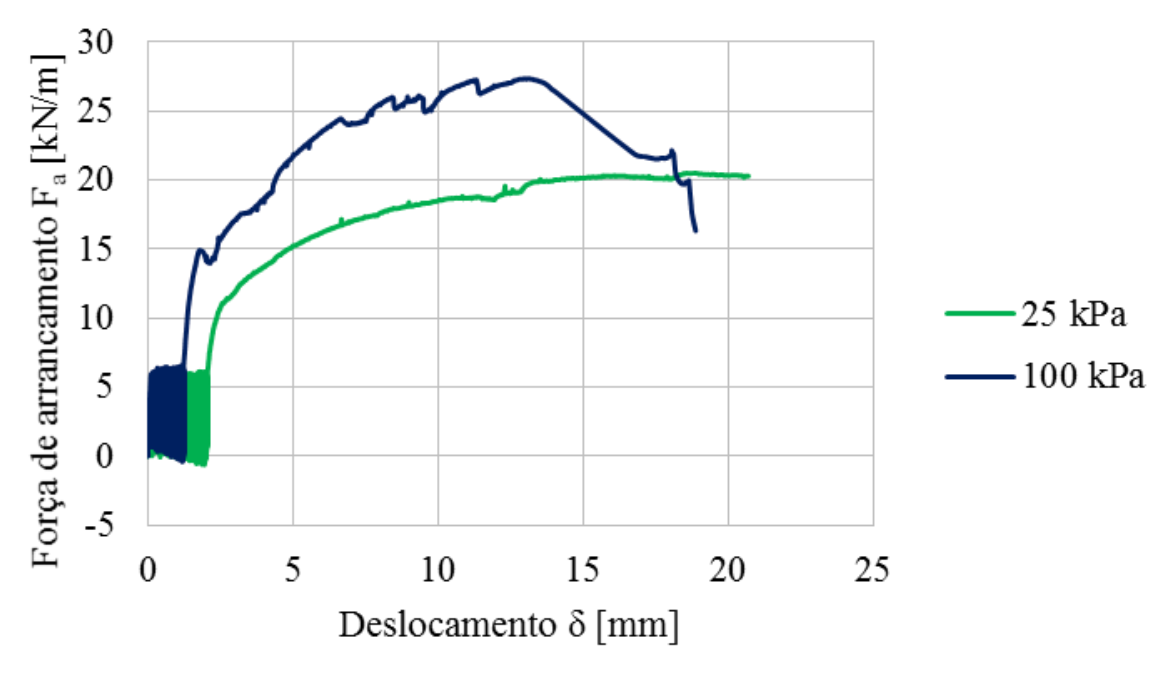

Figura 4.42. Arrancamento cíclico e resistência pós-ciclagem no equipamento de grandes dimensões

Assim, em complemento aos resultados anteriores, a seguir é mostrada tanto a variação da força de arrancamento durante e após a aplicação dos ciclos de carga para cada tensão de confinamento (25 e $100 \mathrm{kPa})$, como também o comportamento da geogrelha nos ensaios de arrancamento monotônico para poder realizar as respectivas comparações.

\subsubsection{Tensão de confinamento de $25 \mathrm{kPa}$}

Analisando os resultados de arrancamento monotônico e resistência pósciclagem separadamente para cada tensão de confinamento, confirma-se a afirmação realizada anteriormente com relação à distribuição das tensões de confinamento sobre a geogrelha e ao efeito do carregamento dinâmico na resistência obtida nos dois equipamentos, pois no caso da tensão de confinamento de $25 \mathrm{kPa}$ no equipamento de grandes dimensões, a curva de resistência pós-ciclagem esteve por baixo da correspondente ao arrancamento monotônico inicial (Figura 4.43), quando no equipamento de pequenas dimensões aconteceu o contrário.

Além disso, a redução do grau de confinamento na interface solo-geossintético por causa do carregamento dinâmico é evidente, pois como pode ser percebido nas curvas da Figura 4.43 a seguir, no arrancamento monotônico inicial apresentou-se ruptura da inclusão enquanto que na curva de resistência pós-ciclagem observa-se um arrancamento quase perfeito com uma resistência inferior à obtida inicialmente. 


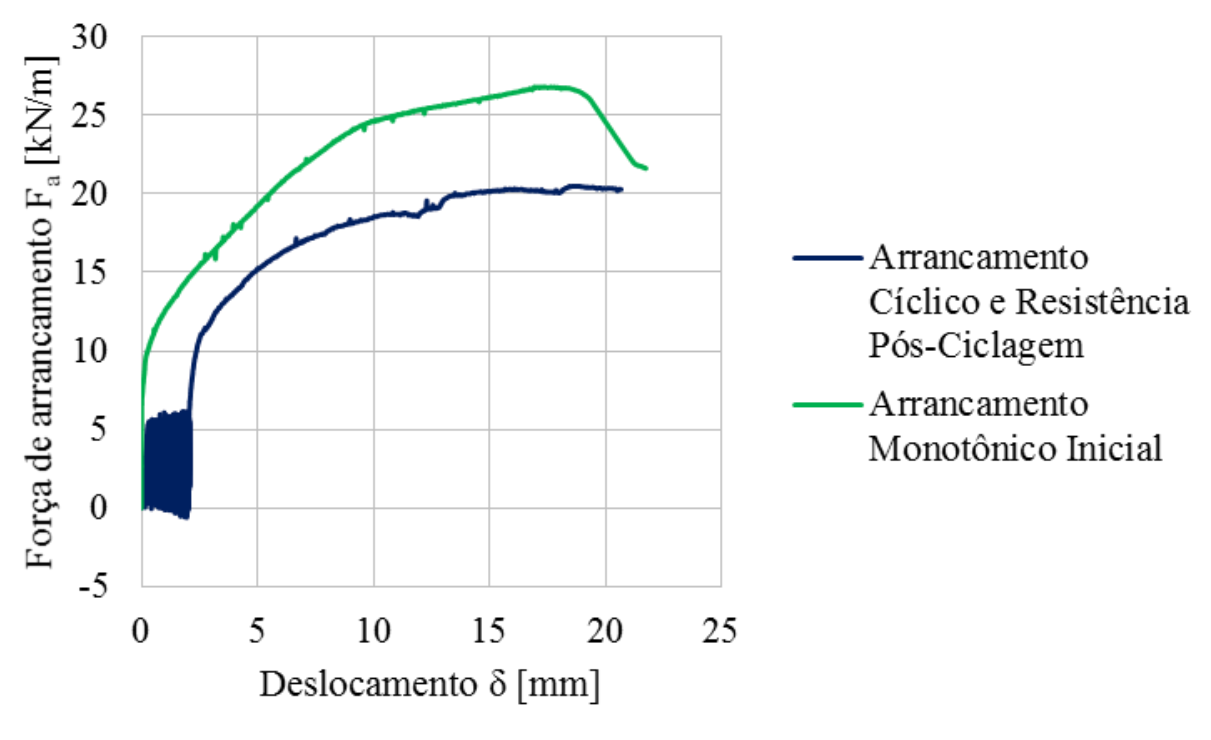

Figura 4.43. Resistência pós-ciclagem e resistência ao arrancamento monotônico no equipamento de grandes dimensões $-25 \mathrm{kPa}$

Por outro lado, na Tabela 4.12 a seguir são mostrados os valores de resistência obtidos tanto no arrancamento monotônico inicial como no arrancamento após a aplicação dos 10.000 ciclos de carga, sendo maior no primeiro caso e apresentando uma diferença percentual de $23,58 \%$ entre si.

Dessa maneira, confirma-se a redução do grau de confinamento na interface solo-geossintético, pois com a aplicação do carregamento dinâmico no equipamento de grandes dimensões, foi mais fácil arrancar a geogrelha inserida na estrutura de solo reforçado.

Tabela 4.12. Valores de resistência ao arrancamento monotônico inicial e pósciclagem no equipamento de grandes dimensões $-25 \mathrm{kPa}$

\begin{tabular}{lc}
\hline \multicolumn{2}{l}{ Resistência ao arrancamento monotônico [kN/m] } \\
\hline Inicial & 26,83 \\
Pós-ciclagem & 20,50 \\
Diferença percentual & $23,58 \%$ \\
\hline
\end{tabular}

Adicionalmente, com a comparação das exumações realizadas após os ensaios de arrancamento monotônico e cíclico para a tensão de confinamento de $25 \mathrm{kPa}$ (Figura 4.44), é possível perceber que a amostra utilizada no ensaio de arrancamento monotônico inicial apresentou falha em alguns dos nós da extrema direita, enquanto que 
a correspondente ao ensaio de arrancamento cíclico e de resistência pós-ciclagem, mesmo apresentando um leve efeito de borda, não sofreu nem falha nem ruptura.

Assim, as análises realizadas anteriormente com relação ao efeito dos ciclos de carga no equipamento de grandes dimensões são confirmadas mais uma vez, pois a redução da aderência entre o solo e a geogrelha permitiu o arrancamento perfeito da inclusão.

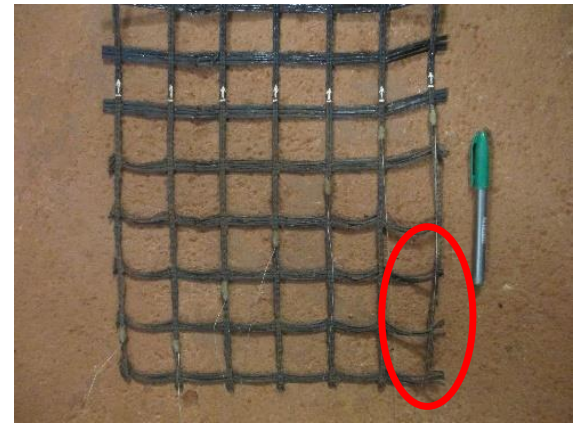

a. Arrancamento monotônico inicial

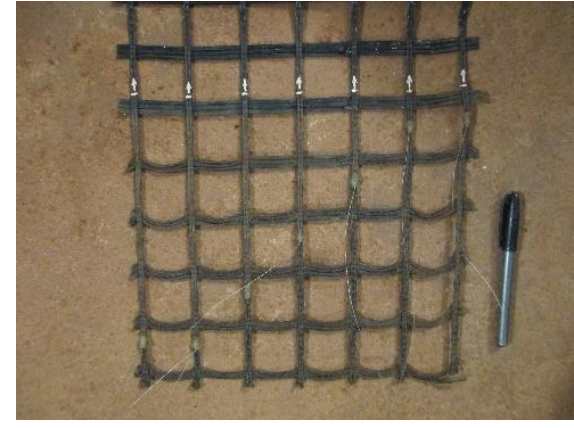

b. Arrancamento cíclico e resistência pós-ciclagem

Figura 4.44. Exumação das geogrelhas após os ensaios de arrancamento monotônico e cíclico no equipamento de grandes dimensões $-25 \mathrm{kPa}$

Como foi comentado nos resultados de arrancamento cíclico, nos ensaios realizados no equipamento de grandes dimensões não se apresentou movimentação da caixa durante o carregamento dinâmico, permitindo assim o registro dos deslocamentos na etapa cíclica através dos cinco tell-tales e dos dois sensores do tipo LVDT.

Sendo assim, na Figura 4.45 a seguir é mostrado um detalhe dos ciclos de carga para a determinação do módulo de cisalhamento de interface $\mathrm{G}_{\mathrm{i}}$, levando em consideração o estipulado na norma ASTM D 7499 M - 09 e no relatório DTFH61-01X-00068 da Administração Federal de Rodovias (FHWA em inglês) realizado por Perkins et al. (2004). 


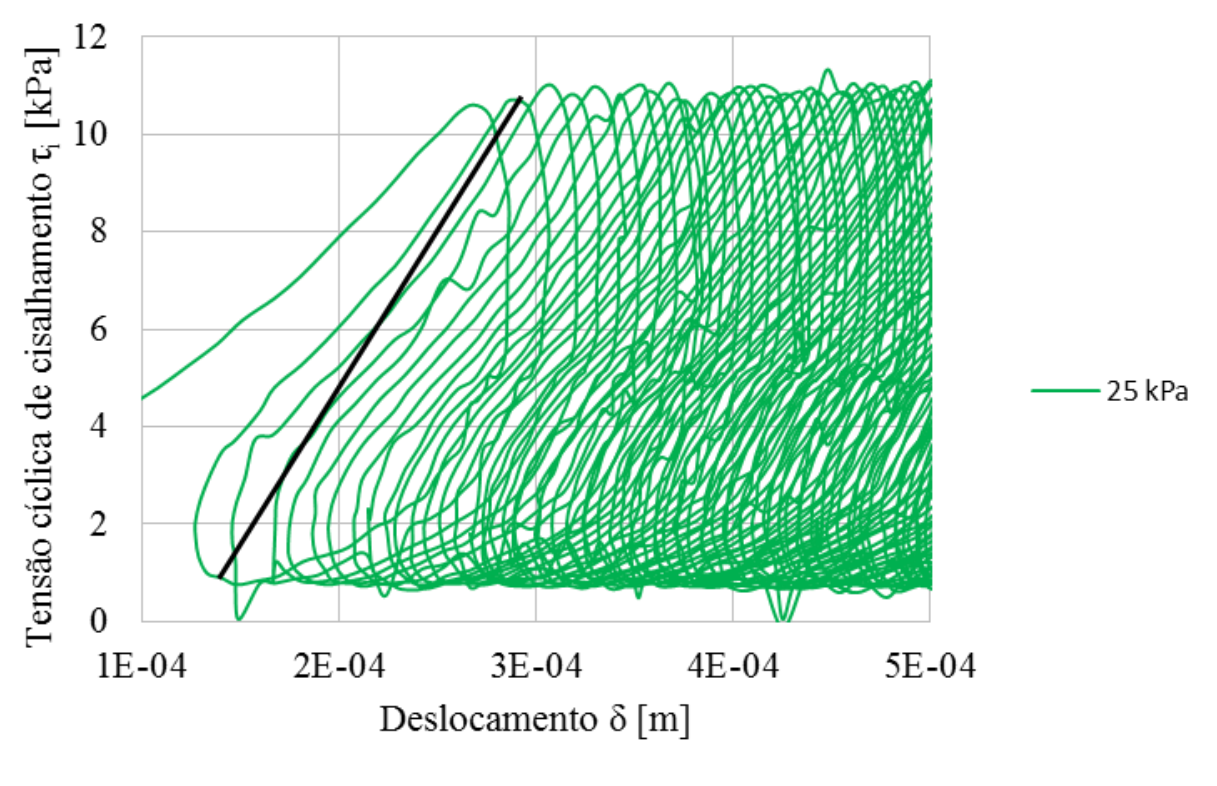

Figura 4.45. Detalhe dos ciclos de carga para a obtenção do módulo de cisalhamento de interface $\mathrm{G}_{\mathrm{i}}-25 \mathrm{kPa}$

Dessa maneira, a partir do gráfico mostrado na Figura 4.45 e das recomendações especificadas tanto na norma ASTM D 7499 M - 09 como no relatório realizado por Perkins et al. (2004), na Tabela 4.13 a seguir são mostrados os parâmetros obtidos do gráfico anterior para a determinação do módulo de cisalhamento de interface $\mathrm{G}_{\mathrm{i}}$.

Tabela 4.13. Parâmetros para a obtenção do módulo de cisalhamento de interface $G_{i}-$ $25 \mathrm{kPa}$

\begin{tabular}{ccccc}
\hline $\begin{array}{c}\boldsymbol{\tau}_{\text {i máx }} \\
{[\mathbf{k P a}]}\end{array}$ & $\begin{array}{c}\boldsymbol{\tau}_{\text {i min }} \\
{[\mathbf{k P a}]}\end{array}$ & $\begin{array}{c}\boldsymbol{\delta}_{\text {máx }} \\
{[\mathbf{m}]}\end{array}$ & $\begin{array}{c}\boldsymbol{\delta}_{\min } \\
{[\mathbf{m}]}\end{array}$ & $\begin{array}{c}\mathbf{G}_{\mathbf{i}} \\
{[\mathbf{k P a} / \mathbf{m}]}\end{array}$ \\
\hline 10,59 & 0,90 & $2,95 \mathrm{E}-04$ & $1,40 \mathrm{E}-04$ & 62516,13 \\
\hline
\end{tabular}

\subsubsection{Tensão de confinamento de $100 \mathrm{kPa}$}

Levando em consideração o fenômeno ocorrido nos ensaios de arrancamento cíclico no equipamento de pequenas dimensões, onde o grau de confinamento não era tão alto quanto no de grandes dimensões por causa da distribuição das tensões sobre a geogrelha, é correto pensar que neste caso a ação dinâmica reduza o grau de confinamento na interface solo-geossintético, tal como foi mostrado no item anterior. 
Assim, com o aumento da tensão de confinamento de 25 para $100 \mathrm{kPa}$, a tendência vai ser a mesma com a ação do carregamento dinâmico, pois ao se tratar do mesmo equipamento onde a distribuição de tensões sobre a geogrelha é a mesma, os ciclos de carga vão diminuir o confinamento na interface solo-geossintético mas em menor escala devido à dificuldade para tracionar a inclusão, resultando assim numa resistência pós-ciclagem menor do que a do arrancamento monotônico inicial mas com curvas mais próximas entre si, como mostrado na Figura 4.46 a seguir.

Além disso, apesar de ter ocorrido ruptura nos dois tipos de ensaio por causa da intensidade da tensão de confinamento aplicada, na Figura 4.46 também é possível observar que a curva correspondente ao ensaio de arrancamento cíclico e resistência pós-ciclagem foi mais pronunciada e a ruptura aconteceu depois do que a do ensaio de arrancamento monotônico, precisamente por causa da diminuição do grau de confinamento na interface devida à ação dinâmica, como comentado anteriormente.

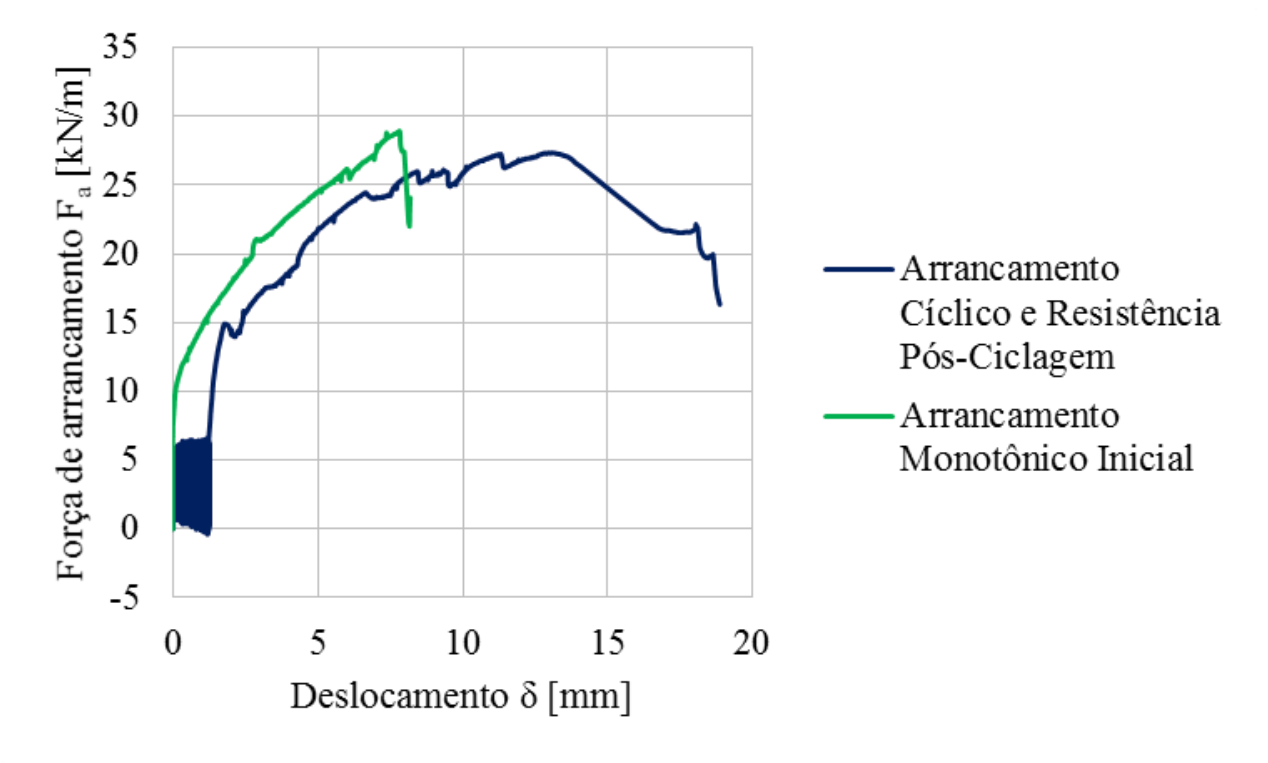

Figura 4.46. Resistência pós-ciclagem e resistência ao arrancamento monotônico no equipamento de grandes dimensões $-100 \mathrm{kPa}$

Por outro lado, na Tabela 4.14 a seguir são mostrados os valores de resistência obtidos tanto no arrancamento monotônico inicial como no arrancamento após a aplicação dos 10.000 ciclos de carga, sendo maior no primeiro caso mas apresentando agora uma diferença percentual de 5,48\% entre si.

Dessa maneira, confirma-se mais uma vez a redução do grau de confinamento na interface solo-geossintético por causa da ação dinâmica no equipamento de grandes 
dimensões e, com o aumento da tensão de confinamento, a proximidade entre as curvas devido à dificuldade para tracionar a geogrelha e passar de um estado mais compacto a menos compacto.

Tabela 4.14. Valores de resistência ao arrancamento monotônico inicial e pósciclagem no equipamento de grandes dimensões $-100 \mathrm{kPa}$

\begin{tabular}{lc}
\hline \multicolumn{2}{l}{ Resistência ao arrancamento monotônico [kN/m] } \\
\hline Inicial & 28,93 \\
Pós-ciclagem & 27,35 \\
Diferença percentual & $5,48 \%$ \\
\hline
\end{tabular}

Com as exumações realizadas à geogrelha após os ensaios também é possível confirmar o efeito do carregamento dinâmico aplicado, pois no ensaio de arrancamento cíclico são percebidas deformações consideráveis nos elementos transversais da amostra, enquanto que no ensaio de arrancamento monotônico, as deformações do corpo de prova foram muito menores por causa do elevado grau de confinamento na interface solo-geossintético.

Além disso, nas fotografias da Figura 4.47 também pode-se observar a causa da diminuição brusca nos valores de resistência registrados pela célula de carga, sendo que no caso monotônico foi devido à ruptura do elemento longitudinal esquerdo da região não confinada, enquanto que no ensaio de arrancamento cíclico foi pela falha num nó da região confinada.

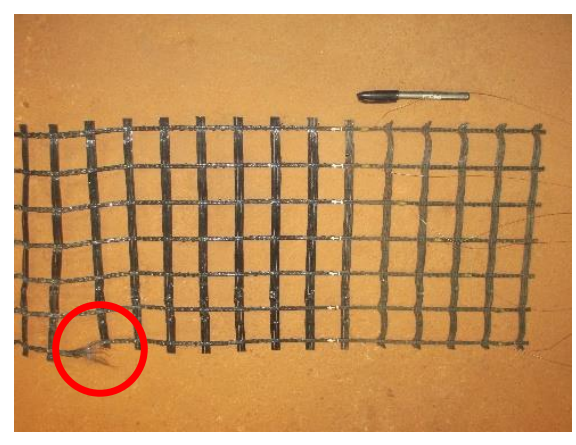

a. Arrancamento monotônico inicial

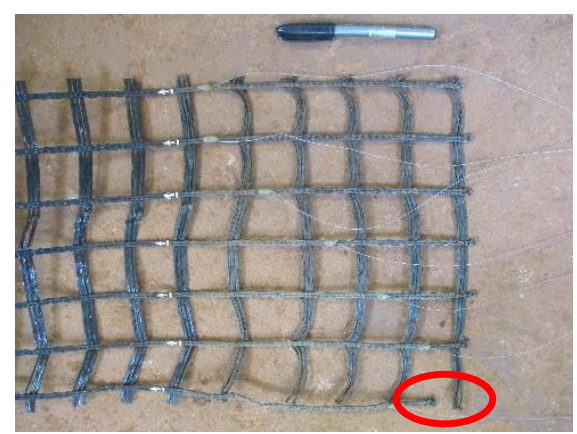

b. Arrancamento cíclico e resistência pós-ciclagem

Figura 4.47. Exumação das geogrelhas após os ensaios de arrancamento monotônico e cíclico no equipamento de grandes dimensões $-100 \mathrm{kPa}$ 
Por outro lado, na Figura 4.48 a seguir é mostrado o detalhe dos ciclos de carga obtidos com a tensão de confinamento de $100 \mathrm{kPa}$ para a determinação do módulo de cisalhamento de interface $G_{i}$, levando em consideração o estipulado na norma ASTM D 7499 M - 09 e no relatório DTFH61-01-X-00068 da Administração Federal de Rodovias (FHWA em inglês) realizado por Perkins et al. (2004).

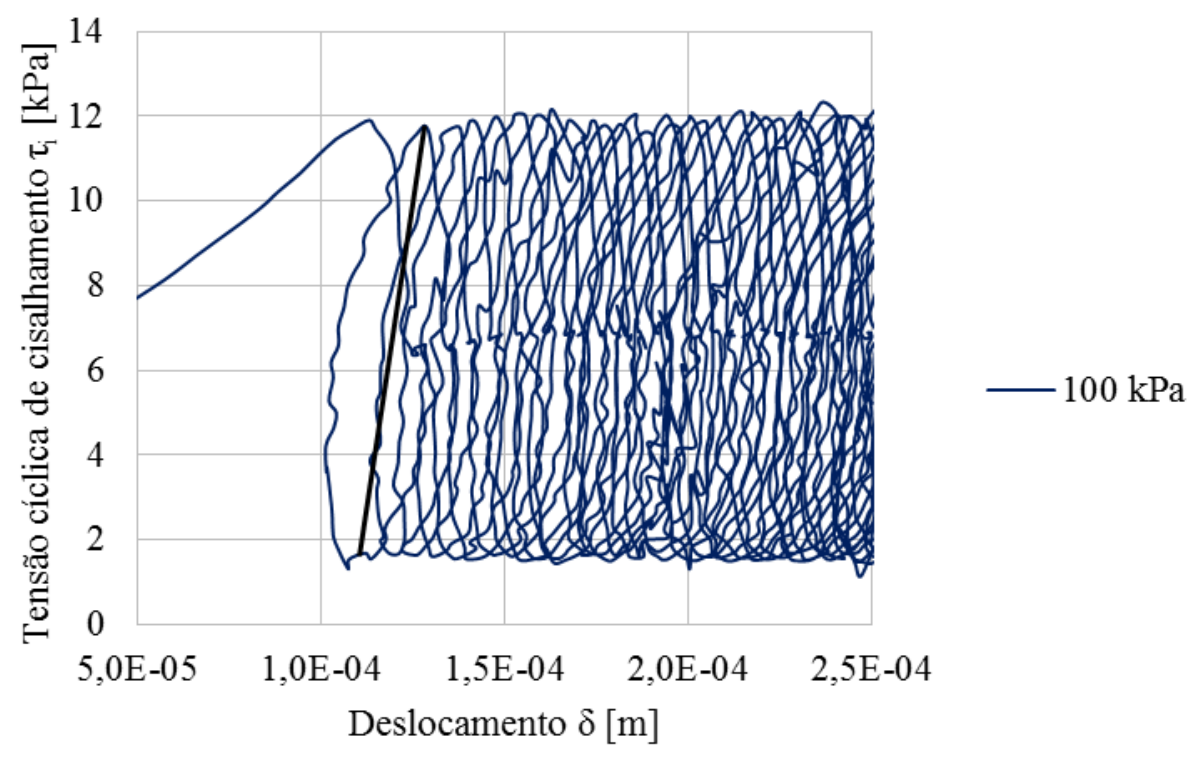

Figura 4.48. Detalhe dos ciclos de carga para a obtenção do módulo de cisalhamento de interface $\mathrm{G}_{\mathrm{i}}-100 \mathrm{kPa}$

Se levar em consideração as características dos ciclos de carga no ensaio com tensão de confinamento de $25 \mathrm{kPa}$ e comparar com os do ensaio com a maior tensão de confinamento aplicada, é possível perceber a diferença na declividade da reta utilizada para determinar o módulo de cisalhamento de interface $\mathrm{G}_{\mathrm{i}}$.

Assim, é correto pensar que com o aumento da tensão de confinamento o material tenha maior rigidez e portanto, um maior módulo de cisalhamento de interface. Dessa maneira, a partir do gráfico mostrado na Figura 4.48 e das recomendações especificadas tanto na norma ASTM D 7499 M - 09 como no relatório realizado por Perkins et al. (2004), na Tabela 4.15 a seguir são mostrados os parâmetros obtidos para a determinação do módulo de cisalhamento de interface $G_{i}$ para a tensão de confinamento de $100 \mathrm{kPa}$, o qual foi aproximadamente 10,72 vezes maior do que o obtido para a tensão de confinamento de $25 \mathrm{kPa}$. 
Tabela 4.15. Parâmetros para a obtenção do módulo de cisalhamento de interface $G_{i}-$ $100 \mathrm{kPa}$

\begin{tabular}{ccccc}
\hline $\begin{array}{c}\tau_{\text {i máx }} \\
{[\mathbf{k P a}]}\end{array}$ & $\begin{array}{c}\boldsymbol{\tau}_{\text {i min }} \\
{[\mathbf{k P a}]}\end{array}$ & $\begin{array}{c}\boldsymbol{\delta}_{\text {máx }} \\
{[\mathbf{m}]}\end{array}$ & $\begin{array}{c}\boldsymbol{\delta}_{\min } \\
{[\mathbf{m}]}\end{array}$ & $\begin{array}{c}\mathbf{G}_{\mathbf{i}} \\
{[\mathbf{k P a} / \mathbf{m}]}\end{array}$ \\
\hline 11,60 & 1,55 & $1,29 \mathrm{E}-04$ & $1,14 \mathrm{E}-04$ & 670000,00 \\
\hline
\end{tabular}

\subsubsection{Comparação dos resultados obtidos nos dois equipamentos}

O fato de ter utilizado o mesmo sistema de aplicação de cargas, as mesmas condições de compactação, confinamento e carregamento, também permitiu realizar comparações entre os resultados obtidos nos ensaios de arrancamento cíclico tanto no equipamento de pequenas como de grandes dimensões.

No caso dos ensaios de arrancamento cíclico, as comparações dos resultados obtidos somente puderam ser realizadas com o trecho da curva correspondente à resistência pós-ciclagem, pois como foi mencionado anteriormente, durante a aplicação dos ciclos de carga apresentou-se movimentação da caixa de pequenas dimensões e não foi possível registrar os respectivos deslocamentos através da instrumentação utilizada.

Além disso, com a exumação realizada aos corpos de prova depois de cada ensaio foi possível complementar as análises, pois com ela existe uma visão mais clara da influência do carregamento dinâmico na resistência ao arrancamento da inclusão para as duas tensões de confinamento.

Assim, a seguir é mostrada a comparação das resistências obtidas após a aplicação dos 10.000 ciclos de carga em cada equipamento, com as respectivas análises e comentários para cada tensão de confinamento.

\subsubsection{Tensão de confinamento de $25 \mathrm{kPa}$}

Lembrando os resultados mostrados anteriormente para cada equipamento, no caso da menor tensão de confinamento apresentou-se arrancamento da inclusão tanto no equipamento de pequenas como de grandes dimensões, sem presença de ruptura nem falha de algum elemento e nó, respectivamente.

Assim, na Figura 4.49 a seguir mostra-se a comparação das curvas obtidas a partir dos ensaios de arrancamento cíclico em cada equipamento, onde é possível 
observar uma pequena queda de resistência na curva correspondente ao equipamento de pequenas dimensões, enquanto que na do equipamento de grandes dimensões não aconteceu o mesmo fenômeno.

Dessa maneira, confirma-se a afirmação realizada anteriormente com relação ao efeito do carregamento dinâmico na resistência pós-ciclagem, onde foi de compactação no equipamento de pequenas dimensões e de alívio no de grandes dimensões, cuja diferença esteve relacionada com a distribuição das tensões de confinamento sobre a geogrelha.

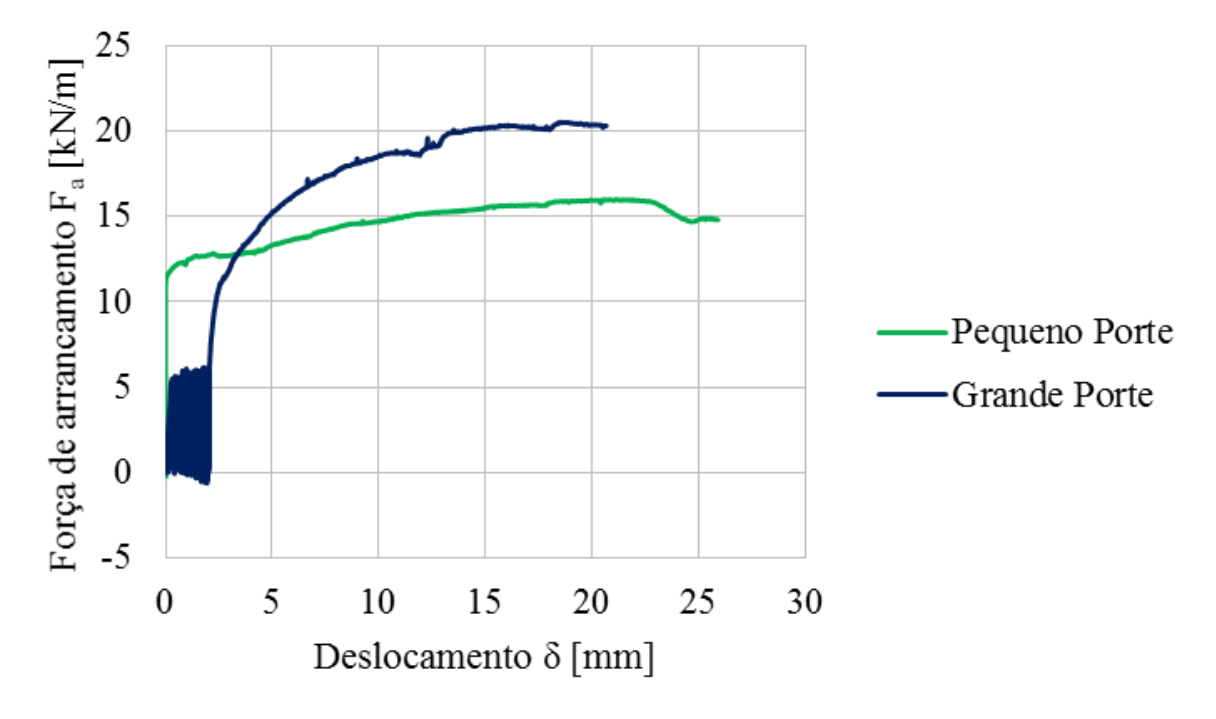

Figura 4.49. Comparação do arrancamento cíclico e da resistência pós-ciclagem nos dois equipamentos $-25 \mathrm{kPa}$

Além das afirmações realizadas anteriormente, na Figura 4.49 observa-se que a curva correspondente ao equipamento de grandes dimensões foi superior que a correspondente ao de pequenas dimensões, o qual indica que para a menor tensão de confinamento, o efeito de compactação causado pelo carregamento dinâmico no equipamento de pequeno porte não foi suficiente para superar a resistência obtida no outro caso.

Sendo assim, na Tabela 4.16 a seguir são mostrados os valores de resistência ao arrancamento obtidos após a aplicação dos 10.000 ciclos de carga, onde a resistência pós-ciclagem no equipamento de grandes dimensões teve um incremento de $28 \%$ com relação à obtida no de pequenas dimensões. 
Tabela 4.16. Comparação dos valores de resistência pós-ciclagem - $25 \mathrm{kPa}$

\begin{tabular}{ccc}
\hline Equipamento & Resistência ao arrancamento [kN/m] & $\mathbf{G p / P p}$ \\
\hline Pequeno porte & 15,98 & 1,28 \\
Grande porte & 20,50 & \\
\hline
\end{tabular}

Adicionalmente, a exumação das geogrelhas utilizadas nos ensaios de arrancamento cíclico com a menor tensão de confinamento, mostra uma grande semelhança no comportamento das inclusões dos dois equipamentos, pois a deformação dos elementos transversais foi parecida e não se evidenciou ruptura nem falha dos corpos de prova.

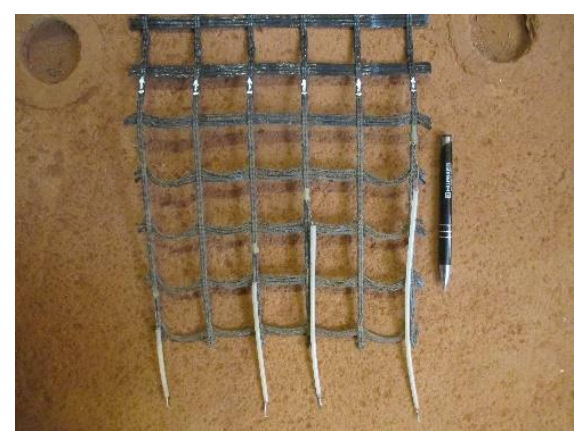

a. Pequenas dimensões

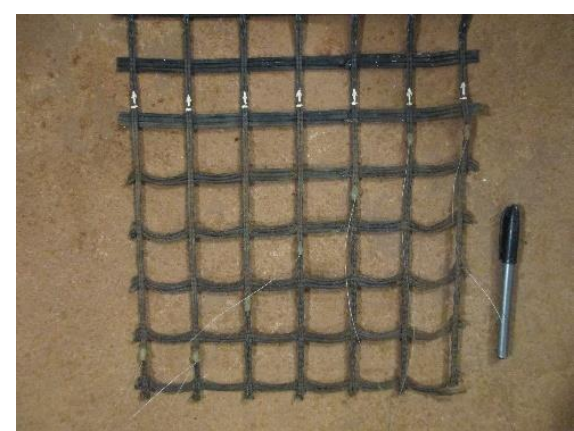

b. Grandes dimensões

Figura 4.50. Exumação das geogrelhas após os ensaios de arrancamento cíclico nos dois equipamentos $-25 \mathrm{kPa}$

\subsubsection{Tensão de confinamento de $100 \mathrm{kPa}$}

Com relação aos resultados de arrancamento cíclico obtidos com a maior tensão de confinamento, em ambos equipamentos ocorreu ruptura da inclusão após a aplicação dos 10.000 ciclos de carga, mas aconteceu primeiro no de pequeno porte por causa do elevado grau de confinamento na interface solo-geossintético.

Assim, na Figura 4.51 a seguir mostra-se a comparação das curvas de resistência pós-ciclagem de cada equipamento, onde é possível observar uma queda brusca na resistência para ambos casos, sendo mais pronunciada no de pequenas dimensões.

Por outro lado, apesar da resistência pós-ciclagem ter sido menor no equipamento de pequenas dimensões do que no de grandes dimensões, o comportamento e a tendência das curvas mostram um crescimento superior do primeiro 
caso sobre o segundo, confirmando assim que o efeito do carregamento dinâmico foi de compactação e de alívio de tensões na interface solo-geossintético, respectivamente.

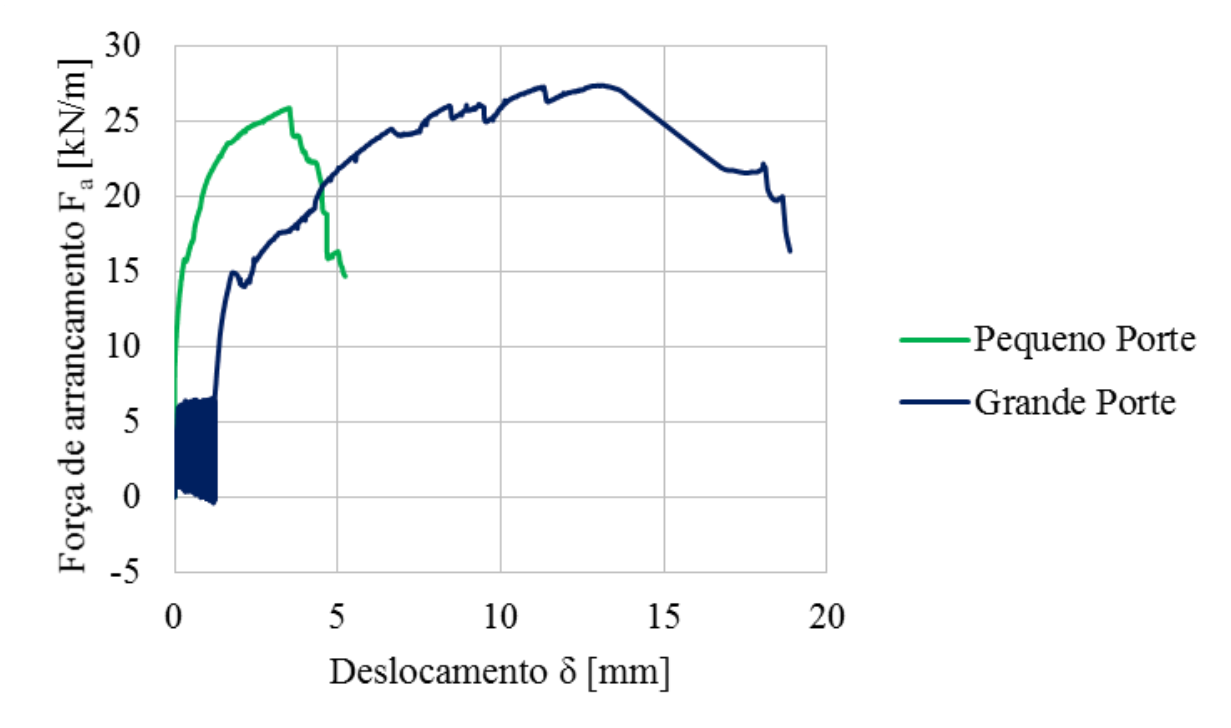

Figura 4.51. Comparação do arrancamento cíclico e da resistência pós-ciclagem nos dois equipamentos $-100 \mathrm{kPa}$

Como complemento às curvas de arrancamento cíclico e de resistência pósciclagem mostradas anteriormente na Figura 4.51, na Tabela 4.17 a seguir são apresentados os valores de resistência ao arrancamento obtidos após a aplicação dos 10.000 ciclos de carga, onde a resistência pós-ciclagem no equipamento de grandes dimensões teve um incremento de $6 \%$ com relação à obtida no de pequenas dimensões por causa da ruptura da inclusão.

Tabela 4.17. Comparação dos valores de resistência pós-ciclagem - $100 \mathrm{kPa}$

\begin{tabular}{ccc}
\hline Equipamento & Resistência ao arrancamento [kN/m] & $\mathbf{G p / P p}$ \\
\hline Pequeno porte & 25,84 & 1,06 \\
Grande porte & 27,35 & \\
\hline
\end{tabular}

Adicionalmente, a exumação das geogrelhas utilizadas nos ensaios de arrancamento cíclico com a tensão de confinamento de $100 \mathrm{kPa}$ (Figura 4.52), mostra deformações mais acentuadas no corpo de prova correspondente ao equipamento de grandes dimensões, confirmando assim o alívio de tensões na interface solo-geogrelha causado pela aplicação dos ciclos de carga. 
Além disso, também é possível observar que a geogrelha do equipamento de pequenas dimensões apresentou falha num nó da região não confinada, enquanto que a do equipamento de grandes dimensões ocorreu na região confinada.

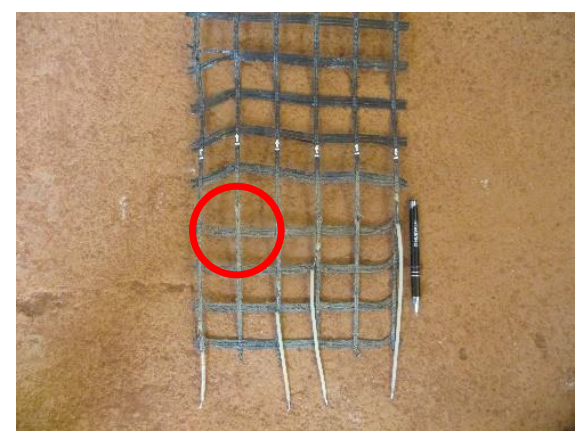

a. Pequenas dimensões

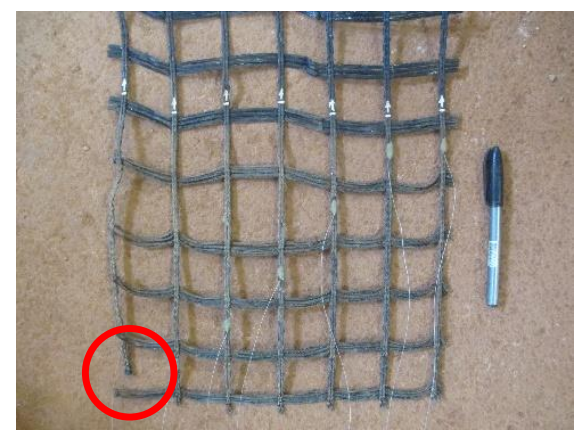

b. Grandes dimensões

Figura 4.52. Exumação das geogrelhas após os ensaios de arrancamento cíclico nos dois equipamentos $-100 \mathrm{kPa}$

Com base nos resultados mostrados ao longo do Capítulo 4, no próximo capítulo serão apresentadas as respectivas conclusões e as sugestões para trabalhos futuros, as quais permitirão dar continuidade aos temas abordados nesta pesquisa, aprofundando ainda mais nos efeitos gerados pelas solicitações dinâmicas nas geogrelhas e melhorando cada vez mais os resultados obtidos. 


\section{Capítulo 5}

\section{CONCLUSÕES E SUGESTÕES PARA TRABALHOS FUTUROS}

Com as solicitações de arrancamento monotônico e cíclico aplicadas à geogrelha inserida na interface dos solos argiloso e arenoso utilizados, foi possível avaliar o seu comportamento mecânico nos equipamentos de pequenas e grandes dimensões do Laboratório de Geossintéticos da EESC-USP e a sua interação com os solos que constituíam as respectivas estruturas.

Dessa maneira, foram obtidos resultados interessantes relacionados à diferença no grau de confinamento da geogrelha por causa da distribuição das tensões em cada equipamento, ao efeito dos elementos transversais na variação das tensões e à influência do carregamento cíclico na resistência pós-ciclagem.

Além disso, as exumações realizadas aos corpos de prova após a execução dos ensaios permitiram confirmar os resultados obtidos, assim como perceber fisicamente o que realmente aconteceu na interface solo-geossintético para cada condição analisada.

Por outro lado, durante a realização dos ensaios e com os resultados obtidos em cada caso, perceberam-se aspectos importantes que precisam ser levados em consideração nos próximos trabalhos a serem desenvolvidos na mesma linha de pesquisa, os quais podem melhorar e acrescentar as contribuições realizadas atualmente com relação à aplicação dos geossintéticos em obras de engenharia.

Levando em consideração a análise dos resultados e os aspectos comentados anteriormente, a pesquisa realizada permitiu concluir que:

- Apesar de ter levado em consideração a relação entre o tamanho dos corpos de prova e o acréscimo de tensões por causa das camadas de solo acima da inclusão em cada equipamento, a diferença no grau de confinamento observada e manifestada nas resistências ao arrancamento monotônico, deveram-se à melhor distribuição das tensões sobre a geogrelha instalada no 
equipamento de grandes dimensões, pois por causa do espaço livre entre as paredes internas da caixa e a região ocupada pela geogrelha, conseguiu-se uma melhor expansão da bolsa de ar sobre todo o corpo de prova, sendo mais efetiva com o aumento da tensão de confinamento;

- O aumento do efeito de borda com o incremento da tensão de confinamento no equipamento de pequenas dimensões foi por causa da concentração de tensões na região central do corpo de prova, pois com o espaço reduzido entre as paredes internas da caixa e à região ocupada pela inclusão, os extremos ficaram menos confinados e se apresentaram maiores deformações nos elementos transversais correspondentes, como também falha em alguns dos seus nós;

- Levando em consideração a conclusão anterior, a redução do efeito de borda com o incremento da tensão de confinamento no equipamento de grandes dimensões foi evidentemente por causa da melhor distribuição das tensões sobre o corpo de prova, pois com o espaço existente entre as paredes internas da caixa e a região ocupada pela inclusão, tanto os extremos como a região central da geogrelha foram afetados uniformemente pela bolsa de ar, chegando assim na ruptura de um elemento longitudinal da região não confinada e menores deformações nos elementos transversais com a maior tensão aplicada;

- Com o aumento da tensão de confinamento em ambos os equipamentos, a localização dos pontos de medição dos deslocamentos na geogrelha toma maior importância no equipamento de grandes dimensões do que no de pequenas dimensões, pois ao se apresentar uma melhor distribuição das tensões sobre a inclusão, o corpo de prova tende a se deslocar de forma mais homogênea reduzindo o efeito de borda, e os pontos mais próximos à garra ou ponto de aplicação da carga, são os primeiros em se movimentar e apresentar os maiores deslocamentos;

- À medida que a tensão de confinamento aumenta, a distribuição das tensões no corpo de prova tende a ser mais homogênea no equipamento de grandes dimensões em função do espaço livre entre as paredes laterais da caixa e a inclusão, implicando que os valores de resistência e as curvas de força de arrancamento versus deslocamento fiquem mais próximos entre si para os 
dois equipamentos;

- Apesar das envoltórias de resistência não terem sido obtidas a partir dos mesmos fenômenos nos dois equipamentos (arrancamento nas tensões de confinamento de 25 e $50 \mathrm{kPa}$ no equipamento de pequenas dimensões e tração confinada no de grandes dimensões para todas as tensões de confinamento), os parâmetros de resistência de interface obtidos permitem ter uma ideia da interação entre o solo e a geogrelha, sendo a adesão o mais influente em ambos os equipamentos, mas maior no de grandes dimensões por causa do elevado grau de confinamento na interface devido à melhor distribuição das tensões sobre a inclusão;

- A variação da tensão de confinamento é influenciada pela ação dos elementos transversais da inclusão, pois no momento em que o ensaio de arrancamento inicia, existe uma diminuição nos valores registrados por causa do arrasto do material contido nas aberturas da geogrelha que por sua vez desconfina o solo da interface, continuando com um novo aumento nos valores devido ao rearranjo das partículas;

- A variação das tensões horizontais apresenta o mesmo comportamento da tensão de confinamento, mas são registrados maiores valores na região central do corpo de prova por causa da concentração de tensões que ali existe. Adicionalmente, com o aumento do confinamento aplicado, o alívio de tensões a partir do início do ensaio tende a ser mais pronunciado pois a força necessária para levar o solo de um estado compacto a um estado mais fofo, é cada vez maior;

- No equipamento de pequenas dimensões, o efeito do carregamento dinâmico com o aumento da tensão de confinamento é de compactação, pois ao comparar os gráficos de resistência pós-ciclagem e de resistência ao arrancamento monotônico, evidencia-se sempre uma tendência de superioridade do primeiro sobre o segundo, respectivamente, existindo maior afastamento entre as curvas com a tensão de $100 \mathrm{kPa}$ do que com a de $25 \mathrm{kPa}$;

- À medida que aumenta a tensão de confinamento no equipamento de grandes dimensões, o carregamento cíclico tende a desconfinar o material da interface por causa da melhor distribuição das tensões sobre a geogrelha, 
pois ao comparar os gráficos de resistência pós-ciclagem e de resistência ao arrancamento monotônico, evidencia-se sempre uma tendência de inferioridade do primeiro em comparação ao segundo, respectivamente, existindo maior proximidade entre as curvas com a tensão de $100 \mathrm{kPa}$ do que com a de $25 \mathrm{kPa}$ devido à dificuldade para tracionar a inclusão;

- Com o aumento da tensão de confinamento, o material apresenta maior rigidez, e portanto, o módulo de cisalhamento de interface $\mathrm{G}_{\mathrm{i}}$ chega a ser até 10,72 vezes maior no caso da tensão de $100 \mathrm{kPa}$ em comparação ao da tensão de $25 \mathrm{kPa}$, cujos valores correspondem a $670000 \mathrm{kPa} / \mathrm{m}$ e $62516,13 \mathrm{kPa} / \mathrm{m}$, respectivamente.

Adicionalmente, com os resultados obtidos perceberam-se aspectos importantes que precisam ser levados em consideração nos próximos trabalhos a serem desenvolvidos na mesma linha de pesquisa. Dessa maneira, as sugestões para as próximas pesquisas relacionadas com arrancamento monotônico e cíclico são as seguintes:

- Sendo que a diferença no grau de confinamento da interface nos dois equipamentos foi por causa da distribuição das tensões sobre a inclusão, seria bom utilizar bolsas de ar mais flexíveis que pudessem se expandir com maior facilidade sobre toda a superfície da caixa;

- Avaliar a influência do comprimento da caixa de grandes dimensões nos resultados de arrancamento monotônico, cíclico e de resistência pósciclagem;

- Com os mesmos tipos de solo utilizados, realizar ensaios de arrancamento com uma geogrelha de maior resistência à tração para evitar a sua ruptura e a falha dos seus nós, podendo assim obter parâmetros de resistência de interface adequados para as condições analisadas;

- Com o intuito de obter os parâmetros de resistência de interface e o módulo de cisalhamento de interface para cada material, seria bom realizar ensaios de arrancamento monotônico e cíclico nos dois tipos de solo por separado;

- Realizar ensaios de arrancamento monotônico, cíclico e de resistência pósciclagem com solos de subleito de menor resistência (CBR inferior a 4\%);

- Melhorar o suporte de adaptação do equipamento de pequenas dimensões, pois com a sua fixação adicional nas paredes laterais da caixa de grandes 
dimensões, evitaria se a sua movimentação durante o carregamento cíclico e os deslocamentos da geogrelha nos ciclos de carga seriam registrados pelos transdutores;

- Sendo que a capacidade do sistema de aplicação de carga dinâmica corresponde a 10.000 ciclos, seria interessante dar continuidade aos ensaios de arrancamento cíclico com o intuito de determinar o número de ciclos que suporta a estrutura analisada;

- Realizar ensaios de arrancamento cíclico sob diferentes tensões de confinamento para poder determinar a variação do módulo de cisalhamento de interface $\mathrm{G}_{\mathrm{i}}$ em função da tensão aplicada;

- Estimar a correlação entre os resultados de arrancamento cíclico com os obtidos através do carregamento cíclico vertical do eixo padrão numa estrutura de pavimento real;

- Validar os resultados experimentais por meio de sua simulação numérica; 


\section{REFERÊNCIAS BIBLIOGRÁFICAS}

ALAGiYAWANNA, A. M. N.; SUGIMOTO, M.; SATO, S.; TOYOTA, H., (2001). Influence of longitudinal and transverse members on geogrid pullout deformation. Geotextiles and Geomembranes, Vol. 19, p. 483-507.

ALFARO, M. C.; MIURA, N.; BERGADO, D. T., (1995). Soil-Geogrid reinforcement interaction by pullout and direct shear tests. Geotechnical Testing Journal, Vol. 18, n. 2, p. 157-167.

AL-QADI, I. L.; CORRE, B. J.; BRANDON, T. L.; BHUTTA, S. A.; APPEA, A. K., (1998). Quantifying the separation characteristic of geosynthetic in flexible pavements. IV International Conference on Geosynthetic. Atlanta, USA.

AL-QADI, I. L., (2002). The proper use of geosynthetics in flexible pavements. Geosynthetics $-7^{\text {th }}$ ICG $-2002-$ Lisse.

ANTUNES, L. G. S., (2008). Reforço de pavimentos rodoviários com geossintéticos. Dissertação de Mestrado - Universidade de Brasília. Brasília, Brasil.

AASHTO M 145-91, (2008). Classification of soils and soil-aggregate mixtures for highway construction purposes.

AASHTO T 307-99, (1999). Standard method of test for determining the resilient modulus of soils and aggregate materials.

ASSOCIAÇÃO BRASILEIRA DE NORMAS TÉCNICAS. NBR 6459, (1984). Solo Determinação do limite de liquidez. Rio de Janeiro, Brasil.

ASSOCIAÇÃO BRASILEIRA DE NORMAS TÉCNICAS. NBR 6508, (1984). Massa específica real dos grãos. Rio de Janeiro, Brasil.

ASSOCIAÇÃO BRASILEIRA DE NORMAS TÉCNICAS. NBR 7180, (1988). Solo Determinação do limite de plasticidade. Rio de Janeiro, Brasil. 
ASSOCIAÇÃO BRASILEIRA DE NORMAS TÉCNICAS. NBR 7181, (1988). Solo Análise granulométrica. Rio de Janeiro, Brasil.

ASSOCIAÇÃO BRASILEIRA DE NORMAS TÉCNICAS. NBR 7182, (1988). Solo Ensaio de compactação. Rio de Janeiro, Brasil.

ASSOCIAÇÃO BRASILEIRA DE NORMAS TÉCNICAS. NBR 6502, (1995). Rochas $e$ Solos. Rio de Janeiro, Brasil.

ASSOCIAÇÃO BRASILEIRA DE NORMAS TÉCNICAS. NBR ISO 10319, (2013).

Geossintéticos - Ensaio de tração faixa larga.

ASTM D6706, (2001). Standard test method for measuring geosynthetic pullout resistance in soil.

ASTM D2488, (2009). Standard practice for description and identification of soils.

ASTM D7499/D7499M, (2009). Standard test method for measuring geosynthetic-soil resilient interface shear stiffness.

ASTM D4595, (2011). Standard test method for tensile properties of geotextiles by the wide-with strip method.

BARKSDALE, R. D.; ITANI, S. Y., (1989). Influence of aggregate shape on base behavior. Transportation Research Record, No. 1227, p. 173-182.

BAUER, G. E.; SHANG, Q., (1993). Pullout resistance of large geogrid specimens in site specific soils. Geotechnical Engineering, Vol. 24, n. 1.

BERGADO, D. T.; CHAI, J. C.; MIURA, M., (1996). Prediction of pullout resistance and pullout force-displacement relationship for inextensible grid reinforcements. Soil and Foundations, Vol. 36, n. 4, p. 11-22. 
BROWN, S. F.; JONES, C. P. D.; BRODRICK, B. V., (1983). Discussion of paper: Use of non-woven fabrics in permanente road pavement. Proceeding of the Institution of Civil Engineers, Part 2, Vol. 75.

CAMPOS, M. V. W., (2013). Avaliação da interação solo-reforço por meio de ensaios de cisalhamento cíclico de interface. Dissertação de Mestrado - Escola de Engenharia de São Carlos, Universidade de São Paulo. São Carlos, Brasil.

CHANG, D. T.; SUN, T. S.; HUNG, F., (1995). Pullout mechanism of geogrids under confinement by sandy and clayey soils. Transportation Research Record, No. 1474, p. 64-72.

COLLIN, J. G.; KINNEY, T. C.; FU, X., (1996). Full scale highway load test of flexible pavement systems with geogrid reinforced base courses. Geosynthetics International, Vol. 3, n. 4, p. 537-549.

CUELHO, E. V.; PERKINS, S. W., (2005). Resilient interface shear modulus from shortstrip, cyclic, pullout tests. Montana State University, USA.

CUNHA, M. G., (1991). Estudo do comportamento de estradas vicinais reforçadas com geotêxtil através de modelos físicos. Dissertação de Mestrado - Universidade de Brasília. Brasília, Brasil.

DeMERCHANT, M. R.; VALSANGKAR, A. J.; SCHRIVER, A. B., (2002). Plate load tests on geogrid-reinforced expanded shale lightweight aggregate. Geotextiles and Geomembranes, University of New Brunswick. Fredericton, Canada, n. 20 (2002), p. 173-190.

DEPARTAMENTO DE ESTRADAS DE RODAGEM. DER-SP M53-71, (1974). Ensaio de Suporte Califórnia, de amostras compactadas em laboratório.

DEPARTAMENTO DE ESTRADAS DE RODAGEM, DER-SP. ET-DE-P00/001, (2005). Melhoria e preparo do subleito. Especificação Técnica. 
DEPARTAMENTO DE ESTRADAS DE RODAGEM. DER-SP, (2012). Manual Básico de Estradas e Rodovias Vicinais. Volume I. São Paulo, Brasil.

DUCKWORD, S. M., (2000). Geogrid-soil interaction coefficients for seismic design. Department of Civil Engineering, University of British Columbia, British Columbia, Canada, p. 123.

FANNIN, R. J.; SIGURDSSON, O., (1996). Field observations on stabilization of unpaved roads with geosynthetics. Journal of Geotechnical Engineering, Vol. 122, p. 544-553.

FARRAG, K.; ACAR, Y. B.; JURAN, I., (1993). Pull-out resistance of geogrid reinforcements. Geotextiles and Geomembranes, Vol. 12, n. 3, p. 133-159.

FERREIRA, F. B., (2015). Interação solo-geossintético em condições de carregamento monotónico e cíclico. Tese de Doutorado - Faculdade de Engenharia, Universidade do Porto. Portugal.

GIROUD, J. P.; HAN, J., (2004). Design method for geogrid-reinforced unpaved roads. I. Development of design method. Journal of Geotechnical and Geoenvironmental Engineering, ASCE, Vol. 130, p. 775-786.

GIROUD, J. P.; HAN, J., (2004). Design method for geogrid-reinforced unpaved roads. II. Calibration and applications. Journal of Geotechnical and Geoenvironmental Engineering, ASCE, Vol. 130, p. 787-797.

GONGORA, I. A. G., (2011). Utilização de geossintéticos como reforço de estradas não pavimentadas: influência do tipo de reforço e do material de aterro. Dissertação de Mestrado - Universidade de Brasília. Brasília, Brasil.

GUPTA, B. E. R., (2009). A study of geosynthetic reinforced flexible pavement system. Tese de Doutorado - University of Texas. Austin, USA, p. 281.

HASS, R.; WALLS, J.; CARROLL, R. G., (1988). Geogrid reinforcement of granular bases in flexible pavement. TRR-1188, Transportation Research Board, p. 19-27. 
HAYASHI, S.; SHAHU, J. T.; WATANABE, K., (1999). Changes in interface stresses during pullout tests on geogrid strip reinforcement. Geotechnical Testing Journal, Vol. 22, p. 32-38.

HOE, I. L. and ZENG, L., (2001). Performance of geosynthetic-reinforced asphalt pavements. Journal of Geoenvironmental Engineering, February, p. 117-184.

HOLLEY, T. M., (2009). Development of a test protocol for cyclic pullout of geosynthetics in roadway base reinforcement. Master of Science thesis - Montana State University. Bozeman, Montana.

HOLTZ, D.; CHRISTOPHER, B. R.; BERG, R. R., (1995). Geosynthetic design and construction guidelines. Report No. FHWA-A-HI-95, U.S. Department of Transportation, Federal Highway Administration, National Highway Institute Course, n. 13213. Washington D.C., USA.

http://oglobo.globo.com/brasil/no-brasil-80-das-estradas-nao-contam-com-pavimentacao13710994, outubro de 2014.

http://www.mathworks.com/matlabcentral/answers/uploaded_files/23014/gt2.jpg, julho de 2014

HUFENUS, R.; RUEEGGER, R.; BANJAC, R.; MAYOR, P.; SPRINGMAN, S. M.; BRÖNNIMANN, R., (2006). Full-scale field tests on geosynthetic reinforced unpaved roads on soft subgrade. Geotextiles and Geomembranes, Vol. 24, p. 21-37.

IBRAHIM, S. F.; SOFIA, G. G.; KAREEM, A. I., (2012). Experimental study on geogridreinforced subbase over soft subgrade soil under repeated loading. Journal of Engineering and Development, Vol. 16, No. 3, p. 218-240.

JEWELL, R. A.; MILLIGAN, G. W. E.; SARSBY, R. W.; DUBOIS, D., (1984). Interaction between soil and geogrids. Proceeding, Symposium on Polymer Grid Reinforcement 
in Civil Engineering, Science and Engineering Research Council and Netlon Limited, p. $18-30$.

JORENBY, B. N.; HICKS, R. G., (1986). Base course contamination limits. Transportation Research Record, No. 1095, p. 86-101.

KAKUDA, F. M., (2005). Estudo de ensaios de arrancamento de geogrelha com utilização de um equipamento reduzido. Dissertação de Mestrado - Escola de Engenharia de São Carlos, Universidade de São Paulo. São Carlos, Brasil.

KAKUDA, F. M., (2010). Desenvolvimento e a utilização de um equipamento de grandes dimensões na análise do comportamento mecânico de uma seção de pavimento sob carregamento cíclico. Tese de Doutorado - Escola de Engenharia de São Carlos, Universidade de São Paulo. São Carlos, Brasil.

KLEIN, R. J.; VIDAL, D. M.; RODRIGUES, R. M., (2003). Estudo dos efeitos nas propriedades do material compactado em obras de reforço de base de pavimentos com geossintéticos. IV Simpósio Brasileiro de Geossintéticos, ABMS. Porto Alegre - RS, Brasil.

LATHA, G. M., (2013). Performance evaluation of geosynthetic reinforced unpaved roads. Research Report. Indian Institute of Science. Bangalore.

LENG, J., (2002). Characteristics and behaviour of geogrid-reinforced aggregate under cyclic load. Ph.D., Department of Civil Engineering, North Carolina University. North Carolina, USA, p. 164.

LING, H. I.; MOHRI, Y.; KAWABATA, T., (1998). Tensile properties of geogrids under cyclic loadings. Journal of Geotechnical and Geoenvironmental Engineering, August.

LOPES, M. L.; LADEIRA, M., (1996). Influence of the confinement, soil density and displacement ratio on soil-Geogrid interaction. Geotextiles and Geomembranes, Vol. 14 , n. 10 , p. 543-554. 
MACCAFERRI do Brasil, (2012). Refuerzo y estabilización de suelos. Necesidades y soluciones. CD-ROM, Distribuição Gratuita MM12 0029 - 05/12. Brasil, p. 15.

MARMITT, H. M.; CASAGRANDE, M. D. T.; CERATTI, J. A. P., (2010). Caracterização das propriedades resilientes de três britas graduadas utilizadas em pavimentos no sul do Brasil. Teoria e Prática na Engenharia Civil, n. 15, p. 63-69.

MENDOZA, F. M. L.; LÁZARES, W. G., (2003). Ensayo de módulo resiliente. XIV Congreso Nacional de Ingeniería Civil. Iquitos, Perú.

MEYER, N.; NERNHEIM, A.; KÖHLER, U., (2004). Geosynthetic-soil interaction under cyclic loading. Proceedings of the Third European Geosynthetics Conference EuroGeo 3, p. 635-639.

MIRANDA, L. P., (2013). Análise do comportamento mecânico de pavimento reforçado com geossintético sob carregamento cíclico em modelo físico de verdadeira grandeza. Dissertação de Mestrado - Pontifícia Universidade Católica do Rio de Janeiro. Rio de Janeiro, Brasil.

MOHAMMAD, L. N.; PUPPALA, J. A.; ALAVILLI, P., (1995). Resilient properties of laboratory compacted subgrade soils. Transportation Research Record, n. 1504, p. 87102.

MORACI, N.; CARDILE, G., (2009). Influence of cyclic tensile loading on pullout resistance of geogrids embedded in a compacted granular soil. Geotextiles and Geomembranes, Mediterranea University of Reggio Calabria. Reggio Calabria, Italy, n. 27 (2009), p. 475-487.

MORACI, N.; CARDILE, G., (2011). Deformative behavior of different geogrids embedded in a granular soil under monotonic and cyclic pullout loads. Geotextiles and Geomembranes, Vol. 32, p. 104-110. 
NAKAMURA, T.; MITACHI, T.; IKEURA, I., (2003). Estimating method for the in-soil deformation behavior of geogrid base on the results of direct box shear test. Soil and Foundations, Vol. 43, n. 1, p. 47-57.

NAPA G., G. F., (2011). Implementação de ensaios de arrancamento cíclico de geossintéticos. Dissertação de Mestrado - Escola de Engenharia de São Carlos, Universidade de São Paulo. São Carlos, Brasil.

NCHRP 1-37A, (2004). Guide for Mechanistic-Empirical Design of New and Rehabilitated Pavement Structures. National Cooperative Highway Research Program - Final Report for NCHRP 1-37A Project (2004)..

NCHRP, (2004). Laboratory determination of resilient modulus for flexible pavement design. National Cooperative Highway Research Program - Research Results Digest. Transportation Research Board, n. 285.

NAYERI, A.; FAKHARIAN, K., (2009). Study on pullout behavior of uniaxial HDPE geogrids under monotonic and cyclic loads. International Journal of Civil Engineering, Vol. 7, n. 4, p. 211-223.

NERNHEIM, A.; MEYER, N., (2004). Cyclic pull-out tests on geogrids. International Conference on Geotechnical Engineering. Sharjah, United Arab Emirates.

OCHIAI, H.; OTANI, J.; HAYASHIC, S.; HIRAI, T., (1996). The pull-out resistance of geogrids in reinforced soil. Geotextiles and Geomembranes, Vol. 14, p. 19-42.

PALMEIRA, E. M.; MILLIGAN, G. W. E., (1989). Scale and other factors affecting the results of the pullout tests of grids buried in sand. Geotechnique 39, n. 3, p. 551-584.

PALMEIRA, E. M.; ANTUNES, L. G. S., (2010). Large scale tests on geosynthetic reinforced unpaved roads subjected to surface maintenance. Geotextiles and Geomembranes, Vol. 28, p. 547-558. 
PERKINS, S. W. and ISMEIK, M., (1997). A synthesis and evaluation of geosyntheticreinforce base layer in flexible pavement: Part I. Geosynthetic International, Vol. 4, n. 6.

PERKINS, S. W. and ISMEIK, M., (1997). A synthesis and evaluation of geosyntheticreinforce base layer in flexible pavement: Part II. Geosynthetic International, Vol. 4, n. 6.

PERKINS, S. W., (1999). Constitutive modeling of geosynthetic. Geotextiles and Geomembranes, Montana State University. Bozeman, USA, n. 18 (2000), p. 273-292.

PERKINS, S. W., (1999). Mechanical response of geosynthetic-reinforced flexible pavements. Geosynthetic International, Vol. 6, n. 5, p. 347-382.

PERKINS, S. W. and CUELHO, E. V., (1999). Soil-Geosynthetic interface strenght and stiffness relationships from pullout tests. Geosynthetic International, Vol. 6, n. 5, p. 321-346.

PERKINS, S. W. et al., (2002). Mechanistic-empirical models for reinforced pavements. Geosynthetics $-7^{\text {th }}$ ICG - Lisse.

PERKINS, S. W.; CHRISTOPHER, B. R.; LACINA, B. A.; KLOMPMAKER, J., (2012). Mechanistic-empirical modeling of geosynthetic-reinforced unpaved roads. International Journal of Geomechanics, ASCE, Vol. 12, p. 370-380.

PIMENTEL, K. C. A., (2007). Estradas não-pavimentadas e ferrovias reforçadas com geossintéticos. Tese de Doutorado - Universidade de Brasília. Brasília, Brasil.

RAJU, D. M.; FANNIN, R. J., (1998). Load-strain-displacement response of geosynthetics in monotonic and cyclic pullout. Canadian Geotechnical Journal, Vol. 35, n. 2, p. 183 193.

RAJU, D. M.; LO, S. C. R.; GOPALAN, M.; GAO, J., (1998). On large-scale laboratory pull-out testing. Geotechnical Engineering Journal, Vol. 29, n. 2, p. 123-155. 
RAVI, K.; DASH, S. K.; VOGT, S.; BRAEU, G., (2014). Behavior of geosynthetic reinforced unpaved roads under cyclic loading. Indian Geotechnical Journal, Vol. 44, n. 1, p. $77-85$.

SANTOS, A. R.; PASTORE, E. L.; JUNIOR, F. A.; CUNHA, M. A., (1988). Estradas vicinais de terra. Manual técnico para conservação e recuperação. IPT. Segunda Edição. São Paulo, Brasil.

SIEIRA, A. C. C. F., (2003). Estudo experimental dos mecanismos de interação sologeogrelha. Tese de Doutorado - Pontifícia Universidade Católica do Rio de Janeiro. Rio de Janeiro, Brasil.

SUGIMOTO, M.; ALAGIYAWANNA, A. M. N.; KADOGUCHI, K., (2001). Influence of rigid and flexible face on geogrid pullout tests. Geotextiles and Geomembranes, Vol. 19, p. 257-277.

TEIXEIRA, S. H. C., (1999). Construção e calibração de um equipamento de ensaios de arrancamento de geossintéticos. Dissertação de Mestrado - Escola de Engenharia de São Carlos, Universidade de São Paulo. São Carlos, Brasil.

TEIXEIRA, S. H. C., (2003). Estudo da interação solo-geogrelha em testes de arrancamento e a sua aplicação na análise e dimensionamento de maciços reforçados. Tese de Doutorado - Escola de Engenharia de São Carlos, Universidade de São Paulo. São Carlos, Brasil.

UZAN, J., (1985). Characterization of granular material. Transportation Research Record, No. 1022 , p. 52-59.

VERTEMATTI, J. C./Coordenador, (2004). Manual brasileiro de geossintéticos. Ed. Blucher. São Paulo, Brasil. 
VIANA, H. M. F., (2007). Estudo do comportamento resiliente dos solos tropicais grossos do interior do Estado de São Paulo. Tese de Doutorado - Escola de Engenharia de São Carlos, Universidade de São Paulo. São Carlos, Brasil.

VILAR, O. M., (S/D). Mecânica dos Solos - Resistência ao Cisalhamento. Apostila da disciplina - Escola de Engenharia de São Carlos, Universidade de São Paulo. São Carlos, Brasil.

VOOTTIPRUEX, P.; BERGADO, D. T.; OUNJAICHON, P., (2000). Pullout and direct shear resistance of hexagonal wire mesh reinforcement in weathered Bangkok clay. Geotechnical Engineering Journal, Vol. 31, p. 43-62.

WEBSTER, S. L., (1993). Geogrid reinforced base courses for flexible pavement for light aircraft: test section construction, behavior under traffic, laboratory tests, and design criteria. US Army Corps of Engineers. Vicksburg Mississippi, USA. 